UNIVERSIDADE DE BRASÍLIA

FACE - FACULDADE DE ECONOMIA, ADMINISTRAÇÃO E CONTABILIDADE DEPARTAMENTO DE ECONOMIA PROGRAMA DE PÓS-GRADUAÇÃO EM ECONOMIA

JOANA D'ARC BARDELLA CASTRO

USOS E ABUSOS DA VALORAÇÃO ECONÔMICA DO MEIO AMBIENTE:

ENSAIOS SOBRE APLICAÇÕES DE MÉTODOS DE FUNÇÃO DEMANDA NO BRASIL

BRASÍLIA 


\section{USOS E ABUSOS DA VALORAÇÃO ECONÔMICA DO MEIO AMBIENTE: ENSAIOS SOBRE APLICAÇÕES DE MÉTODOS DE FUNÇÃO DEMANDA NO}

\section{BRASIL}

Tese apresentada ao Programa de Pós-Graduação do Departamento de Economia da Faculdade de Economia, Administração e Contabilidade da Universidade de Brasília, como requisito para obtenção do título de Doutor em Economia.

Orientador: Prof. Dr. Jorge Madeira Nogueira

\section{BRASÍLIA}


Ficha catalográfica elaborada automaticamente, com os dados fornecidos pelo(a) autor(a)

C355u

Castro, Joana D'arc Bardella

Usos e abusos da valoração econômica do meio ambiente:ensaios sobre aplicações do método de função demanda no Brasil / Joana D'arc Bardella Castro; orientador Jorge Madeira Nogueira. -- Brasília, 2015 $251 \mathrm{p}$.

Tese (Doutorado - Doutorado em Economia) - Universidade de Brasília, 2015.

1. Valoração Econômica do meio ambiente. 2. Método de função demanda. 3. Método de Valoração Contingente. 4. Método Custo de Viagem. 5. Método Preço Hedônico. I. Nogueira, Jorge Madeira, orient. II. Título. 


\section{JOANA D'ARC BARDELLA CASTRO}

\section{"Usos e Abusos da Valoração Econômica do Meio Ambiente: Ensaios sobre Aplicações de Métodos Função Demanda no Brasil"}

Tese aprovada como requisito para a obtenção do título de Doutor em Economia do Programa de Pós-Graduação em Economia - Departamento de Economia da Universidade de Brasília $\mathrm{ECO} / \mathrm{UnB}$. A Comissão Examinadora foi formada pelos profe\$sores:

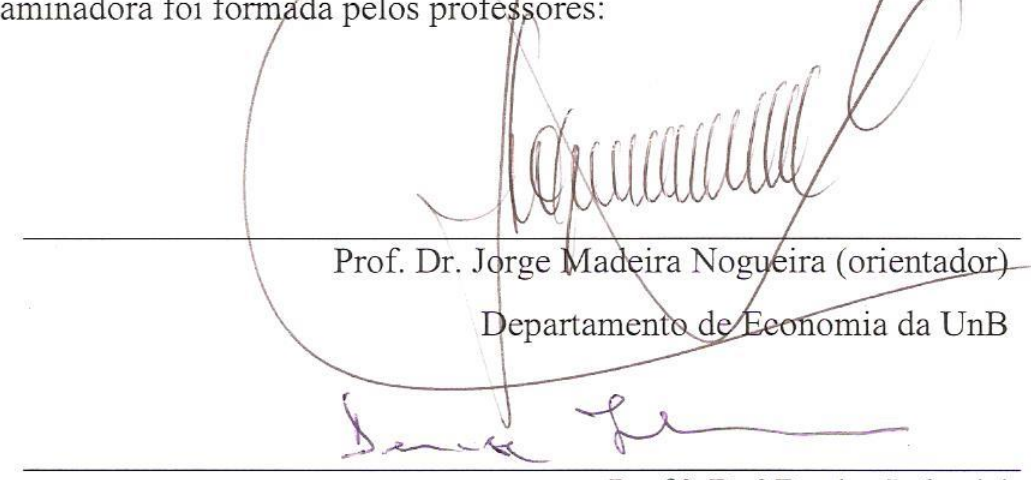

Prof. ${ }^{\text {a }}$. Dr. ${ }^{\text {a }}$ Denise Imbroisi

Departamento de Economia da UnB

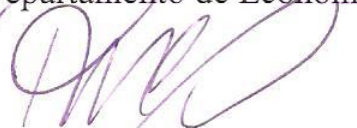

Prof. Dr. Pedro Henrique Zuchi da Conceição Departamento de Economia da UnB

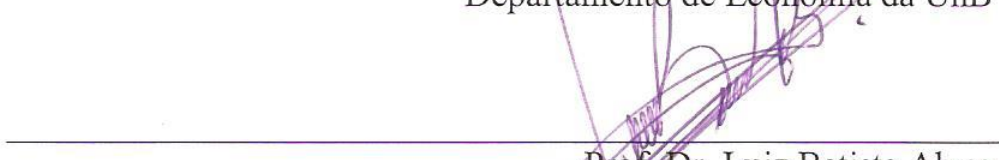
Prof. Dr. Luiz Batista Alves

Universidade Estadual de Goiás - UEG

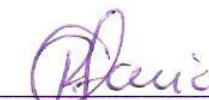

Prof. Dr. Ricardo Coelho de Faria

Universidade Católica de Brasília - UCB

Brasília, 12 de junho de 2015. 


\section{DEDICATÓRIA}

Ao meu horizonte e fim, pelo seu amor, companheirismo, atenção e perdão nos meus momentos de fraqueza, pela minha ausência em sua vida nos momentos de reflexão e pela paciência em me esperar horas a fio na UnB para que hoje eu pudesse saber um pouquinho mais. A você, Mário, dedico esta tese, fruto de tanto trabalho. Sem sua presença em minha vida seria impossível realizar este trabalho. Com você aprendi que o amor transforma, faz crescer e moldar nossas aptidões.

Aos meus amores (filhos), Flávio, Larissa, Isabella, Rebeca, meu agradecimento especial. Vocês são a razão de minha vida. Ao Flávio, que todo final de semana queria saber que dia eu terminaria para poder ficar só mais um pouquinho com ele. À Larissa, por almoçar todos os dias comigo e compreender que não sou perfeita, porque uns dias eram só alegria outros nem tanto. Por me lembrar sempre que a vida é feita de força de vontade, humildade e amor incondicional. À Isabella, companheira inseparável, pela sua beleza interior, paz e tranquilidade; por dedicar horas de seus momentos de folga em me ajudar com as traduções dos textos em inglês e em me ouvir, mesmo quando não estava entendendo nada do que eu falava; por ficar em silêncio me apoiando; às vezes se arriscava em perguntar: "O que mesmo a senhora está querendo me dizer?”. À Rebeca, alegria e vibração positiva, por toda ajuda no computador; por ficar me ouvindo repetir sempre a mesma coisa para uma apresentação em congressos ou aqui na UnB; com seu sorriso meigo no final falava: "Se repetir mais umas trinta vezes ficará melhor, vamos recomeçar". A vida ao lado dos meus filhos é sempre um recomeço.

Aos meus netos Rafael e Geovana, que nasceram no meio de toda essa intensa atividade. Vocês me fazem lembrar, com gestos e frases, as coisas mais simples do cotidiano, me fazem reparar cenas bonitas que ninguém vê. Vocês amassam meu coração, clareiam meus sentimentos e dão leveza ao meu dia. Obrigado por escolherem ser meus netos e estarem aqui comigo. Ao pequeno Henrique que está chegando, que você possa por onde caminhar levar ao mundo mais compreensão e respeito a todos os seres vivos e não vivos, que seus passos possam gravar nessa terra o suor do trabalho honesto, a fé em um Deus maior e a grandiosidade de um coração que ama. A Amanda filha de coração o que Deus me presenteou nessa jornada, por seu sorriso, beleza e por todos os momentos de aprendizagem a seu lado, por me mostrar que a vida pode ser especial, que somos todos diferentes, mas que na estrada da vida todos somos iguais perante o Pai. 
Ao meu Pai (in memoriam) - sei que torce por mim onde estiver, obrigado por seus conselhos, por nossas conversas e por me apoiar quando eu mesma nem sabia que estava à beira de um abismo - e à minha mãe, que me acompanha toda madrugada com suas orações de joelho, para que eu consiga realizar tudo que precisa ser feito e na hora que precisa estar pronto. Por suas noites mal dormidas, pensando em meu bem-estar e por morar comigo, agitando meu dia. Sem ela, essa vida seria muito monótona.

As minhas irmãs, Regina e Miriam, por compartilharem comigo momentos tão raros, mas não menos importantes, conversas intermináveis, que só o coração consegue realizar. E ao meu irmão, onde estiver; obrigado por simplesmente me amar. 


\section{AGRADECIMENTOS}

À Universidade de Brasília (UnB), pela valiosa oportunidade de acesso ao curso de Doutorado em Economia, na área de Economia Agrícola e do Meio Ambiente e ofertado por um dos maiores centros brasileiros de formação superior.

Aos professores componentes da banca de defesa do exame de qualificação e da tese, Professores Luiz Batista (UEG), Denise Imbroisi (UnB), Pedro Zuchi (UnB), e Ricardo Coelho Faria (UCB) e Waldecy Rodrigues (UFT), pelos comentários avaliativos/corretivos, essenciais ao aperfeiçoamento e aprovação do estudo.

Ao meu orientador, Professor Jorge Madeira Nogueira, por me receber tão carinhosamente quando aqui cheguei, por me avisar dos percalços que encontraria e por se preocupar comigo nessa caminhada. Quero agradecer profundamente por seu ensinamentos, com palavras e atitudes. Não falo somente de seus conhecimentos como professor, mas como mestre que se posiciona frente a vida, é incansável em sua luta, é firme em suas decisões, é amoroso ao extremo quando percebe nossas fraquezas e acolhe cada um de nós em seu coração como se fôssemos seus filhos. Guerreiro indomável frente às dificuldades. Sua voz se torna doce quando precisa chamar nossa atenção, percebe nossa dor como se fosse a sua dor, tem compaixão por nossa ignorância e tenta, com todo seu conhecimento, amenizar nossos erros. Obrigada por sua orientação segura, por suas histórias, seu sorriso, que tanto acalma o coração. Por me lembrar que uma tese não é um romance. Sempre procurei um espelho por mestre, finalmente a procura cessou.

Ao Professor Pedro Zuchi, pela alegria com que ministrava as aulas e fazia com que os dias ficassem mais amenos e ensolarados. A sua maior qualidade como professor é a generosidade como nos trata e ao seu sorisso largo ao perceber nossa ignorância. São momentos inesquecíveis.

Ao Professor Marcelo Torres, pelos valiosos ensinamentos, por exigir de cada um de nós nosso melhor, pelas palavras de apoio e incentivo, pela compreensão frente a nossa falta de saber.

Ao Professor Ricardo Araújo, pelo apoio e incentivo quando aqui cheguei, por acreditar nesse momento e antecipá-lo com suas palavras de incentivo.

Aos meus amigos (acredito que posso me referir assim) Liliane e Claudiano, pela oportunidade da convivência, pelos momentos de descontração em sala de aula e fora dela, pelas conversas via e-mail para que pudéssemos desabafar e continuar em frente, pelos trabalhos compartilhados, ora tão difíceis ora tão prazerosos, enfim, pelos abraços na hora que mais precisei. 
Aos meus colegas, Cristina Galvão, Maria Daniele, Carolina Bernardo, Debora Santiago, Dainy Flores, Daniel e André, por todos os momentos compartilhados, vocês deram brilho aos meus dias na UnB.

A Inez amiga que leu meus apontamentos incansavelmente, colocando todas as vírgulas e pontos e apontando as frases incompletas que eu pensava ter escrito, mas que na realidade estava apenas no meu imaginário.

Às secretárias: Waneska, pela atenção em me socorrer ao telefone e pessoalmente, por conversar comigo amenidades depois de um ou dois puxões de orelha (bem merecidos) de meu orientador, você é um porto seguro na UnB. A Carina e Joana Dark, pela atenção dispensada na secretária, e ao Assistente Rafael, pelo sorriso tímido sempre que me encontrava e pela atenção e cuidado em questões operacionais importantes.

Aos meus grandes amigos de caminhada, José, Serafim, Romualdo, Alberto, Maria, Flora, Malbatã, Davi, vocês são luzes na minha vida, presença constante no caminho de quem mal sabe caminhar. Obrigado por todos os conselhos, opiniões e força quando em queda eu fraquejava, acredito que sem vocês nada seria igual.

Por fim, aos guerreiros da Luz, a Deus, que me encaminhou, que me iluminou em todo o processo. Pela ajuda e inspiração na hora em que não conseguia escrever uma só palavra. Aos conselhos que recebo dia e noite, por me acolher como sua filha, por me amar sempre, independente de quem sou, por me amparar e me alertar para o bem. Por nunca ter desistido de mim com toda minha pequenez. 
Há um descuido e um descaso na salvaguarda de nossa casa comum, o planeta Terra. Solos são envenenados, ares são contaminados, águas são poluídas, florestas são dizimadas, espécies de seres vivos são exterminadas; um manto de injustiça e de violência pesa sobre dois terços da humanidade. Um princípio de autodestruição está em ação, capaz de liquidar o sutil equilíbrio físico-químico e ecológico do planeta e devastar a biosfera, pondo assim em risco a continuidade do experimento da espécie homo sapiens e demens.

Leonardo Boff (1999, p. 20). 


\section{RESUMO}

A valoração ambiental, um conjunto de métodos para atribuir valor a um bem ou serviço que ainda não possui mercado, vem ganhando espaço na preocupação dos pesquisadores, no intuito de apresentar um valor que corresponda à importância que o ativo, o bem ou o serviço representa para a comunidade em que estejam inseridos. Há, no entanto, uma absoluta escassez de estudos avaliando essas aplicações de métodos de valoração econômica. Tem-se a impressão de que a análise crítica de procedimentos de pesquisa tem sido pouco praticada em valoração econômica ambiental no Brasil. O objetivo principal desta tese é avaliar o atual estado-das-artes em valoração econômica do meio ambiente no Brasil. Analisando todo e qualquer aplicação dos métodos função demanda no período de 1985 a 2014. A fonte básica para levantamento das referências técnicas e acadêmicas foi a rede mundial de computadores. Além dessa fonte, foram também consultados os bancos bibliográficos das universidades que possuem programa de pósgraduação com linha de pesquisa direcionada ao meio ambiente. O Método de Valoração Contingete (MVC) apresenta deficiências em suas aplicações no Brasil, em particular frequentes vieses; inadequada a descrição do cenário; o uso de amostra pouco significativa e abrangente. Quanto ao Método Custos de Viagem (MCV) alguns locais que foram valorados coexistiam inevitavelmente com mais de um destino, mas esses foram ignorados para o cálculo da equação de demanda. Alguns trabalhos não apresentam teste de validade do construto e convergência. Outro problema é o momento da coleta de dados: ou usaram somente o período de alta temporada, o que pode ter superestimado o valor, ou usaram baixa temporada, o que subestimou o valor. No que tange aos estudos sobre o Método Preço Hedônico (MPH) as mais frequentes criticas recaem sobre o tamanho escolhido para a amostra, tipos de variáveis utilizadas, modelo econométrico, análises superficiais dos resultados, omissões de qualidades adjacentes ao imóvel, entre outras. Existe carência de trabalhos teóricos que explicitem ao leitor/pesquisador as deficiências e vantagens do método.

Palavras Chaves - Métodos Função demanda. Método Valoração Contingente. Método Custos de Viagem. Método Preço Hedônico. 


\begin{abstract}
The environmental valuation, which is a set of methods to assign value to a good or service that does not have market has been gaining ground in the concern of researchers in order to provide a value that matches the importance of the asset, good or service has for the community to which they belong. There is, however, an absolute scarcity of studies evaluating such applications economic valuation methods. One gets the impression that the critical analysis of research procedures has been little practiced in environmental economic valuation in Brazil. The main objective of this thesis is to evaluate the current state-of-art in economic valuation of the environment in Brazil. Analyzing each and every application demand function methods from 1985 to 2014. The basic source for raising the technical and academic references was the World Wide Web. In addition to this source, banks of universities that have graduate program line of research directed to the environment were also consulted. The Contingent Valuation Method presents deficiencies in its applications in Brazil, particularly frequent biases; inadequate description of the scenario; the use of minor and comprehensive sample. As for the Travel Cost Method some sites that were valued inevitably coexisted with more than one destination, but these were ignored for the calculation of the demand equation. Some researches do not present any validity tests of the construct and convergence. Another problem is the time of data collection: or only used the period of high season, which may have overestimated the amount used or low season, which underestimated the value. With respect to studies on the Hedonic Price Method most critics are directed to the size chosen for the sample, types of used variables, econometric model, superficial analyzes of the results, omission of adjacent qualities to the property, among others. There is lack of theoretical works which explain to the reader / researcher the deficiencies and advantages of the method in a more clear way.
\end{abstract}

Key Words - Methods Function demand. Contingent Valuation Method. Travel costs method. Hedonic price method. 


\section{LISTA DE FIGURAS E GRÁFICOS}

Figura 1.1 - Categorias dos valores ambientais $\quad 35$

Figura 1.2 - Relação entre o valor econômico do recurso ambiental e os serviços ecossistêmicos 38

Gráfico 2.1 - Curva de Demanda Marshalliana e o excedente do consumidor 56

Gráfico 2.2 - Variação Compensatória e Variação Equivalente 59

Gráfico 2.3 - Excedente Copensatório para um aumento de quantidade 63

Gráfico 2.4 - Excedente Equivalentepara um aumento de quantidade $\quad 65$

Gráfico 2.5 Curva de Demanda Ordinária (Marshall) e Compensada (Hicks) 67

Gráfico 3.1 - Número de trabalhos com o uso do MVC- Brasil 1999 -2014 81

Gráfico 3.2 - Áreas de conhecimentos dos estúdos empíricos- 1997-2014 81

Gráfico 3.3 - Instituições de Ensino que mais colaboraram com os trabalhos teóricos sobre o MVC - 1999 - 2014

Gráfico 3.4 - Estados que tiveram ativos ambientais valorados pelo MVC - 1997 $-2014$

Gráfico 3.5 - Subdivisão dos trabalhos da área Patrimônio Histórico Cultural$2004-2014 \quad 84$

Gráfico 3.6 - Subdivisão dos trabalhos da área de saúde humana - 2002- $2014 \quad 85$

Gráfico 3.7 - S Subdivisão dos trabalhos da área de recursos hidricos - 1999- $2014 \quad 86$

Gráfico 3.8 - Subdivisão dos trabalhos da área de Conhecimento tradicional$1998-2014$

Gráfico 3.9 - Bens que causam impacto à saúde - 2002-2014 $\quad 88$

Gráfico 3.10 - Recursos hídricos - 1999 - 2014

Gráfico 3.11- Bens culturais e patrimônio histórico - 2004 - 2014

Gráfico 3.12 - Conhecimento tradicional - 1998 - 2014

Gráfico 3.13 - Vieses apresentado nos trabalhos sobre bens que causam impactos a saúde - 2002 - 2014

Gráfico 3.14 - Vieses apresentado nos trabalhos sobre bens culturais e patrimônio histórico - 2004 - 2014

Gráfico 3.15 - Vieses apresentado nos trabalhos sobre recursos hidricos - 19992014 
Gráfico 3.16 - Vieses apresentado nos trabalhos sobre conhecimento tradicional $-1998-2014$

Gráfico 4.1 - Estados que tiveram alguns ativos ambientais valorados pelo MCV- 1993 - 2014

Gráfico 4.2 - Instituições de ensino que mais colaboraram com pesquisas usando o MCV- 1993 - 2014

Gráfico 4.3 - Produção de artigos com o uso do MCV - Brasil 1993 - 2014

Gráfico 5.1 - Produção de artigos com o uso do Método Preços Hedônicos$1987-2014$

Gráfico 5.2 - Classificação dos trabalhos que usam MPH segundo qualidade dos vetores adjacentes ao imóvel- 1987-2014

Gráfico 5.3 - Estados brasileiros que foram avaliados pelo MPH com variável ambiental- 1987-2014

Gráfico 5.4 - Instituições de ensino que colaboraram com as pesquisas empíricas usando o MPH - 1987 - 2014

Gráfico 6.1 - Trabalhos Internacionais mais citados no Brasil- MVC, MCV e $\mathrm{MPH}$

Gráfico 6.2 - Trabalhos nacionais mais citados no Brasil- MVC, MCV e MPH

Gráfico 6.3 - Motivos de valoração ambiental no Brasil - MVC, MCV e MPH

Gráfico 6. 4 - Instituições de Ensino que mais colaboraram com a divulgação das técnicas de valoração ambiental - MVC, MCV, MPH no Brasil

Gráfico 6.5 - Visão geral de trabalhos escritos sobre ativos ambientais na Região Centro-Oeste do Brasil

Gráfico 6.6 - Visão geral de trabalhos escritos sobre ativos ambientais na Região Sudeste do Brasil

Gráfico 6.7 - Visão geral de trabalhos escritos sobre ativos ambientais na Região Sul do Brasil

Gráfico 6.8 - Visão geral de trabalhos escritos sobre ativos ambientais na Região Noreste do Brasil

Gráfico 6.9 - Visão geral de trabalhos escritos sobre ativos ambientais na Região Norte do Brasil

Gráfico 6.10 - Trabalhos de Valoração Ambiental Métodos- MVC, MCV, MPH no Brasil- 1993-2014 
Gráfico 6.11- Produção de trabalhos teóricos segundo método e ano - 1998 -

2014

Gráfico 6.12- Trabalhos teóricos por Instituição de Ensino e ano de publicação1998- 2014

Gráfico 6.13 Produção de trabalhos teóricos sobre Métodos de Valoração por região e ano- 1998-2014 


\section{LISTA DE QUADROS}

Quadro 1.1 - Fórmulas desagregadas do VET de acordo com seus principais proponentes (1983-2010).

Quadro 1.2 - Classificação dos métodos de valoração ambiental segundo diversos autores no período de 1983 a 2000.

Quadro 1.3 - Classificação dos métodos de valoração ambiental segundo diversos autores no período de 2001 a 2007.

Quadro 1.4 - Métodos de Valoração Equivalentes.

Quadro 2.1 - Dualidade entre medidas de Maximização da utilidade e minimização de gastos.

Quadro 2.2 - Relação entre medidas de bem-estar

Quadro 3.1 - Principais publicações por área de conhecimento e assunto do Método de Valoração Contingente de 1970 até 2013.

Quadro 3.2 - Possíveis vieses do Método de Valoração Contingente. 76

Quadro 3.3 - Classificação dos mecanismos da captação da DAP 77

Quadro 3.4- Formas de abordagem do MVC

Quadro 3.5 - Problemas de aplicação do Método de Valoração Contingente e os vieses Associados.

Quadro 3.6 - Itens indispensáveis a um relatório de Pesquisa para o Método de Valoração Contingente.

Quadro 3.7 - Avaliação de relatório de estudos brasileiros para o Método de Valoração Contingente.

Quadro 3.8 - Sugestões de checklist detalhado para um relatório de pesquisa com uso de MVC.

Quadro 4.1 - Pesquisa em Parques Brasileiros que foram valorados pelo Método de Custo de Viagem- Brasil (1977-2013)

Quadro 4.2 - Principais trabalhos que utilizaram o Método Custo de Viagem em balneários, rios e praias no Brasil (1998-2010)

Quadro 4.3 - Avaliação de relatório de estudos brasileiros com o uso do Método Custo de Viagem

Quadro 4.4-Sugestões de checklist para um relatório de pesquisa para o Método Custo de Viagem.

Quadro 5.1 - Aplicações do Método do Preço Hedônico

Quadro 5.2 - Características detalhadas das propriedades residenciais - Método do Preço Hedônico 
Quadro 5.3-Formas funcionais mais frequentes usadas no Método do Preço Hedônico

Quadro 5.4 -Limitações e vieses do Método do Preço Hedônico

Quadro 5.5 - Características ambientais inclusas nos trabalhos no Brasil (19972013)

Quadro 5.6 - Itens indispensáveis a um relatório de Pesquisa - Método do Preço Hedônico

Quadro 5.7 - Avaliação de relatório de estudos brasileiros com o uso do Método do Preço Hedônico

Quadro 5.8 - Sugestões de checklist detalhado para um relatório de pesquisa com uso de MPH

Quadro A.1 -Quantidade de trabalhos empíricos que usaram o Método de Valoração Contingente por Estado Brasileiro (APÊNDICE A)

Quadro A.2 -Número de publicações sobre o para o Método de Valoração Contingente (1997-2013) (APÊNDICE A)

Quadro A.3 - Valores atribuídos aos Bens e/ou serviços ambientais pelo Método de Valoração Contingente no Brasil (1997-2013) (APÊNDICE A)

Quadro A.4 - Trabalhos teóricos da valoração contingente no Brasil (APÊNDICE A)

Quadro A.5 - Trabalhos empíricos analisados que utilizaram o Método Valoração Contingente no Brasil (APÊNDICE A)

Quadro B.1 - Trabalhos empíricos com o uso do Método Custo de Viagem - Brasil (1993-2013) (APÊNDICE B)

Quadro B.2 -Caraterísticas e modelos utilizados para pesquisas com o uso do Método Custo de Viagem (APÊNDICE B)

Quadro B.3 - Trabalhos empíricos analisados que utilizaram do Método Custo de Viagem no Brasil (APÊNDICE B)

Quadro C.1 -Pesquisas Teóricas sobre Preços Hedônicos (1999-2013) (APÊNDICE C)

Quadro C.2 - Trabalhos Empíricos sobre Valoração com o uso do Método de Preços Hedônicos no Brasil (1987-2013) (APÊNDICE C)

Quadro C.3 - Trabalhos empíricos analisados que utilizaram do Método Preços Hedônicos no Brasil 


\section{LISTA DE TABELAS}

Tabela 6.1 - Quantidade de Trabalhos empíricos por métodos e por regiões no Brasil -1993-2014

Tabela 6.2 - Número de Trabalhos empíricos sobre os métodos de valoração MVC, MCV e MPH por tipos de bens e por regiões no Brasil 1993-2014

Tabela A.1 - Produção de trabalhos com o uso do MVC- Brasil 1999 2014 (APÊNDICE A)

Tabela A.2 - Áreas de conhecimento dos estudos empíricos- 1997 -2014 (APÊNDICE A)

Tabela A.3 - Estados que tiveram atrativos ambientais valorados pelo MVC1997-2014 (APÊNDICE A)

Tabela A.4 - Subdivisão dos trabalhos da área Patrimônio histórico cultural2004 -2014 (APÊNDICE A)

Tabela A.5 - Subdivisão dos trabalhos da áreas de saúde humana - 20022012 (APÊNDICE A)

Tabela A.6 - Subdivisão dos trabalhos da área de recursos hídricos - 19992014 (APÊNDICE A)

Tabela A.7 - Subdivisão dos trabalhos da área de Conhecimento tradicional1998 -2014 (APÊNDICE A)

Tabela A.8 - Bens que causam impacto à saúde - 2002-2014 (APÊNDICE A)

Tabela A.9 - Recursos hídricos - 1999 - 2014 (APÊNDICE A)

Tabela A.10 - Bens culturais e patrimônio histórico - 2004 - 2014 (APÊNDICE A)

Tabela A.11 - Bens Conhecimento tradicional (APÊNDICE A)

Tabela A.12 - Vieses apresentado nos trabalhos sobre bens que causam impactos a saúde - 2002 - 2014 (APÊNDICE A)

Tabela A. 13 - Vieses apresentado nos trabalhos sobre bens culturais e patrimônio histórico - 2004 - 2014 (APÊNDICE A)

Tabela A.14- Vieses apresentado nos trabalhos sobre recursos hídricos - 1999- 
Tabela A.15 - Vieses apresentado nos trabalhos sobre conhecimento tradicional - 1998 - 2014 (APÊNDICE A)

Tabela B.1 - Estados que tiveram alguns ativos ambientais valorados_pelo MCV- 1993 - 2014 (APÊNDICE B)

Tabela B.2- Instituições de ensino que mais colaboraram com pesquisas usando o MCV- 1993 - 2014 (APÊNDICE B)

Tabela B.3- Produção de artigos com o uso do Método Custo de Viagem Brasil 1993 - 2014 (APÊNDICE B)

Tabela C.1- Produção de artigos com o uso do Método Preços Hedônicos1987 -2014 (APÊNDICE C)

Tabela C.2- Classificação dos trabalhos que usam MPH segundo qualidade dos vetores adjacentes ao imóvel- 1987-2014 (APÊNDICE C)

Tabela C.3- $\quad$ Estados brasileiros que foram avaliados pelo MPH com variável ambiental- 1987-2014 (APÊNDICE C)

Tabela C.4- Instituições de ensino que colaboraram com as pesquisas empíricas usando o MPH - 1987 - 2014 (APÊNDICE C)

Tabela D.1 - Autores internacionais mais citados em trabalhos brasileiros MVC - 1999 - 2014 (APÊNDICE D)

Tabela D.2 - Autores nacionais mais citados em com o uso do MVC, MCV e MPH - 1999- 2014(APÊNDICE D)

Tabela D.3 - Motivos de valoração ambiental no Brasil - MVC, MCV e MPH (APÊNDICE D)

Tabela D.4 - Instituições de Ensino que mais colaboraram com a Divulgação das técnicas de valoração ambiental - MVC, MCV, MPH no Brasil (APÊNDICE D)

Tabela D.5 - Trabalhos empíricos com o uso dos métodos de valoração ambiental - MVC, MCV, MPH para região Centro-Oeste do Brasil (APÊNDICE D)

Tabela D.6 - Trabalhos empíricos com o uso dos métodos de valoração ambiental - MVC, MCV, MPH para região Sudeste do Brasil (APÊNDICE D) 
Tabela D.7 - Trabalhos empíricos com o uso dos métodos de valoração ambiental - MVC, MCV, MPH para região Sul do Brasil (APÊNDICE D)

Tabela D.8- Trabalhos empíricos com o uso dos métodos de valoração ambiental - MVC, MCV, MPH para região Nordeste do Brasil (APÊNDICE D)

Tabela D.9 - Trabalhos empíricos com o uso dos métodos de valoração ambiental - MVC, MCV, MPH para região Norte do Brasil (APÊNDICE D)

Tabela D.10 - Trabalhos de Valoração Ambiental Métodos MVC, MCV, MPH no Brasil- 1993-2014(APÊNDICE D)

Tabela D.11 - Artigos teóricos publicados por ano, instituição de ensino e por tipo de método - 1998-2014

Tabela D.12 - Trabalhos teóricos por região ano de publicação - 1998 - 2014

Tabela D.13 - Trabalhos teóricos por ano e por instituição de ensino - 1998 2014 


\section{LISTA DE SIGLAS}

ADEMI - Associação das Empresas do Mercado Imobiliário de Pernambuco

AL - Alagoas

BA - Bahia

BID - Banco Interamericano de Desenvolvimento

BNH - Banco Nacional da Habitação

CENARGEN - Centro Nacional de Pesquisa de Recursos Genéticos e Biotecnologia

DAP - Disposição a Pagar

DAR - Disposição a Receber

DF - Distrito Federal

EMBRAPA - Empresa Brasileira de Pesquisa Agropecuária

IBGE - Instituto Brasileiro de Geografia e Estatística

IC - Item completo

IES - Instituições de Ensino Superior

IIC - Item Incompleto

INR - Item Não Realizado

IPEA - Instituto de Pesquisa Econômica Aplicada

IPSP - Instituto Politécnico de São Paulo

JB/FZB-BH - Jardim Botânico da Fundação Zoo-Botânica de Belo Horizonte

ML - Modelo de Logit Misto

MA - Maranhão

MCR - Método Custo Reposição

MCO - Método Custo de Oportunidade

MCV - Método Custo de Viagem

MCVI - Método do Custo de Viagem Individual

MDR - Método Dose-resposta

MEA - Millenium Ecosystem Assessment Report

MMA - Ministério do Meio Ambiente

MPH - Método de Preço Hedônico

MQO - Mínimos Quadrados Ordinários

MVC - Método de Valoração Contingente

MX- modelo de logit polinomial 
NOAA - National Oceanic and Atmospheric Agency

PA - Pará

PNB - Produto Nacional Bruto

POD - Parque Ecológico e de Uso Múltiplo Olhos D’água

PROCAV - Programa de Canalização de Córregos, Implantação de Vias e Recuperação

Ambiental e Social de Fundos de Vales

PUC-Rio - Pontifícia Universidade Católica do Rio

RUM - Random Utility Maximization

RN - Rio Grande do Norte

RO - Rondônia

SABESP - Companhia de Saneamento Básico do Estado de São Paulo

SEDNA - Arquitetura, Engenharia e Construção LTDA.

SNUC - Sistema Nacional de Unidades de Conservação

UCB - Universidade Católica de Brasília

UEG - Universidade Estadual de Goiás

UEL- Universidade Estadual de Londrina

UEMS - Universidade Estadual do Mato Grosso do Sul

UERJ - Universidade Estadual do Rio de Janeiro

UESC - Universidade Estadual de Santa Catarina

UFF - Universidade Federal Fluminense

UFG - Universidade Federal de Goiás

UFMG - Universidade Federal de Minas Gerais

UFMT - Universidade Federal do Mato Grosso

UFPE - Universidade Federal de Pernambuco

UFPEL - Universidade Federal de Pelotas

UFPI - Universidade Federal do Piauí

UFPR - Universidade Federal do Paraná

UFRJ - Universidade Federal do Rio de Janeiro

UFRS - Universidade Federal do Rio Grande do Sul

UFSC - Universidade Federal de Santa Catarina

UFT - Universidade Federal do Tocantins

UFU - Universidade Federal de Uberlândia

UFV - Universidade Federal de Viçosa

UnB - Universidade de Brasília 
UNESCO - Organização das Nações Unidas para a Educação, Ciência e Cultura.

UNICAMP - Universidade de Campinas

UNOCHAPECÓ - Universidade Comunitária da Região de Chapecó

UPF - Universidade de Passo Fundo

USP - Universidade de São Paulo

VC - Valoração Contingente

VE - Valor de Existência

VERA - Valor Econômico dos Recursos Ambientais

VET - Valor Econômico Total

VH - Valor de Herança

VNU - Valor de Não Uso

VPU- Valor de Possível Uso

VO - Valor de Opção

VQO - Valor de Quase-Opção

VU - Valor de Uso

VUD - Valor de Uso Direto

VUI - Valor de Uso Indireto 


\section{SUMÁRIO}

CONSIDERAÇÕES INICIAIS .................................................................................................23

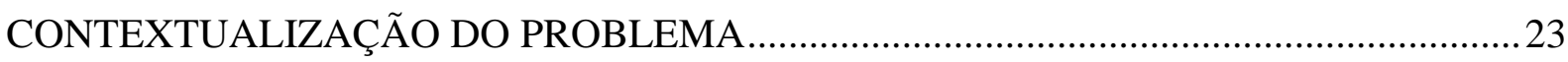

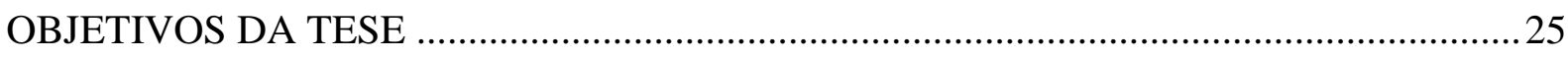

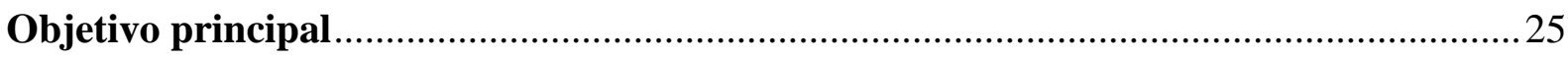

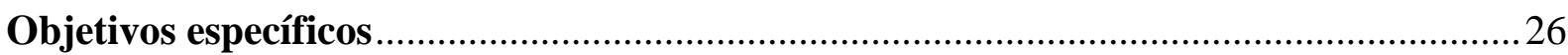

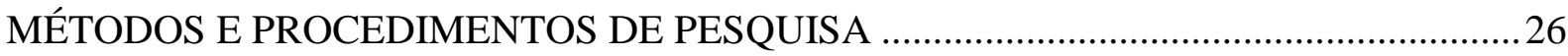

ESTRUTURA DA TESE E CONTEÚDOS DOS CAPÍTULOS...............................................27

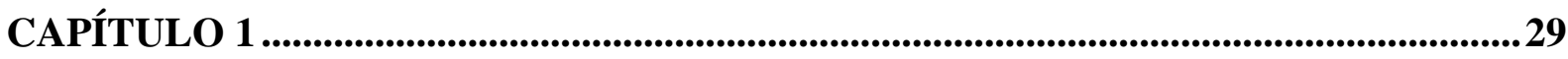

VALORAÇÃO ECONÔMICA DO MEIO AMBIENTE:.....................................................29

APRESENTAÇÃO PANORÂMICA ..........................................................................................29

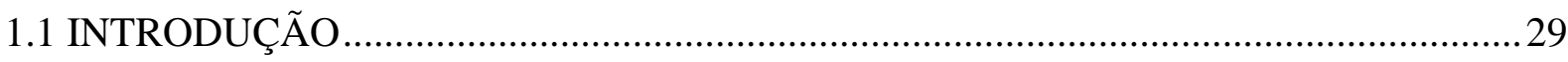

1.2 CONSIDERAÇÕES ECONÔMICAS SOBRE VALOR ……………………………......... 30

1.3 A RELEVÂNCIA DA VALORAÇÃO AMBIENTAL ……………………………......... 32

1.4 AS DIVERSAS CLASSIFICAÇÕES DOS MÉTODOS DE VALORAÇÃO......................38

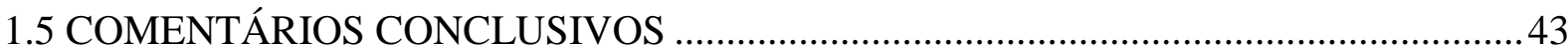

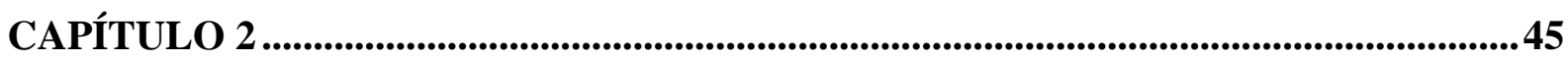

MOLDURA CONCEITUAL DOS MÉTODOS FUNÇÃO DEMANDA .............................45

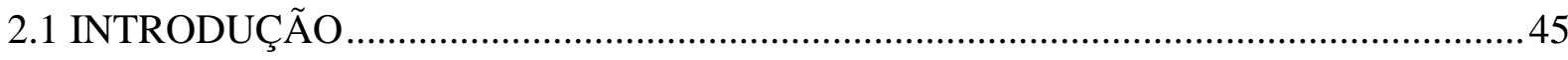

2.2 AS PREFERÊNCIAS DO CONSUMIDOR: A ESCOLHA ……………………………....47

2.4 MEDIDAS DE BEM-ESTAR E OS BENS E SERVIÇOS AMBIENTAIS ........................54

2.5 MICROECONOMIA DA VALORAÇÃO: O DESEJÁVEL E O POSSÍVEL ....................64

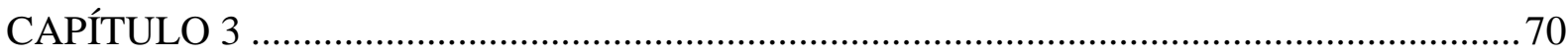

VALORAÇÃO CONTINGENTE:.....................................................................................70

QUEM PERGUNTA O QUE QUER, OBTÉM O QUE NÃO QUER..................................70

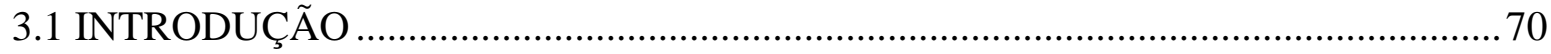

3.2 EVOLUÇÃO TEMPORAL DO MÉTODO DE VALORAÇÃO CONTINGENTE ......71

3.3 AS APLICAÇÕES DO MVC NO BRASIL: QUANTITATIVOS .................................. 80 
3.4 ANÁLISES GERAIS DAS APLICAÇÕES DO MVC NO BRASIL ...............................87

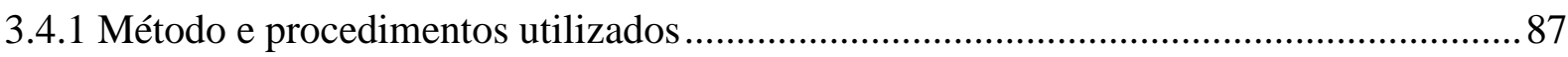

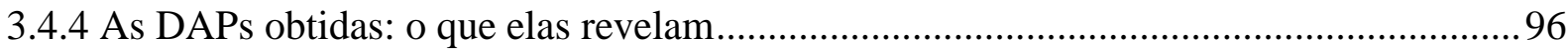

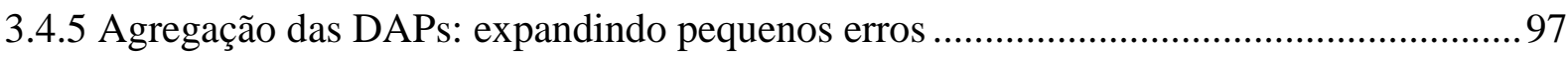

3.5 ANÁLISES PONTUAIS DOS VIESES EM ESTUDOS BRASILEIROS DO MVC........99

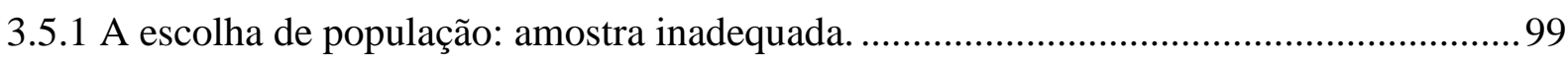

3.5.2 Instrumento da pesquisa: a projeção do cenário ....................................................... 104

3.5.3 Relatórios dos estudos pelo MVC e a validade de conteúdo....................................... 109

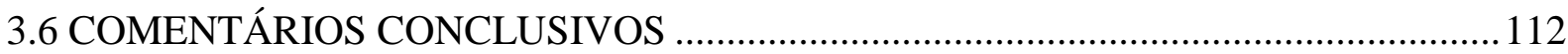

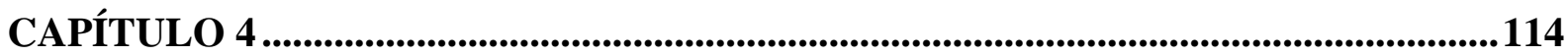

VÁRIOS CAMINHOS UM OBJETIVO: O MÉTODO CUSTOS DE VIAGEM...........114

4.1 INTRODUÇÃ

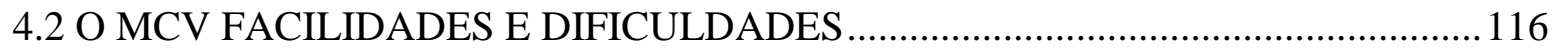

4.2.1 Aplicações do MCV e análises dos dados obtidos .................................................. 119

4.3 CONTORNANDO AS LIMITAÇÕES DO MCV EM 67 ANOS DE PESQUISA ......123

4.4 O MÉTODO CUSTOS DE VIAGEM APLICADO NO BRASIL .................................126

4.5 ANÁLISES DE ESTUDOS BRASILEIROS DE VALORAÇÃO COM O MCV .......... 135

4.5.1 Análises gerais das aplicações do MCV: pequenos erros, grandes problemas ..............135

4.5.2 Análises pontuais dos vieses em estudos brasileiros para valoração ambiental no uso do

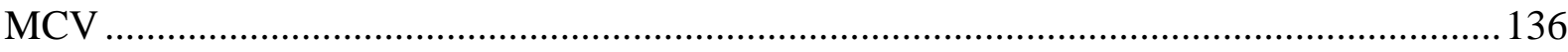

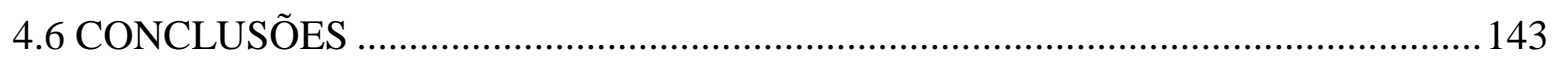

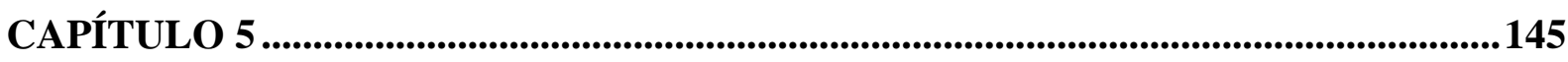

O PRAZER, A ESCOLHA, O CONSUMO E A QUALIDADE DE VIDA: O MÉTODO

DOS PREÇOS HEDÔNICOS .....................................................................................................145

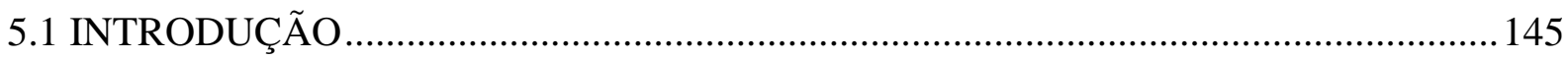

5.2 CARACTERÍSTICAS, PERCALÇOS E PROFICUIDADES DO MPH ........................ 146

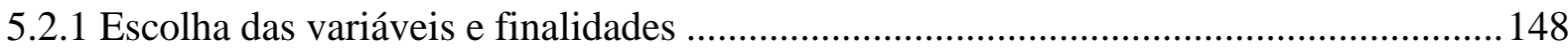


5.2.2 A função de preços hedônicos e os problemas econométricos. 149

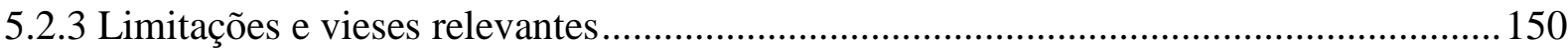

5.3 APLICAÇÕES DO MPH: HISTÓRICO E ESTUDOS RECENTES ............................. 152

5.3.1 Estudos recentes do MPH: as publicações estrangeiras ............................................ 152

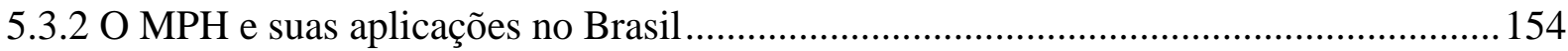

5.4 ANÁLISES DE ESTUDOS BRASILEIROS DE VALORAÇÃO COM O MPH........... 160

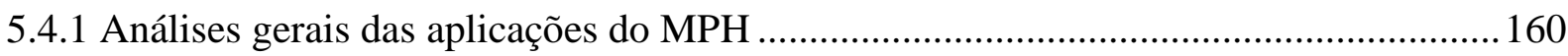

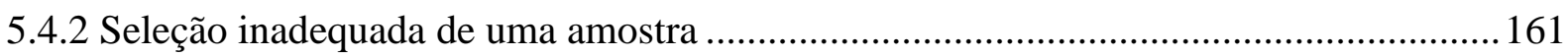

5.4.3 Instrumento da pesquisa: a caracterização do objeto valorado.................................... 162

5.4.4 Relatórios dos estudos pelo MPH e a validade de conteúdo ........................................ 163

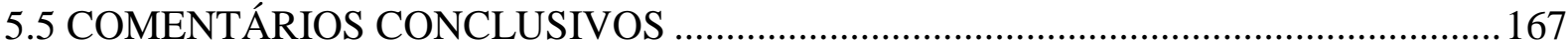

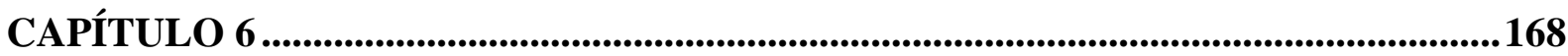

UMA AVALIAÇÃO GERAL DA EXPERIÊNCIA BRASILEIRA ...............................168

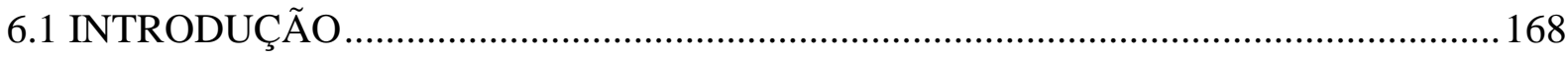

6.2 OS AUTORES E SUAS OBRAS: O QUE DIZEM AS REFERÊNCIAS......................169

6.3 RESULTADOS DE VALORAÇÃO AMBIENTAL NO BRASIL ................................. 171

6.3.1 Motivos de valoração e fontes de financiamento .................................................... 171

6.3.2 Panorama da valoração ambiental por região no Brasil .............................................. 174

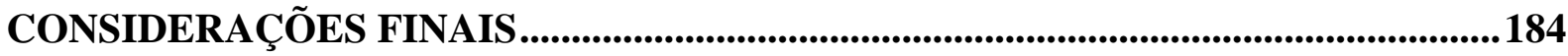

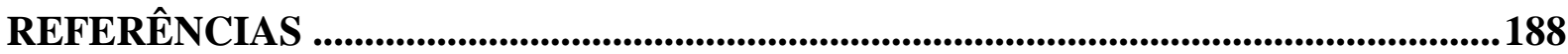

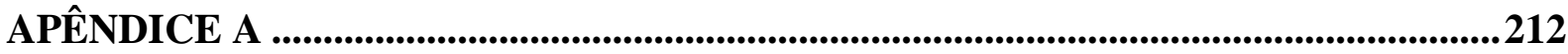

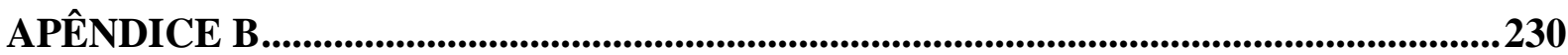

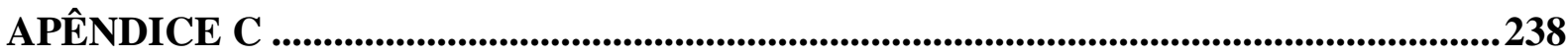

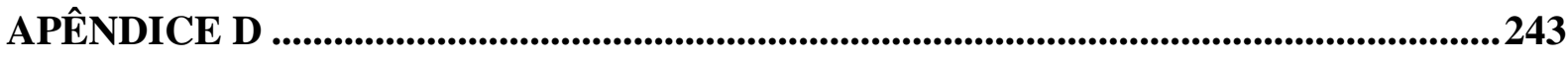

ANEXO A 


\section{CONSIDERAÇÕES INICIAIS}

\section{CONTEXTUALIZAÇÃO DO PROBLEMA}

Esta é uma pesquisa sobre valoração econômica do meio ambiente. No entanto, ela não é mais uma aplicação de um dos métodos de valoração econômica para estimar o valor de uma alteração em um bem, um serviço ou um patrimônio ambiental. O seu objetivo é analisar as aplicações de alguns desses métodos de valoração por pesquisadores brasileiros sobre aspectos distintos do nosso capital natural. O observador atento percebe um crescimento significativo que será demonstrado ao longo desta Tese - de exercícios de valoração econômica no país. Esse crescimento tem sido motivado por diversos fatores: curiosidade científica, auxílio ao desenho, implantação ou avaliação de políticas, programas ou projetos ambientais, subsídio a processos e/ou decisões judiciais, para mencionar os mais importantes.

Os mercados para bens e serviços ambientais apresentam falhas ou simplesmente não existem. A manutenção e/ou a preservação dos bens ambientais podem não estar entre as prioridades dos interesses individuais, de empresas ou, até mesmo, do governo. Em outras palavras, não são incorporados ao cálculo financeiro, pois não possuem preço de mercado. No entanto, podem ser essenciais para a sociedade ou para alguns de seus grupos sociais. Dito de outra forma, eles possuem valor econômico. Decisões baseadas apenas em estimativas financeiras podem levar à degradação ou ao desaparecimento desses ativos ambientais. A valoração ambiental vem ao encontro desses anseios para cobrir essa lacuna entre os valores financeiros e os econômicos.

A valoração ambiental, que é um conjunto de métodos para atribuir valor a um bem ou serviço que ainda não possui mercado, vem ganhando espaço na preocupação dos pesquisadores, no intuito de apresentar um valor que corresponda à importância que o ativo, o bem ou o serviço representa para a comunidade em que estejam inseridos. Por essas razões, estudos e pesquisas na área econômica, ecológica e ambiental têm voltado os olhos para a valoração de recursos naturais. Uma razão simples para o fato é que a tomada de decisão dos agentes socioeconômicos e políticos torna-se mais precisa, pois identifica, com mais clareza, os custos e os benefícios, sejam eles econômicos, sociais, individuais ou coletivos, relacionados ao uso do recurso ambiental. Dessa forma, o processo de tomada de decisão, quanto ao mais adequado manejo dos recursos naturais em forma de bens ou serviços ambientais, torna-se mais eficaz e eficiente. Essa é uma das explicações para o intenso crescimento das aplicações de métodos de valoração econômica do meio ambiente no Brasil. 
Há, no entanto, uma absoluta escassez de estudos avaliando essas aplicações de métodos de valoração econômica. Exceto por poucos estudos que aferem um número muito limitado de utilizações de certos métodos (ver, por exemplo, May, Veiga Neto e Pozo (2000), Abad (2002), Aiache (2003) na sequência desta Tese), as centenas de aplicações de valoração econômica do meio ambiente realizadas no Brasil não têm sido objeto de pesquisas científicas de maior folego. Tem-se a impressão de que a "análise crítica de procedimentos de pesquisa" - característica essencial de qualquer ciência - tem sido pouco praticada em valoração econômica ambiental no Brasil.

Essa lacuna de investigações científicas é preocupante. Valorar os recursos ambientais é uma atividade complexa. O valor econômico de um elemento do capital natural depende de relações entre os sistemas econômico e ecológico. Valor é uma "grandeza que atribui qualidades ao objeto e permite priorizar, comprar, decidir e agir racionalmente sobre ele" (SOUZA, 2000, p. 176). Para isso, muitas vezes a valoração econômica do meio ambiente associa valores dependentes das preferências dos consumidores e dessas com sua capacidade de pagamento. Por outro lado, a valoração econômica do meio ambiente constitui-se em um conjunto de métodos e técnicas que buscam estimar valores para alterações nos ativos ambientais e nos bens e serviços prestados pela natureza, bem como para os impactos ambientais decorrentes das ações antrópicas (MADONADO, 2006). Segundo Motta (2001), a valoração econômica do meio ambiente envolve cinco aspectos, a saber:

- Sustentabilidade biológica: atuando como função do meio ambiente na cadeia alimentar e na matriz de suprimentos e como ação de proteção sustentável dos recursos naturais;

- Enfoque ecológico: como elemento de análise da capacidade de suporte e resiliência dos recursos naturais em uso e como subsídio às ações mitigadoras de degradação dos recursos naturais;

- Estratégia de defesa do capital natural: como forma de manter o capital natural e como função estratégica dos recursos naturais para o desenvolvimento dos países;

- Subsídio à gestão ambiental: como forma de defesa ética do meio ambiente e como suporte à formulação de políticas públicas ambientais;

- Enfoque nos aspectos econômicos: como forma de estimação dos preços dos ativos naturais que não são cotados no mercado convencional, como mecanismo de mensuração monetária das externalidades oriundas de projetos de investimentos, como mecanismo de internalização de custos ambientais e como método de estimação de indenizações judiciais. 
Os vários métodos de valoração econômica, por outro lado, precisam ainda ser bem estruturados às novas realidades e o aprofundamento teórico faz-se necessário para que não seja criada uma falsa impressão de rigor dos resultados, o que já foi comentado por Mueller (2007). Assim, todo método de valoração deve ser baseado em uma sólida teoria para que os valores obtidos possam ser confiáveis e interpretáveis. Ademais, todo e qualquer método de valoração econômica deve ser aplicado de acordo com certos procedimentos metodológicos e operacionais para que possa gerar resultados confiáveis. Cabe ainda ressaltar que os resultados obtidos a partir de aplicações desses métodos devem ser generalizados com cautela para que não representem distorções da realidade.

Já podemos, então, especificar um pouco mais esta pesquisa. Ela busca avaliar o atual estado-das-artes em valoração econômica do meio ambiente no Brasil. Por "atual”, entendemos as últimas três décadas, entre 1985 e 2014. Já o termo "estado-das-artes" aqui denota os trabalhos - técnicos e acadêmicos, teóricos e aplicados - que tratam de métodos de valoração econômica do meio ambiente, realizados no Brasil e/ou por pesquisadores brasileiros. Finalmente, por "avaliar" entendemos procedimentos que envolvem para cada estudo de valoração: a) identificar; b) resumir; c) entender seus objetivos, moldura conceitual, desenho metodológico, procedimentos de aplicação, manipulações estatísticas e obtenção dos resultados; d) comparar "c" ao recomendado pela literatura científica; e e) assinalar os aspectos robustos e frágeis dos estudos investigados. Essas são as cinco etapas que garantem, nós sugerimos, o rigor analítico necessário de uma perspectiva científica.

\section{OBJETIVOS DA TESE}

\section{Objetivo principal}

O objetivo principal desta tese é avaliar o atual estado-das-artes em valoração econômica do meio ambiente no Brasil. Esse objetivo implica a necessidade do estudo de valoração realizado no período de 1985 a 2014 seja submetido às cinco etapas que acabamos de mencionar. Assim procedendo temos a expectativa de darmos contribuições relevantes para o atual nível de conhecimento sobre aspectos conceituais e operacionais dos métodos de valoração econômica do meio ambiente. 


\section{Objetivos específicos}

1. Realizar amplo levantamento bibliográfico - on-line e em bibliotecas universitárias de publicações acadêmicas e técnicas que tratam de métodos de valoração econômica do meio ambiente, publicadas no Brasil e/ou por pesquisadores brasileiros sobre o Brasil;

2. Apresentar estatísticas descritivas sobre cada método aplicado em relação ao tipo de estudo, instituições realizadoras, autores, objeto valorado e distribuição geográfica desse objeto;

3. Efetuar revisão bibliográfica sobre as molduras conceituais e procedimentos metodológicos que fundamentam os métodos função demanda de valoração econômica do meio ambiente;

4. Resumir cada estudo sobre métodos função demanda de valoração econômica do meio ambiente realizado no Brasil ou por autores brasileiros, destacando seus objetivos, o método aplicado, os procedimentos metodológicos, os resultados obtidos e as deduções obtidas a partir desses resultados;

5. Proceder à análise dos estudos que aplicam um determinado método em relação a três aspectos - conceitual ou metodológico - considerados relevantes na literatura especializada no método em tela: a seleção da amostra, o instrumento da pesquisa usado para a obtenção das disposições a pagar; e o conteúdo dos relatórios dos estudos.

6. Destacar os aspectos robustos e os frágeis mais comuns nos estudos analisados, à luz do que preconiza a boa prática de aplicação de métodos função demanda de valoração econômica do meio ambiente em relação aos três aspectos analisados para cada método.

\section{MÉTODOS E PROCEDIMENTOS DE PESQUISA}

A base procedimental de toda esta pesquisa é a revisão crítica de literatura científica e técnica relacionada com aplicações de valoração econômica do meio ambiente. Nossa pesquisa bibliográfica caracteriza-se por um delineamento transversal por causa dosdiferentes métodos de valoração que são analisados. Como já assinalado, neste trabalho são expostos métodos de valoração de função demanda, conforme classificação analisada no Capítulo 1 a seguir. Os métodos de função demanda são essencialmente três: Valoração Contingente, Custos de Viagem e Preço Hedônico. Apesar de nosso levantamento ter identificado e catalogado inúmeros estudos utilizando os métodos função de produção, decidimos não analisa-los aqui 
para evitar riscos de análises superficiais, dado o grande número de aplicações de métodos função demanda. Por isso, concentra nossos esforços naqueles três métodos.

A fonte básica para levantamento das referências técnicas e acadêmicas foi a rede mundial de computadores. As principais ferramentas de busca utilizadas foram SciELO, Google Acadêmico e Portal Capes (Periódicos). As buscas mais intensas ocorreram entre dezembro de 2013 e dezembro de 2014. Nessas buscas, foram utilizadas como palavras-chave: valoração ambiental, valoração do meio ambiente, métodos de valoração do meio ambiente, valor do ativo ambiental, valoração pelo método (utilizou-se o nome do método). Os operadores booleanos ${ }^{1}$ ou quase-booleanos também foram utilizados. Além disso, fez parte da busca por artigos o nome do pesquisador ou do trabalho, já que as palavras-chave não eram suficientes para acessar o trabalho de pesquisa ${ }^{2}$. Além dessas fontes, foram também consultados os bancos bibliográficos das universidades que possuem programa de pós-graduação com linha de pesquisa direcionada ao meio ambiente.

Das diferentes fontes, obtivemos estudos materializados, em sua maioria, na forma de artigos. Também foram analisadas dissertações e teses. Depois de catalogados, lidos e resumidos, os trabalhos foram submetidos à análise quantitativa de conteúdo, com estimativas de número de trabalhos por método de valoração, bens, serviços ou ativos ambientais valorados por estado, por instituições de ensino superior (IES), órgãos públicos ou instituições privadas, modelos estatísticos usados, entre outros. Para uma subamostra dos estudos, uma avaliação correlacionando teoria à prática foi efetivada, procurando identificar se existia uma coerência nessa práxis.

\section{ESTRUTURA DA TESE E CONTEÚDOS DOS CAPÍTULOS}

O trabalho está dividido em seis capítulos, além das Considerações Iniciais e das Considerações Finais. O primeiro capítulo da Tese (Capítulo 1) apresenta uma visão panorâmica dos métodos de valoração econômica do meio ambiente, com base em uma revisão da literatura especializada. A ele segue o Capítulo 2, com uma apresentação da moldura conceitual relacionada especificamente aos métodos de função demanda. Esses métodos têm

\footnotetext{
${ }^{1}$ Os operadores booleanos são usados para relacionar termos ou palavras em uma expressão de uma pesquisa. Combina dois ou mais termos, de um ou mais campos de busca.

${ }^{2}$ No Brasil, diferentemente de outros países com tradição em pesquisa nessa área, as palavras-chave mudam muito. Não há um padrão de descritores para se ter acesso aos trabalhos escritos no país. Os poucos descritores existentes muitas vezes não são de conhecimento dos pesquisadores, que colocam as palavras-chave que melhor lhes aprovem.
} 
como base teórica as preferências dos consumidores. Procurou-se explicar os fatores que levam o consumidor a escolher uma cesta de bens, analisando-se o bem-estar por meio das medidas Marshallianas e Hicksianas, além de se fazer uma breve explanação entre as medidas de bemestar e a valoração do meio ambiente.

Cada um desses três métodos é tratado em um capítulo específico (compondo, assim, os capítulos 3, 4 e 5). Esses três capítulos apresentam estruturas iguais para facilitar uma apresentação coerente desta pesquisa. Assim, cada um deles é iniciado com uma apresentação geral (seção 3.1 a 3.2, 4.1 a 4.2 e 5.1) das características conceituais e operacionais do método objeto de análise no capítulo. Na seção seguinte (3.3, 4.3 e 5.2) são detalhados os quantitativos sobre as aplicações do método no Brasil ou por brasileiros. Na próxima seção $(3.4 ; 4.4,5.3)$ são analisados três aspectos de cada método considerados como aspectos basilares para uma aplicação rigorosa do método de valoração econômica do meio ambiente. A penúltima seção (3.5, 4.5 e 5.4) detalha a análise do capítulo, discutindo com maiores detalhes pelo menos dois estudos nos quais o método de valoração é aplicado. Os estudos devem ter características opostas: pelo menos um representando uma aplicação rigorosa e o outro uma aplicação que deve ser evitada. Cada um desses três capítulos é encerrado com uma seção de Considerações Finais (3.6, 4.6 e 5.5) sobre os principais resultados alcançados e com uma sugestão de "boas práticas na aplicação de método" correspondente ao capítulo. Uma lista em tópicos com essas recomendações está inclusa no respectivo capítulo.

O Capítulo 6 apresenta uma grande síntese dos principais resultados e das contribuições de nossa investigação. Ele é redigido com a preocupação de chamar a atenção de um iniciante na prática da valoração econômica do meio ambiente para a serventia, as exigências e as armadilhas do uso desses métodos. Entendemos, também, que o Capítulo permite uma amarração ainda mais clara dos diversos capítulos e seções da Tese. Encerramos o texto com Considerações Finais sobre análises complementares que podem (e devem) ser realizadas em futuras pesquisas sobre os usos e abusos dos métodos de valoração econômica do meio ambiente. 


\section{CAPÍTULO 1 \\ VALORAÇÃO ECONÔMICA DO MEIO AMBIENTE: APRESENTAÇÃO PANORÂMICA}

"To be or not to be, that's the question".

W. Shakespeare (1623)

\subsection{INTRODUÇÃO}

Parafraseando o poeta e dramaturgo inglês William Shakespeare, valorar ou não valorar o meio ambiente parece dominar as preocupações de certos economistas. Em inúmeros escritos sobre valoração, algumas questões são formuladas: por que é importante valorar o meio ambiente? Por que o interesse em valorar o capital natural aumentou nas últimas décadas? No imaginário humano, valorar a beleza natural é praticamente desnecessário fazê-lo porque, segundo se acredita, ela estará no mesmo lugar daqui a 50 ou 100 anos. Nos acostumados a tudo isso a custo zero. Quando na realidade custará muito, se tudo isso tiver que ser recuperado para não colocar em risco a sobrevivência não só humana, mas de todos os seres vivos.

Se o meio ambiente tiver um valor explícito, o ser humano será, com certeza, mais cuidadoso, para que, devido à escassez, os valores dos bens e serviços fornecidos pelo capital natural sofram aumentos abusivos. Ao se constatar a perda do bem-estar, os indivíduos procurarão minimizar sua falta e, na busca por soluções, um novo comportamento poderá ser aprimorado e incorporado às tomadas de decisões. As preferências poderão se manifestar e o valor do meio ambiente será revelado com mais acuidade.

$\mathrm{Na}$ tentativa de aperfeiçoamento da mensuração monetária, diversos métodos de valoração foram desenvolvidos e aplicados no contexto da economia do meio ambiente. Nenhum método é inteiramente apropriado para se avaliar um bem ambiental. Porém, eles podem ser combinados e cada um deles pode ser aprimorado, passando a incorporar as características ímpares dos recursos naturais. Quanto mais consistente, mais o valor se aproxima da realidade, e maior credibilidade confere ao método. Dentre os métodos existentes, uma característica chama a atenção: a divisão por presença ou não da função demanda em seu arcabouço teórico.

Os métodos que tem por base a presença da função demanda têm como meta revelar ou obter as preferências dos indivíduos. Fazem parte desse grupo o Método de Valoração 
Contingente (MVC), Método Custos de Viagem (MCV) e Método de Preços Hedônicos (MPH). Os métodos que não contemplam a função demanda estão reunidos em outro grupo que privilegia a função produção. Entre esses métodos estão o Método Dose-Resposta (MDR), Método Custo de Reposição (MCR), Método Custo de Oportunidade (MCO) e o Método Custos Evitados (MCE).

É importante destacar, no entanto, que essa é uma de muitas classificações existentes de métodos de valoração econômica do meio ambiente. Afora essa multiplicidade de classificações, a valoração econômica do meio ambiente gera uma série de controvérsias. Apesar da análise dessas controvérsias estar fora dos limites desta Tese, não podemos ignorálas totalmente, uma vez que alguns de seus aspectos têm consequências sobre o entendimento do que se deseja obter quando se valora economicamente um bem, serviço ou ativo ambiental. Além disso, o uso de um denominador comum chamado unidades monetárias gera, muitas vezes, interpretações bastante distintas daquilo que um economista deseja.

Esses temas compõem este primeiro capítulo desta Tese e está dividido em três partes, além dessa introdução e da conclusão. A primeira (seção 1.2) faz uma reflexão sobre o valor econômico de algo. Já a segunda (seção 1.3) destaca as dificuldades de se valorar o meio ambiente. Na terceira parte (seção 1.4) abordam-se os métodos de valoração e suas equivalências, os valores de uso e não uso, e possível uso que podem ser obtidos via diferentes métodos. Nessa seção são feitos comentários sobre os métodos de valoração e suas classificações em dois períodos distintos, de 1983 a 2000 e de 2001 a 2007, que foram períodos marcantes e com mudanças profundas no modo de classificar e agrupar os métodos.

\subsection{CONSIDERAÇÕES ECONÔMICAS SOBRE VALOR}

Quando se pensa em valor de uma perspectiva econômica neoclássica, instintivamente se pensa em quanto se está disposto a desembolsar por um bem ou serviço. A racionalidade neoclássica leva à relação entre valor e preço. $\mathrm{O}$ valor só existe se o bem ou serviço apresenta algum benefício ao indivíduo (alguma utilidade para ele ou ela). São as características dos bens e serviços percebidos pelos indivíduos que, decodificados, terão ou não significado e, desta percepção, surge o valor. Pelo menos surge o valor de acordo com a lógica da economia neoclássica.

Assim, o valor não é próprio do bem ou serviço, mas é algo dado a esse bem ou serviço pela percepção dos indivíduos. É a sensibilidade projetada na mente consciente das pessoas que faz surgir o valor imputado a algo ou alguma coisa. $\mathrm{O}$ valor é remetido a um 
sentimento muito ligado a abundância ou a escassez, à necessidade primária de sobreviver, a desejos ou aspirações. Somente quando se percebe os benefícios em desembolsar certa quantia que os indivíduos materializam, de forma monetária, o valor. Esse momento é singular e, de forma simbiótica, estabelece uma relação entre o indivíduo e o que está sendo valorado.

É, então, papel de quem se propõe a valorar algo mostrar a conexão entre o objeto e o desejo de adquiri-lo ou preservá-lo. Como saber, no entanto, se o bem ou serviço está sub ou supervalorizado? O valor varia de acordo com a vontade e a necessidade dos indivíduos e isso indica uma dimensão subjetiva. Para torná-la mais objetiva, devem ser estabelecidos critérios de análise. Porém, estabelecer critérios é, por vezes, muito complexo, principalmente se esse bem ou serviço estiver relacionado ao ambiente natural. Estabelecer um benchmark (ponto de referência) e esperar que seja superado por outros ativos é quase impossível, se a avaliação envolver ecossistemas e todas as suas dimensões.

De acordo com a abordagem valor-utilidade (Teoria Utilitarista), a atividade econômica se dá essencialmente entre o ser humano e o meio natural. Aquele atribui valor aos objetos na medida em que estes satisfaçam seus desejos (sua necessidade, sua utilidade). E isso parte de um comportamento subjetivo que varia de indivíduo para indivíduo. O fato de ser subjetivo não impede que seu comportamento seja analisado, desde que esse comportamento apresente coerência e consistência. O comportamento subjetivo pode ser estudado. Pode-se verificar em que medida ele é condicionado por vários fatores que, por sua vez, não são subjetivos. E é essa subjetividade do comportamento que cria as variedades nas preferências, nas escolhas entre diferentes formas de satisfazer necessidades (SINGER, 2004).

Para Singer (2004), a teoria do valor-utilidade é a-histórica, ou seja, julga que o comportamento humano na área econômica é essencialmente idêntico, embora possa mudar na sua manifestação concreta. Na sociedade moderna, o comportamento é mais dinâmico por causa do ritmo de transformação econômica. $\mathrm{O}$ ato de produzir estimula constantemente o consumidor a escolher, a ampliar a escala de seus desejos e a mudá-la. E, na medida em que responde a esses estímulos e que seu comportamento mude, ele torna viável uma série de transformações econômicas. Ele aprende a valorar e a explicar o valor de cada objeto e de cada serviço. É na troca que o valor se manifesta concretamente. Embora o valor seja subjetivo, aparece no comportamento objetivo das pessoas na troca. E é na variação da permuta que surge o preço. Esse preço é uma média de diferentes preços que diferentes indivíduos pagariam por um bem ou serviço. Se o bem custasse a metade, mais indivíduos o comprariam. Há indivíduos que estariam dispostos a pagar qualquer preço e indivíduos que pagariam menos, ou nada, por esse bem. Assim, se explica os preços efetivos no mercado. 
O valor é a razão entre a percepção de benefícios pelo preço, somado à expectativa de compra. Dois bens podem ser vendidos pelo mesmo preço, mas possuírem valores diferentes. Também podem possuir o mesmo valor e serem vendidos por preços diferentes. Quando julgamos algo como de alto custo ou baixo custo é fruto de nossa percepção dos benefícios recebidos na aquisição. Portanto, valor de mercado é a estimativa geral do valor de um bem, de acordo com a média das percepções de um determinado segmento de mercado. Preço de mercado é o preço médio pelo qual se estima vender este produto ou serviço nesse mesmo segmento. Menger (1988) explica a situação de valoração de bens e serviços ambientais quando afirma que o indivíduo, quando faz a avaliação de um bem, não investiga a história da sua origem, mas se preocupa exclusivamente em saber que serventia tem para ele e de que vantagens se privaria não dispondo dele.

\subsection{A RELEVÂNCIA DA VALORAÇÃO AMBIENTAL}

É nessa moldura conceitual que muitos métodos de valoração econômica do meio ambiente são baseados. Existem inúmeras justificativas para se valorar o meio ambiente. As razões expressas por pesquisadores consagrados que se preocupam com a valoração monetária dos recursos ambientais e naturais são: a) Instrumento complementar às decisões judiciais sobre avaliação de danos dos recursos naturais; b) interesse público para que a sociedade possa adicionar considerações para os balanços de custos e benefícios que ajudam a moldar a formulação de políticas governamentais; e c) interesses acadêmicos advindos das instituições de ensino e pesquisa. Ao atribuir valores monetários aos bens ou serviços fornecidos pelo capital natural, os benefícios associados a esse capital natural podem ser diretamente comparados com os valores econômicos de opções de utilizações alternativas de recursos (NUNES; VAN DEN BERGH, 2001). Os resultados dos métodos de valoração econômica ambiental podem fornecer evidências úteis para apoiar políticas de conservação de habitat e quantificar o valor econômico associado com a proteção de recursos biológicos (HANLEY; SHOGREN, 2002).

A importância da valoração ambiental não se esgota na busca por preço que expresse o valor econômico do meio ambiente. Pearce (1993) destacou cinco razões para se proceder a uma valoração:

1. Admitir que o meio ambiente faz parte do desenvolvimento estratégico de uma nação. Caso isso se confirme, todo dano causado ao ambiente provoca pelo menos dois impactos: a) Impacto no Produto Nacional Bruto (PNB), caso fossem computados os 
custos econômicos de danos ambientais; assim, o PNB teria um valor inferior; e b) custos gerais que não estivessem corretamente gravados no PNB deveriam sê-lo, pois o sistema de contas nacionais deve refletir as medidas de agregação de bem-estar.

2. Mudança do atual sistema de contas nacionais. No novo sistema, seria incorporado ao PNB o valor dos danos causados ao meio ambiente, assim como o valor do estoque existente.

3. A valoração serve como instrumento de apoio na definição de prioridades no âmbito das decisões políticas, com base em estimativas de custos e benefícios.

4. Complementação às metodologias convencionais de estudos de viabilidade, porque possibilita estimar custos e benefícios sociais gerados por políticas, programas ou projetos.

5. A valoração deve auxiliar no processo de avaliação do desenvolvimento sustentável, norteando se determinado ativo deve ser sacrificado ou não para ser explorado ou não pelas futuras gerações.

Em outro estudo, Pearce (2001) argumenta que expressar o valor econômico da biodiversidade torna-se um passo fundamental na conservação. As pressões para reduzir a biodiversidade são tão grandes que as chances de se introduzir algum incentivo para a sua proteção, por mais limitado que seja, incrementam as chances de consumação do que se não existisse valor algum. É preocupação, não recente, das economias ambiental e ecológica, internalizar os impactos antrópicos sobre o meio ambiente provocado pelo avanço depredativo nos ecossistemas em busca de soluções para o abastecimento das necessidades humanas de consumo. A valoração ambiental vem ao encontro dos anseios de preservação e exploração sustentáveis.

Na visão de Sukhdev (2010), quantificar e avaliar serviços dos ecossistemas não é diferente de quantificar e valorar bens e serviços produzidos pelos seres humanos, porque em ambos existe a necessidade de se garantir qualidade, reduzir pobreza e se pensar no bem-estar dos indivíduos. Já Turner et al. (2003) afirmam que o uso monetário como critério de mensuração dos benefícios ofertados pela natureza é capaz de estabelecer uma relação transparente com os outros usos de seus ativos e atributos, já que o mercado e a economia são amplamente difundidos em bases monetárias.

Tafuri (2008), citando De Groot (1992), sinalizou alguns motivos para valoração. Entre eles destacam-se: valor da conservação, valor do uso da terra, valor da função ambiental, estudo de risco ambiental e estudo de impacto ambiental. A valoração da conservação procura garantir que o uso do ecossistema seja sustentável. O seu objetivo é o de determinar o valor da proteção 
de certas espécies para determinar prioridade de proteção baseados em critérios como diversidade biológica, riqueza e raridade das espécies.

A valoração do uso da terra dá ênfase ao valor utilitário da natureza, analisando-se benefícios potenciais, valores e conveniência de uma área natural com o valor de espécies ou ecossistemas para agricultura, comércio, turismo, recreação e beleza cênica. Já o estudo de risco ambiental relaciona funções negativas ao ser humano, gerado pela natureza, como condições extremas de clima, terremotos, erupções vulcânicas e riscos biológicos. Algumas delas podem ser agravadas por interferência antrópica. $\mathrm{O}$ estudo de impacto ambiental investiga os efeitos reais e potenciais gerados por atividades humanas. O objetivo é avaliar as consequências de algumas ações para que possa haver prevenção da qualidade de determinado ambiente. E, por fim, a avaliação da função ambiental tem por objetivo mensurar a importância do ecossistema para o bem-estar do ser humano com seus aspectos tangíveis e intangíveis.

Não há apenas múltiplos motivos para se usar métodos de valoração. Eles buscam estimar diferentes componentes do valor econômico relacionado com uma alteração no bem, serviço ou ativo ambiental. Em outras palavras, ao proceder a uma valoração econômica estamos buscando estimar o Valor Econômico Total (VET) de determinado elemento do capital natural. É usual dividir o VET em: Valor de Uso (VU) e Valor de Não Uso (VNU). Essa subdivisão inicial do VET pode ser ainda mais desagregada. O Valor de Uso (VU) é subdividido em: Valor de Uso Direto (VUD) e Valor de Uso Indireto (VUI); Valor de Opção (VO); e Valor de Quase-Opção (VQO), que é derivado do Valor de Possível Uso (VPU). Também se encontram subdivisões para o Valor de Não Uso (VNU): Valor de Existência (VE); Valor de Herança (VH); entre outros. As formulações mais frequentes - longe de representar todas as existentes - estão resumidas no Quadro 1.1, que também apresenta o autor proponente de cada uma delas.

De maneira ilustrativa a Figura 1.1 apresenta esquematicamente as categorias de Valores de Uso, Possível Uso (VPU) e Não Uso. Nela se vê claramente, da esquerda para a direta, o aumento da intangibilidade de valores para o indivíduo. Isso quer dizer que a obtenção do Valor Econômico Total torna-se mais complexo de ser estimado à medida que cresce o interesse por novas pesquisas em campos multidisciplinares. O meio ambiente é um laboratório complexo e atraente, em que toda possibilidade existe, sem restrições aos mecanismos de inovação e ou adaptabilidade. 
Quadro 1.1 - Fórmulas desagregadas do VET de acordo com seus principais proponentes (1983-2010)

\begin{tabular}{|c|c|}
\hline Autor / Ano & Fórmula sugerida \\
\hline Randall e Stoll (1983) & $V E T=V U+V N U$ \\
\hline Motta (1989) com base em Pearce (1989) & $V E T=V U+V O+V E$ \\
\hline $\begin{array}{l}\text { Oliveira Junior (2003) com base em } \\
\text { Munasinghe (1999) }\end{array}$ & $V E T=V U D+V U I+V O+V E+V H$ \\
\hline Nogueira e Medeiros (1999) & $V E T=V U+V O+V Q O+V E$ \\
\hline $\begin{array}{l}\text { Amazonas (2010) com base em Tolmasquim } \\
\text { (2000), Nogueira et al. (1999), Motta (1998), } \\
\text { Marques e Comune (1997) e Figueiroa (1996) }\end{array}$ & $\begin{array}{c}\quad V E T=[V U(V U D+V U I+V O)]+[V P U(V Q O)] \\
+[V N U(V E)] \\
\text { Simplificando Amazonas }(2010): \\
V E T=V U+V P U+V N U\end{array}$ \\
\hline Motta (2011) & $V E R A=(V U D+V U I+V O)+V E$ \\
\hline
\end{tabular}

Fonte: Quadro elaborado pela própria a autora, baseado em Oliveira Junior (2003), Tafuri (2008), Amazonas (2010), Motta (2011) e Santos (2013)

Figura 1.1 - Categorias dos valores ambientais

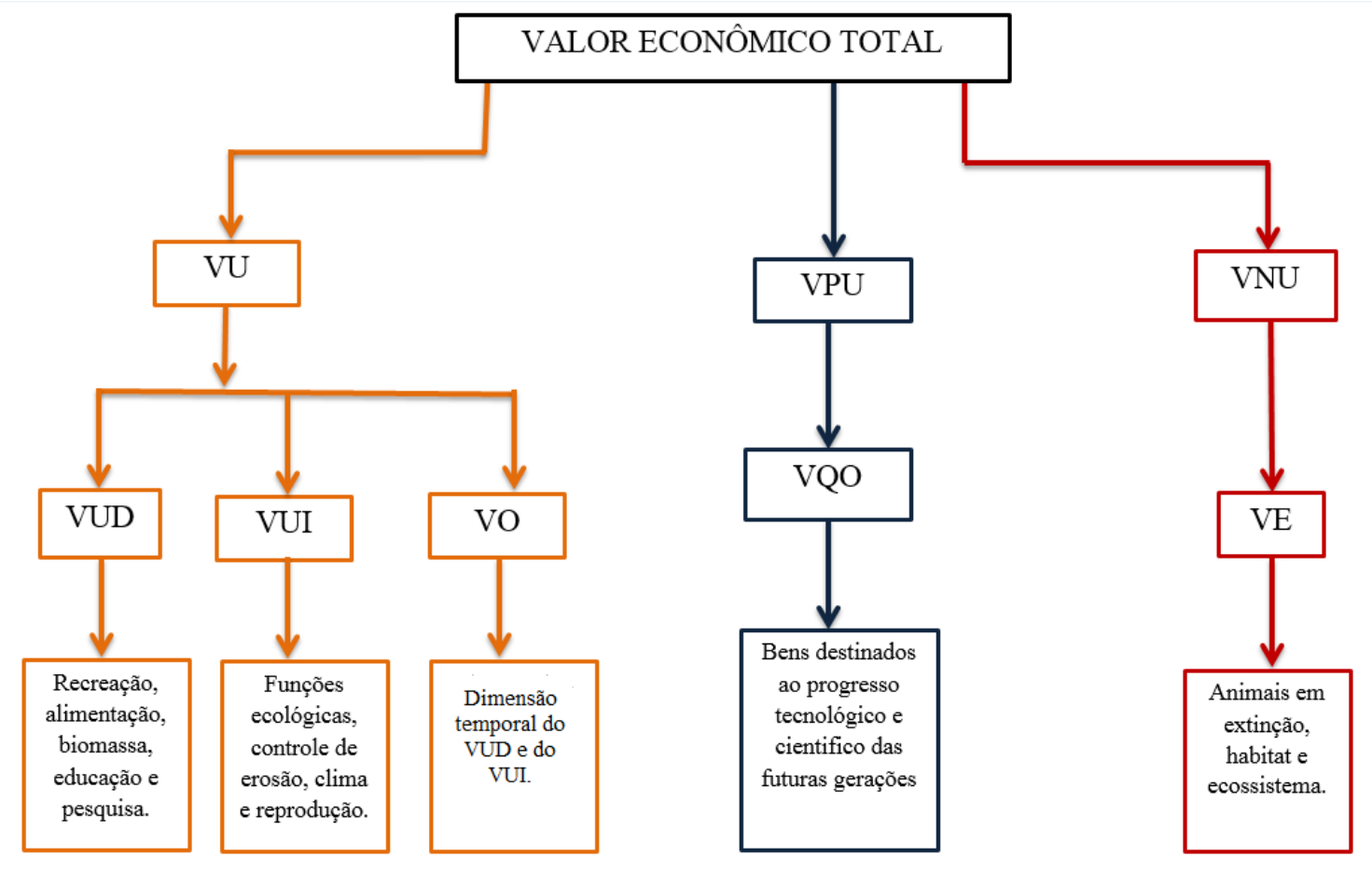

Fonte: Figura idealizada segundo fórmula proposta em Amazonas (2010)

Na visão de Batman e Tuner (1992), nos bens e serviços ambientais são bem distintos o VU e o VNU. O VU se refere ao valor que os indivíduos atribuem a um recurso natural por seu uso efetivo hoje ou no futuro. O VNU representa o valor dissociado do uso; expressa o valor 
de existência ou valor intrínseco, refletindo um valor que reside nos recursos ambientais, independentemente de uma relação com os seres humanos.

Por sua vez, Nogueira, Medeiros e Arruda (2000) argumentam que existe uma subdivisão sutil para o VU. Seu valor está dividido em VU, VO e VQO. O VU deriva do uso que se faz direta ou indiretamente do ambiente. VO é simplesmente evitar o risco de não ter o recurso no futuro. VQO representa o valor de novas opções de uso futuro do recurso, dada uma hipótese de que o conhecimento científico e técnico, econômico ou social possa ser alterado, dilatado ou inovado, criando possibilidades de futura utilização dos recursos ambientais sob investigação.

Matos et al. (2010) subdividem o Valor de Uso em: Valor de Uso Direto (VUD), aquele que contribui diretamente no processo de produção ou consumo, e Valor de Uso Indireto (VUI), aquele que inclui os benefícios derivados dos serviços que o ambiente proporciona para suportar o processo de produção e consumo. Os autores também subdividem os Valores de Opção, que são valores de uso futuro direto e indireto; citam como exemplo a biodiversidade e a preservação de habitats. Os Valores de Não Uso são subdivididos em Valores de Legado (VL), que é valor de uso e não uso para a próxima geração, como habitats e mudanças irreversíveis, e Valor de Existência (VE).

Mota et al. (2010) apresentam como Valor Econômico dos Recursos Ambientais (VERA), e o decompõe em VU e VNU. O VU é subdividido em VUD, VUI e VO. O VNU é representado pelo VE. O exemplo por eles usado para clarificar esse último o conceito é da mobilização da opinião pública para salvar baleias em regiões em que a maioria das pessoas nunca poderá estar ou fazer qualquer uso de sua existência. No entanto, Pearce e Moran (1994) ressaltam que, por meio do VET ou VERA, não é possível captar todo o valor econômico dos recursos naturais. Para os autores, o valor total de um ecossistema excede a soma dos valores das funções individuais devido à existência de valores subjacentes às funções ecológicas.

Fica claro, então que a valoração econômica ambiental lida com diferentes estâncias de valores, afirma Amazonas (2009, p. 2). Ele explica que "diversos valores relacionados ao uso dos recursos ambientais são de motivação não econômica (como a ética de preservação e respeito à vida), mas com importante dimensão econômica". A valoração econômica ambiental consiste, portanto, na identificação de tal dimensão econômica desses valores sociais não econômicos relativos ao ambiente, para que, exercendo em seguida sua "internalização" no processo de decisão.

As instâncias propostas por Amazonas (2009) estão divididas em três aspectos. Primeiro, o conjunto de valores econômicos correntes que, por si só, não conduz ao uso 
sustentável dos recursos ambientais. Segundo, os valores sociais não econômicos relativos à conservação. Terceiro, os valores econômicos derivados da apreensão de tais valores sociais não econômicos e da internalização desses no conjunto das variáveis econômicas. Conclui seu pensamento afirmando que, apesar de os valores e julgamentos humanos relativos à conservação e uso sustentável dos recursos ambientais referirem-se a fatos concretos, é, todavia, algo incerto, relativo e controverso o que sejam tais valores ambientais e quais suas grandezas. Consequentemente, é também incerta, relativa e controversa a forma de mediação entre tais valores sociais não econômicos e as variáveis econômicas. Com isso, também é incerto e controverso o processo de definição normativa dos valores econômicos correspondentes à conservação e uso sustentável dos recursos ambientais.

Isso é, em particular, verdadeiro para o componente valor de existência, uma espécie de legado para outros e para as futuras gerações. Quem sabe também não pensarão da mesma forma, porque o sentir, o agir é passado de geração a geração; é cultural, e interromper esse círculo vicioso é extremamente difícil. Só se percebe a natureza quando ocorrem traumas, ou grandes catástrofes, mudanças pulsantes da própria natureza. Em 1998, Nogueira e Medeiros já questionavam uma posição dos economistas quanto às teorias econômicas que explicassem o valor de existência e uma forma mais efetiva de calculá-la.

Tem se tornado popular uma outra maneira de apresentar-se os componentes do VET do recurso ambiental: a sua capacidade de gerar fluxos de serviços ecossistêmicos, conforme o que foi estabelecido no Millenium Ecosystem Assessment Report-MEA (2005). Esses serviços podem ser: serviços de provisão que geram consumo material direto como água, alimentos; serviços de regulação que regulam as funções ecossistêmicas como purificação da água e do ar; serviços de suporte, que são suportes às funções ecossistêmicas, como formação do solo e fotossíntese; e serviços culturais que geram consumo não material nas formas cultural, intelectual, recreacional, espiritual e científica. A figura 1.2 mostra essa relação com os valores de uso e não uso e a classificação MEA (2005).

Percebe-se que na figura 1.2, assim como na classificação de Motta (2011), a não presença do componente Valor de Quase-Opção (VQO). É nosso entendimento - que será justificado na sequência deste texto - que essa pode ser uma omissão limitadora na busca de um VET que represente o "verdadeiro" valor econômico do ativo ambiental, principalmente quando esse se relacionar com a diversidade biológica, com o seu significativo potencial de novos usos futuros. 
Figura 1.2 - Relação entre o VET do recurso ambiental e os serviços ecossistêmicos

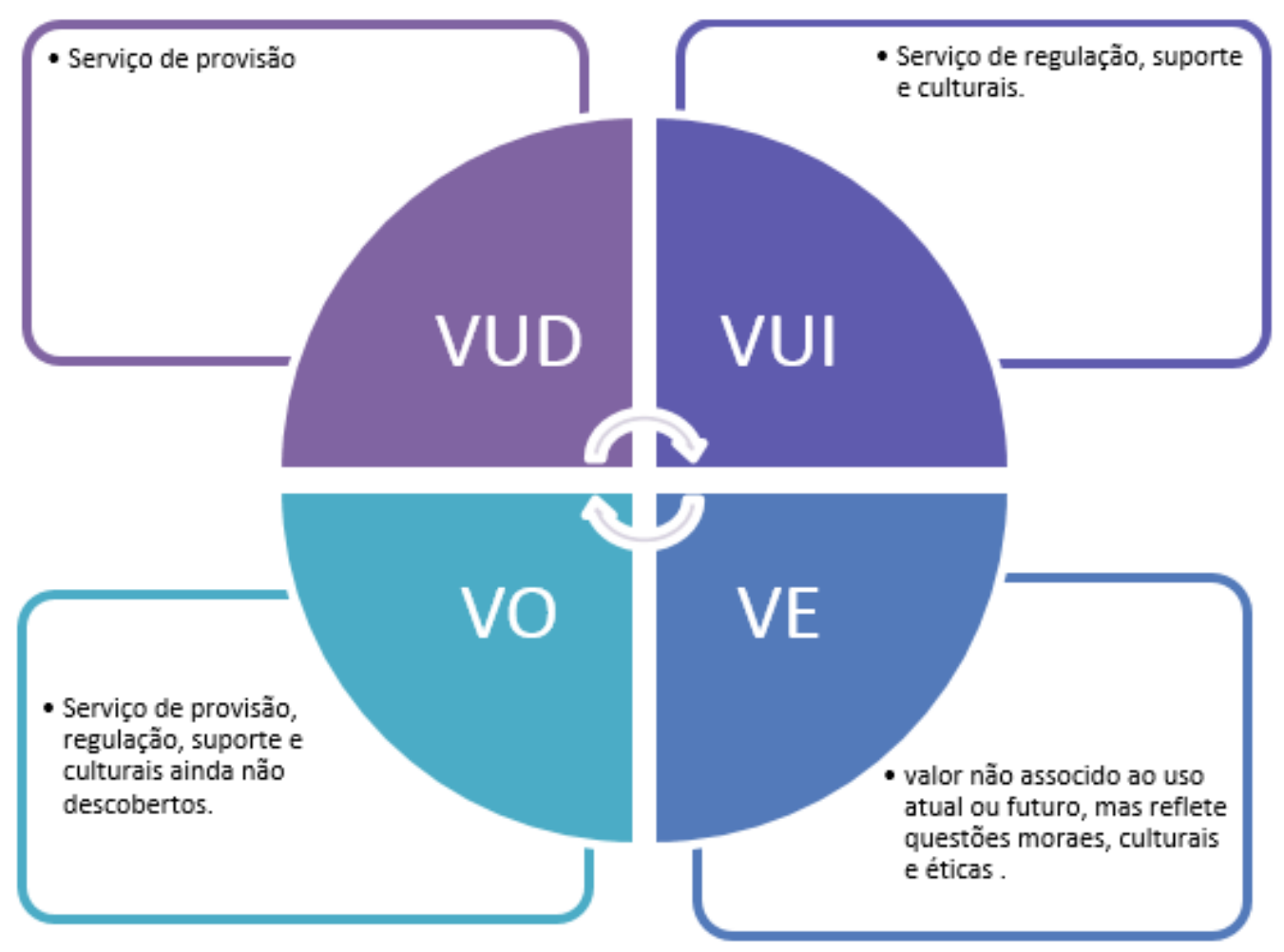

Fonte: Figura elaborada pela autora, com base no texto de Motta (2011, p. 182)

\subsection{AS DIVERSAS CLASSIFICAÇÕES DOS MÉTODOS DE VALORAÇÃO}

Diferentes estudos classificam os métodos de valoração econômica de maneira distinta. Ainda é difícil chegar a um consenso. Nogueira e Medeiros (1998) advertem para as divergências existentes, mas admitem que todos têm o mesmo foco: apresentar cada método com suas potencialidades e fragilidades. Uma das classificações mais referenciadas é a de Hufschmidt et al. (1983). Eles dividiram os métodos em mercados reais, método substitutos e métodos hipotéticos. Já Bateman e Turner (1992) dividiram em duas abordagens com curva de demanda e sem curva de demanda. Pearce (1993) dividiu os métodos em quatro grupos: método convencional, função de produção doméstica, método de preços hedônicos e métodos experimentais. Suas subdivisões, bem como de outros autores mencionados, podem ser vistas no Quadro 1.2. 
Quadro 1.2 - Classificação dos métodos de valoração ambiental segundo diversos autores - 1983 a 2000

\begin{tabular}{|c|c|c|c|}
\hline Ano & Autor & Classificação & Tipo de método \\
\hline \multirow{13}{*}{1983} & \multirow{13}{*}{ Hufschmidt et al. } & \multirow{6}{*}{ Mercados reais } & Mudança no valor de produção \\
\hline & & & Perda de salário / lucros \\
\hline & & & Gastos preventivos \\
\hline & & & Custo de reposição \\
\hline & & & Projeto sombra \\
\hline & & & Análise de custo eficiência \\
\hline & & \multirow{5}{*}{ Mercados substitutos } & Bens de mercados como substitutos \\
\hline & & & Valor da propriedade \\
\hline & & & Métodos Custo de Viagem \\
\hline & & & Abordagem diferencial de salário \\
\hline & & & Aceitação e compensação \\
\hline & & \multirow{2}{*}{ Mercados hipotéticos } & Disposição a Pagar \\
\hline & & & Escolha sem Custo \\
\hline \multirow{5}{*}{1992} & \multirow{5}{*}{ Bateman e Turner } & \multirow{2}{*}{$\begin{array}{l}\text { Abordagem com curva de } \\
\text { demanda }\end{array}$} & Método de Preferência Expressa (MVC) \\
\hline & & & $\begin{array}{l}\text { Métodos de preferencias revelada (MCV e } \\
\text { MPH) }\end{array}$ \\
\hline & & \multirow{3}{*}{$\begin{array}{l}\text { Abordagem sem curva de } \\
\text { demanda }\end{array}$} & Método Dose Resposta (MDR) \\
\hline & & & Método de Custo Reposição (MCR) \\
\hline & & & $\begin{array}{l}\text { Método de Comportamento Migratório ou } \\
\text { Evitado (MCE) }\end{array}$ \\
\hline \multirow{8}{*}{1993} & \multirow{8}{*}{ Pearce } & \multirow{2}{*}{$\begin{array}{c}\text { Abordagens Mercado } \\
\text { Convencional }\end{array}$} & Dose Resposta \\
\hline & & & Custos de reposição \\
\hline & & \multirow{2}{*}{$\begin{array}{l}\text { Funções de Produção } \\
\text { Doméstica }\end{array}$} & Gasto Evitados \\
\hline & & & Custo de Viagem \\
\hline & & \multirow{2}{*}{$\begin{array}{l}\text { Métodos de Preços } \\
\text { Hedônicos }\end{array}$} & Preços de Casa Ou Terras \\
\hline & & & Salários pelo Risco \\
\hline & & \multirow[b]{2}{*}{ Métodos Experimentais } & Método de Valoração Contingente \\
\hline & & & $\begin{array}{l}\text { Ordenação Contingente (estabelecida / } \\
\text { fixa) }\end{array}$ \\
\hline \multirow[t]{4}{*}{1993} & \multirow[t]{4}{*}{ Hanley e Spash } & & Método de Valoração Contingente \\
\hline & & \multirow[t]{3}{*}{ Forma Indireta } & Método Preço Hedônicos \\
\hline & & & Método Custo de Viagem \\
\hline & & & Método de Dose-Resposta \\
\hline \multirow[t]{5}{*}{1998} & \multirow[t]{5}{*}{ Motta } & \multirow[t]{2}{*}{ Função Produção } & Produtividade Marginal \\
\hline & & & Mercado de Bens Substitutos \\
\hline & & \multirow[t]{3}{*}{ Função Demanda } & Valoração Contingente \\
\hline & & & Preços Hedônicos \\
\hline & & & Custo de Viagem \\
\hline \multirow{9}{*}{1998} & \multirow{9}{*}{\multicolumn{2}{|c|}{ David e Richards }} & Preço de Mercado \\
\hline & & & Custos de Reposição \\
\hline & & & Gastos Preventivos \\
\hline & & & Proxy/ Produtos Substitutos \\
\hline & & & Mudança na Produtividade \\
\hline & & & Custos de Viagem \\
\hline & & & Custo de Oportunidade \\
\hline & & & Preço Hedônico \\
\hline & & & Método de Valoração Contingente \\
\hline
\end{tabular}

Fonte: Quadro elaborado pela própria autora, baseado em Santos (2013)

Hanley e Spash (1993) admitem a divisão dos métodos em duas partes que chamaram de forma direta e forma indireta. Método também utilizado por Ortiz (2003), porém com 
subdivisões diferentes. Motta (1998) classificou os métodos em Função Produção e Função Demanda. Nunes e Van Den Bergh (2001) também fazem bipartição, chamando-os de Preferência Revelada e Estado de Preferência. Maia; Romeiro e Raydon (2004) dividem em Métodos Diretos e Métodos Indiretos. De Fries e Pagiola (2005) dividem os métodos em preferência revelada, declarada e outros métodos. Para os autores, a valoração de bens, recursos ou serviços ambientais é um processo de duas etapas. A primeira envolve a identificação dos serviços que estão sendo valorados e a segunda compreende a valoração propriamente dita, quando são quantificados os impactos observados. A subdivisão pode ser conferida no quadro 1.3 .

Barbier (2007) não separa os métodos em grupos, mas acrescenta em suas considerações o método de comportamento evitado, também citado por Nunes e Van Den Bergh (2001), que aplicam esse modelo ao efeito que a poluição provoca sobre a saúde. A mesma maneira de proceder pode ser encontrada em David e Richards (1998), que não se preocuparam em agupar os métodos, mas apenas em identificá-los, incluindo sua consideração ao Método de Custo de Oportunidade.

Existe uma divergência de nomenclatura que pode ser observado ao se ler os diversos trabalhos que envolvem valoração do meio ambiente a equivalência dos métodos que foi realizada por Nogueira, Medeiros e Arruda (2000) tendo como base os autores Bateman e Turner (1992), Hanley e Spash (1993) e Pearce (1993). Em 2013, Santos realizou a equivalência de trabalhos usando os pesquisadores Motta (1998), Barbier (2007), David e Richards (1998) e Maia, Romer e Reydon (2004), o que pode ser visualizada no Quadro 1.4.

Nesta Tese, a abordagem dos métodos será feita com base em de Bateman e Turner (1992), em que os métodos são divididos em dois aspectos: com curva de demanda e sem curva de demanda. Os métodos que apresentam a função demanda são: Valoração Contingente, Custo de Viagem e Preço Hedônico. E os métodos que não apresentam curva de demanda, mas partem de uma curva de produção, são: Dose Resposta, Custo Reposição e Custo de Oportunidade. Como já destacado, o presente estudo analia apenas os Métodos de Função demanda. 
Quadro 1.3 - Classificação dos métodos de valoração ambiental segundo diversos autores - 2001 a 2007.

\begin{tabular}{|c|c|c|c|}
\hline Ano & Autor & Classificação & Tipo de método \\
\hline \multirow{5}{*}{2001} & \multirow{5}{*}{$\begin{array}{c}\text { Nunes e Van Den } \\
\text { Bergh }\end{array}$} & \multirow{4}{*}{$\begin{array}{l}\text { Preferência } \\
\text { Revelada }\end{array}$} & Custo de Viagem \\
\hline & & & Preço Hedônico \\
\hline & & & Comportamento evitado \\
\hline & & & Função Produção \\
\hline & & $\begin{array}{l}\text { Estado de } \\
\text { Preferência }\end{array}$ & Valoração Contingente \\
\hline \multirow{9}{*}{2003} & \multirow{9}{*}{ Ortiz } & \multirow{2}{*}{ Métodos Diretos } & Valoração Contingente \\
\hline & & & Ranqueamento Contingente \\
\hline & & \multirow{7}{*}{ Métodos Indiretos } & Custo de viagem \\
\hline & & & Preços Hedônicos \\
\hline & & & Custo Reposição \\
\hline & & & Gatos Defensivos \\
\hline & & & Produtividade Marginal \\
\hline & & & Transferências de Benefícios \\
\hline & & & $\begin{array}{l}\text { Capital Humano ou Produção } \\
\text { Sacrificada }\end{array}$ \\
\hline \multirow{8}{*}{2004} & \multirow{8}{*}{$\begin{array}{l}\text { Maia; Romeiro e } \\
\text { Reydon }\end{array}$} & \multirow{3}{*}{ Métodos Diretos } & Método d Valoração Contingente \\
\hline & & & Preços Hedônicos \\
\hline & & & Custo de Viagem \\
\hline & & \multirow{5}{*}{ Métodos Indiretos } & Produtividade Marginal \\
\hline & & & Custos Evitados \\
\hline & & & Custos de Reposição \\
\hline & & & Custos de Controle \\
\hline & & & Custos de Oportunidade \\
\hline \multirow{8}{*}{2005} & \multirow{8}{*}{ DeFries e Pagiola } & \multirow{5}{*}{$\begin{array}{l}\text { Preferência } \\
\text { Revelada }\end{array}$} & Produtividade Marginal \\
\hline & & & Custo de Doença, capital humano \\
\hline & & & Custo de Reposição e variantes \\
\hline & & & Custo de viagem \\
\hline & & & Preços Hedônicos \\
\hline & & \multirow{2}{*}{$\begin{array}{c}\text { Preferência } \\
\text { Declarada }\end{array}$} & Contingente \\
\hline & & & Modelo de Escolha \\
\hline & & Outros Métodos & Transferência de Benefícios \\
\hline \multirow{6}{*}{2007} & \multirow{6}{*}{\multicolumn{2}{|c|}{ Barbier }} & Custo de Viagem \\
\hline & & & Comportamento Evitado \\
\hline & & & Preço Hedônico \\
\hline & & & Função Produção \\
\hline & & & Custo de Reposição \\
\hline & & & Estado de Preferência \\
\hline
\end{tabular}

Fonte: Quadro elaborado pela própria autora, com base em Costa (2012) e Santos (2013) 
Quadro 1.4 - Métodos de Valoração Equivalentes

\begin{tabular}{|c|c|c|}
\hline Método de Valoração & Método Equivalente & Autores \\
\hline \multirow{4}{*}{ MVC } & Disposição a pagar & 3 \\
\hline & Aceitação e Compensação & 3 \\
\hline & Valoração Contingente & $1 / 4 / 5 / 6 / 7 / 9 /$ \\
\hline & Estado de Preferencia & 8 \\
\hline $\mathrm{MCV}$ & Método Custos de Viagem & $1 / 3 / 4 / 5 / 6 / 7 / 8 / 9$ \\
\hline \multirow{5}{*}{ MPH } & Valor de Propriedade & 3 \\
\hline & $\begin{array}{l}\text { Abordagem Diferencial de } \\
\text { Salário }\end{array}$ & 3 \\
\hline & Preços de Casas ou Terras & 4 \\
\hline & Salários pelo Risco & 4 \\
\hline & Preço Hedônico & $1 / 5 / 6 / 7 / 8 / 9$ \\
\hline \multirow{5}{*}{ MDR } & $\begin{array}{llll}\text { Mudança no } & \text { Valor } & \text { da } \\
\text { Produção } & & & \\
\end{array}$ & 3 \\
\hline & Dose- Resposta & $4 / 5$ \\
\hline & Função produção & $6 / 8$ \\
\hline & Produtividade Marginal & $1 / 7$ \\
\hline & Mudança na Produtividade & 9 \\
\hline \multirow{2}{*}{ MCR } & Custo de Reposição & $3 / 4 / 7 / 8 / 9 /$ \\
\hline & Projeto Sombra & Sem equivalência \\
\hline \multirow{5}{*}{ MCE } & Perda de Salários / Lucros & 3 \\
\hline & Gastos Preventivos & $3 / 9$ \\
\hline & Gastos Evitados & $4 / 7$ \\
\hline & Custo de Controle & 7 \\
\hline & Comportamento Evitado & $6 / 8$ \\
\hline \multirow{5}{*}{ MPM } & Análise Custo Eficiência & 3 \\
\hline & $\begin{array}{l}\text { Bens de Mercado como } \\
\text { substitutos }\end{array}$ & $3 / 1$ \\
\hline & Preço de Mercado & 9 \\
\hline & Proxy/ Produtos Substitutos & 9 \\
\hline & Custos de Oportunidade & $7 / 9$ \\
\hline \multirow[b]{2}{*}{ Sem Equivalente } & Escolha sem custos & 3 \\
\hline & $\begin{array}{l}\text { Ordenação } \\
\text { (preferência estabelecida / } \\
\text { fixa) }\end{array}$ & 4 \\
\hline
\end{tabular}

Fonte: Santos (2013), com adequações

Nota: (1) Motta (1998); (2) Bateman e Turner (1992); (3) Hufschidt et al. (1983); (4) Pearce (1993); (5) Hanley e Spash (1993); (6) Nunes e Van Den Bergh (2001); (7) Maia, Romeiro e Reydon (2004); (8) Barbier (2007); (9) David e Richards (1998). 


\subsection{COMENTÁRIOS CONCLUSIVOS}

Três métodos de valoração econômica do meio ambiente estão presentes em todas as classificações apresentadas na seção anterior: o Valoração Contingente (MVC), o Custos de Viagem (MCV) e o Preços Hedônicos (MPH). Esses compõem as Abordagens com Curva de Demanda (de acordo com Bateman e Turner, 1992) ou os Métodos Função Demanda (segundo Mota, 1997). Nós iremos estudar esses três métodos nesta Tese, para que possamos realizar análises aprofundadas de aplicações de cada um deles. Os demais merecem compor uma futura agenda de pesquisa de qualquer estudioso em valoração econômica do meio ambiente.

Usar um método de valoração é, por vezes, uma empreitada difícil. Valorar aquilo que ainda não tem valor é tarefa árdua. Compilar todos os dados para se produzir o valor de uma alteração em um bem, serviço ou ativo ambiental é um trabalho técnico, que exige perícia. Como uma técnica, precisa ser rigorosamente empregada. O trabalho é específico para cada caso e não pode se negligenciado, usando dados similares, porque o valor pode não ser preciso e perícias judiciais, auditorias, políticas ambientais, custos de oportunidade da ação de degradar (ou preservar) bem como a flexibilização de se empreender uma ação dependem do quão preciso for a aplicação do método de valoração.

Os métodos de valoração ambiental, como todo procedimento, têm limitações que precisam ser vencidas, ou contornadas. Mota et al. (2010) assinalam quatro limitações para a valoração econômica:

1. A metodologia usada requer que haja informações necessárias sobre os custos e os benefícios estimados para um melhor ordenamento de preferências.

2. Observação com vistas a ordenar o nível de agregação dos ecossistemas e o tipo de avaliação.

3. Problemas de decisão intertemporal, porque as estimativas devem estar em valor presente; isso pode favorecer a geração presente em detrimento das gerações futuras.

4. Observação do grau de arbitrariedade associado à agregação de preferências dos indivíduos na sociedade. O problema reside em atribuir pesos aos benefícios e custos da exploração dos recursos naturais aos agentes envolvidos e os critérios a serem adotados nessas questões.

Vencidas as limitações e escolhido o método apropriado para valorar o ativo escolhido, ainda deverá ser lembrado que mensurar as preferências dos indivíduos sobre as alterações em seu meio ambiente não se trata de transformar um bem ambiental num produto de mercado 
(PEARCE, 1993). Mas, através do valor arrogado ao ativo ambiental pelos indivíduos e sua representatividade para a coletividade, tratá-lo como escasso e preservar, cuidar, ou fazer melhor uso possível. Caso o ativo ambiental seja desrespeitado e venha se tornar mais escasso o "valor" permitirá tomar decisões seguras contra o infrator e comportará reparos adequados. Também é via o valor que os indivíduos se posicionarão contra ou a favor das decisões legais. Tudo isso é particularmente verdadeiro para aplicações de MVC, MCV e MPH. Todos três têm sido utilizados intensamente para valorar bens, serviços e ativos ambientais no Brasil. Diversos são os desafios para uma aplicação tecnicamente rigorosa de qualquer um deles. Quão rigorosas têm sido as aplicações deles no Brasil? Em consequência, quão confiáveis têm sido os valores obtidos dessas aplicações? Respostas para essas perguntas serão apresentadas nos próximos capítulos da Tese. Para que rigor e confiabilidade sejam alcançados, o primeiro passo - nós sugerimos - é enquadrar cada um deles em uma adequada moldura conceitual, uma vez que números sem teoria são inúteis. Assim, nossa próxima empreitada é (re)apresentar a estrutura teórica em que se baseiam os métodos função demanda de valoração econômico do meio ambiente. 


\section{CAPÍTULO 2}

\section{MOLDURA CONCEITUAL DOS MÉTODOS FUNÇÃO DEMANDA}

\subsection{INTRODUÇÃO}

De uma perspectiva econômica, mensurar valores envolve o uso de teoria econômica e de métodos e procedimentos robustos que reflitam determinados pressupostos teóricos. No entanto, valorar economicamente alterações em bens, serviços ou ativos ambientais envolve, também, outros tipos de conhecimentos além dos teóricos e técnicos da ciência econômica. Como enfatizado por Freeman III (2003), estimar o valor monetário de benefícios sobre a saúde humana de uma redução da poluição do ar envolve - implícita ou explicitamente conhecimento científico sobre a relação entre concentração de poluentes e a saúde humana.

Ignorância desse conhecimento biológico/ecológico/médico pode representar uma barreira para a obtenção e a análise de informações sobre o valor econômico de um bem, serviço ou ativo ambiental. No entanto, igualmente problemático é mostrar desconhecimento sobre a teoria econômica que emoldura os procedimentos de valoração econômica. Os valores monetários obtidos de procedimentos de valoração não têm significado algum se manipulados e analisados sem respaldo das molduras conceituais que orientam (ou deveriam orientar) o desenho de procedimentos metodológicos que lhe deram origem.

Valor econômico só pode ser definido em termos de algum critério implícito que identifique algo que possa ser considerado um bem (serviço) econômico. A essa afirmação Freeman III (2003) acrescenta que de uma perspectiva da economia do bem estar neoclássica, um bem é definido em termos do bem-estar de indivíduos. É usual assumir-se que o bem-estar de um indivíduo pode ser representado por uma função de utilidade ordinal, na qual ela ou ele pode ordenar seus desejos, suas preferências. Todos os três métodos função demanda de valoração econômica têm como base teórica as preferências dos consumidores. Essa "origem conceitual" não distingue MVC, MCV e MPH.

$\mathrm{Na}$ verdade, como bem assinala Freeman III (2003), a principal diferença entre esses três métodos - MVC, MCV e MPH - para valorar mudanças em bens/serviços/ativos ambientais reside na fonte de dados e não na moldura conceitual. Os dados obtidos por esses métodos ou são originários de efetivo comportamento humano ("comportamento observado" ou "preferência revelada": MCV e MPH) ou são originários de respostas a questões hipotéticas ("comportamento hipotético" ou "preferência declarada": MVC). Métodos de preferência revelada (MCV e MPH), mais uma vez e correndo o risco de sermos repetitivos, são baseados 
em comportamento efetivo refletindo a maximização de utilidade sujeita a restrições de renda e de preços dos outros bens que entram na cesta de consumo do indivíduo. Essa frase pode ser reiterada para o MVC (preferência declarada) só substituindo comportamento efetivo por comportamento simulado (hipotético).

Essa "origem conceitual" dos três métodos tem sido sistematicamente desconsiderado por "práticos" da valoração econômico ambiental. As causas desses "esquecimentos" são diversas. Analisá-las está além dos objetivos por nós propostos para esta Tese. Em artigo recente $^{3}$, Bernardo, Nogueira e Cruz Neto (2015) atribuem esse vácuo conceitual ao "exercício de valoração" de qualidade técnica questionável realizado por R. Costanza e co-autores no famoso artigo publicado em Nature em 1997. Tal exercício transmitiu a ideia de que valoração econômica do meio ambiente nada mais é do que operações algébricas básicas entre números, quantidades e valores. Nada mais longe da verdade.

Todo aquele que aplica um método de valoração econômica deve ter o cuidado para não descaracterizar ou fugir da base teórica à qual pertence o método utilizado. O objetivo central deste capítulo é relembrar a fundamentação teórica dos métodos de valoração função demanda. Usamos o verbo relembrar propositadamente. Não temos a pretensão que este capítulo represente uma contribuição ao estado-das-artes em teoria de valoração econômica. Ao partimos do fato de que economistas buscam medir valores que são baseados em preferências de indivíduos, queremos resumir aqui os principais componentes de teorias de preferências, escolhas, interações e bem-estar com base em referências bibliográficas que estão disponíveis para qualquer interessado em praticar valoração econômica.

Buscamos, assim, um capítulo sem novidades ${ }^{4}$, mas que deseja ser didático ao extremo da nossa capacidade. Desta forma, estaremos contribuindo para que nenhum outro aplicador de MVC, MCV e MPH repita os erros tão frequentes em termos de aplicações existentes, em especial o de gerar valores monetários que em nada significam em termos de valores econômicos de bens, serviços e ativos ambientais. Além disso, o presente texto será por nós referenciado em análises que faremos nos próximos capítulos sobre as aplicações práticas dos três métodos de valoração.

\footnotetext{
${ }^{3}$ BERNARD, Carolina Tavares da Silva; NOGUEIRA, Jorge Madeira e CRUZ NETO, Claudiano Carneiro. "Valoração de nada e precificação de tudo? A herança maldita das valorações dos serviços ecossistêmicos de R. Costanza." Artigo a ser apresentado no Encontro Anual da Sociedade Brasileira de Economia Ecológica, 2015.

${ }^{4}$ Durante o Exame de Qualificação de Tese de Doutorado, um dos examinadores sugeriu que retirássemos todo este capítulo da estrutura da Tese. Consideramos com cuidado essa sugestão, mas decidimos manter o capítulo. No entanto, a sugestão indicou a necessidade de evitar uma simples repetição daquilo que está presente em livrostexto de microeconomia e elaborar um texto de microeconomia ambiental da valoração econômica. $\mathrm{O}$ texto que se segue está baseado em quatro referências centrais: Freeman III (2003), Hanley e Spash (1995), Barzev (2002) e Nogueira, Medeiros e Arruda (2000).
} 
Nesse contexto, o capítulo aborda a relação entre medidas de bem-estar e a valoração de bens e serviços ambientais decorrentes de alterações qualitativas e/ou quantitativas das preferências do consumidor por um determinado bem ou serviço ambiental. Ao longo do seu desenvolvimento, procuraremos sempre que possível usar exemplos relacionados ao uso do capital natural. Ele está dividido em quatro partes, além desta introdução e da conclusão. Na primeira (seção 2.2), explicam-se as formas a partir das quais o consumidor escolhe uma cesta de bens e como agem dentro do princípio da racionalidade, tendo como base os pressupostos sobre as preferências. Na segunda parte (seção 2.3), faz-se uma breve explanação entre de como as preferências emolduram as curvas de demandas de consumidores, retomando as ideias de Marshall e Hicks e relacionando-as com a demanda por (quantidade e qualidade de) bens e serviços ambientais. E, na terceira (seção 2.4), faz-se uma relação entre as medidas de bemestar e suas aplicações na valoração econômica aos bens e serviços ambientais.Na quarta (2.5) é feita uma comparação entre as curvas de demanda ordinária e compensada.

\subsection{AS PREFERÊNCIAS DO CONSUMIDOR: A ESCOLHA}

O processo de valorar economicamente o meio ambiente ocorre via a medição e a quantificação da quantidade e da qualidade de um bem, serviço ou ativo ambiental. Alterações específicas na quantidade e na qualidade do ambiente e dos recursos naturais geram mudanças no bem-estar dos indivíduos (consumidores desses bens ou riscos ambientais). Não obstante, o indivíduo (o consumidor) desconhece o valor de sua utilidade. A única coisa que ela ou ele pode fazer é identificar se se sente "melhor" ou "pior" com uma alteração na quantidade ou na qualidade ambiental via à vis a situação sem essa alteração. Portanto, o consumidor sabe qual nível de utilidade é superior e qual é inferior devido, por exemplo, à deterioração ou à melhoria na qualidade do ambiente, ainda que ela ou ele não saiba o valor de cada um desses níveis de utilidade. Ela ou ele sabe ordenar sua utilidade ${ }^{5}$.

$\mathrm{Na}$ análise econômica marginalista, presume-se que cada indivíduo é capaz de determinar, por si só, se uma mudança de um estado a outro, aumenta ou diminui o seu bemestar. Isso significa que partimos do princípio da autonomia econômica de cada indivíduo para julgar suas mudanças em seu bem-estar. É exatamente por isso que a teoria da valoração

\footnotetext{
${ }^{5}$ Existem diferentes interpretações de utilidade: a) Utilidade Cardinal: acreditava-se que os consumidores seriam capazes de medir sua utilidade em números cardinais $(1,2,3$, etc.), tendo como unidade de medida o útil; b) Utilidade Ordinal expressa uma ordem hierárquica: primeiro, segundo, terceiro, etc.; portanto, o uso da utilidade ordinal requer que os consumidores possam classificar hierarquicamente as suas preferências, ao invés de atribuir unidades quantificáveis de satisfação; c) Utilidade Marginal: utilidade para cada unidade adicional consumida do bem; e d) Utilidade Total: utilidades acumuladas pelo consumidor.
} 
econômica dos métodos função demanda é baseada nas preferências individuais que são revelados nas decisões do indivíduo, quando ela ou ele é confrontada(o) com uma situação em que deve determinar a maneira mais eficiente de alocar seus recursos.

A análise econômica tradicional normalmente assume que os indivíduos irão revelar um conjunto de preferências pelo consumo de determinados bens e/ou serviços. Além disso, esses indivíduos aceitam que quanto maiores forem as possibilidades de consumo, maiores os seus níveis de satisfação u, mais rigorosamente, de utilidade. A teoria do consumidor considera que as preferências do consumidor para uma determinada quantidade de mercadorias podem ser representadas por meio de uma função contínua que recebe o nome de função de utilidade:

$$
\boldsymbol{U}=U\left(X_{1}, X_{2}, X_{3} \ldots X_{n}\right)
$$

Onde U é o nível de utilidade para o indivíduo que lhe permite o consumo de bens ou serviços, neste caso representados por $\mathrm{X}_{1}, \mathrm{X}_{2}, \mathrm{X}_{3}, \ldots, \mathrm{X}_{\mathrm{n}}$.

$\mathrm{O}$ valor econômico de um bem específico, por exemplo $\mathrm{X}_{1}$, é medido de forma relativa pela quantidade máxima de outros bens e serviços que o indivíduo está disposto a abrir mão para ter uma unidade a mais de $\mathrm{X}_{1}$. Esse indivíduo procurará sempre, de acordo com a sua racionalidade de maximização, manter pelo menos o seu nível de utilidade. Ela ou ele buscará obter um conjunto (cesta) de bens que lhe garantam o mesmo nível de satisfação; isto é, o consumidor individual está em uma posição de indiferença entre essas cestas. No entanto, nem todas estas cestas podem ser alcançadas, dado os preços no mercado e o nível de renda que o indivíduo possui. Esses fatores apresentam-se como restrições à maximização da sua função utilidade.

Como podemos relacionar o explicitado acima com a valoração econômica de uma mudança em um bem, serviço ou ativo ambiental? Mais uma vez nos valemos de Freeman III (2003) que enfatiza: mudanças na qualidade ou na quantidade de um bem (serviço/ativo) ambiental podem afetar o nível de bem estar do indivíduo através de quatro caminhos. Esses caminhos podem ser: a) mudanças nos preços dos bens ou serviços que o consumidor (ou usuário) compram em mercados; b) mudanças nos preços que o consumidor (ou usuário) recebe pelos seus fatores de produção; c) mudanças nas quantidades ou nas qualidades de bens ou serviços não comercializados em mercados mas que compõem a sua função de utilidade (equação 2.1); e d) mudanças nos riscos enfrentados pelo consumidor (ou usuário). Os três primeiros caminhos são explicitados na sequência do presente capítulo, enquanto o último será 
marginalmente tratado aqui ${ }^{6}$.

Tendo isso em mente, a decisão de gasto de consumo como resultado da escolha de uma alternativa viável (i.e., combinações possíveis de bens que um indivíduo pode pagar, dado o seu nível de renda e os preços atuais de mercado) que lhe dará o maior nível de utilidade ou de satisfação, definirá a função de demanda do consumidor (ou usuário) para cada bem de acordo com suas preferências, expectativas, os preços correntes de mercado e a sua renda percebida. Esta função de demanda para cada bem da economia, pode ser escrita como:

$$
X_{1}^{D}=f\left(P_{1}, P_{2}, P_{3 \ldots} P_{n}, I\right)
$$

Onde $\mathrm{P}_{1}$ é o preço de mercado do Xi bem, e I é a renda que o indivíduo recebe. A forma funcional da função demanda mostra as preferências e as expectativas dos indivíduos. Para maximizar a sua utilidade, dado uma quantidade fixa de dinheiro para gastar (sua renda), uma pessoa compra quantidades de bens e serviços que esgotam sua renda total e que a troca da quantidade de duas mercadorias quaisquer ${ }^{7}$ seja igual à relação (de preços) que pode ser trocada no mercado. Esta decisão do consumo individual gera um nível máximo de utilidade que pode ser expressa pela equação:

$$
U=u\left(P_{1}, P_{2}, P_{3}, \ldots P_{n}, I\right)
$$

É de conhecimento que, em geral, se o preço de um bem aumenta, o indivíduo vai comprar menos desse bem e se, pelo contrário, se o preço do bem diminuir, o seu consumo será maior. A isso, economistas denominam lei da demanda.

Uma análise derivada do acima exposto é a relacionada com curvas de demanda. Também é de generalizada noção que uma curva de demanda pode ser definida como a relação funcional entre a quantidade consumida de um bem para cada nível de preço desse bem. A curva da demanda é uma representação específica em um determinado ponto do tempo de uma respectiva função demanda, porque nesse ponto do tempo supõe-se que os outros determinantes da demanda (renda, preferências, expectativas e preços de outros bens) são considerados como permanecendo constantes (a famosa hipótese ceteris paribus). Sob essas hipóteses (e somente

\footnotetext{
${ }^{6}$ O leitor interessado deve consultar Freeman III (2003), Capítulo 8.

${ }^{7}$ A Taxa Marginal de Substituição (TMS) entre as duas mercadorias que representa o número de unidades de uma mercadoria Y que o consumidor está disposto a dar até obter uma unidade de X e permanecer a mesma curva de indiferença.
} 
sob essas hipóteses, que parecem estar sendo esquecidas em exercícios de valoração), a equação 2.2 pode ser "simplificada" para:

$$
X_{1}^{D}=f\left(P_{1}\right)
$$

Nesse ponto, pode-se obter a curva de demanda inversa, que nos permite uma interpretação mais apropriada para uma microeconomia ambiental da valoração econômica. Se representamos a função expressa em (2.4) como em (2.5) teremos que alterar nossa interpretação.

$$
P_{1}=f\left(X_{1}^{D}\right)
$$

A interpretação agora é o preço máximo que o indivíduo está disposto a pagar por uma quantidade específica do bem. Isso é usualmente entendido como a máxima disposição a pagar - DAP - pelo bem, ceteris paribus. Uma outra interpretação rigorosa da curva de demanda inversa seria: ela mede a quantidade de outros bens que o indivíduo está disposto a dar para obter uma maior quantidade do bem $\mathrm{X}_{1}$; ou ainda, ela indica a quantidade de outros bens que o indivíduo está disposto a sacrificar em troca de última unidade comprada do bem $X_{1}$. Quando a quantidade de $X_{1}$ é muito pequena, o consumidor está disposto a abrir mão de um monte de outros bens para obter mais de $\mathrm{X}_{1}$. Aumentando a quantidade de $\mathrm{X}_{1}$, o consumidor está disposto a desistir de menor quantidade de outros bens, na margem, para adquirir mais de $\mathrm{X}_{1}$. Assim, a disposição marginal a pagar diminui à medida que aumenta o consumo do bem $\mathrm{X}_{1}{ }^{8}$

\subsection{DAS PREFERÊNCIAS ÀS DEMANDAS DOS CONSUMIDORES}

Podemos agora sofisticar um pouco mais a nossa revisão de microeconomia da

\footnotetext{
${ }^{8}$ De maneira análoga, a teoria da firma (da produção) pressupõe que a empresa procura maximizar o lucro, dado uma função de produção. Dessa função de produção é possível obter a função de oferta da empresa, se soubermos o preço do bem, os preços dos insumos e dos fatores de produção e a sua tecnologia. Esta oferta indica quantas unidades a empresa está disposta a produzir e vender, dado esses determinantes. Esta função pode ser representada como $\mathbf{X}_{1} \mathbf{S}=\mathbf{f}\left(\mathbf{P}_{1}, \mathbf{P}_{2}, \mathbf{P}_{3}, \ldots, \mathbf{P}_{\mathbf{N}}, \mathbf{T}\right)$, onde T representa a tecnologia da empresa. A curva de oferta representa a relação funcional entre o preço do bem e a quantidade máxima ofertada, supondo que os outros determinantes da oferta permaneçam constante. Tendo em conta que a um preço mais elevado, maior é a quantidade ofertada, essa curva tem uma inclinação positiva. Como no caso da demanda, expressando o preço dependendo da quantidade, permite-nos ver qual é o preço mínimo que o produtor está disposto a aceitar para oferecer uma certa quantidade de um bem, uma vez que essa curva de oferta é obtida a partir da estrutura dos custos marginais da empresa, de tal forma que o preço irá refletir o custo de produção.
} 
valoração ambiental analisando, de maneira mais formal, o "problema do consumidor" de maximizar sua utilidade do consumo sujeito a certas restrições. Assim termos:

$$
\begin{gathered}
\operatorname{Max} U=U\left(X_{1}, X_{2}, X_{3} \ldots, X_{n}\right) \\
\text { s. } \boldsymbol{I} I=\left(P_{1} \cdot X_{1}+P_{2} \cdot X_{2}+\cdots+P_{n} \cdot X_{n}\right)
\end{gathered}
$$

Valendo-nos da formulação de um Multiplicador de Lagrange, temos:

$$
\mathcal{L}=U\left(X_{1}, X_{2}\right)+\lambda\left(I-P_{1} X_{1}-P_{2} X_{2}-P_{n} X_{n}\right)
$$

Derivando em relação a $\mathrm{X}$ - condições de primeira ordem (CPO), obtemos:

1. $\mathcal{L}_{1}=U_{1}-\lambda P_{1}=0$

2. $\mathcal{L}_{2}=U_{2}-\lambda P_{2}=0$

n. $\quad \mathcal{L}_{n}=U_{n}-\lambda P_{n}=0$

$\mathrm{n}+1 . \quad \mathcal{L} \lambda=I-P_{1} \cdot X_{1}-P_{2} \cdot X_{2}-\cdots-P_{n} \cdot X_{n}=0$

Colocando $\lambda$ em evidência:

$$
\lambda=\frac{U_{1}}{P_{1}}=\frac{U_{2}}{P_{2}}=\cdots=\frac{U_{n}}{P_{n}}
$$

ou

$$
\frac{U_{i}}{U_{j}}=\frac{P_{i}}{P_{j}} \forall i=1,2,3, \ldots, n \quad \forall j=1,2,3, \ldots, n
$$

onde, $\operatorname{TMS}\left(\mathrm{X}_{\mathrm{j}}\right.$ por $\left.\mathrm{X}_{\mathrm{i}}\right)=\frac{\boldsymbol{P}_{\boldsymbol{i}}}{\boldsymbol{P}_{\boldsymbol{j}}}$.

Para podermos avançar, precisamos antes interpretar a equação 2.7. Ela nos indica que: a) cada um dos bens adquiridos deve gerar a mesma utilidade marginal para cada cada unidade monetária gasta nele; b) a relação custo-benefício é a mesma para todos os bens i; e c) essa relação, $\lambda$, é o preço-sombra de uma unidade monetária adicional de renda, ou seja, o valor em bens e serviços da renda adicional. Nós voltaremos a essas interpretações um pouco mais adiante quando incluirmos explicitamente a variável ambiental em nossas equações. Por enquanto, desejamos apenas lembrar que valoração econômica - quando efetuada por um dos métodos função demanda - está emoldurada por esses conceitos.

\footnotetext{
${ }^{9}$ Apenas para relembrar, Ui Utilidade Marginal do bem i; e Pi Custo Marginal do bem i, em condições de concorrência perfeito, o seu preço.
} 
Torna-se relevante agora desenvolver deduções semelhantes para a função utilidade indireta com apenas dois bens sendo demandados. Nesse contexto, temos:

$$
\begin{gathered}
\operatorname{Max} U=X . Y \\
\text { s. } \boldsymbol{a} I=X P_{x}+Y
\end{gathered}
$$

Formulando o Multiplicador de Lagrange:

$$
\mathcal{L}=X . Y+\lambda\left(I-X P_{x}-Y P_{y}\right)
$$

Derivando CPO:

1. $\frac{\partial \mathcal{L}}{\partial X}=Y-\lambda P_{x}=0 \triangleright \lambda=Y / P_{x}$

2. $\frac{\partial \mathcal{L}}{\partial Y}=X-\lambda P_{y}=0>\lambda=\frac{Y}{P_{y}} \quad \frac{\partial \mathcal{L}}{\partial \lambda}=I-P_{x} X-P_{y} Y=0$

3. $\frac{\partial \mathcal{L}}{\partial \lambda}=I-P_{x} X-P_{y} Y=0$

Igualando 1 e 2:

4. $\quad \frac{Y}{P_{x}}=X / P_{y} ; X . P_{x}=Y . P_{y}$

Substituindo 4 em 3:

$I-Y . P_{y}-Y \cdot P_{y}=0$

$I=2 . Y . P_{y}$

$Y=I / 2 . P_{y}$

$I-X . P_{x}-X . P_{x}=0$

$I=2 . X . P_{x}$

$X=I / 2 . P_{x}$

O leitor atento já deve ter percebido que essa é a Curva de Demanda Marshalliana, a saber:

$$
\begin{aligned}
& \mathrm{X}^{*}=\mathrm{X}^{\mathrm{M}}(\mathbf{P}, \mathrm{M}) \\
& \mathrm{Y}^{*}=\mathrm{Y}^{\mathrm{M}}(\mathbf{P}, \mathrm{M})
\end{aligned}
$$

Onde M representa a renda total de Marshall (para diferenciar de I a renda disponível) 
e ao substituir os $X^{*}$ e $Y^{*}$ em $U=X Y$ se obtém a Função de Utilidade Indireta: $V=V(P, M)$. A Função de Utilidade Indireta procura maximizar a utilidade sujeito a uma restrição orçamentária. Vamos explorar o que acontece quando trabalhamos com uma Função de Gasto, na qual busca-se minimizar custos sujeito a um nível de utilidade. Isto é:

$$
\begin{gathered}
\operatorname{Min} E=X P_{x}+Y P_{y} \\
\text { s.a. } U=X . Y
\end{gathered}
$$

Formulando Multiplicador de Lagrange:

$$
\mathcal{L}=X . P_{x}-Y . P_{y}+\lambda .\left(U_{0}-X . Y\right)
$$

Derivando CPO:

1. $\frac{\partial \mathcal{L}}{\partial X}=P_{x}-\lambda Y=0>\lambda=P_{x} / Y$

2. $\quad \partial \mathcal{L} / \partial \mathrm{Y}=P_{y}-\lambda X=0>\lambda=\mathrm{Py} / \mathrm{X}$

3. $\quad \partial \mathcal{L} / \partial \lambda=U-X . Y=0$

Igualando 1 e 2:

4. ${ }^{P_{x}} /_{Y}=P{ } /_{X} ; X \cdot P_{x}=Y \cdot P_{y} ; Y=X P_{x} / P_{y}$

Substituindo 4 em 3:

$$
\begin{aligned}
& U_{0}-X\left(\frac{X P_{x}}{Y}\right)=0 \\
& U_{0}-Y\left(\frac{Y P_{y}}{X}\right)=0
\end{aligned}
$$

Mais uma vez, leitor vigilante nota que esta é a Curva de Demanda Hicksiana:

$$
\begin{aligned}
& X^{*}=X . H(P, U) \\
& Y^{*}=Y . H(P, U)
\end{aligned}
$$


Onde $\mathrm{H}$ é a renda total de Hicks e ao substituir os $\mathrm{X}^{*}$ e $\mathrm{Y}^{*}$ em $E=X P_{x}+Y P_{y} \quad$ se obtém a Função de Gasto (Despesa) E = E (P, U), que como já destacado, minimiza custos sujeito a um nível de utilidade. Qualquer uma das duas abordagens - a função de utilidade indireta (maximizar a utilidade sujeito a uma restrição orçamentária) ou a função despesa (minimizar o custo de sujeito a um nível de utilidade) - fornece um ponto ótimo de consumo. Abordagens são válidas e produzem os mesmos resultados. Além disso, se pode passar da função de utilidade indireta para a função de despesa, e vice-versa, evidenciando uma dualidade. A maneira de fazer isso é descrita no Quadro 2.1, que reintroduz o tratamento desejável de problemática ambiental.

Estabelecidas as duas curvas de demanda (de Marshall e de Hicks) precisamos agora relacioná-las com aquilo que nos interessa diretamente: com a melhoria da qualidade de um ativo ambiental, a água, por exemplo. Vamos supor que uma pessoa experimenta um aumento em seu bem-estar derivado da melhoria na qualidade da água que usufrui (consome). Ela se sente melhor. Essa é uma sensação puramente subjetiva. Como economistas (ambientais) desejamos expressá-la (a sensação) em algum tipo de unidade de medida que seja fácil de entender e, além disso, permita comparar a situação de duas pessoas diferentes. Esse desafio não é simples, mas a análise econômica oferece algumas alternativas para expressar, em unidades monetárias, essas mudanças subjetivas em bem-estar pessoal.

\subsection{MEDIDAS DE BEM-ESTAR E OS BENS E SERVIÇOS AMBIENTAIS}

A microeconomia nos indica maneiras de expressar, em termos monetários, mudanças em algo tão subjetivo como bem-estar pessoal. O excedente líquido do consumidor pode, com efeito, ser usado para medir essas mudanças. O excedente do consumidor é a área que está entre a curva de demanda de um indivíduo para um bem qualquer (ou seja a sua disposição a pagar DAP por esse bem) e o preço que esse indivíduo efetivamente paga. Esse é excedente do consumidor marshalliano, sua medida de bem estar. Ele pode ser representada no quadro 2.1. 
Quadro 2.1- Dualidade entre medidas de maximização da utilidade e minimização de gastos

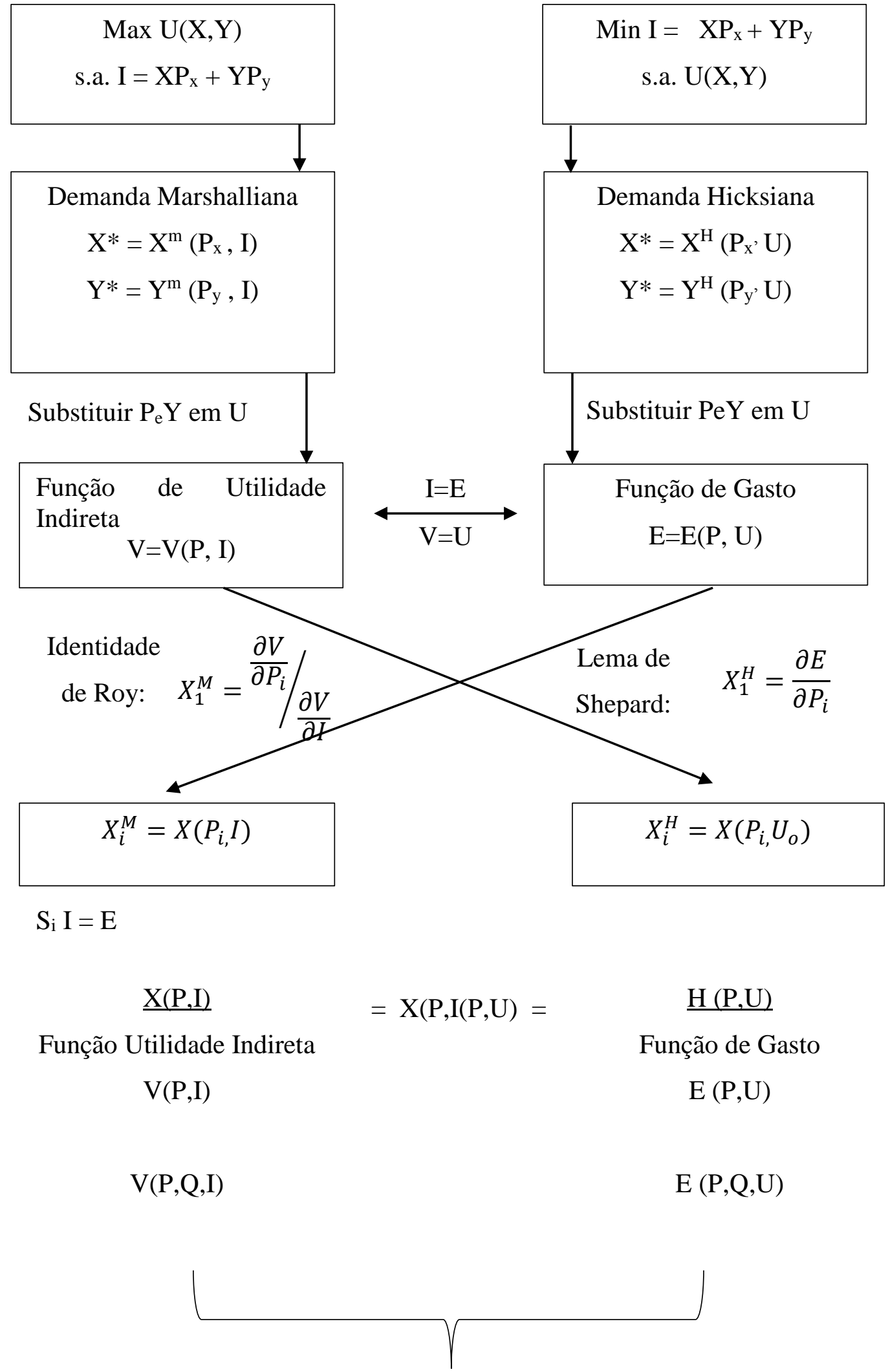

Introduzindo a Variável "Qualidade Ambiental”

Fonte: Barzev (2002) 
Gráfico 2.1 - Curva de Demanda Marshalliana e o excedente do consumidor

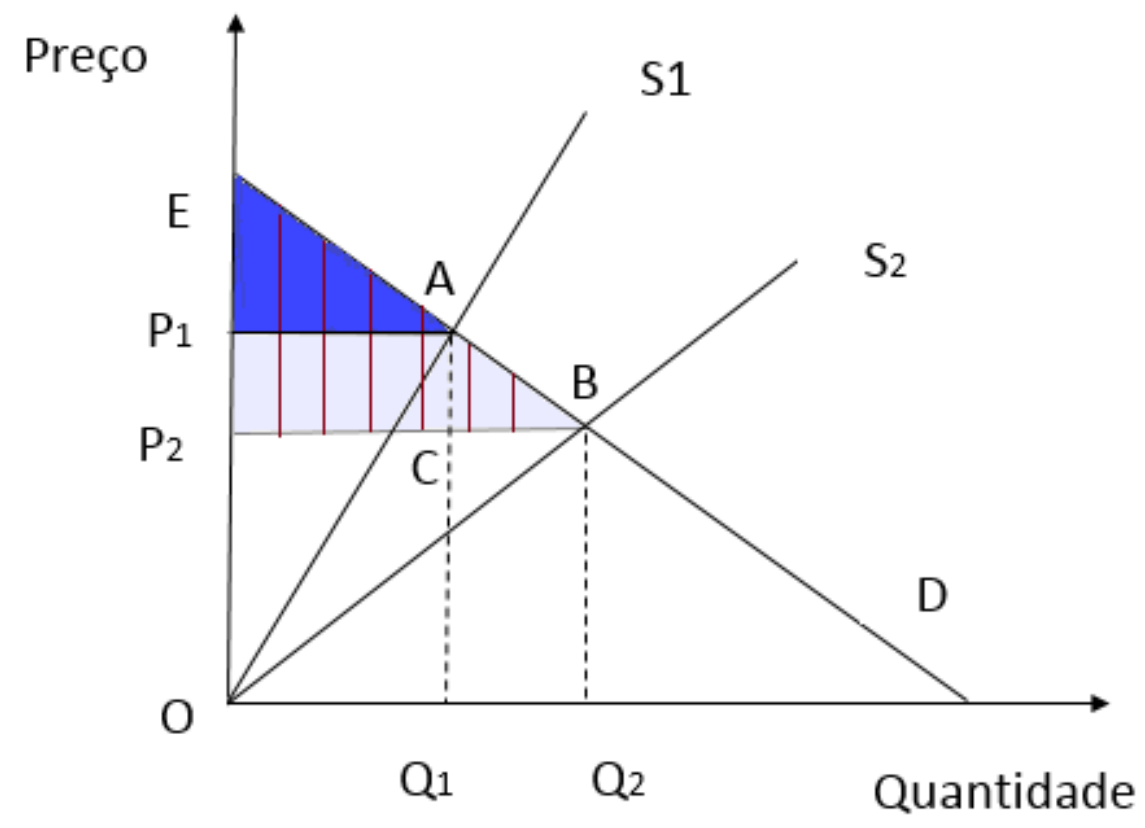

Fonte: Gráfico elaborado pela própria autora com base em Freeman III (2003) e Hanley e Spash (1995).

No gráfico 2.1 $\mathrm{P}_{1}$ é o preço e $\mathrm{Q}_{1}$ a quantidade de equilíbrio inicial. Ocorre um deslocamento da curva de oferta para baixo (por algum motivo há uma redução no custo de ofertar o bem em questão), o novo preço de equilíbrio $\mathrm{P}_{2}$ é menor que o preço de equilíbrio anterior $\mathrm{P}_{1}$. Dessa forma, a quantidade de equilíbrio se altera, aumentando de $\mathrm{Q}_{1}$ para $\mathrm{Q}_{2}$. $\mathrm{O}$ excedente do consumidor ao preço $\mathrm{P}_{1}$ é representado pela área do triângulo EAP1. Com a mudança do preço para $\mathrm{P}_{2}$, o excedente passa a incluir a área formada pelos pontos $\mathrm{P} 1 \mathrm{ABP} 2$, passando o excedente do consumidor a ser representado pela área EBP2. Assim, quando ocorre uma redução no preço de equilíbrio ou um aumento na quantidade ofertada, a variação (positiva) do excedente do consumidor será a área P1ABP2. Se houver um aumento no preço de equilíbrio ou uma redução na quantidade ofertada, ocorre uma variação negativa do excedente do consumidor ${ }^{10}$.

Marshall (1920) estendeu sua análise sobre a demanda de apenas um indivíduo para todo o mercado. Ao assim proceder negligenciou o fato de que a mesma soma de dinheiro

\footnotetext{
${ }^{10}$ A expressão matemática do excedente do consumidor marshalliano é $\mathrm{EC}=\int \mathrm{X}(\mathrm{P}, \mathrm{I}) \mathrm{DP}$.
} 
representa diferentes quantidades de satisfação para diferentes pessoas. Além disso, ele mesmo apontou limitações do excedente do consumidor, quando existe efeito renda. $\mathrm{O}$ efeito renda decorre do aumento do poder aquisitivo real dos consumidores, em consequência da redução do preço de uma mercadoria, proporcionando um excedente de renda para compras adicionais.

O problema em se usar variações no excedente do consumidor, como medida de mudanças no bem-estar, está em que ela não neutraliza o efeito-renda que também é produzido pela queda no preço. Em consequência, não são capturadas mudanças na utilidade marginal da renda que ocorrem e que provocam alterações em todas as utilidades marginais dos bens consumidos. Viana (2005) alerta para cálculo incorreto quando usar o excedente consumidor Marshalliano, por apresentar problemas de ordem teórica como no caso de múltiplas mudanças de preços. O valor integral depende da ordem em que os preços variam. $\mathrm{O}$ Excedente do Consumidor só teria solução única se as derivadas-preços cruzadas dos bens fossem iguais ou se as elasticidades renda dos bens cujos preços variassem fossem iguais a zero ou, ainda, se as curvas de demanda tivessem elasticidade -renda unitária.

Com o objetivo de estabelecer medidas mais precisas para o caso de múltiplas mudanças de preços, John Hicks propôs conceitos alternativos do excedente do consumidor. Existem quatro medidas de bem- estar definidas por Hicks (1945): variação compensatória, variação equivalente, excedente compensatório e excedente equivalente.

\section{- Variação Compensatória}

A Variação Compensatória (VC) é dada pelo montante de dinheiro que, diante de uma mudança, o indivíduo teria que pagar (ou receber) para que seu nível de bem-estar permaneça inalterado. Vamos usar o exemplo de Barzev (2002) para consolidar o conceito de VC: suponha que a administração pública de uma cidade está considerando a viabilidade de um projeto de distribuição de água potável para a municipalidade. Não é difícil argumentar que a purificação da água aumenta o bem-estar dos habitantes. No entanto, deseja-se precisar quanto, para que se tenha uma estimativa monetária desses benefícios. Só assim eles serão comparáveis aos custos de construção e operação de uma planta de tratamento.

A VC é a quantidade de dinheiro que se retirada do indivíduo (consumidor de água potável) após a mudança (com a disponibilidade de água potável) irá deixa-lo no mesmo nível de bem-estar original (sem a disponibilidade de água potável). Portanto, a VC será:

(i) valor máximo que o indivíduo está disposto a pagar (sua máxima DAP) por uma mudança favorável; ou 
(ii) valor mínimo que o indivíduo está disposto a aceitar (sua mínima DAC) como compensação por uma alteração desfavorável.

Em termos formais:

$$
V C=E\left(P, Q^{0}, U^{0}\right)-E\left(P, Q^{1}, U^{0}\right)=\int Q_{1} \partial \mathrm{E} / \partial Q_{i}\left(P, Q^{0}, U^{0}\right) d Q_{i}
$$

Onde:

$\mathrm{Q}^{0}$ é a qualidade ambiental antes de mudanças.

$\mathrm{Q}^{1}$ é a qualidade ambiental após mudanças.

$\left(\mathrm{Q}^{1}<\mathrm{Q}^{0}\right)$ qualidade ambiental inicial é o melhor, traz um maior nível de bem-estar para o consumidor.

$E\left(P, Q^{0}, U^{I}\right)$ é a função de despesas é quando a deterioração é evitada.

$E\left(P, Q^{1}, U^{1}\right)$ é a função de despesas com a deterioração na qualidade ambiental.

Uma outra maneira de expressar a VC é:

$$
V\left(P, Q^{1}, M \pm V C\right)=V\left(P, Q^{0}, Y\right)=U^{0}=V C
$$

Com sinal: (+) para DAC y (-) para DAP.

A Variação Compensatória (VC) do nosso exemplo proposto pode ser analisada com a ajuda do Gráfico 2.2. Aceitamos, para facilidade de ilustração, que as preferências do consumidor de água podem ser representadas pelas já mencionadas curvas de indiferença. Temos, portanto, no Gráfico 2.2, a seguinte situação: medimos a quantidade de água potável consumida no eixo horizontal (X); no eixo vertical medimos a quantidade consumida de todos os outros bens $(\mathbf{Y})$, refletidas ambas em termos de um numerário (unidades monetárias de utilidade constante). Por outro lado, a restrição orçamentária do consumidor e o preço relativo de água potável em relação aos preços das demais mercadorias são representados pela inclinação da reta de restrição orçamentária $\mathbf{V}_{\mathbf{0}} \mathbf{V}_{\mathbf{0}}$, no Gráfico representada por $\boldsymbol{\alpha}$. Nessa situação, o consumidor está localizado no ponto A na curva de indiferença $\mathbf{I}^{\mathbf{0}}$ que representa seu nível de bem-estar nas condições iniciais propostas. 


\section{Gráfico 2.2- Variação Compensatória e Variação Equivalente}

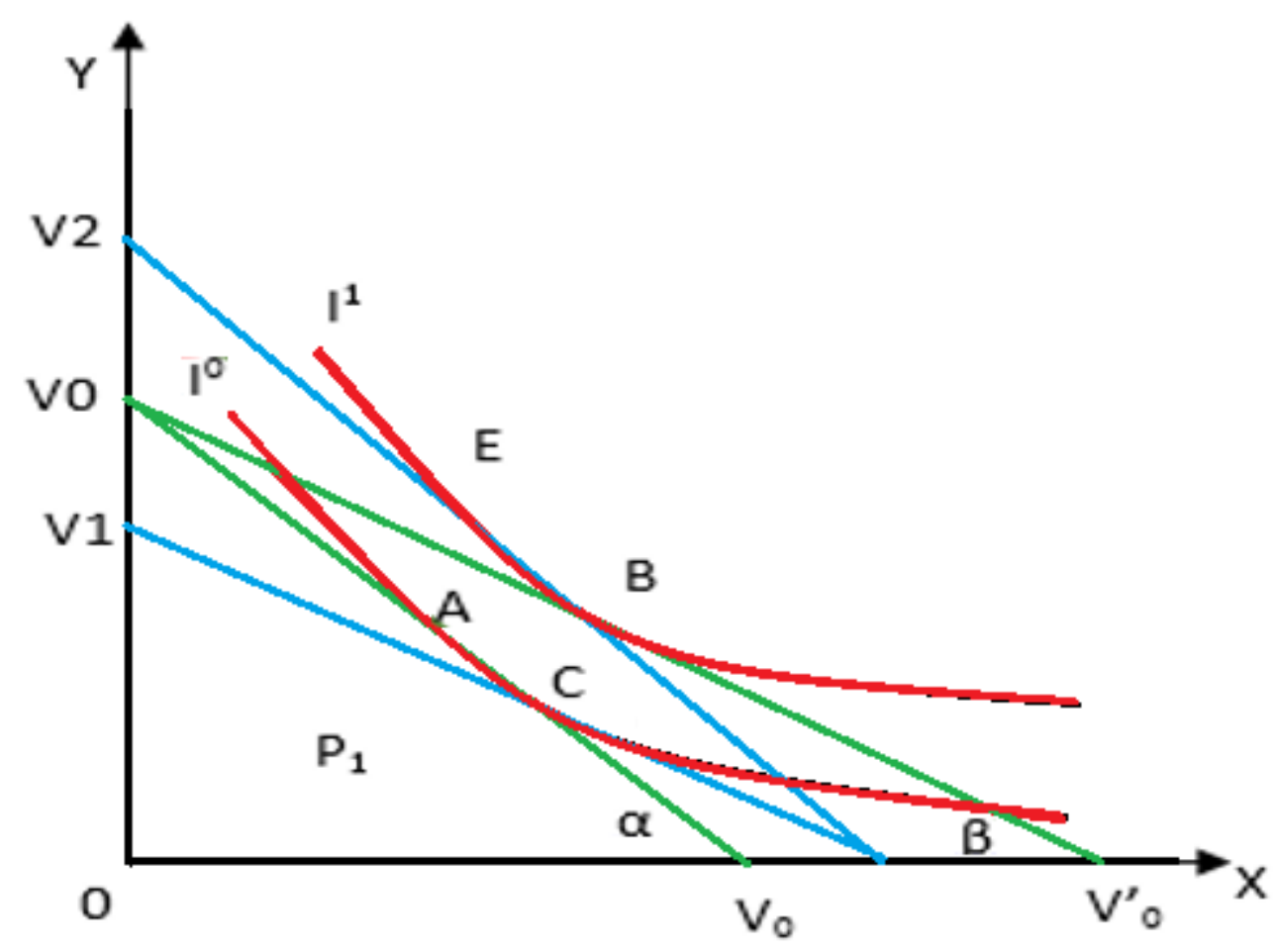

Fonte: Barzev (2002)

Vamos agora considerar o novo cenário: o abastecimento municipal de água potável reduz seu preço (ou melhora a sua qualidade, causando o mesmo efeito sobre o bem-estar do consumidor). Em consequência, a linha de restrição orçamentária gira em torno do ponto Vo no eixo vertical (que mede o poder de compra em termos de dinheiro) em sentido anti-horário. $\mathrm{O}$ declive da linha mede os preços relativos da água potável em relação aos das outras mercadorias, que agora está representado por $\boldsymbol{\beta}$. Na nova situação o consumidor está localizado no ponto $\mathbf{B}$, atingindo o nível de bem-estar representado por curva de indiferença $\mathbf{I}^{\mathbf{1}}$.

Como podemos medir essa melhoria de bem-estar em termos monetários? Uma possibilidade consiste em estimar o montante de dinheiro que subtraído da renda do consumidor que, diante do novo preço da água, lhe permitiria manter inalterado o seu nível de bem-estar original $\left(\mathbf{I}^{\mathbf{0}}\right)$. Este seria o montante $\mathbf{V}_{\mathbf{0}} \mathbf{V}_{\mathbf{1}}$ : a variação compensatória. Assim, se privarmos o nosso consumidor desse montante, mantendo os novos preços relativos da água tratada, o colocaremos no ponto $\mathbf{C}$, atingindo o nível de bem-estar da curva de indiferença original: $\mathbf{I}^{\mathbf{0}}$. A variação compensatória parece, portanto, ser um bom indicador monetário da mudança no bemestar produzido. 


\section{- Variação Equivalente}

Poderíamos, alternativamente, ter perguntado à pessoa pelo montante de dinheiro que teríamos que lhe dar para alcançar o mesmo nível de bem-estar como se a água da torneira fosse potável, quando essa água não o for, uma vez que a purificação da água não foi realizada. Em outras palavras: qual seria o aumento de renda necessário para que ela ou ele pudesse atingir a curva de indiferença de $\mathbf{I}^{\mathbf{1}}$, com o preço da água mantido em seu nível original a (isto é, sem a purificação da água). Esta medida é a variação equivalente (VE).

A VE é o montante de dinheiro que deverá ser entregue ao consumidor se a mudança não ocorrer, mas fazendo-o passar a um novo nível de bem-estar como se a mudança tivesse ocorrido. Portanto, a VE será:

iii) valor máximo que o indivíduo está disposto a pagar (sua máxima DAP) para evitar uma mudança desfavorável.

iv) valor mínimo que o indivíduo está disposto a aceitar como compensação (sua mínima DAC) para renunciar a uma mudança favorável.

Em termos formais:

$$
V E=E\left(P, Q^{0}, U^{0}\right)-E\left(P, Q^{1}, U^{1}\right)=\int Q_{1} \partial \mathrm{E} / \partial Q_{i}\left(P, Q, U^{0}\right) d Q_{i}
$$

Também a VE pode ser expressa por meio da função utilidade indireta (V) do indivíduo, a saber V $(\mathrm{P}, \mathrm{Q}, \mathrm{M})=\mathrm{E}(\mathrm{P}, \mathrm{Q}, \mathrm{U})$, que pelo Lema de Shepard-Uzawa na teoria da dualidade:

$$
V\left(P, Q^{0}, M \pm V E\right)=V\left(P, Q^{1}, Y\right)=U^{1}=V E
$$

Com sinal: (+) para DAC y (-) para DAP.

Voltando ao Gráfico 2.2, podemos observar que esta medida seria equivalente à distância de $\mathbf{V}_{0} \mathbf{V}_{2}$. Nesse contexto, se a partir da situação original (preços relativos iguais a $\alpha$ e o consumidor localizado em A) aumentamos a renda do consumidor por esse valor mantendo os preços constantes, ela ou ele será movido para o ponto E. Ele ou ela alcançará, portanto, o nível de utilidade refletido na Curva de Indiferença $I^{1}$, que teria sido alcançado após a mudança proposta. 
Variação Compensada (VC) e Variação Equivalente (VE) são, portanto, duas medidas alternativas que procuram refletir a mesma coisa: o aumento do bem-estar que envolve a pessoa, derivado do fato de que as autoridades municipais tornem a água potável. Além disso, essas medidas poderiam ser aplicadas no caso de um agravamento da situação da qualidade da água.

Poderia acontecer também, prosseguindo com o exemplo acima, que a prefeitura do município estivesse contemplando a possibilidade de permitir novos assentamentos de população ou um aumento da produção agrícola, com consequente uso de fertilizantes e pesticidas ou, ainda, certas obras de infraestrutura pública que exigissem uma fonte alternativa de água não potável. Os danos causados à população poderiam ser medidos, novamente, por meio de duas vias alternativas:

a) que montante de dinheiro teríamos que pagar a cada família para que aceitasse a mudança; ou para que se declarasse indiferente entre ter a água potável e manter o nível de renda original; ou para seguir com a água não potável e ter um aumento no seu rendimento equivalente a essa quantia?

No Gráfico 2.2, essa situação é caracterizada pela passagem de B (lócus original) para A (quando a água corrente deixa de ser potável: aumenta o custo da água potável). A resposta para a pergunta acima seria equivalente ao montante $\mathrm{V}_{0} \mathrm{~V}_{2}$ : por esse montante a pessoa alcançaria, em E, a curva de indiferença original (neste caso $\mathrm{I}^{1}$ ). Esta seria a variação compensatória (VC).

b) que montante de dinheiro o consumidor estaria disposto a pagar para evitar a mudança, de tal forma que se sentiria indiferente entre não ter água potável, ou tê-la, mas com uma redução em sua renda exatamente igual a esse montante?

No Gráfico 2.2, esse montante seria $\mathrm{V}_{0} \mathrm{~V}_{1}$. Se privarmos nosso consumidor desse montante e mantivermos os preços originais (inclinação de $\mathrm{V}_{0} \mathrm{~B}$, neste caso), o consumidor passaria de B para C. Com isso o nível de bem-estar que lhe permite a alteração proposta $\left(\mathrm{I}^{0}\right)$. Esta é a variação equivalente (VE).

O leitor atento já percebeu que a Variação Compensatória (VC) será igual à Variação Equivalente (VE) se a elasticidade renda da demanda por um bem qualquer - vamos chamar de Bem X - for igual a zero. No caso do Bem X ser um bem normal, VE será maior do que a VC para uma redução no preço de X. Obviamente, VE será menor do que VC para um aumento no preço do Bem X. Hanley e Spash (1993) destacam que quanto maior for a elasticidade renda da demanda pelo Bem X, maior será à diferença entre VC e VE. Mais ainda, quanto maior for a elasticidade renda da demanda pelo Bem X, maior será a diferença entre VC/VE e o excedente 
do consumidor marshalliano. Isso tem consequências para a interpretação de um resultado de valoração econômica ambiental. Voltaremos a esse ponto em breve.

\section{- Excedente Compensatório}

Em complemento às duas medidas de variação (compensatória e equivalente) há duas medidas Hicksianas de excedente (compensatório e equivalente). Essas medidas de excedente são especificamente para uso quando a escolha do nosso consumidor está relacionada com uma quantidade discreta de um bem ao invés de uma quantidade contínua desse bem. Dito de outra maneira, o bem em questão é indivisível (HANLEY e SPASH, 1993) e, assim, medidas de excedente são relevantes em situações nas quais os bens públicos são discretos.

Lançando mão de um exemplo de Hanley e Spash (1993, p. 36): se o bem público em questão é qualidade do ar, uma redução na quantidade de $\mathrm{SO}_{2}$ em uma determinada área será um ato de política pública sem que consumidores possam escolher a quantidade de $\mathrm{SO}_{2}$ que eles desejam consumir. Essa situação contrasta com a realidade de bens privados na qual consumidores ajustam livremente seu consumo. Vamos nos valer do Gráfico 2.3 para analisarmos como a restrição de impossibilidade de escolha da quantidade desejável do bem afeta as medidas de bem-estar do nosso consumidor.

O Gráfico 2.3 mostra o impacto de uma política pública que aumenta a quantidade do bem $\mathrm{X}_{1}$. Com o aumento da quantidade disponível de $\mathrm{X}_{1}$, ceteris paribus, seu preço se reduz e isso aumenta o poder de compra do nosso consumidor. Assim, a reta de restrição orçamentária se desloca para a direita. Antes do aumento da quantidade disponível ele estava consumindo $\mathrm{q}_{1}$ na curva de utilidade $U_{0}$. No entanto, com o menor preço de $X_{1}$, ele passa a consumir $q_{1}$ na curva de utilidade $U_{1}$. Se desenvolvêssemos o raciocínio da variação compensatória (veja anteriormente neste capítulo), a renda do nosso consumidor seria reduzida para que ele retornasse para o seu nível de utilidade original $\mathrm{U}_{0}$, porém mantendo o preço menor de $\mathrm{X}_{1}$.

Aqui, entretanto, nosso consumidor não pode ajustar a quantidade consumida de $X_{1}$ na medida que sua renda real se altera; ela ou ele deve permanecer em q2. O resultado é que menos renda é retirada dele ou dela antes que sua utilidade alcance $\mathrm{U}_{0}$ porque nosso consumidor é forçado a consumir $\mathrm{q}_{1}$. Como resultado, seu excedente compensatório (EC) é $\mathrm{m}_{0}-\mathrm{m}_{\mathrm{cs}}$, enquanto

que a variação compensatória (VC) seria $\mathrm{m}_{0}-\mathrm{m}_{1}$. É essencial perceber que o resultado final não é mais alcançado em um ponto de tangência, porque o consumidor é cingido em sua habilidade de ajustar seu consumo a uma mudança em sua renda. 
Gráfico 2.3 - Excedente Compensatório para um aumento de quantidade

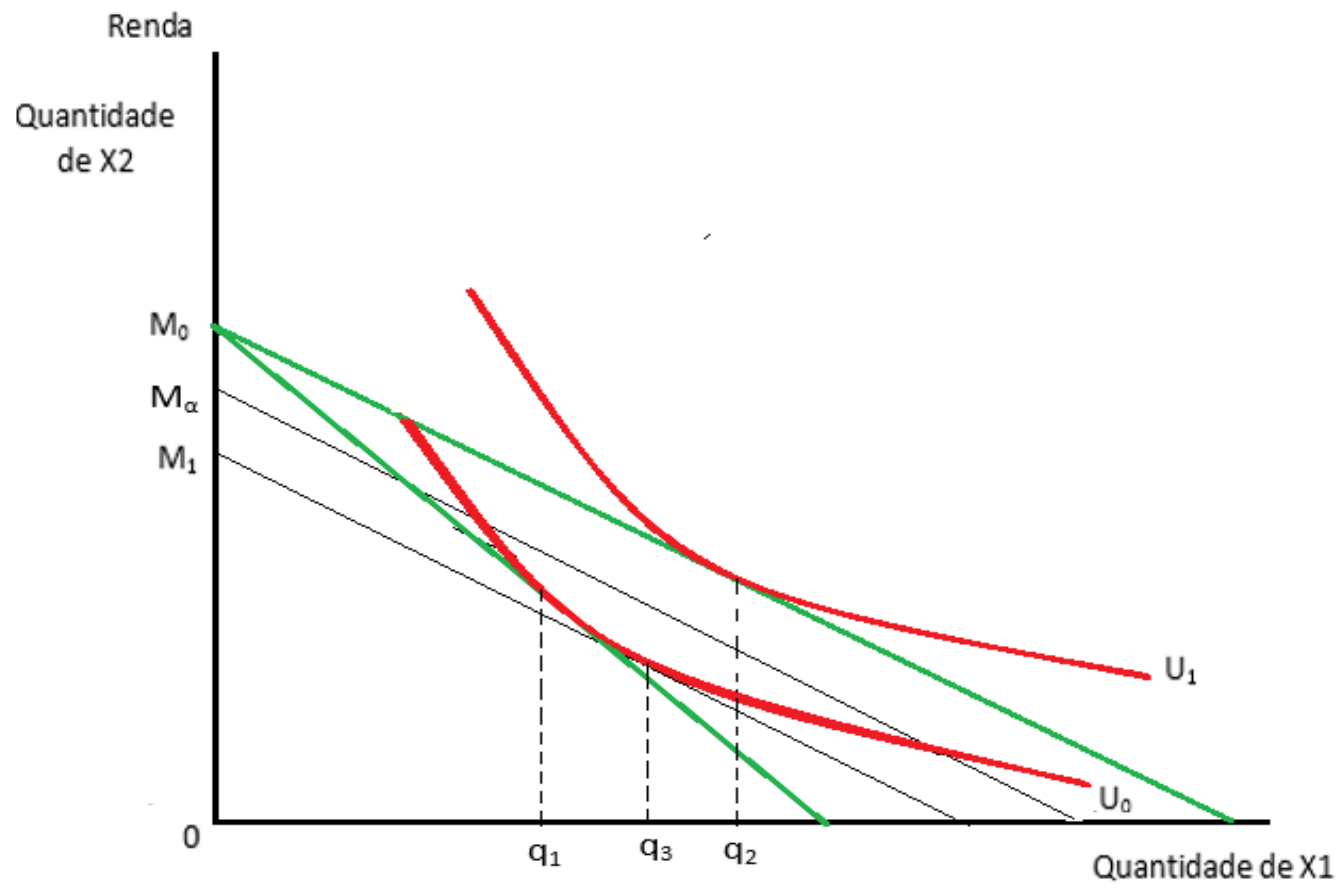

Fonte: Hanley e Spash (1993)

\section{- Excedente Equivalente}

Vamos retornar ao exemplo do bem público qualidade do ar mencionado acima. Dessa vez nossa hipótese é que o governo resolve adiar qualquer ação para reduzir a quantidade de $\mathrm{SO}_{2}$ em uma determinada área. Ele adia a política pública de combate a esse poluente. Esse governo gostaria de saber qual seria o montante de benefício sacrificado por ter adiado tal política de redução de $\mathrm{SO}_{2}$. Que medida de perda de bem-estar seria mais apropriada? Nesta hipótese o consumidor está "forçado" a permanecer no mesmo nível de consumo $\left(\mathrm{de}^{\mathrm{SO}} \mathrm{O}_{2}\right)$ que estava antes da decisão governamental de adiar a implantação da política. Isto é, ela ou ele é obrigado a permanecer no mesmo nível original de consumo. Podemos mostrar a resposta a essa pergunta com a ajuda do Gráfico 2.4 .

$\mathrm{O}$ excedente equivalente (EE) mostra que o nosso consumidor iria requerer um aumento na renda que lhe permitisse alcançar $\mathrm{U}_{1}$, uma vez que $\mathrm{U}_{1}$ seria o nível de utilidade que a política de redução de emissões permitiria que o nosso consumidor alcançasse. Caso esse aumento de renda ocorresse, o consumidor compraria mais de $\mathrm{X}_{1}$ chegando à quantidade $\mathrm{q}_{4}$. Entretanto, como o consumidor está "forçado" a permanecer consumindo q q $_{1}$ pois a política de 
redução de emissões foi adiada), ele ou ela precisaria de um incremento de renda ainda maior para alcançar $\mathrm{U}_{1}$. Assim, sua variação equivalente (VE) seria $\mathrm{m}_{0}-\mathrm{m}_{2}$; no entanto, seu excedente equivalente (EE) é $\mathrm{m}_{\mathrm{o}}-\mathrm{m}$ es

\subsection{MICROECONOMIA DA VALORAÇÃO: O DESEJÁVEL E O POSSÍVEL}

Muitos bens e serviços ambientais são aquilo que o economista denomina bens públicos. Em consequência, alterações neles observadas (ou simuladas) devem refletir mudanças no bemestar dos seus consumidores capturadas nas medidas de excedentes (compensatório e equivalente) que acabamos de analisar. Isso já foi assinalado por Mitchell e Carson (1989) em seu clássico trabalho sobre valoração contingente há mais de vinte anos. No entanto, em uma avaliação anterior, Freeman III (1979) argumentou que essas duas medidas de excedente seriam muito restritivas e desnecessárias. Freeman III (1979) acreditava que, no caso de bens públicos, os excedentes e as variações seriam medidas equivalentes de bem-estar para os casos compensatório e equivalente, respectivamente. Não obstante, ele também argumentava que o enfoque a ser escolhido deveria ser determinado pelas características do bem ou do serviço sob análise.

Por isso, Hanley e Spash (1993) assinalam que de uma perspectiva do rigor teórico, medidas de excedente devem ser empregadas quando a mudança na quantidade é imposta e quando o consumidor não tem a liberdade de ajustar a quantidade consumida. Cabe assinalar, no entanto, que a maioria dos estudos se concentra na escolha entre variação compensatório (VC) e variação equivalente (VE) e entre essas e o excedente do consumidor (EC) marshalliano. Há, por outro lado, um certo consenso de que apesar das VC e VE serem consistentes com a definição teórica de bem-estar, nenhuma das duas é observável diretamente de informações de mercado. Já o EC marshalliano é observável a partir de informações de mercado.

As três medidas alternativas para valorar mudanças no bem-estar funcionam para o caso em que o indivíduo pode ajustar as quantidades consumidas dos bens (EC, VC e VE). Aplicadas a uma mesma modificação na oferta de um bem (alterações de preço ou de quantidade ou de qualidade do bem oferecido), as três medidas não refletem a mesma avaliação da mudança de bem-estar que a modificação de oferta produz na pessoa. 
Gráfico 2. 4 - Excedente Equivalente para um aumento de quantidade

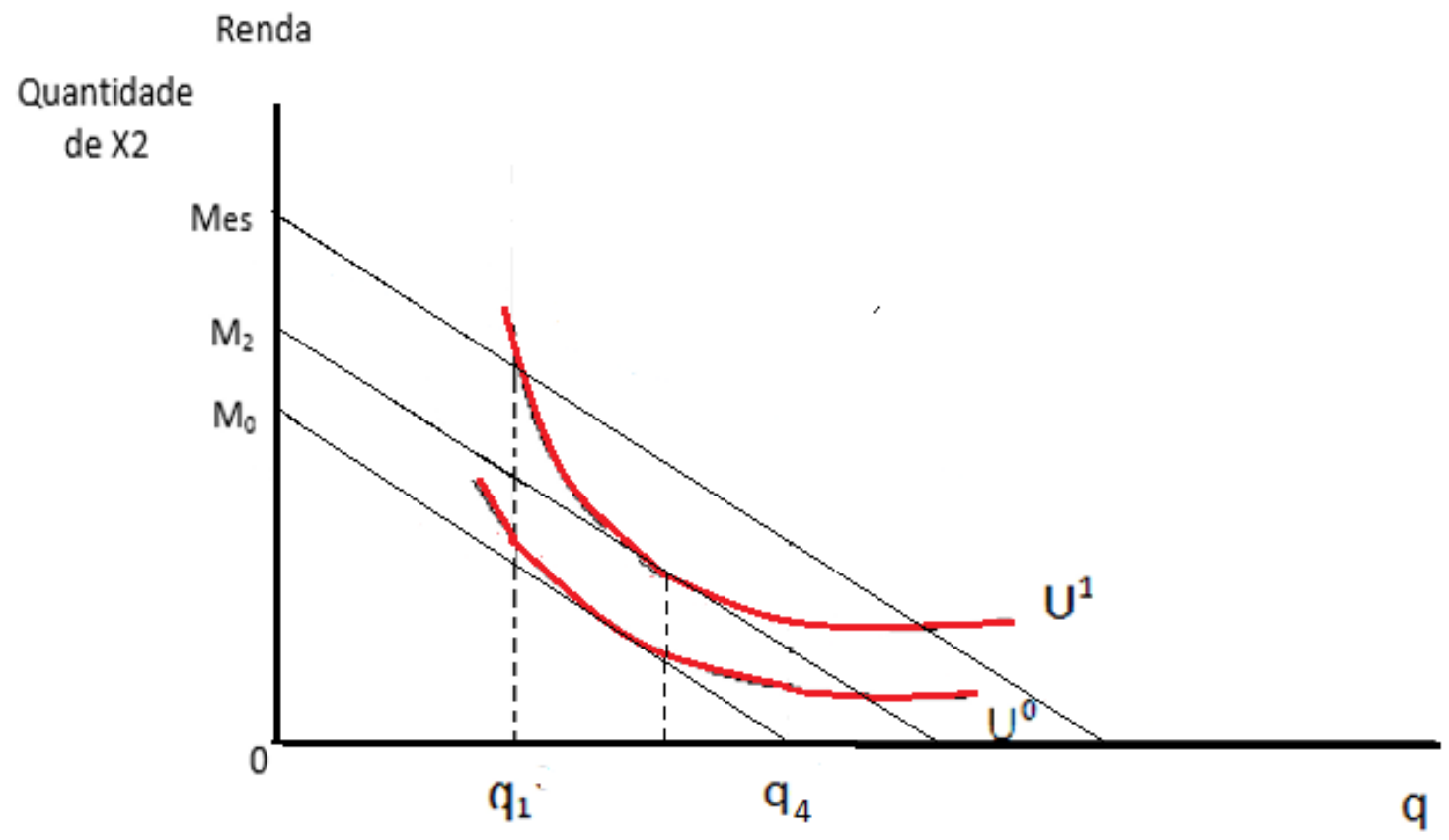

Fonte: Hanley e Spash (1993)

No caso de uma queda no preço ou uma melhoria nas condições do bem ofertado considerado (ou melhoria na qualidade ambiental), teremos: $\mathrm{VC}<\mathrm{EC}<\mathrm{VE}$. Ou seja, a variação equivalente extrapola o excedente do consumidor e esse supera a variação compensatória. Quando somos confrontados com um aumento no preço ou uma deterioração nas condições de oferta (piora da qualidade ambiental), a situação se inverte: $\mathrm{VC}>\mathrm{EC}>\mathrm{VE}$. $\mathrm{O}$ excedente do consumidor aparece, em ambos os casos, ocupando a posição intermediária, entre a variação equivalente e variação compensatória. Isso sugere a possibilidade (e a conveniência) de se usar o excedente do consumidor como uma aproximação das medidas VC e VE, mais robustas teoricamente.

A partir do Gráfico 2.2 e fazendo algumas derivações podemos avaliar as consequências dessa escolha por conveniência. Em primeiro lugar, derivamos a curva de demanda ordinária (ou de Marshall) e as curvas de demanda compensadas (de Hicks), que estão representadas na parte inferior do Gráfico 2.5. Para uma melhor visualização, essa porção inferior é destacada no Gráfico 2.5. Neste, a variação compensatória (VC) associada com uma redução no preço do bem é igual à área $\mathbf{x}$. Já a variação equivalente (VE) associada com a mesma redução de preço 
é dada pela área $\mathbf{x}+\mathbf{z}+\mathbf{w}$. Finalmente, o excedente do consumidor $(\mathrm{EC})$ é igual à área $\mathbf{x}+\mathbf{z}$.

É sabido, além disso, que a diferença entre essas três medidas será muito maior quanto maior for a elasticidade renda da demanda pelo bem cujo preço muda. Assim, as três medidas seriam idênticas quando a elasticidade-preço da demanda pelo bem fosse igual a um. Nesse caso, desapareceria o efeito-renda e as três curvas de demanda seriam apenas uma. Como esse não é geralmente o caso, o analista é forçado a escolher uma entre elas, sabendo que a seleção de uma ou outra altera a avaliação que as mudanças provocaram no bem-estar do consumidor.

O uso do excedente do consumidor (EC) é motivada pela facilidade do seu cálculo em exercícios de valoração.

Os métodos função demanda de valoração econômica do meio ambiente objetivam capturar dos indivíduos a DAP ou a DAC, de forma direta e indireta, ante a hipótese de mudança no bem, serviço ou ativo ambiental. Se o bem ou recurso ambiental não apresenta valor expresso para consumo, cria-se o cenário hipotético com características similares ao que se quer valorar, oportunizando aos indivíduos expressarem suas preferências por meio de relações intrínsecas já existentes entre produtos comercializados no mercado (mercado real) e bens que ainda não tem valor comercial (mercado hipotético) ${ }^{11}$.

$\mathrm{O}$ valor derivado da função utilidade tem por base a teoria do bem-estar econômico neoclássico. Sua premissa aponta o indivíduo como o melhor juiz de seu bem-estar. Ninguém melhor do ele para quantificar e qualificar o que é melhor ou pior, e determinar seu nível ótimo. O bem-estar de cada indivíduo não depende apenas do consumo individual de bens e serviços privados, mas da quantidade e da qualidade de outros bens e serviços fora do mercado, como os bens públicos, recursos naturais, saúde, recreação, contemplação, entre muitas outras opções.

O MVC depende diretamente das escolhas dos indivíduos e tem por base teórica a teoria das preferências do consumidor, via função utilidade marginal. Estimar a DAP significa derivar medidas Hicksianas para o tradeoffs das escolhas dos indivíduos entre os bens ambientais e o consumo de outros bens. A relação entre o método de valoração e sua teoria de base confere um rigor científico ao trabalho de valoração.

\footnotetext{
11 A inexistência de um mercado tradicional preconizado pela teoria microeconômica dificulta a estimação de valores atribuídos aos recursos ambientais. A dificuldade de mensuração se eleva quando o objetivo constitui a mensuração dos valores de não-uso. No caso dos valores de uso, as dificuldades estão na derivação dos valores indiretos, de opção e de quase-opção.
} 
Gráfico 2.5- As curvas de Demanda Ordinárias(Marshall) e Compensads (Hicks)

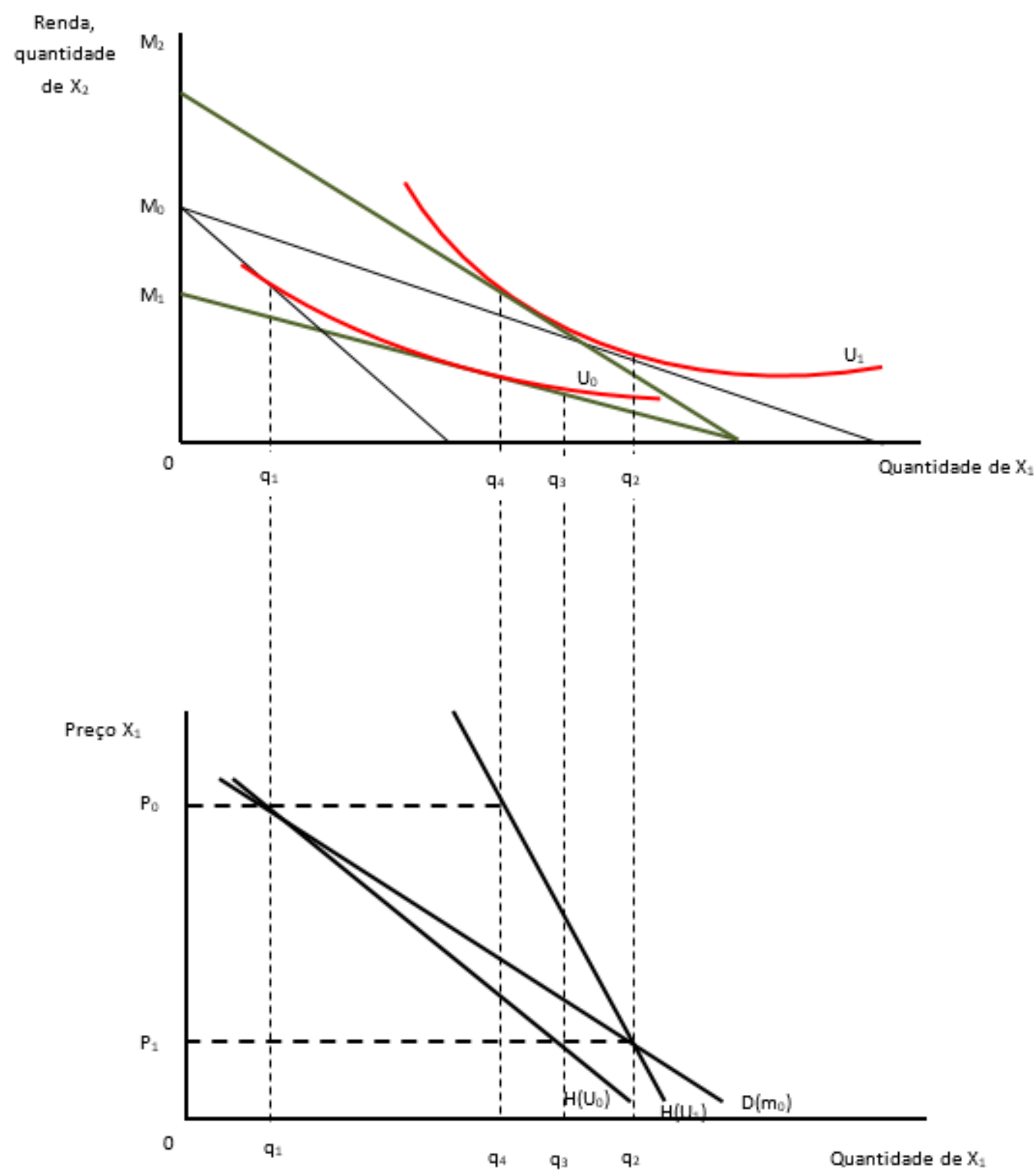

Preços $\mathrm{X}_{1}$

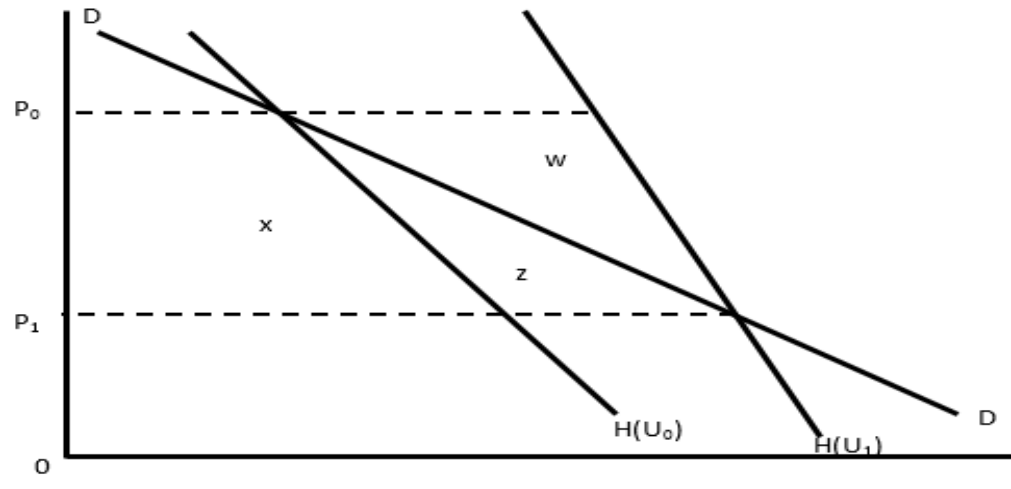

Quantidade de $\mathrm{X}$

Fonte: Hanley e Spash (1993) 
Hanley e Spash (1993) afirmam que as medidas EC e EE são aplicados nos casos em que os preços variam, porém a quantidade consumida são fixas. E as medidas VC e VE se aplicam quando o consumidor é livre para ajustar suas quantidades após mudança de preços.

No quadro 2.2 pode-se perceber as relações entre disposição a pagar, disposição a receber compensação, variação compensatória, variação equivalente, excedente compensatório e excedente equivalente.

Quadro 2.2 Relação entre medidas de bem-estar

\begin{tabular}{|l|l|l|}
\hline \multicolumn{1}{|c|}{ Variáveis } & \multicolumn{1}{c|}{ Disposição a pagar } & \multicolumn{1}{c|}{ Compensação exigida } \\
\hline Aumento de quantidade & Excedente compensatório & Excedente equivalente \\
\hline Queda de preço & $\begin{array}{l}\text { Excedente compensatório e } \\
\text { Variação compensatória }\end{array}$ & $\begin{array}{l}\text { Excedente equivalente e } \\
\text { Variação equivalente }\end{array}$ \\
\hline Queda de quantidade & Variação equivalente & Excedente compensatório \\
\hline Aumento de preço & $\begin{array}{l}\text { Excedente equivalente e } \\
\text { Variação equivalente }\end{array}$ & $\begin{array}{l}\text { Excedente compensatório e } \\
\text { Variação compensatória }\end{array}$ \\
\hline
\end{tabular}

Fonte: Mitchell e Carson, 1989

Se o bem ambiental a ser valorado apresenta características compostas, a valoração se dará por esse mercado e seu subgrupo é composto pelo MVC, que tem por objetivo captar diretamente a DAP/DAC caso haja variação no bem estar do indivíduo decorrente de uma melhora ou piora da qualidade de um bem ou serviço ambiental. A partir desses dados, estimase uma função demanda que, pela variação do excedente do consumidor, estima-se a variação do bem-estar dos indivíduos.

Se o bem ambiental a ser valorado apresenta características/atributos que possam ser classificados como complementares, a valoração ambiental se dará pelo mercado de bens e serviços privados complementares. Quando se consegue valorar um ativo ambiental a partir do valor de mercado de um bem privado, diz-se que seu complementar é perfeito. Se o ativo ambiental a ser valorado tem um complemento perfeito, sua demanda pode ser estudada a partir da sua função demanda pelo bem complementar. Assim, os métodos com essas características se subdividem em dois subgrupos, Método dos Preços Hedônicos e Método dos Custos de Viagem.

O MCV tem como base a teoria do comportamento do consumidor em mercados relacionados. As opções de alocação dos recursos dos indivíduos estão listados em equipamentos de lazer, alimentação, viagens, bilhetes de entradas a parques ou locais de uso público, e esses gastos são formadores de curvas de demandas, base para valoração de recursos 
naturais. O MPH também utiliza a teoria da escolha e bem-estar que, por meio das preferências por esse ou aquele local, faz parte das escolhas de moradia ou aquisição de empreendimentos para uso comercial. A relação se faz entre o preço do imóvel e o local a ser valorado. Os benefícios advindos dos recursos naturais conferem ao bem de mercado maior valor. Como exemplo, têm-se residências perto de lagos, parques ou longe de poluição de fábricas.

Entendemos que o tratamento teórico apresentado neste capítulo cumpre os objetivos que desejamos alcançar com a aplicação de métodos função demanda. $\mathrm{O}$ valor monetário de uma mudança no bem-estar humano derivada de uma mudança em um bem, serviço ou ativo ambiental. Aqui temos a teoria por trás dos números, pois números sem teoria não significa coisa alguma. 


\section{CAPÍTULO 3}

\section{VALORAÇÃO CONTINGENTE: \\ QUEM PERGUNTA O QUE QUER, OBTÉM O QUE NÃO QUER}

\subsection{INTRODUÇÃO}

O Método de Valoração Contingente (MVC) busca, por meio de entrevistas, "revelar as preferências dos indivíduos por bens ou serviços ambientais não comerciais" (BLAKEMORE; WILLIAMS, 2008, p. 1470). É amplamente utilizado para avaliar os impactos ambientais e fazer estimativa da disposição a pagar (DAP) pelo recurso natural. O método se sustenta nos pilares da Teoria do Consumidor (ver Capítulo 2), especificamente nas preferências reveladas no momento da escolha. A estimativa do valor monetário se dá a partir dos conceitos da DAP por um bem ou serviço ecossistêmico ou da Disposição a Receber Compensação (DAC) pela sua perda.

O desenvolvimento de uma aplicação de MVC depende de cinco componentes essenciais: a) estabelecer cenário em um questionário: desenho de um mercado hipotético, que consiste na descrição do bem ou serviço que se deseja avaliar; b) aplicar questionário: obtenção dos dados, captar atitudes por meio de entrevistas; c) estimar a função demanda e a disposição a pagar pelo bem ou serviço; d) avaliar as propriedades estatísticas da função demanda gerada; e e) deduzir do valor da disposição a pagar da amostra: a partir do qual e com base no modelo, faz-se a inferência para a população (HANLEY; SHOGREN; WHITE, 1997).

O MVC instiga o imaginário dos indivíduos que, ao serem abordados, pensam sobre o cenário que lhes é apresentado e o problema existente. Isso estimula o pensamento em dar valor a aquilo que achavam não ter, e, ao se defrontar com tal responsabilidade, o consumidor passa a contribuir com um olhar diferenciado para o alvo que se quer atingir. O Método tornou-se uma ferramenta empregada para que pessoas possam expressar suas preferências e a disposição a pagar por elas. O desafio do MVC está em ajustar o que todas as pessoas pensam e produzir um valor que as represente.

Os principais objetivos deste capítulo são: a) entender como se tem selecionado a amostra em aplicações brasileiras; b) analisar o emprego do questionário nesses estudos; e c) 
avaliar o conteúdo do relatório final das pesquisas efetivadas. Isso posto, este capítulo foi dividido em quatro partes, além dessa parte inicial e das conclusões. A primeira (seção 3.2) caracteriza o MVC em seus aspectos robustos e frágeis por meio da evolução temporal dos desenvolvimentos teóricos e empíricos do método. A segunda (seção 3.3) mostra as aplicações do método no Brasil, nos seus aspectos quantitativos, referentes às contribuições das instituições de ensino, locais de abrangência e assunto valorado. A terceira (seção 3.4) analisa a obtenção da DAP no Brasil, cenários desenhados, vieses na forma de obtenção da DAP e o que elas revelam e quem são seus aplicadores. Na quarta parte (seção 3.5), destaca-se por meio de estudos por área de abrangência como foram selecionadas as amostras, feitas as projeções de cenários e escritos os relatórios finais que deveriam oportunizar a comprovação e a validade dos conteúdos. Na quinta parte (seção 3.6), procura-se apresentar as lições aprendidas e perspectivas do MVC no Brasil.

\subsection{EVOLUÇÃO TEMPORAL DO MÉTODO DE VALORAÇÃO CONTINGENTE}

Por volta de 1947, Ciriacy-Wantrup escreveu sobre os benefícios da prevenção da erosão do solo. Ele observou que alguns desses benefícios, como a redução do assoreamento, estavam relacionados a características de bem público e sugeriu que uma maneira de obter informações sobre a demanda por esses bens seria pedir diretamente aos indivíduos sobre o quanto estariam dispostos a pagar por sucessivos incrementos da redução do problema. No entanto, ele nunca tentou implementar essa ideia (STAVINS, 2005). Um estudioso contemporâneo de sua época, Bowen (1943) propôs, escrevendo sobre embelezamento de paisagem, a utilização de pesquisas estruturadas com a opinião pública de bens sociais, bens coletivos ou bens extra-mercado. Na compilação de dados, percebeu que era possível obter curvas de demanda individuais para certos bens e que a curva de demanda agregada era obtida apenas pela soma da taxa marginal de substituição dos vários indivíduos. ${ }^{12}$

Pouco depois, Samuelson (1954) desenvolveu um trabalho que mostrou o problema do comportamento estratégico dos indivíduos ao obter benefícios de bens públicos e criticou veladamente as pesquisas feitas diretamente com as pessoas por apresentarem respostas divergentes entre interesses pessoais e comportamento coletivo. Isso, segundo Samuelson (1954), depreciava as respostas e a pesquisa perdia sua credibilidade. A atual controvérsia sobre

\footnotetext{
12 O grande problema era estimar a taxa marginal individual da curva de substituição. O dilema mais tarde foi resolvido pela utilização de enquetes, questionários e entrevistas, usando-se apenas uma variável.
} 
a validade de pesquisas com MVC originou-se quando foi reconhecido que valores de uso passivo descritos por Krutilla (1967) poderiam ser estimados a partir da valoração contingente (HAAB et al., 2013). Entre 1950 e 1960, foram desenvolvidas, nos EUA, pesquisas para saber a opinião da população quanto à disposição de pagar por recreação - serviços florestais e parques nacionais - e projetos de recreação com o uso de água. Elas foram as precursoras da avaliação contingente.

O MVC foi utilizado empiricamente pela primeira vez pelo economista R.Davis (1963), quando entrevistou 121 caçadores e visitantes no bosque de Maine (EUA) para estimar o valor de recreação da área. Para ele, ao considerar a renda e as preferências dos entrevistados, os valores obtidos para a disposição a pagar (DAP) apresentavam significativa consistência econômica. Seu trabalho ainda hoje é revisitado pelos detalhes metodológicos apresentados, abrangência de termos econômicos, amostragem e tratamento estatístico. A partir de então, o MVC passou a ser aplicado em outras áreas relacionadas ao bem-estar humano além da área ambiental, em especial em pesquisas sobre a saúde. Acton (1973) e Jones-Lee (1976) o aplicaram em pesquisas sobre correlação entre redução de risco da vida humana e a restrição orçamentária dos indivíduos. No setor de transporte, os trabalhos seminais são de Davidson (1973) e Louviere (1974).

Ao longo dos anos, muitos trabalhos sobre MVC foram escritos, tanto nos EUA como em toda Europa. Por volta de 1994, eles já eram 450 e, no final da década, chegavam a casa dos 1.600 trabalhos produzidos em mais de 40 países. O Quadro 3.1 apresenta os trabalhos mais comentados e que propuseram modificações e adaptações relevantes na metodologia do MVC, até 2013. Os trabalhos foram classificados por área para melhor visualização, mas sem nenhuma intenção de esgotar o assunto. 
Quadro 3. 1 - Principais publicações por área de conhecimento e assunto do MVC de 1970 até 2013

\begin{tabular}{|c|c|c|c|}
\hline $\begin{array}{l}\text { Área de } \\
\text { conhecimento }\end{array}$ & Assunto & Autores & Ano \\
\hline \multirow{8}{*}{ Administração } & \multirow{4}{*}{ Marketing } & Fiedler & 1972 \\
\hline & & Jonhson & 1974 \\
\hline & & McFadden & 1986 \\
\hline & & Louviere, Hensher e Swait & 2000 \\
\hline & Acesso a serviços públicos próximo à casa & Peterson e Worrall & 1970 \\
\hline & Segurança em rodoviária & Hoinville e Berthoud & 1970 \\
\hline & Tratamento de esgoto & McConnell e Ducci & 1989 \\
\hline & Informações de preços de supermercado & Devine e Marion & 1979 \\
\hline Economia & Redução de valores de Ativos de riscos & Mishan & 1971 \\
\hline \multirow{10}{*}{ Saúde } & \multirow{3}{*}{ Morbidade } & Loehman & 1982 \\
\hline & & Berger et al. & 1987 \\
\hline & & Magat, Viscusi e Huber & 1988 \\
\hline & Opção de drogas como função terapêutica & Johannesson e Fagerberg & 1992 \\
\hline & Taxas de desconto para tratamento & Ganiats et al. & 2000 \\
\hline & Avaliação de serviços farmacêuticos & Reardon e Pathak & 1988 \\
\hline & Pagar para reduzir o tempo em lista de espera & Pröpper & 1990 \\
\hline & Segurança alimentar & Ortega et al. & 2012 \\
\hline & Benefícios da mitigação das mudanças climáticas & Longo et al. & 2012 \\
\hline & Cuidados informais com a saúde & Mentzakis, Ryan e McNamee & 2013 \\
\hline \multirow{5}{*}{ Transporte } & \multirow{3}{*}{ Escolha por modal de transporte } & Hensher & 1994 \\
\hline & & Meyer, Levon e Louviere & 1978 \\
\hline & & Andersson & 2008 \\
\hline & Previsão de trafego aéreo a curta distância & Davidson & 1973 \\
\hline & Uso de veículos com combustíveis alternativos & Brownstone, Bund e Train & 2000 \\
\hline \multirow{5}{*}{ Recreação } & \multirow{3}{*}{ Recreação ao ar livre } & McConnell & 1977 \\
\hline & & Cocheba e Langford & 1978 \\
\hline & & Bateman e Jones & 2003 \\
\hline & Congestionamento em áreas de esqui & Walsh, Miller e Gilliam & 1983 \\
\hline & Mergulho em plataforma de petróleo & Roberts, Thompson e Pawlyk & 1985 \\
\hline \multirow{23}{*}{ Meio ambiente } & \multirow{3}{*}{ Qualidade do ar } & De Loehman & 1982 \\
\hline & & Tolley et al. & 1986 \\
\hline & & Wang e Zhang & 2009 \\
\hline & \multirow{6}{*}{ Qualidade da água } & Gramlich & 1977 \\
\hline & & Greenley, Walsh e Young & 1981 \\
\hline & & Mitchell e Carson & 1986 \\
\hline & & Gupta e Mythili & 2008 \\
\hline & & Metcalfe et al. & 2012 \\
\hline & & Kwak, Yoo e Kim & 2013 \\
\hline & Recuperação de áreas de mineração de carvão & Randal et al. & 1978 \\
\hline & Valor de licença de caça ao pato & Bispo e Heberlein & 1979 \\
\hline & Risco de mortalidade em acidente de usina nuclear & Mulligan & 1978 \\
\hline & Perdas com depósito de resíduos tóxicos & $\begin{array}{l}\text { Smith, Desvousges e Freeman } \\
\text { III }\end{array}$ & 1985 \\
\hline & Benéficos estéticos de uma usina geotérmica & Thaver & 1981 \\
\hline & Impactos relacionados de turbinas eólicas & Drechsler et al. & 2011 \\
\hline & \multirow{4}{*}{ Proteção de espécies ameaçadas de extinção } & Samples, Dixon e Gower & 1985 \\
\hline & & Hanley et al. & 2003 \\
\hline & & Hanley et al. & 2010 \\
\hline & & Bateman et al. & 2009 \\
\hline & Preservação de rios & Walsh, Sander e Loomis & 1985 \\
\hline & \multirow{3}{*}{$\begin{array}{l}\text { Proteção de águas subterrâneas, zonas úmidas e } \\
\text { florestas }\end{array}$} & Poe et al. & 2000 \\
\hline & & Brander et al. & 2006 \\
\hline & & Lindhjem et al. & 2007 \\
\hline
\end{tabular}

Fonte: Quadro baseado em textos comentados em Carson e Hanemann (2005), Carson (2012), Jacobsen e Hanley (2009) e Kwak, Yoo e Kim (2013). 
No corrente século, a valoração contingente tornou-se um das mais difundidas técnicas de valoração de recursos não transacionados em mercado. Sua proeminência se deve à sua flexibilidade e capacidade de estimar o valor econômico total (VET), incluindo valor de existência (ou de não uso). O valor de existência pode ser um componente importante, se não o principal, de diversos recursos ambientais. O MVC é o único capaz de captar esse componente do valor, já que o valor de existência não deixa uma trilha comportamental que possa ser rastreada por técnicas de preferência revelada. Kling, Phaneuf e Zhao (2012) fornecem uma equilibrada interpretação da utilidade do MVC, principalmente quando discorrem sobre o incentivo à compatibilidade das respostas. O método tem sido muito utilizado pela simplicidade (relativa) e baixa dificuldade (também aparente) da aplicação.

Até 2011, mais de 7.500 trabalhos acadêmicos e estudos sobre MVC foram publicados. Em relação a livros, há em torno de 25 publicados (CARSON; LOUVIERE 2011). Carson (2012) discorre sobre o progresso feito pelos pesquisadores nos últimos 20 anos e ao apresentar o MVC como uma ferramenta útil à avaliação. O próprio Hausman (2012) (seu principal oponente) reconhece que existe uma leitura seletiva de mudanças positivas do método (HAAB et al., 2013).

A lista de dificuldades com aplicações do MVC é longa. Aqui se destacam apenas as mais referenciadas na literatura como viés estratégico, o do ponto inicial, e o voto de protesto. O viés estratégico resulta da percepção do entrevistado quanto à verdadeira cobrança pelo bem ou serviço ambiental em função da DAP declarada. Esse efeito pode ser neutralizado a partir do desenho do survey, ao informar ao entrevistado sobre a implementação ou não do projeto ambiental, bem como a utilização de questionários do tipo referendum ${ }^{13}$. O viés do ponto inicial ocorre se o entrevistado é influenciado no processo de escolha de um valor do bidding game. Valores altos ou baixos para o bidding game podem influenciar a verdadeira DAP do entrevistado, subestimando-a ou superestimando-a. Para minimizar esse viés, torna-se necessário estimar o mais precisamente possível os pontos máximos e mínimos do bidding game, seja por meio da pesquisa piloto ou pela aplicação da técnica Delphi. Já o viés de protesto se refere à possibilidade do entrevistado expressar seu protesto conta algum conteúdo da pesquisa ou contra algo relacionado ao recurso natural. O entrevistado não declara sua DAP para conservar um recurso naural como forma de protesto contra majoração dos impostos, desempenho da dministração do recuros natural e outros.

No entanto esses não são os únicos. Hausman (2012) afirma existirem três problemas:

\footnotetext{
${ }^{13}$ Isso será explicado adiante.
} 
o viés hipotético que leva a valoração contingente a superestimar o valor - uma justificativa aceitável se encontra em Carson (2012) ${ }^{14}$; a grande diferença entre a disposição a pagar e a disposição a aceitar compensação - uma justificativa plausível se encontra em Kling, Phaneuf e Zhao (2012); o problema de escopo muito abrangente - Amiran e Hagen (2010) mostram que a substituição limitada entre mercado e bens ambientais pode resultar em um comportamento racional e deixar de apresentar sensibilidade ao escopo.

Além disso, Hausman (2012) também alerta para escessez de informação, dado o tempo limitado para cada pessoa inquerida, uma vez que, assim como pesquisa de opinião em geral, ela atende a alguns requisitos. Pode ser muito difícil para os respondentes realizar o exercício mental de ligar o bem à utilidade, e, desse modo, o seu lançamento de DAP é um lançamento aquém ou além da realidade. Nesse caso, a consulta à opinião de especialistas é preferível. Diamond e Hausman (1994) concluem que os estudos de VC não medem as preferências que eles se propõem a medir, e, portanto, "deveria ser abandonada". Os autores acreditam que são pesquisas de opinião, e não têm muito a contribuir para a formulação de política pública bem informada $^{15}$.

O MVC é, por definição, impossível de ser validado externamente. Como se baseia em mercados hipotéticos, nunca haverá dados de transações reais que confirmem ou rejeitem as estimativas encontradas. A pesquisa poderá ser dirigida e gerar resultados duvidosos (ROSA; GAMA; DIAS, 2012). A operacionalização de um estudo que utilize o MVC pode se tonar muito onerosa, se o pesquisador foi criterioso e se achar necessário um teste de validade em pesquisas consequentes.

Apesar dessas e de outras dificuldades, a aplicação cuidadosa do MVC tem o potencial de aprimorar uma avaliação econômica, já que possibilita a inclusão de custos e benefícios que, de outra forma, ficariam fora da análise. Assim, é um método que pode fornecer estimativas de valores plausíveis, bem como informações sobre a extensão do mercado e opinião pública e, portanto, pode ser um (mas não o único) instrumento à disposição dos tomadores de decisão política. No Quadro 3.2, são colocados os principais vieses da valoração contingente quando não tomadas as devidas precauções. Nos últimos 20 anos, muito se tem escrito para demostrar como contornar esses problemas.

\footnotetext{
14 Não obstante, o teste de validade elimina o viés hipotético, como comprovado por Vossler e Evans (2009), Herriges et al. (2010), Vossler e Poe (2011) e Vossler, Doyon e Rondeau (2012).

${ }^{15} \mathrm{O}$ que Hausman (2012) mais contesta é usar a VC em formação de políticas públicas e em processos judiciais.
} 
Quadro 3.2 - Possíveis Vieses do Método de Valoração Contingente

Estratégico - quando o pesquisado influência no resultado da pesquisa declarando um alto valor de disposição a pagar.

Ponto inicial - ocorre se o usuário é influenciado no processo de escolha de um valor inicial no momento de expressar sua DAP.

Instrumento de pagamento - quando a escolha do valor do pagamento é alterada pelas implicações causadas pelo modo de pagar.

Informação - quando a informação do recurso natural não foi bem entendida pelo agente pagador.

Hipotético - A natureza hipotética dos mercados em estudos podem levar a respostas sem sentido.

Protesto - refere à possibilidade do usuário expressar seu protesto contra a pesquisa ou parte dela, influenciado por sua condição social, econômica ou política.

Problema da parte-todo - dificultar a distinção entre o ativo valorado e um conjunto maior de ativos ambientais.

Obediência ou caridade (ou viés da conveniência social) - resulta do constrangimento do entrevistado em declarar respostas nulas ou de demonstrar uma intenção considerada socialmente negativa.

Subatividade - é fruto da diferença entre a soma das estimativas do valor de diversos ativos e a estimativa conjunta desses mesmos ativos. Essa diferença resulta do fato de existirem substitutos para os serviços ambientais gerados pelos ativos analisados e não por má especificação da pesquisa.

Sequência de agregação - no caso em que diversos bens estão sendo analisados separadamente, as estimativas podem mudar conforme seja a ordem apresentada para o entrevistado.

Decisão de baixo custo - respondentes racionais sabem que o custo de expressar um compromisso ético é pequeno, pois acreditam que sua resposta individual tem baixa probabilidade de influenciar a decisão de proteger o meio ambiente.

Especificação teórica - o cenário específico é incoerente com a teoria econômica

Especificação da qualidade - surge quando os parâmetros ambientais apresentados são interpretados de modo diferente daquele que o pesquisador deseja.

Escolha da população e seleção da amostra - a população indicada não representa adequadamente a população beneficiada, e a amostra selecionada não representa adequadamente as características da população a ser considerada.

Fonte: Nogueira; Medeiros e Arruda (2000), Faria e Nogueira (2000), Motta (2001), Araújo e Ramos (2005), com adaptações

No que concerne esta Tese, uma questão particurlamente relevante é: uma pergunta hipotética reflete uma resposta hipotética? Isso pode ser, em especial, verdadeiro para quem não tem experiência de mercado. Quando a disposição é a pagar, os resultados tendem a ser 
muito baixos (com base em suas preferencias e restrição orçamentária). Quando a disposição é aceitar compensação, a resposta tende a ser alta, pois não há limites orçamentários. Existe ainda substancial incerteza quanto à forma e como os pesquisadores devem executar e interpretar testes de validade utilizando paradigmas comportamentais alternativos: se as mesmas anomalias comportamentais aparecem, tanto declarado quanto no comportamento real; se um levantamento válido imitar escolhas reais ou procurar imitar com o fim de suscitar “verdadeiras” preferências - neoclássicos ou não (KLING; PHANEUF; ZHAO, 2012).

Uma primeira influência na DAP decorre das características dos participantes, se eles estão diretamente relacionados ao problema ou não, sua restrição orçamentária, suas preferências, se as pessoas querem ser agradáveis (altruístas) ou não, mudanças de humor e opinião ao longo do tempo, tradição em responder questionários e outras mais (JOHNSTON, 2006). Uma outra influência está relacionada diretamente à pergunta (escopo), se o bem avaliado é único ou está incorporado a um mais abrangente, se a questão está sendo bem entendida pelo entrevistado, se o entrevistado distingue prejuízos fixos de temporários.

As dificuldades enfrentadas pelos pesquisadores para a obtenção da DAP verdadeira ou a mais real possível levou à criação de mecanismos para facilitar a resposta dos entrevistados, sem que isso pudesse influenciar ou conduzir a obtenção de respostas com viés. Mitchell e Carson (1989) apresentam extensa lista de referências desses estudos e chegam à conclusão que nenhum mecanismo é totalmente neutro, mas apresentou uma classificação com seus prós e contras. Eles dividiram os mecanismos em dois critérios: quanto à natureza da informação obtida e quanto ao número de perguntas formuladas. No quadro 3.3 apresenta-se um resumo dos mecanismos para a captação da DAP.

Quadro 3.3 - Classificação dos mecanismos da captação da DAP

\begin{tabular}{|l|l|l|}
\hline Número de perguntas & Valor explicito da DAP & Indicador discreto da DAP \\
\hline Uma pergunta & $\begin{array}{l}\text { *Formato aberto - lances } \\
\text { livres (open-ended) } \\
\text { *Cartões de pagamento }\end{array}$ & *Referendum \\
\hline $\begin{array}{l}\text { Séries de perguntas } \\
\text { interativas }\end{array}$ & $\begin{array}{l}\text { *Jogos de leilão- (bidding } \\
\text { games) }\end{array}$ & $\begin{array}{l}\text { *Referendum com Follow- } \\
\text { up }\end{array}$ \\
\hline
\end{tabular}

Fonte: Mitchell e Carson (1989) com adaptações.

As questões abertas apresentam como dificuldades: em uma pergunta imaginar um valor justo, em se tratando de bens ambientais, porque não existe um parâmetro tão apropriado 
quanto no mercado, resultando daí respostas com valores muito discrepantes. Se, alternativamente, se for feita uma série de perguntas, por um lado, facilita a opinião dos indivíduos pesquisados, mas, por outro, pode induzir respostas viesadas (HAMMACK; BROWN,1974).

No caso do uso de cartões de pagamento, apresenta ao entrevistado diversos cartões com valores entre os quais deverá escolher apenas um. Esse método foi desenvolvido por Mitchell e Carson (1989) com o intuído de eliminar o viés do ponto inicial e para superar a alta taxa de não resposta das perguntas diretas. Albertini, Boyle e Welsh (2003) afirmam que os lances são afetados dependendo da ordem dos valores apresentados(ordem crescente ou decrescente). No formato bidding game a pergunta é elaborada de forma a se obter do indivíduo um valor monetário que já representa sua máxima DAP por meio de um jogo interativo de valores. Inicia-se com um valor mediano e, conforme a resposta, aumenta-se ou reduz-se o valor inicial. Essa técnica foi introduzida por Davis (1963).

As questões são elaboradas no modo Referendum com o intuito de se obter apenas uma indicação da máxima DAP. Esse método foi introduzido por Bishop e Herberlein (1979). A amostra da população é subdividida em grupos. A cada um desses grupos aplica-se uma pergunta do tipo; você estaria disposto a pagar tanto $\mathrm{R} \$$.... pelo bem ou serviço ambiental? Sim ou Não? O valor é sistematicamente mudado ao longo da amostra para uma avaliação da frequência das respostas dadas perante diferentes níveis de lances. Nessa técnica o indivíduo não tem uma segunda chance de encontrar o valor adequado, e simula mercados reais frente a um preço previamente estabelecido. Uma dificuldade desse método é a exigência de amostras maiores. Porém, por causa de sua simplicidade e sua estreita relação com o comportamento de escolha em mercados com preços fixados, facilitou o uso de modelos econométricos. Cameron e James (1987) fezeram uso do modelo probit e Cameron (1988) o modelo logit.

O Referendum com Follow-up é um melhoramento da técnica do Referendum convencional, negociando com o entrevistado um segundo valor selecionado aleatoriamente com o objetivo de confirmar a resposta inicial. Esse método induz a resposta a dois tipos de vieses, o de obediência e o de ponto de partida. Carson e Groves (2007) mostraram que um referendo dessa extensão não é necessário. Hanemann; Loomis e Kanninen (1991) também usaram a questão dicotômica, porém enquadrado como um referendo além de responderem sim ou não, os lances são inseridos numa linha em branco e pode aparecer outro valor. O quadro 3.4 apresenta de forma suscinta as formas de abordagem do MVC. 
Quadro 3.4- Formas de abordagem do MVC

\begin{tabular}{|c|c|c|}
\hline $\begin{array}{c}\text { Forma de } \\
\text { abordagem }\end{array}$ & Tipo de questionamento & Problemas / ou soluções \\
\hline $\begin{array}{l}\text { Lances livre ou } \\
\text { forma aberta } \\
\text { (open-ended) - } \\
\text { forma direta }\end{array}$ & Quanto você está disposto a pagar? & $\begin{array}{l}\text { Apresenta alta operacionalidade, podendo } \\
\text { ser aplicada via envio postal, entrevista } \\
\text { pessoal ou por telefone. } \\
\text { Quantidade de informações nulas ou e } \\
\text { protesto. } \\
\text { Vulnerabilidade para viés estratégico, } \\
\text { superestimação ou subestimação no } \\
\text { processo de avaliação }\end{array}$ \\
\hline $\begin{array}{l}\text { Jogos de leilão } \\
\text { (bidding game) } \\
\text { - forma direta }\end{array}$ & $\begin{array}{l}\text { Cria-se um leque de valores e } \\
\text { negocia-se com os indivíduos. } \\
\text { Inicia-se com um valor médio ou } \\
\text { mediano e pergunta se o indivíduo } \\
\text { está disposto a pagar se a resposta } \\
\text { for sim o valor é aumentado, se não } \\
\text { apresenta-se valore menores. }\end{array}$ & $\begin{array}{l}\text { Simplicidade da questão a qual facilita a } \\
\text { resposta do entrevistado. } \\
\text { Técnica cansativa, devido a vários lances, e } \\
\text { diminui a qualidade das respostas. As vezes } \\
\text { a pessoa aceita um valor na expectativa de } \\
\text { que a pesquisa logo se encerre }\end{array}$ \\
\hline $\begin{array}{ll}\text { Cartões } & \text { de } \\
\text { pagamento } & - \\
\text { forma direta } & \end{array}$ & $\begin{array}{l}\text { Apresenta-se ao indivíduo um } \\
\text { quadro com vários valores } \\
\text { ordenados, inclusive o zero. Pede- } \\
\text { se que o indivíduo selecione um. }\end{array}$ & $\begin{array}{l}\text { Aumenta a taxa de resposta ao se oferecer } \\
\text { um auxilio extra ao entrevistado. } \\
\text { Viés na escolha do valor central e na } \\
\text { distribuição das ofertas. }\end{array}$ \\
\hline $\begin{array}{l}\text { Referendum } \\
\text { simples - forma } \\
\text { indireta }\end{array}$ & $\begin{array}{l}\text { Nesse tipo de formato o indivíduo } \\
\text { pode aceitar ou recusar a oferta. } \\
\text { Você está disposto a pagar } \mathrm{R} \$ \mathrm{X} \text { ? } \\
\text { A quantia X é sistematicamente } \\
\text { modificada ao longo da amostra } \\
\text { para avaliar a frequência das } \\
\text { respostas dadas frente a diferentes } \\
\text { níveis de lances. Nesse caso } \\
\text { apenas um valor é apresentado ao } \\
\text { consumidor, e fica aberta a opção, } \\
\text { onde ele aceitaria outro valor. }\end{array}$ & $\begin{array}{l}\text { Como é formulado ao final uma taxa de } \\
\text { aceitação para cada lance, não permite } \\
\text { lances estratégicos. } \\
\text { Baixo índice de respostas nulas. } \\
\text { Pode-se incentivar o viés de aceitabilidade. }\end{array}$ \\
\hline $\begin{array}{l}\text { Referendum com } \\
\text { follow- up forma } \\
\text { indireta }\end{array}$ & $\begin{array}{l}\text { A pergunta é feita ao indivíduo de } \\
\text { forma indagativa se ele está } \\
\text { disposto a pagar } \mathrm{R} \$ \mathrm{X} \text { se a resposta } \\
\text { é positiva o valor vai sendo } \\
\text { aumentado até o limite em que o } \\
\text { entrevistado não aceita pagar. } \\
\text { Caso a resposta inicial seja } \\
\text { negativa o valor vai sendo } \\
\text { diminuído. Assim você pagaria } \\
\mathrm{R} \$ \mathrm{X} \text { ? } 2 \mathrm{X} \text { (ou } 0,5 \mathrm{X} \text { para resposta } \\
\text { não). }\end{array}$ & $\begin{array}{l}\text { A vantagem é que o método consegue captar } \\
\text { a disposição máxima aceito pelos } \\
\text { entrevistados. O processo interativo tem } \\
\text { uma tendência a induzir respostas, na } \\
\text { medida que o pesquisado apresenta } \\
\text { tendência a aceitar os valores subsequentes } \\
\text { (viés de obediência) ou negá-los por admitir } \\
\text { que o primeiro valor é correto (viés do ponto } \\
\text { de partida). }\end{array}$ \\
\hline
\end{tabular}

Fonte: Maia; Romeiro e Reydon (2004); Motta (1998); Faria e Nogueira (1998) com adaptações. 


\subsection{AS APLICAÇÕES DO MVC NO BRASIL: QUANTITATIVOS}

No Brasil, a avaliação contingente foi aplicada em 1995 devido à necessidade de se estabelecer indenizações aos diferentes tipos de impactos ambientais. Os cálculos anteriores, segundo Grasso (1995), eram facilmente rejeitados por não possuírem bases sólidas, devido ao espaço curto de tempo para os peritos avaliarem os danos. Normalmente, eles eram subestimados. Em seu trabalho, Grasso et al. (1995) fazem uma comparação de métodos: Avaliação Contingente e Avaliação de Custos de Viagem sobre o ecossistema manguezal nas regiões de Cananéia e Bertioga. A DAP média foi de US\$ $43,85^{16}$ por mês. Expandido o valor médio para a população visitante por ano (34.212), obteve-se um valor anual agregado de US\$ 18 milhões e US\$ 395 por hectare/ano. Somente $17 \%$ dos entrevistados se dispuseram pagar algum valor. A justificativa dada por Grasso é que o recurso era considerado de livre acesso, sob o domínio público. Além disso, acredita-se também que não havia nenhuma tradição no Brasil para valoração de bens ambientais, como ocorria no EUA e Europa.

A partir de 1995, as instituições educacionais e governamentais viram a necessidade de valorar componentes do patrimônio ambiental. Trabalhos mais sofisticados sobre valoração contingente passaram a ser elaborados. Os trabalhos sobre valoração foram requisitados com o objetivo de reparar danos ambientais provocados pelo descuido em relação ao meio ambiente, no momento da produção de bens, como no da eliminação dos resíduos. Trabalhos de grande monta também se fizeram necessários para valorar as águas brasileiras, ora para uso humano, ora para uso comercial.

No gráfico 3.1 são apresentadas as produções desde 1999 com o uso do MVC, verificase que essas produções têm crescido ao longo dos anos. No total são 106 publicações catalogadas nesse trabalho, considerou-se para análise somente aquelas que não foram publicadas mais de uma vez, assim 16 dessas publicações foram somente catalogadas e 90 analisadas.

\footnotetext{
${ }^{16}$ Todos os dados monetários desta tese estão expressos em dólar para melhor compreensão do significdo dos valores por causa da variação temporal. A tabela de câmbio que está no Anexo A é referente a média anual com dados colhidos do BACEN.
} 
Gráfico 3.1 - Número de trabalhos com o uso do MVC - Brasil - 1998 2014

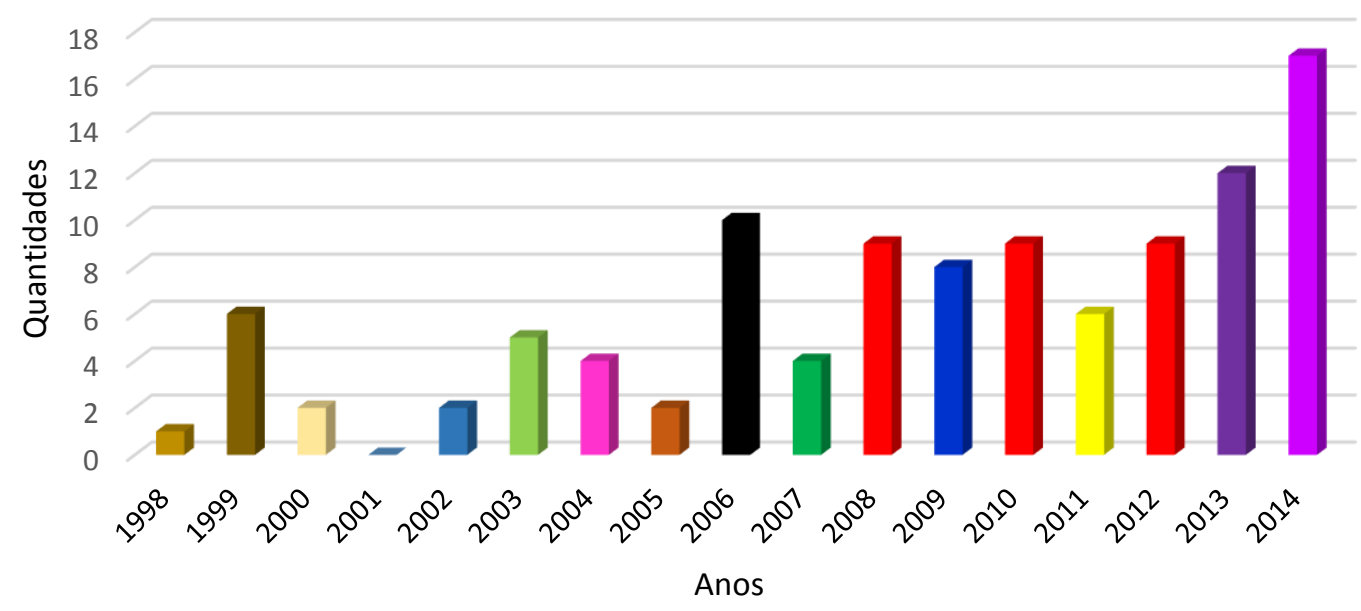

Fonte: Gráfico elabora pela própria autora (2015), com base nas informações apresentadas no Apêndice A tabela A.1

Na verdade, entre os trabalhos escritos sobre valoração, destacam-se os sobre MVC. As contribuições vêm de diversas partes do Brasil, em sua maioria realizados por pesquisadores de Instituições de Ensino Superior (IES). Nesta tese, nos detivemos a quatro grandes áreas de conhecimento, assim subdivididas: conhecimento tradicional (47\%) dos trabalhos, conhecimento sobre recursos hídricos (25\%), conhecimento sobre o patrimônio histórico cultural $(9 \%)$ e conhecimento sobre os impactos à saúde humana (19\%), num total de 90 trabalhos, ver gráfico 3.2.

Gráfico 3.2 - Áreas de conhecimentos dos estudos empíricos1998-2014

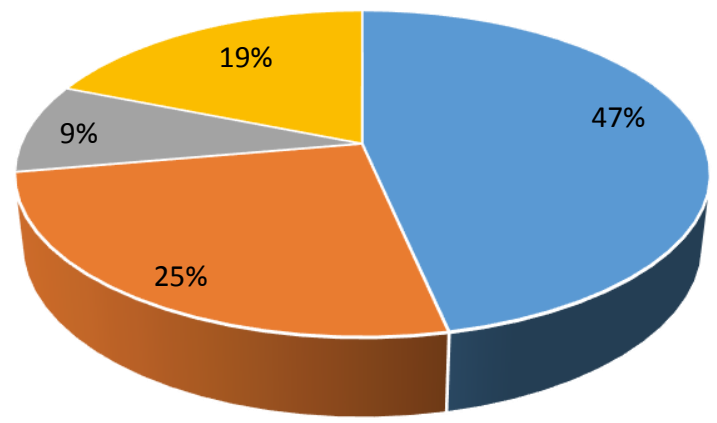

- Conhecimento tradicional

- Recursos hídricos

- Patrimonio histórico cultural

- Impactos sobre a saúde humana

Fonte: Gráfico elabora pela própria autora (2015), com base nas informações apresentadas no Apêndice A, tabela A2 
Quanto aos trabalhos de embasamento teórico e de avaliação metodológica, foram classificados 30 , sendo que $21 \%$ foram escritos por pesquisadores da UnB, $14 \%$ foram produzidos por pesquisadores da UFRJ, 7\% por pesquisadores da PUC- Rio e UFF. Os demais, (15), por diversos pesquisadores das IES em todo Brasil, eles representam 58\% (Ver gráfico 3.3).

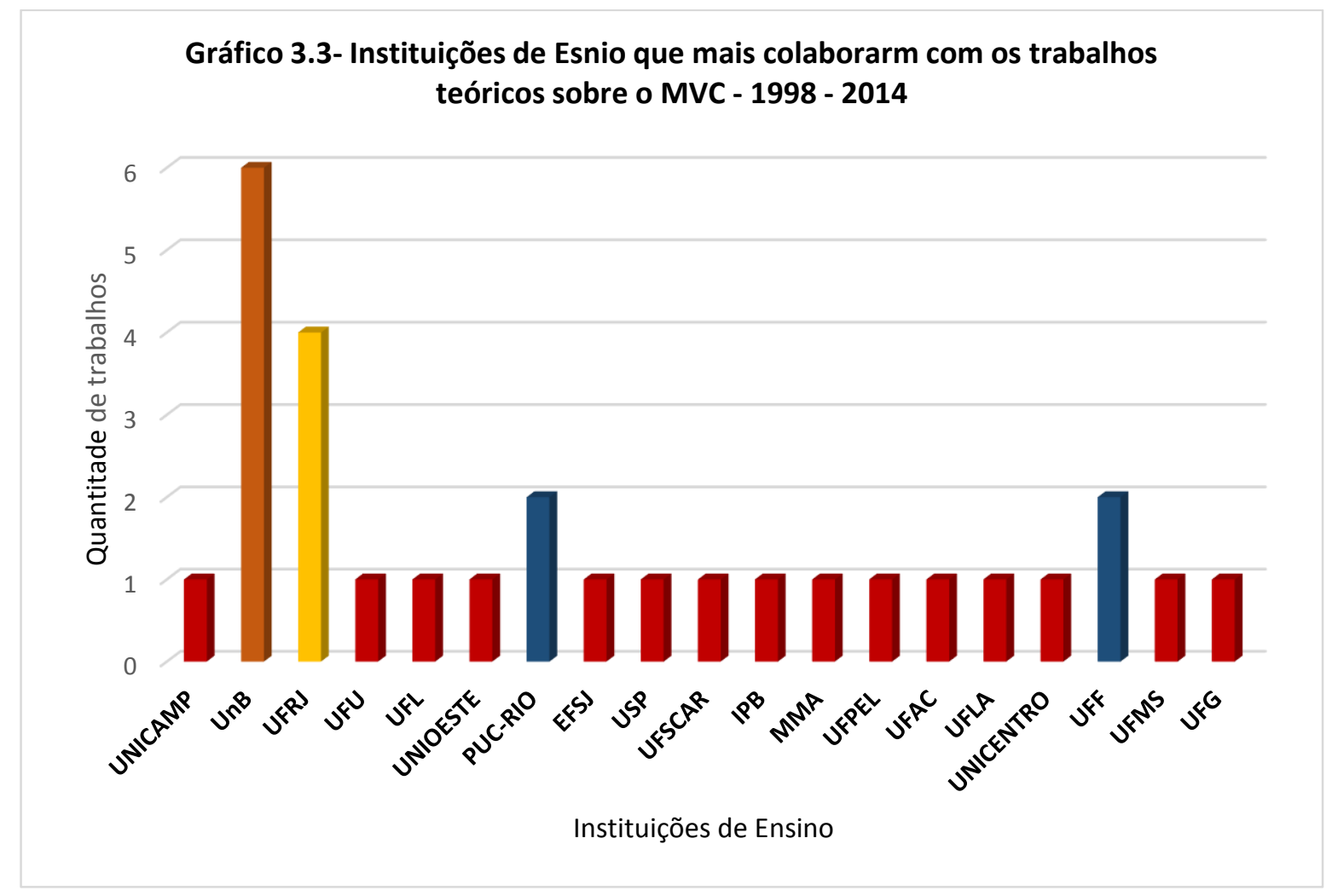

Fonte: Gráfico elaborado pela própria autora (2015), com base nas informações apresentadas no Apêndice A quadro $\mathrm{A}_{2}$

No Brasil, existem inúmeros motivos para valoração, mas alguns Estados receberam mais atenção, e o motivo é o desempenho da IES que direciona seus estudos para pesquisa local ou ativos ambientais de grande importância nacional e mundial como os biomas do Pantanal Mato-grossense, Cerrado e a Mata Atlântica, entre outros. Os estados do Rio Grande do Sul e Minas Gerais foram os que mais tiveram publicações sobre seus ativos ambientais (12\%). São Paulo e Distrito Federal com 11\%. Só não foram encontrados trabalhos publicados sobre ativos ambientais dos estados de Rondônia (RO), Maranhão (MA), e Alagoas (AL), ver gráfico 3.4. 


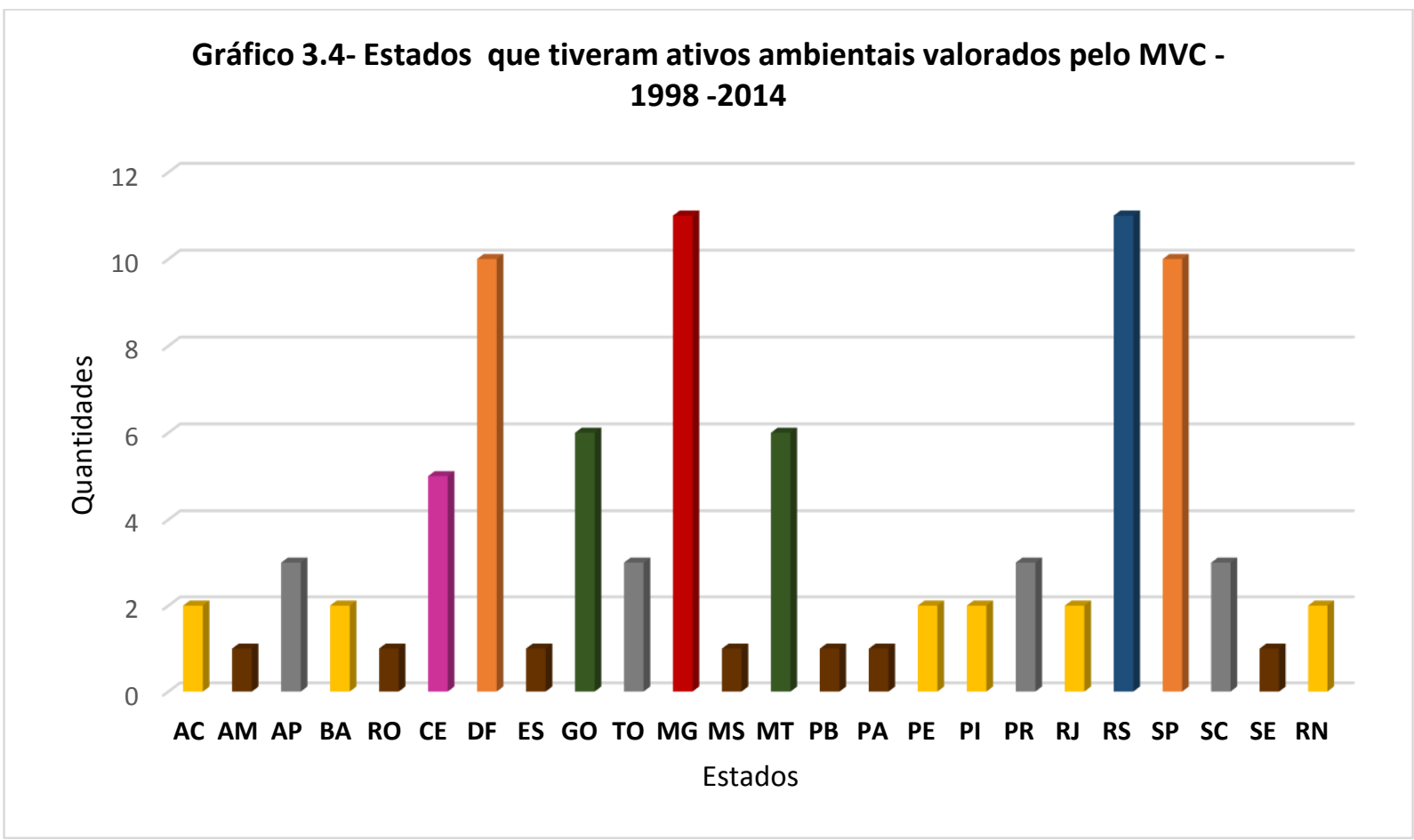

Fonte: Gráfico elaborado pela própria autora (2015), com base nas informações apresentadas no Apêndice A quadro $\mathrm{A}_{3}$

As instituições que mais colaboraram para o avanço do conhecimento nacional sobre valoração contingente foi a UnB, com $8 \%$ dos trabalhos, seguida por UFV e UFMT, com 7\%, UFRS, UFSC, e UEG, $6 \%$. Os demais trabalhos ficaram com aproximadamente $1 \%$ para cada IES. Esses números levam em conta os 90 estudos realizados no Brasil.

\subsubsection{Aplicadores do MVC}

Dos trabalhos de valoração concentrados na área de Patrimônios Histórico e Cultural duas subdivisões foram identificadas. A predominância dos trabalhos (57\%) ficou com o aumento da eficiência no uso dos ativos e para alerta de policy makers (ver gráfico 3.5). Os pesquisadores direcionaram seus estudos visando a:

1) recuperação e preservação dos ativos: Cirino e Lima (2008), Oliveira Filha e Monteiro (2009), Carvalho (2009), Monteiro, Araújo e Amorim (2014), Barcelos (2014), e Freire et al. (2014).

2) aumento da eficiência no uso do ativo e alerta para policy makers: Oliveira e Toguinha (2004), Bem e Giacomini (2011) Mota e Ortiz (2013), e Oliveira (2014). 


\section{Gráfico 3.5 Subdivisão dos trabalhos da área Patrimônio Histórico \\ Cultural- 2004 -2014}

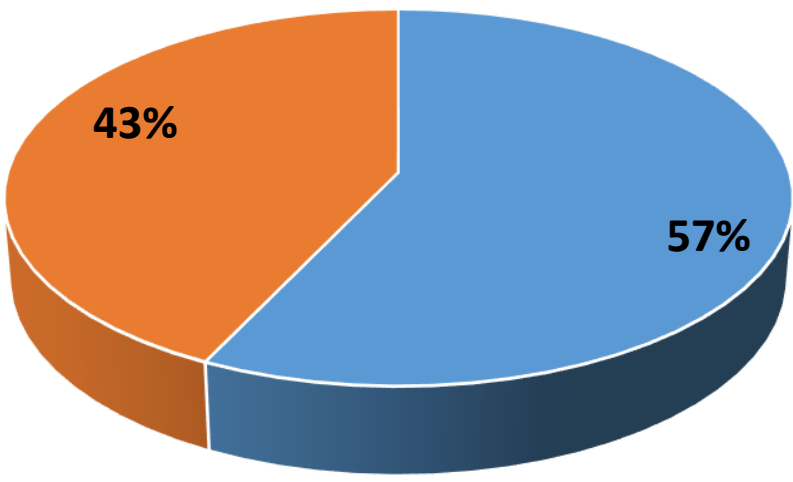

- Recuperação e preservação dos ativos

Aumento da eficiência no uso do ativo e alerta para policy makers

Fonte: Gráfico elaborado pela própria autora (2015), com base nas informações apresentadas no Apêndice A Tabela A4

Nas pesquisas diretamente relacionadas ao impacto sobre a saúde humana predominam estudos direcionados à poluição do solo, água e ar (46\%), (ver gráfico 3.6). As pesquisas foram divididas em três dimensões:

1) reciclagem, coleta seletiva e lixo: Lucena e Távora Junior (2006), Gonçalves et al. (2011), Rodrigues e Santana (2012) e), e Silva et al. (2013);

2) poluição de solo, ar e água: Freitas, Pereira e Maia (2004), Silva e Lima (2006), Mack-Knight (2008), Fernandez (2008), Pontes (2009) Lourenço et al. (2012) e Rabêlo Neto et al. (2014);

3) benefícios do ativo para a saúde, recuperação, manutenção e policy makers: Hidelbrand, Graça e Hoeflich (2002), Souza e Mota (2006), Volanova, Chichorro e Arruda (2010), Gullo (2010) e Paula, Silva e Mereira (2014). 


\section{Gráfico 3.6- Subdivisão dos trabalhos da área de saúde humana -} 2002- 2014

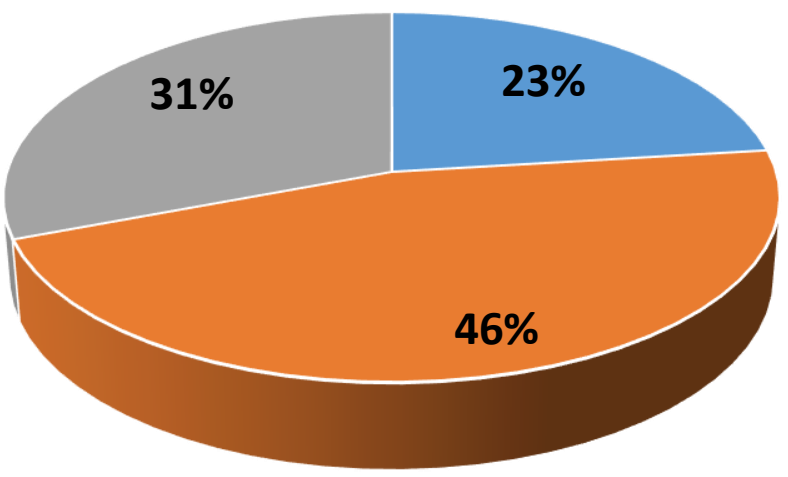

- Reciclagem, coleta seletiva e lixo

- Poluição de solo, ar e água

Benefícios do ativo para a saúde, recuperação, manutenção e policy makers

Fonte: Gráfico elaborado pela própria autora (2015), com base nas informações apresentadas no Apêndice A Tabela A5

Quanto aos recursos hídricos, os assuntos permearam em torno de dois grandes grupos sendo que o primeiro é o predominante com $60 \%$ das pesquisas (ver gráfico 3.7):

1) Garantir o benefício de uso permanente, recuperação e manutenção do ativo: Belluzzo Junior (1999), Carramaschi, Cordeiro Neto e Nogueira (2000), Fontenele (2001), Silva; Fernandes e Lirio (2003), Mattos (2006), Souza e Silva Junior (2006), Rossarolla, Silveira e Cruz (2007), Rodrigues e Farias (2008), Corbeti; Alvim e Dias. (2010), Machado (2011), Silveira (2011), Rodrigues e Faria (2012), Silveira, Cirino e Prado Filho (2013) Resende et al. (2013).

2) Suscitar aporte financeiro por meio de políticas públicas: Souza e Silva Junior (2006), Fernandes e Kuwahara (2006), Barbisan et al. (2009), Rodrigues, Nogueira e Carvalho (2009), Mota et al. (2010), Freitas et al. (2010), Pizaia (2010), Machado (2011), Souza et al. (2014) e Sousa e Cunha (2013). 


\section{Gráfico 3.7 -Subdivisão dos trabalhos da área de recursos hidricos - 1999- 2014}

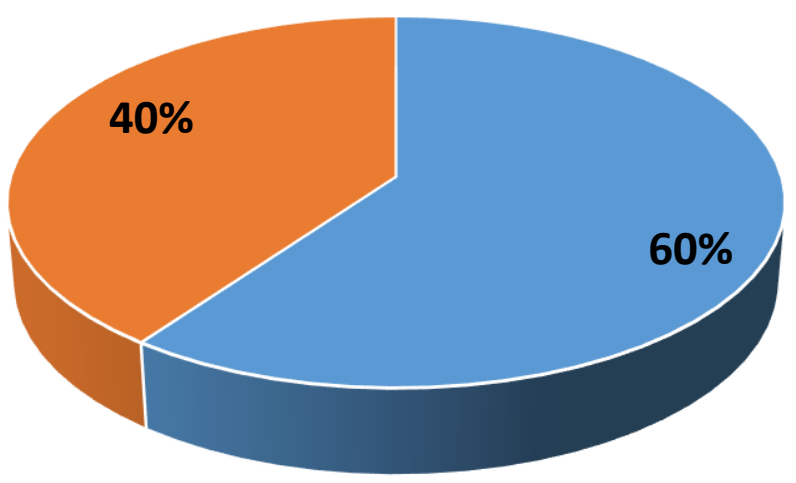

- Garantir o benefício de uso permanente, recuperação e manutenção do ativo

Suscitar aporte financeiro por meio de políticas públicas

Fonte: Gráfico elaborado pela própria autora (2015), com base nas informações apresentadas no Apêndice A Tabela A6

Dos trabalhos selecionados como conhecimento tradicional, $59 \%$ se preocuparam com proteção e conservação do ativo valorado (ver gráfico 3.8) e os outros foram assim classificados:

1) requalificação do meio ambiente: Barbisan, Pandolfo e Reinehr (2009), Máximo, Silva e Máximo (2009), Brugnaro (2010), Moraes, Araujo e Paixão (2010), Povoa e Tosta (2011), Castro (2014), Lopes e Castro (2014), Cintra e Castro (2014), Castro e Castro (2014) e Araujo (2014), Sosnoski, Silva e Moraes (2014).

2) proteção e conservação do ambiente valorado: Faria e Nogueira (1998), Obara (1999), Araújo (2002), Adams et al. (2003), Barbisan (2009), Silva e Lima (2004), Serra et al. (2004), Benetiz (2005), Braga, Abadallah e Oliveira (2005), Viana (2006), Pugas (2006), Mattos et al. (2007), Alves Filho e Valadares (2008), Póvoa e Ribeiro (2009), Morgado et al. (2011), Bocato e Cunha (2013), Corrêa e Ferreira (2013), Justo e Rodrigues (2014), Henderson et al. (2014), Carneiros (2014), Camargo (2014), Almeida et al. (2014) Souza et al. (2014) e Corrêa e Almeida (2014).

3) captação de recursos: Stampe, Tocchetto e Florissi (2008), Borja (2011), João e Baasch (2012,), Silva, Bacarji e Rodrigues (2012) Facco e Jacosdki (2013), Vasconcelos (2014). 


\section{Gráfico 3.8 -Subdivisão dos trabalhos da área de Conhecimento tradicional- $1998-2014$}

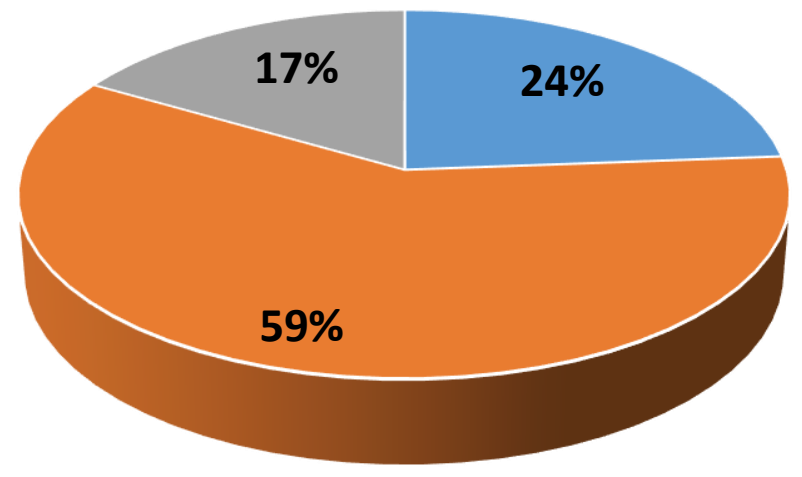

- Requalificação do meio ambiente

- Proteção e Conservação do ambiente valorado

- Captação de recursos

Fonte: Gráfico elaborado pela própria autora (2015), com base nas informações apresentadas no Apêndice A Tabela A7

\subsection{ANÁLISES GERAIS DAS APLICAÇÕES DO MVC NO BRASIL}

\subsubsection{Método e procedimentos utilizados}

\subsubsection{Bens que causam impacto à saúde}

Dos trabalhos analisados por área de conhecimento ${ }^{17}, 8 \%$ eram da área de Ciências Sociais aplicadas; 53,84\%, de Engenharias; e 38,2\%, Ciências da Saúde (Gráfico 3.9 a). A importância dada à área de conhecimento resulta no tipo de trabalho final apresentado. Observou-se a riqueza de detalhes relativos à área de conhecimento que cada grupo apresenta, talvez pela própria formação dos profissionais, que exige conhecimentos técnicos específicos. Exemplo disso são os trabalhos de Lucena e Távora Junior (2006) e Mac-Knight (2008). Porém, $44 \%$ se preocuparam com a pesquisa piloto (gráfico 3.9 b); $50 \%$ não usaram modelos econométricos ou probabilísticos para explicar os dados, apresentando apenas tabulações e

\footnotetext{
${ }^{17}$ A classificação por área de conhecimento segue a mesma usada pelo CNPQ.
} 
gráficos (gráfico 3.9 c). Trabalhos recomendados pela qualidade dos resultados são os de Silva e Lima (2006) e Rodrigues e Santana (2012). A forma de elicidar a DAP ficou assim dividida: $55 \%$ dos casos usaram open-ended; 32\%, referendum com follow-up; e 13\%, referendum simples, (Ver gráfico 3.9 d).

Gráfico 3.9- Bens que causam impacto à saúde - 2002-2014

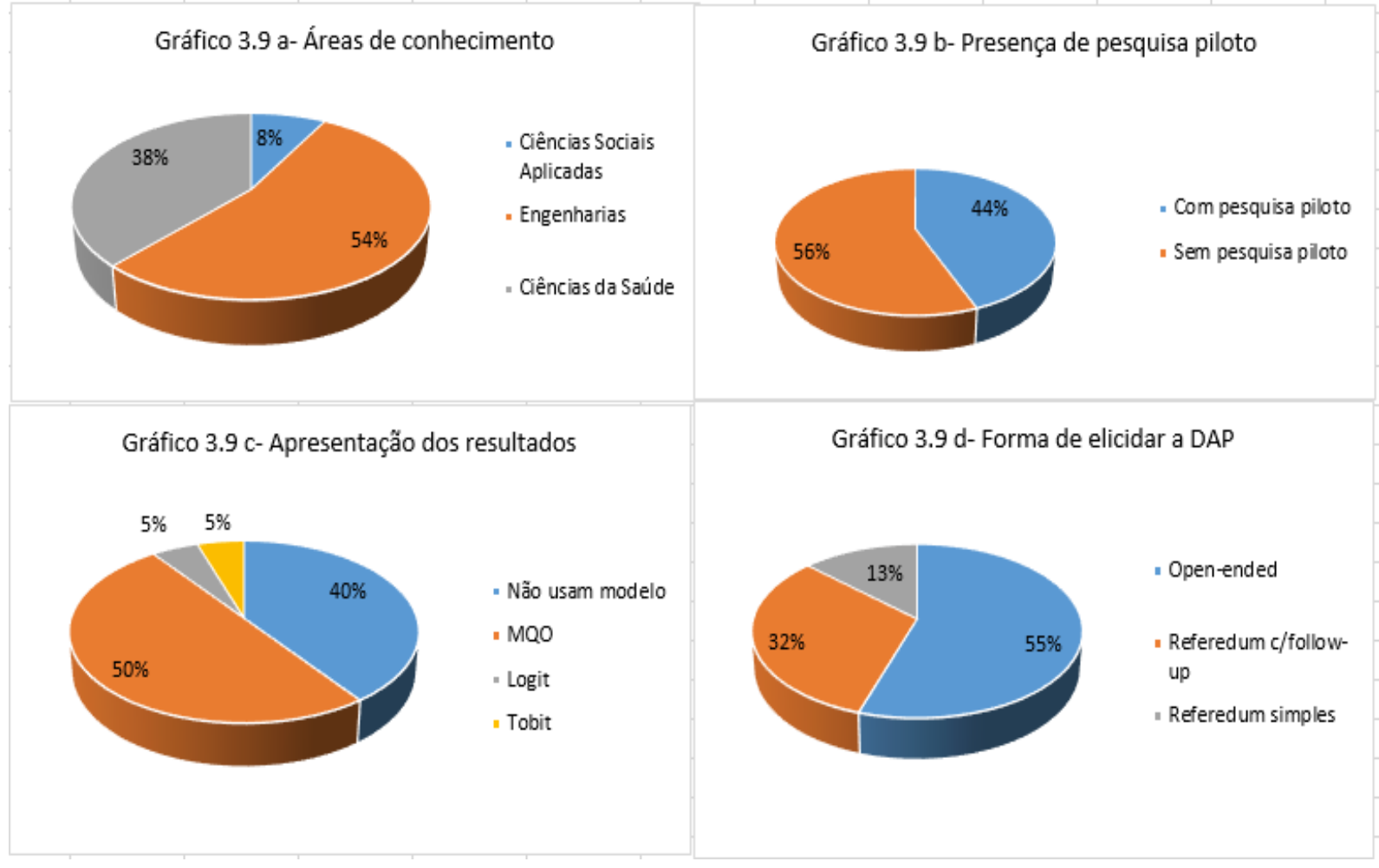

Fonte: Gráfico elaborado pela própria autora (2015), com base nas informações apresentadas no Apêndice A Tabela A8

\subsubsection{Recursos Hídricos}

Esse grupo de pesquisadores está assim dividido: 50\% de Ciências Sociais aplicadas, $28 \%$ de Engenharias, $17 \%$ de Ciências Humanas e 5\% de Ciências da Saúde. A forma de apresentar os dados é rica em detalhes com fotografias e mapas. É o grupo que mais intensamente trabalhou a comparação dos dados com diferentes modelos. $68 \%$ optaram por open-ended; 9\%, referendum simples; 14\%, referendum com follow-up e $9 \%$ jogos de leilão. Com escolha dicotômica crescente e decrescente foi utilizado por Souza e Silva Junior (2006). Alguns pesquisadores $(16,7 \%)$ promoveram treinamento aos colaboradores para aplicação de 
questionários. Para a apresentação dos resultados $29 \%$ usaram o MQO e $28 \%$ não usaram nenhum modelo, somente estatística descritiva. (Ver gráfico 3.10)

Gráfico 3.10- Recursos hídricos - 1999 - 2014

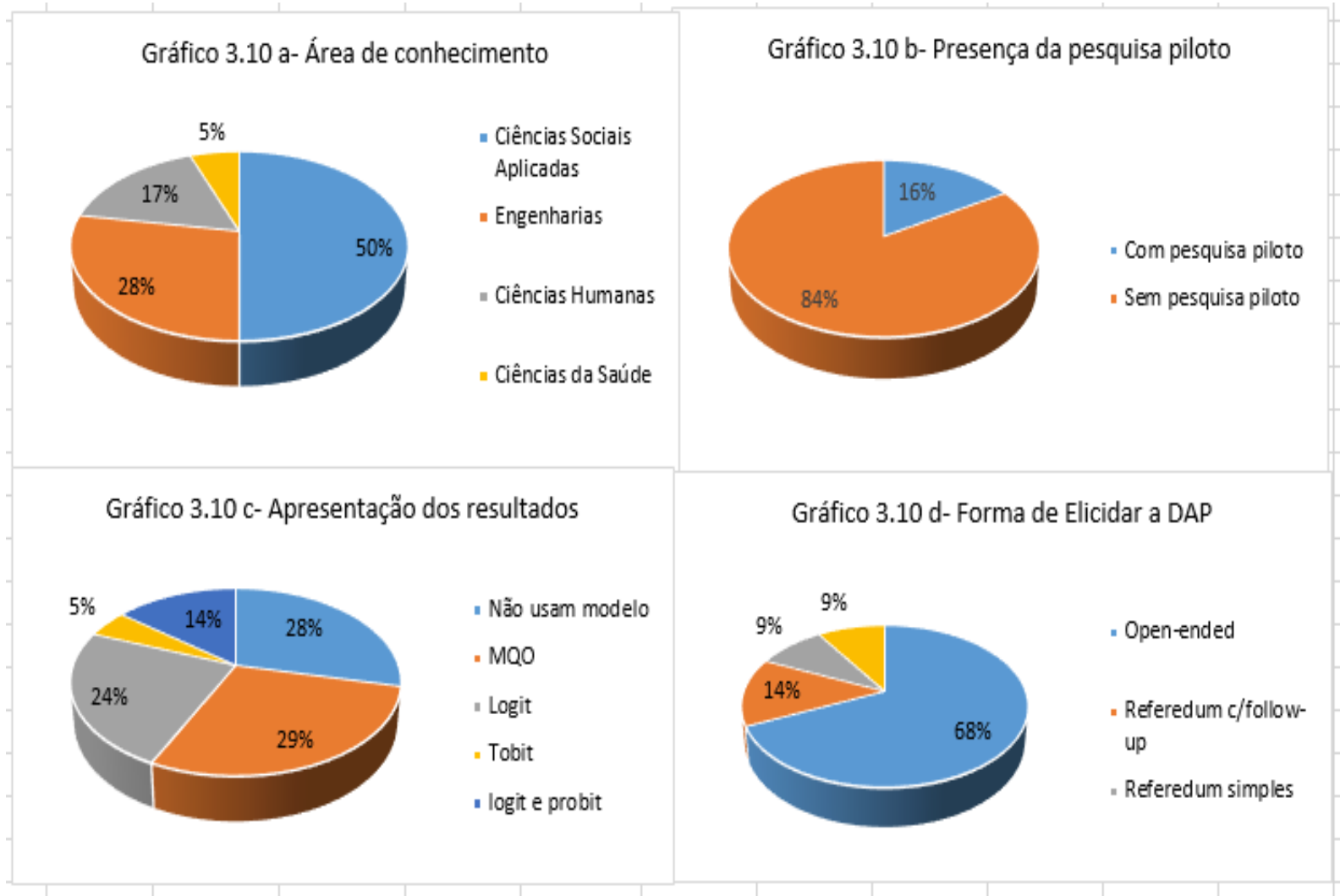

Fonte: Gráfico elaborado pela própria autora (2015), com base nas informações apresentadas no Apêndice A Tabela A9

\subsubsection{Bens culturais e patrimônio histórico}

As áreas de conhecimento desse grupo são assim distribuídas: 50\% de Ciências Sociais Aplicadas e 50\% Ciências Humanas. Os trabalhos têm um delineamento descritivo das características físicas dos ativos ambientais com particularidades singulares, como o de Carvalho (2009). Dos artigos analisados 30\% fizeram pesquisa piloto para ajustar os questionários. Quanto ao uso de modelo econométrico, $80 \%$ não o usaram para explicar os dados. Para a elicidação da DAP, (40\%), usaram Referendum com follow-up e (60\%) Referendum e open-ended (ver gráfico 3.11). 
Gráfico 3.11- Bens culturais e patrimônio histórico - 2004 - 2014

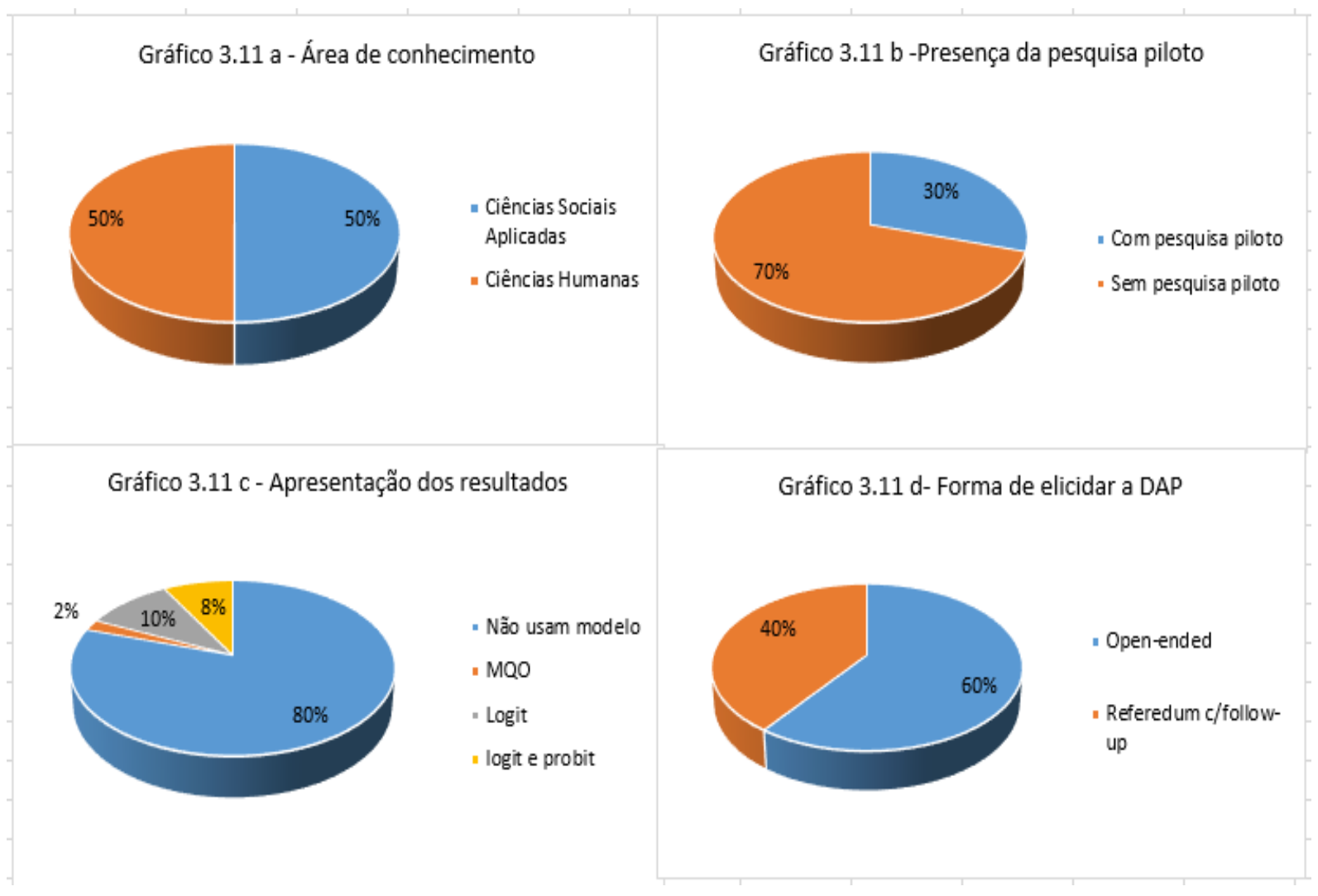

Fonte: Gráfico elaborado pela própria autora (2015), com base nas informações apresentadas no Apêndice A Tabela A10

\subsubsection{Conhecimento tradicional}

Esse é o maior grupo. É composto por 55\% de pesquisadores da área de Ciências Sociais aplicadas (todos Economistas), por 31\% de pesquisadores das Ciências Humanas e por 14\% áreas das Engenharias. Esse grupo conta com uma grande diversidade de bens e ativos pesquisados, entre quais estão: feira do livro, cobertura arbórea, áreas de preservação permanente e de proteção ambiental, parques, zoológico, áreas degradadas, matas, praias, entre outros. O teste piloto foi realizado por $38 \%$ dos pesquisadores. Quanto aos métodos, $41 \%$ utilizaram referendum com follow -up; 40\% com referendum simples e 19\%, open-ended; Os trabalhos econométricos dessa área são mais elaborados, apresentando aplicações com diferentes técnicas, (Ver gráfico 3.12). 
Gráfico 3.12 - Conhecimento tradicional - 1998 - 2014

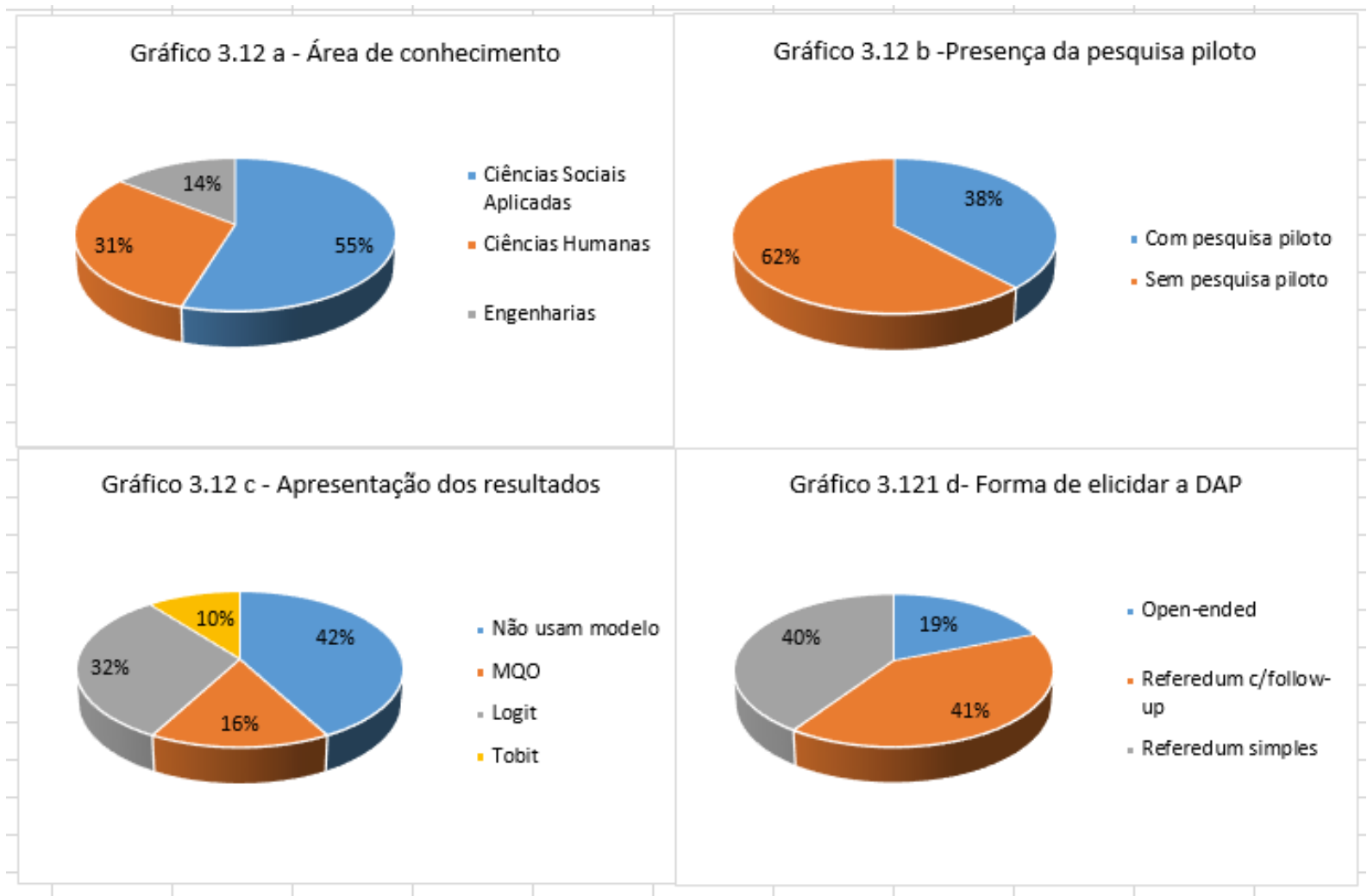

Fonte: Gráfico elaborado pela própria autora (2015), com base nas informações apresentadas no Apêndice A Tabela A11

\subsubsection{Avaliação geral das aplicações analisadas}

Em todos os trabalhos verificou-se uma grande preocupação com o referencial teórico e econométrico. Os trabalhos procuram citar referências estrangeiras e nacionais, explicam termos e fórmulas. No entanto, não há uma grande preocupação em detalhar a pesquisa de campo, em expressar suas experiências junto à população ou criticar o trabalho, para que, ao ser lido, outros pesquisadores possam dele retirar lições e tenham subsídios para adaptar o MVC uma determinada situação. Nos trabalhos apresentados, quando os autores se referem ao questionário, procuram apresentar número de questões e as etapas que esse questionário contempla, como no caso de Sousa e Mota (2006), Volanova, Chichorro e Arruda (2010), Silva et al. (2013). Isso mostra o avanço nas pesquisas. Em diversos artigos analisados, coloca-se o número de questões, mas não há uma descrição do que é perguntado. Há, também, casos em que o questionário não está no apêndice da pesquisa para verificação (dissertações e teses), o 
que oportunizaria um grande aprendizado nessa etapa. A tabulação dos dados também não contempla o número de questões informado no texto: alguns artigos revelam que existiam 28 questões por exemplo, mas, somente são apresentados os resultados de 20.

Ainda em relação aos questionários, os autores afirmam ter feito uma pesquisa piloto e ter readequado o questionário, porém não deixam claro ao leitor que adequações foram feitas. Seria interessante que isso fosse apresentado para que novas pesquisas não incorressem no mesmo erro. O trabalho de Viana et al. (2011) faz essa observação com muita propriedade.

Também fica aqui uma pergunta sobre o tamanho ideal do questionário. Nos artigos analisados, apresentam-se no mínimo 10 (SOUZA; CUNHA, 2013) e no máximo 33 questões. Todas elas chegam a uma DAP que afirma ser confiável. Quanto aos métodos de obtenção da DAP, ainda existem muitos trabalhos usando somente a técnica do open-ended. Em torno de $50 \%$ dos trabalhos usaram essa alternativa. Alguns questionamentos podem ser levantados: Essa é a técnica mais fácil de ser aplicada? As outras técnicas são inadequadas? Os consumidores que vão avaliar os ativos, apresentam dificuldades com outras técnicas que não seja open-ended?

\subsubsection{Os cenários desenhados: vieses resultantes}

\subsubsection{Bens que causam impacto à saúde}

Nos trabalhos desse grupo o viés em comum foi o voto de protesto com $82 \%$ dos trabalhos, (ver gráfico 3.13). O menor valor foi o encontrado por Silva et al. (2013), de 33,33\%, e o maior de Lucena e Távora Junior (2006), com $82 \%$. O viés de protesto foi recorrente, no qual se reafirma a excessiva carga tributária no país e a obrigatoriedade do governo de cuidar dos bens e serviços ambientais.

O trabalho de Lucena e Távora Júnior (2006) teve por objetivo captar a DAP dos cidadãos pela melhoria da qualidade ambiental que poderia ser alcançada no caso houvesse uma redução na disposição do lixo em aterros sanitários e um aumento na reciclagem para as cidades de Recife e Jaboatão dos Guararapes em Pernambuco. Utilizou do modelo referendum e uma amostra de 498 questionários. Poucos (18\%) dos indivíduos se mostraram dispostos a pagar pela melhoria na qualidade ambiental provocada pela redução da disposição dos resíduos no aterro. As causas para uma DAP zero foram os motivos econômicos e motivos políticos. Existe 
a crença de que as ações propostas para reciclagem e melhoria ambiental deveriam ser financiadas pelas esferas governamentais e também a descrença de que o dinheiro arrecado seria destinada aos fins propostos.

\section{Gráfico 3.13-Vieses apresentado nos trabalhos sobre bens que causam impactos a saúde - 2002 - 2014}

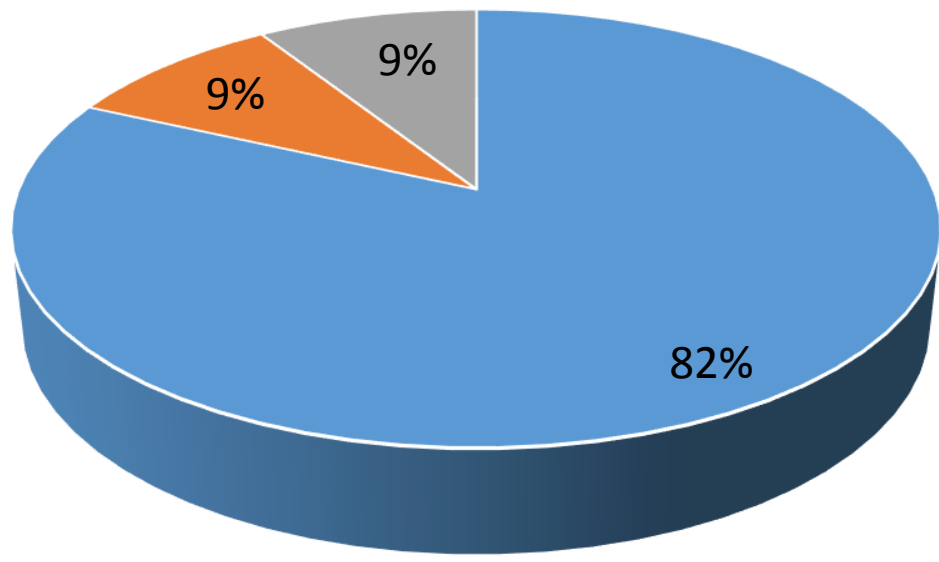

- Viés de protesto

" Viés de informação

- Não revelado

Fonte: Gráfico elaborado pela própria autora (2015), com base nas informações apresentadas no Apêndice A Tabela A12

\subsubsection{Bens culturais e patrimônio histórico}

O viés mais recorrente foi o de protesto (67\%), com uma média de 32,69\% dos respondentes (Ver gráfico 3.14). O trabalho de Carvalho (2009)) foi o que apresentou menor porcentagem de protesto $(13,75 \%)$. Ela expôs, na formação do cenário, um caderno de fotografias. Oliveira e Touguinha (2004) apresentam em seu trabalho a presença de viés do instrumento, isso porque utilizaram dados da DAP em percentual. Eles afirmam que as pessoas não tem noção do significado em porcentagem e a DAP tende a ser superestimada, e aconselha que a DAP seja em valor absoluto. 


\section{Gráfico 3.14 - Vieses apresentado nos trabalhos sobre bens culturais e patrimônio histórico - 2004 - 2014}

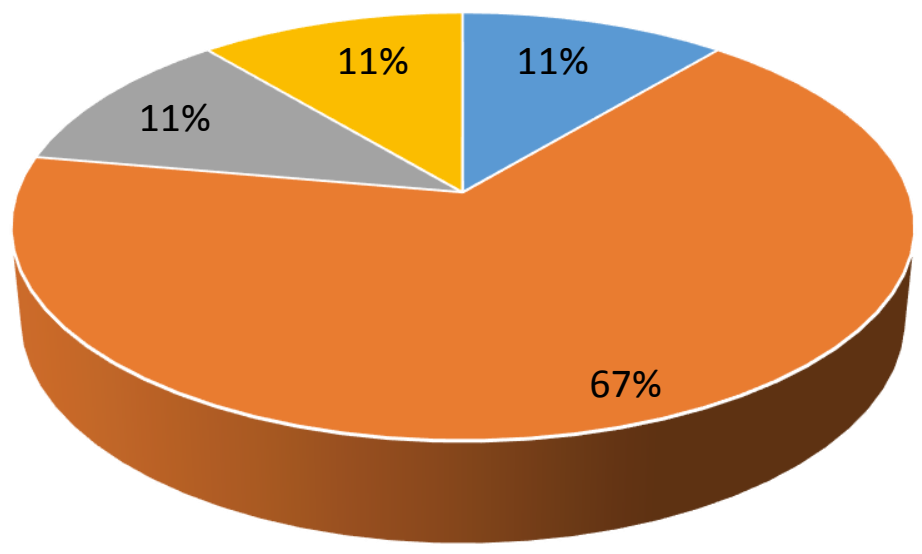

- Viés de instrumento

- Viés de protesto

- Viés de escopo

Não revelado

Fonte: Gráfico elaborado pela própria autora (2015), com base nas informações apresentadas no Apêndice A Tabela A13

\subsubsection{Recursos Hídricos}

Esse é o grupo com problemas nos cenários propostos. É também de onde podem ser tiradas as melhores lições para aperfeiçoamento do método. Muitas respostas nulas ou de protesto tendem a comprometer a qualidade da valoração a ser efetuada. Os viéses apresentados na área de recursos hídricos foram: protesto (44\%). Desses 15\% afirmam ser obrigação governamental cuidar dos recursos hídricos. Viés de informação (26\%), viés hipotético (9\%) viés de veículo de pagamento e ponto final (4\%), isso pode ser observado no gráfico 3.15.

Nos trabalhos de Gonçalves et al. (2011) e Rodrigues e Faria (2008), realizados no mercado rural com produtores e consumidores, observaram-se as menores porcentagens em recusa ao pagamento $(14,81 \%)$, e nenhum dos votos era de protesto, sendo que a média dos outros trabalhos variava em torno de 30\%. Carramasch, Cordeiro Neto e Nogueira (2000, p. 75) já chamavam a atenção para o fato de que os métodos de avaliação que "dependem das respostas das pessoas, como produtores rurais, com relação a preços ou disponibilidade de pagar a DAP, podem ser frágeis [...]. Os resultados devem ser tratados com extrema cautela [...]”. 


\section{Gráfico 3.15 -Viéses apresentado nos trabalhos sobre recursos hidricos - 1999- 2014}

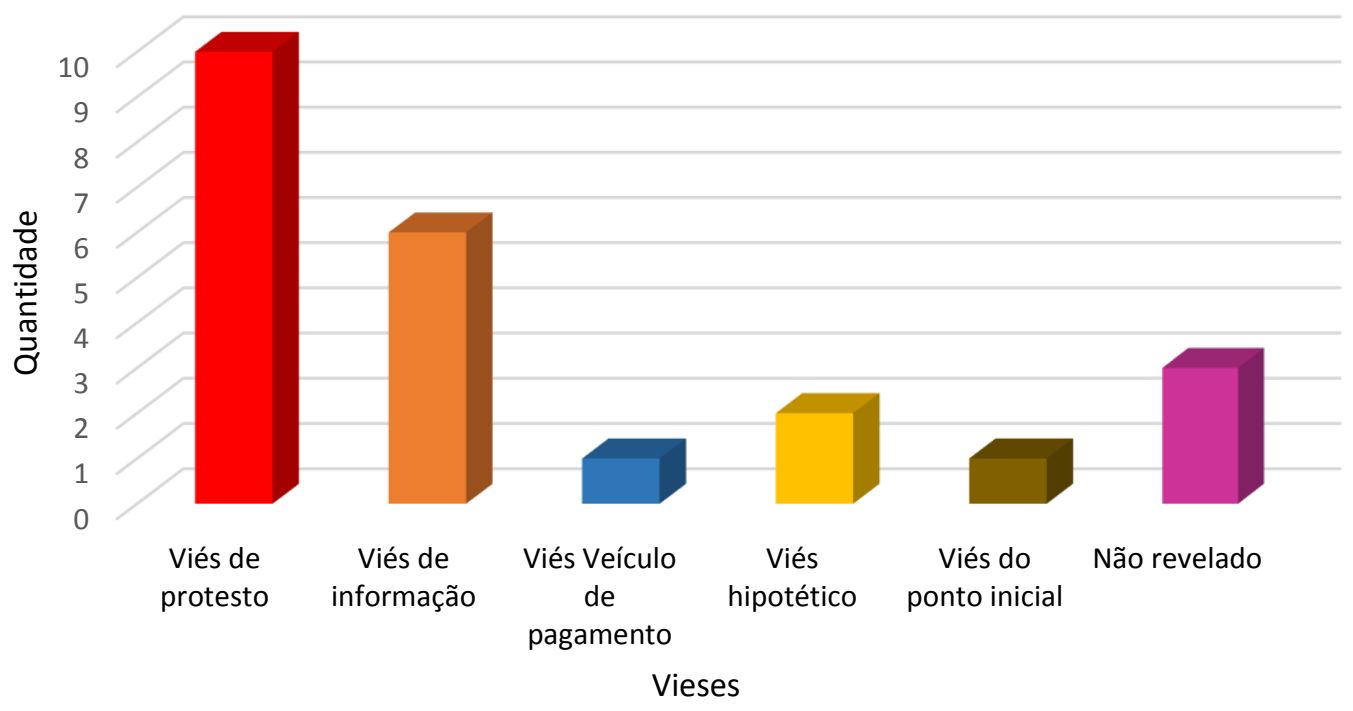

Fonte: Gráfico elaborado pela própria autora (2015), com base nas informações apresentadas no Apêndice A Tabela A14

O trabalho de Freitas et al. (2010) obteve o maior índice de DAP zero, 81\%, sendo que deste $58 \%$ foram protestos; os outros motivos foram: a renda não permite (28\%), não tem interesse sobre o assunto (3\%) e viés de informação (11\%). Outro trabalho que merece ser pesquisado é o de Souza e Silva Junior (2006), que também apresenta uma tabela sobre vieses associados às DAPs nulas, entre eles, o viés de veículo de pagamento e protesto. O trabalho de Forgiarini, Silveira e Cruz (2007) teve problemas com uso de palavras difíceis ao entendimento coletivo como a palavra "conflito", e 48\% não entenderam o cenário apresentado.

O trabalho de Souza e Cunha (2013), que valorou o Rio Amazonas no litoral da capital amapaense, recebeu como resposta que "a natureza não tem preço" ou "não há como mensurar". Isso mostra um cenário pouco revelador e pergunta inadequada. Em contraste, temse o trabalho de Sousa et al. (2012) sobre a área de “Olho D’água da Chuva”, que apresentou a menor recusa sobre a DAP, somente $8 \%$.

\subsubsection{Conhecimento tradicional}

Dos 42 trabalhos apresentados nessa área, $60 \%$ apresentaram viés de protesto, $22 \%$ não deixaram claro qual o viés que tinham encontrado para a recusa da DAP, (Ver gráfico 3.16). 
O cenário que mais chamou a atenção foi o proposto por Obara (1999) com o uso de painel fotográfico. Ele obteve um índice muito baixo de recusa a DAP, $15 \%$, e o viés encontrado foi o do ponto inicial. Esse viés também foi obtido por Faria e Nogueira (1998), que tentaram minimizar usando consulta a especialista através da Técnica Delphi que produziu valoração menos dispersa. Mattos et al. (2007) são enfáticos ao afirmarem que encontraram viés de subdesenvolvimento por causa das altas taxas tributárias impostas pelo governo brasileiro. Eles usaram o termo viés de subdesenvolvimento no lugar de viés de protesto: $40 \%$ dos participantes recusaram pagar.

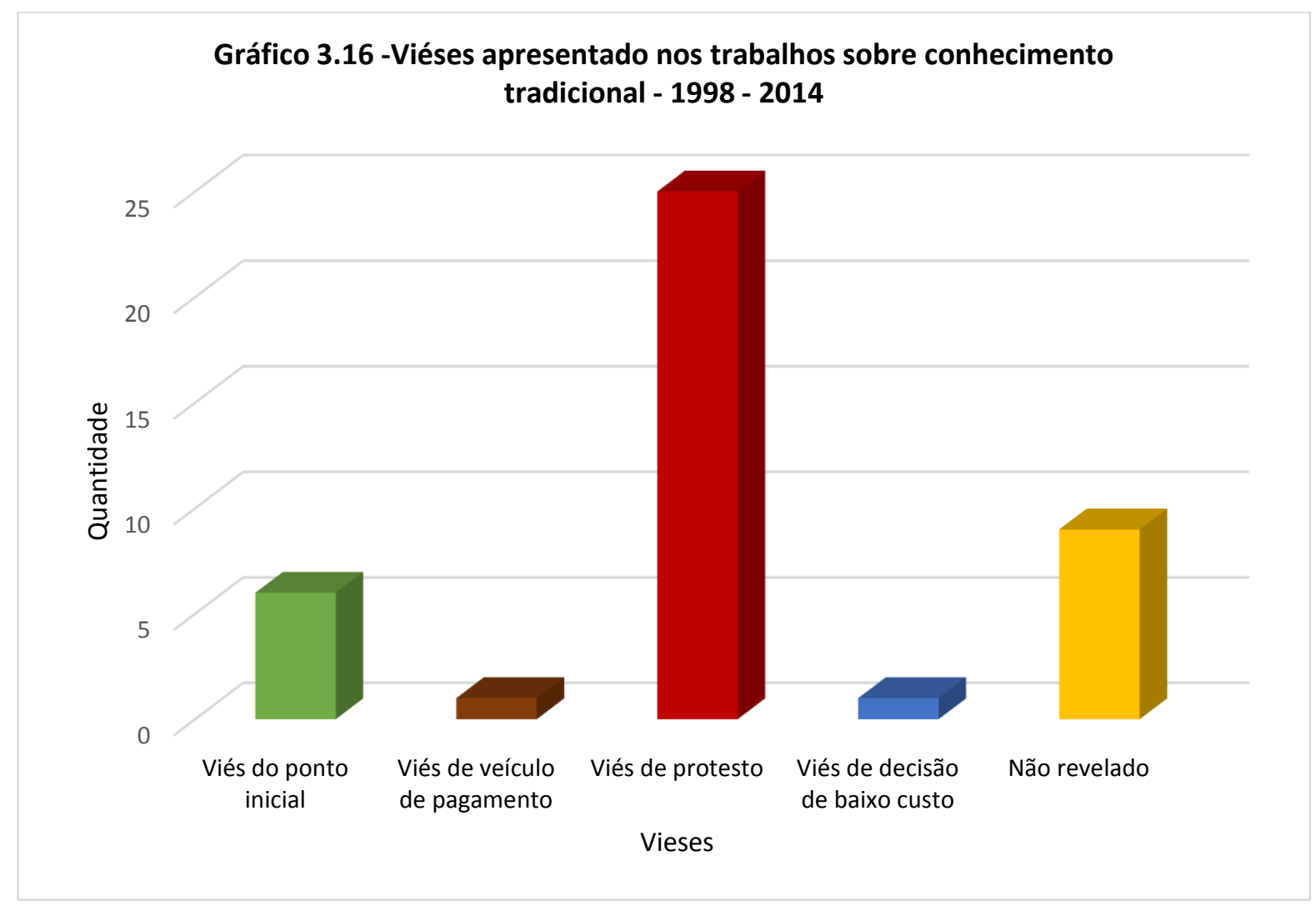

Fonte: Gráfico elaborado pela própria autora (2015), com base nas informações apresentadas no Apêndice A Tabela A15

\subsubsection{As DAPs obtidas: o que elas revelam}

Ao optar ou não pelo pagamento de um bem ou serviço o indivíduo está revelando um comportamento. As DAPs de protesto nos trabalhos analisados variaram de 8\% (SOUZA et al., 2012) a 82\% (LUCENA; THÁVORA JUNIOR, 2006). Isso talvez revele que os indivíduos não 
estariam satisfeitos com a situação econômica e social que o País estava atravessando na época da pesquisa. Esses resultados, por si só, não podem ser vistos como um indicador de satisfação ou não com a preservação do meio ambiente. Eles apenas não desejavam retirar de suas rendas um valor a mais para pagar aquilo que achavam que já estavam pagando.

Em contrapartida, as DAPs trazem algumas revelações: na área da saúde, os indivíduos almejam melhor qualidade das águas, ar e solo, do ambiente em que estão inseridos, parques para recreação, tratamento sanitário e redução no risco de morbidade. Nas áreas que se referem ao Patrimônio Histórico e Cultural, os indivíduos estão dispostos a pagar por melhor infraestrutura dos parques para turismo, por políticas públicas que recuperem e conservem os patrimônios públicos, museus e árvores milenares.

Os indivíduos almejam, por meio do conhecimento tradicional, preservar riquezas naturais como praias, restingas, matas ciliares, árvores, recuperar áreas degradadas, proteger estações ecológicas, parques, horto florestal, zoológico e até melhorar a qualidade das estradas, entre outros. Quando se trata de recursos hídricos, a preferência é conservar lagoas para subsistência através da pesca, pagar por água para irrigação de lavouras, pagar por água de melhor qualidade para consumo humano, reduzir poluição, conservar melhor os recursos hídricos para consumo e lazer.

\subsubsection{Agregação das DAPs: expandindo pequenos erros}

Pequenos erros na obtenção das DAPs podem levar a grandes distorções na avaliação dos ativos ambientais. Um exemplo encontrado é o de Sousa e Cunha (2013), em que 60 pessoas, que passeavam na orla da Cidade de Macapá, entre elas turistas estrangeiros, expressaram o valor de US\$ 3.111.726.095,44 para valorar o Rio Amazonas. Muitos trabalhos brasileiros relatam problemas sobre tamanho de amostra como o de Belluzzo Junior (1999), Cirino e Lima (2008) e Oliveira Filha e Monteiro (2009).

$\mathrm{O}$ valor da DAP está relacionado à mudança no bem-estar humano (ver Capítulo 2). Sua média agregada à população, nos remete as estimativas sobre o valor que a coletividade imputa a mudanças no bem ou serviço ambiental valorado. A gravidade do erro varia de pesquisa para pesquisa. Por exemplo, se a quantidade estabelecida é de 100 respondentes, dois invalidam os questionários por erro de preenchimento, cinco se recusam a expressar a DAP, três não aceitam participar da pesquisa, então na realidade só foram válidos 90 questionários. A amostra ficou menor do que o rigor do método e o da estatística exigem. Por exemplo, procedimento estatístico, que está relacionado com o tamanho da amostra, perde a função de potência, que 
mede a probabilidade de rejeitar a hipótese nula quando é falsa e aumenta à medida que aumenta o tamanho da amostra. Mitchell e Carson (1989) fornecem uma explicação sobre isso em seu texto Using Surveys to Value Public Goods: The Contingent Valuation Method.

Outro ponto que merece ser revisto é a técnica de amostragem que elege os respondentes. Se forem eleitos indivíduos fora do escopo da pesquisa, a amostra torna-se tendenciosa e os valores expressos da DAP, quando inferido da população, poderão estar aquém ou além de uma realidade de mercado. Se os dados forem usados para estabelecer determinada política pública, poderão superestimar ou subestimar os valores, prejudicando toda comunidade. Um exemplo é o de Sousa e Cunha (2013), que elegeram participantes da amostra pessoas que não conheciam o bem ambiental e a partir delas desejavam estimar o valor de uso desse bem ambiental. ${ }^{18}$

Existem alguns procedimentos para que os valores obtidos para a amostra reflitam de maneira mais precisa os valores da população. Esses procedimentos devem ser seguidos em razão dos potenciais vieses de seleção e de não aleatoriedade da amostra. O primeiro é o ajuste de valores da média da amostra. Segundo Morrison (2000), pode-se substituir as características socioeconômicas da população nas variáveis independentes da equação de regressão. Por exemplo, se a renda média da amostra for maior que da população, a média da renda da população pode ser usada para calcular qual seria sua DAP média. Esse procedimento é limitado porque preferências são imperfeitamente relacionadas a tais características.

Outra possibilidade para melhorar a representatividade da amostra é fazer um ajuste baseado nas não-respostas, caso sejam aleatórias, para não causarem problemas nas estimativas, uma vez revelado o motivo. Morrison (2000) exemplifica uma variação de resultado quando são feitos processos de ajuste. A DAP média da amostra pesquisada foi de US\$85,77. Fazendo o ajuste para transferência, segundo as variáveis socioeconômicas, a DAP caiu para US\$78,81. A classificação de todos os não respondentes simplesmente como tendo DAP zero fez com que a DAP média fosse para US\$37,91. Classificando os não respondentes pela motivação, ou seja, excluindo parte das respostas para que não interferissem diretamente no resultado, chegou-se a uma DAP de US\$51,98 (VASCONCELOS, 2012, p. 90).

Pelo exemplo citado, pode-se observar que pequenos ajustes na amostra se transformam

\footnotetext{
18 A codificação dos dados pode ser fonte de outro problema para o valor da DAP, que pode sofrer distorções. Para que isso não ocorra, o pesquisador deve recorrer às técnicas apropriadas. No entanto, raramente se consegue evitar todas as fontes de erro (erro de amostragem limitada, erro de não cobertura, erro de medição, erro de não resposta). Um projeto realista de uma boa pesquisa procura minimizar os erros relevantes e faz os ajustes nos postos de coleta de dados, quando necessário Haab; Kenneth e McConnell (2003).
} 
em grandes problemas de inferência populacional. O processo de agregação pode gerar variações no benefício total calculado de magnitudes maiores do que variação de medida da DAP.

O que é a DAP sozinha? Nada. Ela faz parte do processo de valoração que compreende estimar as populações beneficiadas. Tendo isso em vista, faz-se necessário que o questionário utilizado na pesquisa inclua perguntas que gerem informações, não apenas para o teste de validação da DAP, mas também para a maneira que esta será agregada. "A identificação da distância ao recurso, familiaridade, motivações, são ferramentas úteis que fazem com que as estimativas de benefício agregado sejam mais precisas e válidas" (VASCONCELOS, 2012, p. 99). Portanto, a DAP obtida pode sim revelar a verdadeira preferência do consumidor, desde que a manipulação dos dados não mascare sua opinião.

\subsection{ANÁLISES PONTUAIS DOS VIESES EM ESTUDOS BRASILEIROS DO MVC}

\subsubsection{A escolha de população: amostra inadequada.}

Uns dos grandes problemas do MVC é a escolha da população de forma adequada, porque quando não há representatividade entre a população impactada com a mudança ambiental e a população identificada ou beneficiada (alvo) na pesquisa, cria-se o viés de seleção. Os dois vieses possíveis nessa situação são o de população e o de amostra, que são complementares. Como encontrar a população relevante e dela retirar a amostra para que a inferência populacional realmente represente o bem a ser valorado é uma questão de perspicácia do pesquisador experiente e do objetivo do estudo. Existem algumas maneiras já consagradas para se selecionar a população com base no potencial de uso atual e futuro. Deve-se considerar quem vai pagar e quem vai ser beneficiado. Segundo relatório do Painel NOAA (1993), é necessário ter todo cuidado com o processo de agregação para considerar a população escolhida relevante.

Segundo Gil (2001), uma boa amostra precisa ser significativa e estritamente representativa. Os passos iniciais são verificar quem e quanto são as pessoas envolvidas no objeto de estudo que se deseja investigar, qual a margem de erro mínima aceitável para que não comprometa o resultado final da pesquisa. Como encontrar essa população e dela retirar a amostra para que a inferência populacional realmente represente o bem a ser valorado é uma questão de perspicácia do pesquisador experiente e do objetivo do estudo.

Existem algumas maneiras já consagradas para se selecionar a população com base no 
potencial de uso atual e futuro. Deve-se considerar quem vai pagar e quem vai ser beneficiado. Segundo relatório do Painel NOAA (1993), é necessário ter todo cuidado com o processo de agregação para considerar a população escolhida relevante. A seleção poderia ter como base uma lista telefônica e o uso da técnica de amostragem sistemática. Porém Scuman (1996) verificou erro de cobertura nessa técnica. Nem sempre os telefones dos indivíduos estão cadastrados em uma lista disponível ao público e a população e a amostra poderiam ficar comprometidas. Outra fonte de dados seriam os cadastros das prefeituras para verificar o número de habitações. O problema aqui reside na informalidade. Nem sempre (apesar de obrigatório) o documento habite-se do imóvel é registrado, o que compromete o número real do total de residências usado para o cálculo da amostra. Outra fonte que poderia ser consultada é a do número de eleitores de um município, que dependendo da época da coleta de dados, pode estar incompleta.

Quando se seleciona uma estrutura de amostragem, cada unidade da amostra deve ter uma probabilidade conhecida de seleção a partir da população de tamanho específico conhecido (HAAB; MACCONNELL, 2003). Estudos de valoração contingente exigem amostras grandes por causa das diferentes respostas, já observavam Mitchell e Carson (1989). Ou seja, o erro padrão da média da DAP é diretamente proporcional ao seu desvio padrão e inversamente proporcional ao tamanho da amostra. Assim, o erro padrão pode ser reduzido com o aumento do tamanho da amostra. Na prática, a maioria dos estudos escolhe o tamanho da amostra em função do orçamento existente para a pesquisa. Uma estimativa com limites de erro pode deixar grandes dúvidas sobre se realmente os benefícios excedem os custos.

\subsubsection{Exemplos por área da aplicação do $M V C$}

Alguns trabalhos brasileiros, entre os já selecionados para análise de conteúdo quanto à escolha da população, tamanho da amostra e técnica de amostragem, foram selecionados para se ilustrar a aplicação do MVC.

\section{Estudo 1 - Área de recursos hídricos}

No trabalho de Barbisan et al. (2009) os autores usaram os dados do Censo fornecido pelo IBGE (2005) equivalente a 2.340 unidades residenciais, totalizando uma população de 78.452 habitantes. O estudo objetivou uma área junto ao Rio Passo Fundo, sujeita a inundação, na cidade de Passo Fundo (RS). A DAP foi com vistas a valorar economicamente possíveis 
intervenções urbanísticas e ambientais. O questionário piloto foi aplicado em 49 residências, em 2004. A amostra definitiva, 150 questionários, teve como parâmetro o limite de confiança de $90 \%$. A população da cidade era de 183.300 habitantes, segundo contagem do IBGE (2007). A cidade apresentava uma taxa de crescimento populacional de 1,67\% e um índice de urbanização de $97,21 \%$. Os dados habitacionais quantitativos sobre a média geral de moradores por domicílio foram fornecidos pelo IBGE (2004).

A coleta de dados ocorreu da seguinte forma: 50 questionários foram aplicados em residências a uma faixa de $200 \mathrm{~m}$ do objeto de estudo, 50 numa faixa entre $200 \mathrm{~m}$ e 400m e mais 50 questionários em uma faixa com mais de 400m, para melhor estratificação de dados. A população residente na área de ocupação irregular não foi entrevistada. Entre os pesquisados 4\% afirmam que moravam menos de um ano no local (mobilidade urbana). Houve uma indisposição a pagar variando entre 50\% e 70\%, à mediada que se afastavam da faixa inicial. A DAP variou de US\$2,38 a US\$7,21 e, considerando a região com 2.340 unidades, a DAP totalizou entre US\$ 66.946,65 até US\$202.430,48

Apesar de o estudo usar um aporte estatístico, os autores salientam que a DAP apresentada é uma pequena parcela da população do município. Portanto se traduz numa pequena parcela dos benefícios a serem gerados pela intervenção urbanística e recuperação dos danos ambientais existentes causados por ligações clandestinas de esgotos e lançamento de lixo no Rio Passo Fundo. Os autores sugerem que o gestor público deveria fazer uma avaliação mais detalhada dos custos e benefícios para a viabilização de projetos de recuperação do dano.

A recuperação ambiental urbana do rio e suas encostas beneficiaria toda a população, num total de 45.825 residências, segundo dados apresentados. Se a amostra fosse de $10 \%$, a quantidade de entrevistas seria de 458 questionários aproximadamente em todo município. E o gestor teria um valor aproximado para a tomada de decisão. Outro fator que interferiu na amostra foram os anos consultados pelo IBGE para a coleta de dados 2004, 2005 e 2007, com censo ocorrido em 2000. Faltou uniformidade aos dados. O estudo não esclarece como foram selecionados os indivíduos para responder os questionários (150). Também não revela qual a DAP da primeira amostra. Somente revela que dos 49 questionários aplicados, 33 (67,35\%) foram respostas positivas e $16(32,65 \%)$ negativas. Assim, não se pode afirmar que o tamanho da amostra utilizada na segunda etapa foi estatisticamente significante para a população.

\section{Estudo 2 - Área do patrimônio histórico e cultural}

Para trabalhos de valoração centrados nos patrimônios históricos e culturais o trabalho 
de Bem e Giacomini (2011) será o representante. O artigo apresenta resultados de um projeto que avaliou e quantificou o valor que 237 agentes econômicos do município de Canoas (RS), que estavam dispostos a pagar por bens culturais, públicos ou quase públicos. A busca pela população se deu com base nos dados da RAIS (2009), divididos em faixas salariais. O estudo concluiu que os canoenses demandam uma cesta de bens culturais concentrados em poucos bens culturais como: bares e boates, acesso à internet, TV a cabo, livros didáticos e cinema. No entanto, estão dispostos a aumentar a demanda apenas nos bens de menor preço, como bares e boates, acesso à internet e livros. A DAP aumenta com a renda e tende a estabilidade entre 6 a 9 salários; porém diminui com a idade. A DAP média foi de US\$ 140,40 ${ }^{19}$.

A pesquisa busca base de dados (RAIS) atualizados, faz uso dos cálculos de proporção para estabelecer o número de pessoas pesquisadas, porém não deixa claro como encontrou os indivíduos, nem qual a técnica de amostragem utilizada. A amostra foi menos que $10 \%$ para um total de 2.484 pessoas empregadas em 2008. Não apresentou fórmula estatística para o cálculo. Os autores afirmam que a cultura se configura como uma importante forma de inclusão social em diferentes setores e segmentos da sociedade, amenizando o desemprego e a pobreza. No entanto, os indivíduos escolhidos para compor a população pesquisada eram os formalmente empregados. As pessoas que trabalhavam na informalidade não foram identificadas, mas ocasionalmente responderam ao questionário porque bastavam receber x salários mínimos em seu trabalho para responder ao questionário. Assim, a população seria formada por pessoas que tivessem em idade para o trabalho e trabalhando.

\section{Estudo 3 - Área da saúde}

Na área da saúde, o trabalho selecionado foi o de Silva e Lima (2006). Eles abordaram os problemas provocados pela poluição do ar em razão das queimadas existentes no Estado do Acre e os prejuízos causados à saúde. A população escolhida foi a da cidade de Rio Branco, capital do Estado, que na época contava com 284.555 habitantes. Os dados foram consultados no IBGE. A amostra consta de 225 indivíduos, com um erro de 10\%. Mais 10\% foram adicionados à amostra para dar maior confiabilidade, totalizando 248 entrevistados. A fórmula usada para o cálculo da amostra foi para população infinita (acima de 100.000 observações). Os indivíduos foram escolhidos em sorteio, sendo de 10 bairros, dois por região, e que não oferecessem risco aos pesquisadores. Foram entrevistados os chefes de família das residências

\footnotetext{
${ }^{19}$ A tabela de Câmbio de valores (BACEN) esta no anexo A
} 
nas ruas principais dos bairros. A amostragem foi assistemática. Na rua, escolheu-se o lado direito para a seleção de uma residência sim e outra não, e no lado esquerdo uma residência sim e duas não. Os questionários foram aplicados proporcionalmente em relação à população total do bairro. A DAP média foi de US\$10,24.

Nesse estudo, pode se observar que o tamanho escolhido para a amostra foi obtido com rigor estatístico e com riqueza de detalhes. Os autores não citam o ano base de busca no IBGE, mas fazem os cálculos com base no número de habitantes do município. Eles explicam de forma clara como se deu a coleta de dados, oportunizando a outros pesquisadores seguirem os mesmos passos traçados no projeto de pesquisa. Isso não significa que encontrarão os mesmos valores, porque as pessoas mudam de opinião, mas valores aproximados. Outros pesquisadores poderão comprovar do valor da DAP em estudos futuros.

\section{Estudo 4 - Conhecimento tradicional}

Para representar a área de conhecimento tradicional, o artigo eleito foi o de Viana et al. (2011). Os autores fizeram a valoração ambiental do Parque Ecológico e de Uso Múltiplo Olhos D'água - POD, em Brasília (DF). O estudo teve como objetivo estimar o valor total, de uso e existência do parque. O valor estimado foi de US\$13.830,62 por mês, com uma DAP estimada em US\$2,08 para valor de uso. Também apresentaram o cálculo para o valor de existência. US\$1,42, num total de US\$1.263,99. A população pesquisada morava nas quadras circunvizinhas ao parque, tanto quadras comerciais como as residenciais localizadas na Asa Norte/Plano Piloto. ${ }^{20}$

A população total (6.633) foi informada através das unidades consumidoras por quadra. Quanto à escolha da amostra, nada foi comentado. No questionário foi perguntado o endereço para verificar se a pessoa entrevistada residia na região delimitada. O valor de uso foi calculado quando o respondente afirmava visitar o parque e o valor de existência, quando afirmava ao contrário. A amostra contou com 230 questionários aplicados, mas quanto ao valor a que chegaram (230 questionários) nada foi esclarecido. O valor de uso foi calculado por 119 respondentes e o de existência por 31 indivíduos. Os autores acreditam na limitação do estudo e não verificaram a robustez e influências das variáveis sobre a DAP. Admitem também que a amostra não foi significativa e recomendam novos estudos.

Nesse estudo, como se pode notar, o tamanho escolhido para a amostra não foi

\footnotetext{
${ }^{20}$ Sendo elas 212, 412, 213, 214, 215, 415, 216, 416.
} 
significante, somente $3,47 \%$ da população estimada. Isso indica que o erro amostral se tornou muito grande e a DAP poderia ser superestimada ou subestimada. Outro problema apresentado foi quanto à determinação da população - "somente quadras perto do parque". Essa amostra é inconsistente para o cálculo do valor de existência porque a maioria das pessoas frequenta o parque e o cálculo do valor de existência deve ser composto por consumidores, possíveis consumidores e improváveis consumidores. A amostra poderia se estender a cidade de Brasília. Os autores admitem no final da conclusão um possível erro.

\subsubsection{Instrumento da pesquisa: a projeção do cenário}

A definição do cenário em MVC é uma de suas mais delicadas etapas porque apresenta muitos detalhes que não podem ser negligenciados. Por meio da descrição do cenário, as informações serão levadas aos indivíduos que julgarão se em suas cestas de consumo existe a possibilidade de destinar parte se seu orçamento para preservar, recompor ou modificar ativos ambientais. Desse modo, a descrição deve ser feita da forma mais completa possível, com a maior riqueza de detalhes. Sua configuração deve ser clara e direta.

A maneira como será composto o cenário depende de cada pesquisa. As informações destinadas aos inqueridos podem ser de forma verbal ou escrita, acompanhadas sempre que possível de gráficos (AHEARN; BOYLE; HELLERSTEM, 2006), e imagens e mapas (TEÍSL, 1996). Deve-se descrever de forma neutra e justa (SAMPLES; DIXON; GOWEN, 1986) e apresentar as características físicas do bem, como relevância do recurso, valor agregado, instalações e facilidades existentes. Apresentam-se também os benefícios que proporciona aos indivíduos e à sociedade, a mudança - na qualidade e na quantidade - que a pesquisa está se propondo.

Há ainda a possibilidade de acrescentar ao cenário fotografias, filmes, documentários. Poe e Bishop (1999) alertam para o uso desses recursos, porque os indivíduos podem não gostar e/ou não entender as fotografias e fazer julgamentos errôneos. Hicks (2002) atenta para pistas involuntárias em fotografias, como por exemplo, resíduos químicos em frutas e alimentos geneticamente modificados. As fotografias deverão ser de boa qualidade, de forma que não deixem dúvidas quanto à verdade do cenário, para que esse recurso não gere efeitos indesejáveis.

À medida que os indivíduos vão se inteirando do cenário - percepção subjetiva - devem também ter em mente as mudanças que por acaso poderiam ocorrer se houvesse uma contribuição/ participação positiva individual ou da comunidade. O Painel NOAA (1993) 
recomenda uma descrição precisa e assinala que não existe uma regra única, porém os cenários podem ser testados em grupos focais para permitir aos investigadores se as informações estão sendo entendidas, se são criveis e bem aceitas. É preciso também deixar claro a existência de possíveis substitutos próximos para o recurso.

O modo como a mudança será financiada deve ficar claro ao inquerido. Os pagamentos podem acontecer por meio de um único pagamento, por fluxo de pagamentos, cobrança de ingresso ao local ou via aumento de impostos, alíquotas, contribuições esporádicas, taxas de admissão, donativos entre outros. O instrumento de pagamento deverá ser conhecido, como boleto bancário, cartões de débito ou crédito, via contas de luz, água ou telefone, acréscimo no IPVA entre outros. Além do modo e do instrumento de pagamento, os indivíduos deverão ser informados sobre o cronograma de pagamento assim descriminado: anual, mensal, durante um período de tempo. É importante também informar quem administrará os recursos. As pessoas precisam perceber que existe um equilíbrio entre o que se deseja valorar, o valor e a forma de pagamento.

Hashimura (2008, p.42) fornece um quadro comparativo entre os problemas do cenário e os possíveis vieses a ele relacionados, no qual vou basear a análise dos trabalhos aqui exemplificados, (quadro 3.5).

Quadro 3.5 - Problemas de aplicação do Método de Valoração Contingente e os vieses associados

\begin{tabular}{|l|l|l|}
\hline \multicolumn{1}{|c|}{ Problema } & Viés \\
\hline \multirow{5}{*}{ Descrição do Cenário } & $\begin{array}{l}\text { Que não incentiva o entrevistado a revelar sua } \\
\text { verdadeira DAP }\end{array}$ & Estratégico \\
\cline { 2 - 3 } & $\begin{array}{l}\text { Que possui mecanismos que auxiliam, } \\
\text { indevidamente, o entrevistado a responder o } \\
\text { questionário }\end{array}$ & Entrevistador \\
\cline { 2 - 3 } & $\begin{array}{l}\text { Incompleta e/ou incorreta em relação a } \\
\text { aspectos essenciais }\end{array}$ & Especificação teórica \\
\cline { 2 - 3 } & \begin{tabular}{l} 
Instrumento de pagamento \\
\cline { 2 - 3 }
\end{tabular} & Especificação da qualidade \\
\cline { 2 - 3 } & Especificação do contexto \\
\hline
\end{tabular}

Fonte: Hashimura (2008), com alterações

\subsubsection{Exemplos por área da aplicação do MVC}

\section{Estudo 1}

Na pesquisa de Barbisan et al. (2009), o cenário foi composto de uma descrição 
detalhada do local como moradia (construção de baixo padrão, precária, alvenaria aparente sem acabamento, madeira e em local de ricos de inundação) e infraestrutura (existe rede pública de abastecimento de água, luz elétrica, drenagem pluvial e serviço de coleta de lixo, mas não existe pavimentação asfáltica, não há tratamento de esgoto e o esgoto doméstico é lançado clandestinamente nas águas pluviais). Inexiste vegetação nativa ou mata ciliar junto às margens do rio Passo Fundo e o leito sofre processo de erosão. Existe crescimento desordenado junto às áreas de preservação permanente de mananciais hídricos.

O cenário hipotético foi criado para dois momentos. O primeiro era para a recuperação da área "problemática" - termo usado no texto. E o segundo, se houvesse disposição para o pagamento, seria para valorizar os imóveis próximos ao local. A contribuição seria mensal, durante 12 meses.

As respostas variaram muito. Para o primeiro momento, existiu um indisposição ao pagamento de $64 \%$ na primeira faixa até $200 \mathrm{~m}, 68 \%$ até $400 \mathrm{~m}$ e $48 \%$ acima de $400 \mathrm{~m}$. Para o segundo momento a disposição em pagar aumentou com base na promessa de recuperação do local e consequentemente valorização do imóvel. Os valores passaram a ser: $90 \%$ nos primeiros 200m, $100 \%$ até $400 \mathrm{~m}$ e $76 \%$ acima de 400m. No artigo fica claro que os inqueridos ponderaram os custos e benefícios e conseguiram internalizar a necessidade de serem agentes de transformação, desde que os benefícios futuros fossem muito maiores que os custos atuais.

O cenário foi minuciosamente descrito e de fácil entendimento, porém o veículo de pagamento não foi mencionado, nem a entidade responsável para administrar os recursos. $\mathrm{Na}$ primeira etapa, dos 150 indivíduos, 90 não estavam dispostos a pagar; e, na segunda etapa, 17 indivíduos. Entre os que não pagariam estavam votos de protesto e não-resposta. Também não foi dada a opção de atitudes substitutas, como a retirada dos invasores e a revitalização da área por órgãos públicos responsáveis, entre outros. Não houve nenhuma alerta aos respondentes quanto ao orçamento e a nova despesa. Esses fatores podem interferir nas decisões e gerar respostas enviesadas.

\section{Estudo 2}

No cenário proposto por Bem e Giacomini (2011) foi pedido aos entrevistados imaginar um mercado cultural onde eles pudessem comprar bens e serviços culturais, mas não foi devidamente explicado o que é cultura. A não explicação levou os pesquisadores a julgamentos como: "muitas pessoas demostraram inabilidade em compreender completamente a pergunta, o que impossibilitou a obtenção de bons resultados"; "Se pudessem não aumentariam o 
consumo dos bens culturais já adquiridos, mas apenas alguns itens como TV a cabo e livros didáticos. Os indivíduos ao desejarem mais livros didáticos o fazem pela necessidade de uso nas instituições de ensino".

No texto, não se percebe a interação indivíduo - cenário - percepção subjetiva. As possíveis mudanças, caso estivessem dispostos a destinar uma parte maior de seus orçamentos, não foram explicadas. Não foi estimulada uma forma de financiamento (poupança) para gastos futuros com bens e serviços culturais. Percebe-se no artigo a presença do viés estratégico, de importância, especificação teórica, de qualidade e do contexto.

\section{Estudo 3}

A pesquisa de Silva e Lima (2006) apresenta como cenário os males que as queimadas causam à saúde e ao bem-estar dos indivíduos. Foi feita uma associação entre a mortalidade e morbidade respiratória. Os pesquisadores verificaram que, por meio de entrevista, $90 \%$ dos participantes sentiam algum desconforto no período de queimadas. O cenário hipotético criado por eles seria da melhoria da qualidade do ar. A pergunta utilizada para capturar a DAP dos entrevistados foi:

\footnotetext{
O problema da poluição do ar em função das queimadas no Acre atinge toda a população acreana. Observa-se, claramente, que no período de julho a outubro, o malestar causado pela poluição do ar prejudica crianças e adultos. Toda sociedade acreana sofre algum desconforto. Aeroportos são fechados, o cheiro de material queimado é muito forte, irritação ocular atinge muitas pessoas, fagulhas sujam muitas residências e outros problemas são ocasionados. Dentro deste cenário, você aceitaria contribuir, mensalmente,com R \$ (sortear o valor "lance inicial"), através de sua conta de luz, por um período de um ano, para melhorar a qualidade do ar e diminuir os impactos negativos ocasionados pela poluição do ar? (SILVA; LIMA, 2006, p. 178).
}

Na pesquisa, 45,3\% dos entrevistados manifestarrem indisposição em contribuir com tal proposta. Não foi informado no texto sobre votos de protesto ou justificativas para tal recusa. Para os que manifestaram disposição em contribuir, a DAP mensal familiar foi de US\$10,260, e anual US\$123,09. Não foi informado aos inquiridos quem administraria o valor recebido por um ano. O cenário hipotético foi pouco explorado. Os indivíduos não conseguiram abstrair possíveis usos para o valor doado. Não foi informado que os recursos poderiam financiar projetos rurais para implantação de tecnologias mais limpas. O trabalho apresenta viés de importância, especificação da qualidade e do contexto. 


\section{Estudo 4}

No texto de Viana et al. (2011) não se percebe a descrição do cenário atual do parque. Os questionários foram aplicados nas quadras no entorno do Parque - POD, mesmo que nas entrevistas se perceba que $31(13,48 \%)$ indivíduos não frequentavam o parque. O cenário hipotético mostrava os benefícios que seriam implantados no parque tais como melhoria na infraestrutura, pavimentação, trilhas, pontes de madeira, instalação de bebedouros, banheiros, bancos, estacionamento, melhorias no parque infantil e pista de ciclismo. A verba arrecadada seria repassada a uma organização da sociedade civil de interesse público sem fins lucrativos, em que o indivíduo teria direito a voto. O valor da DAP seria cobrado em uma conta de luz. No texto não foi citado o tempo durante o qual seria cobrado o montante na conta de luz, como por exemplo de seis meses a um ano.

O questionário foi aplicado a 230 pessoas, das quais 102 não pagariam (44,22\%). Destes, 63 usaram o voto de protesto contra o setor público. Dos 31 indivíduos que não conheciam o parque, 19 não pagariam, e destes 11 foram votos de protesto. Houve também protesto quanto ao instrumento de pagamento.

A pesquisa deveria ter seguido as recomendações do Painel NOAA e criado um cenário no qual todas as pessoas seriam informadas da atual situação do parque. Os pesquisadores poderiam ter usado painéis fotográficos porque belezas e defeitos podem não ser notadas no dia a dia, seja em momento de descontração ou durante os exercícios. As preocupações diárias nos ofuscam a visão. O uso de fotografia também poderia servir como uma forma de antever que algumas pessoas, mesmo que morando tão perto, podem não conhecer o parque. O Cenário futuro foi bem otimista e colaborou com uma DAP individual de US $\$ 3,25$, pelos usuários e US $\$ 1,42$ pelos não usuários. Como não ficou estipulado o tempo de cobrança, não se sabe por quanto tempo os usuários e não usuários estavam dispostos a pagar.

Quase a metade dos indivíduos inqueridos não aceitou pagar pelos benefícios. O fator gerador pode ser a descrição do cenário que deixou de considerar um grande número de requisitos fundamentais de uma descrição ideal, de tal forma que o cenário apreendido pelos respondentes não representou de forma fiel o bem em análise e seu contexto maior. Em nenhum momento se fez menção das características e atributos ambientais do parque, como regulação térmica e proteção ecossistêmica. 


\subsubsection{Relatórios dos estudos pelo MVC e a validade de conteúdo}

A validade de conteúdo tem por objetivo responder se os elementos desenhados na pesquisa e a análise de dados são consistentes com a teoria econômica, com a prática estabelecida e com o objetivo da valoração (POE, 1998). Um relatório dessa natureza serve a dois propósitos, segundo Boyle (2003). O primeiro seria para fazer uma análise da situação real do ativo ambiental a ser valorado, porque nem sempre os dados primários estão disponíveis para avaliações e verificações mais criteriosas. E o segundo proposito seria para avaliar possibilidades de transferência de valor para a aplicação de novas políticas públicas, seja para implementá-las ou para punir infrações contra o patrimônio ambiental.

Para atingir os objetivos a que se propõe, um relatório de difusão de valoração ambiental requer uma comunicação clara das informações, incluindo detalhes sobre todos os passos alçados na valoração dos ativos. Boyle (2003) disserta sobre esses passos sem contudo estrutura-lós e exemplifica-lós. Decidimos, a partir dessa inspiraçao, proceder uma sistematização mais rigorosa desses passos, sistematização essa que passamos a discutir. Atendido todos os itens, do relatório, os documentos seriam uteis para validar o conteúdo e as estimativas de valor acertadas aos ativos ambientais. O Quadro 3.6 apresenta os itens imprescindíveis.

Quadro 3.6 - Itens indispensáveis a um relatório de Pesquisa do Método de Valoração Contingente

\begin{tabular}{|ll|}
\hline \multicolumn{1}{|c|}{ Itens do relatório de pesquisa } \\
\hline 1. & A aplicação do estudo \\
\hline 2. & A definição teórica do valor \\
\hline 3. & O quadro amostral \\
\hline 4. & Modo de pesquisa e taxas de respostas \\
\hline 5. & Descrição dado ativo ambiental e cenário de valorização da pesquisa \\
\hline 6. & O formato de avaliação contingente utilizado \\
\hline 7. & Características sociodemográficas dos respondentes e uso do recurso \\
\hline 8. & Método de análise de dados, incluindo o tratamento de valores $\$ 0$ e respostas de protesto \\
& e a equação de estimação \\
\hline 9. & Estimativas de tendência central e dispersão dos dados e métodos utilizados para o cálculo \\
& da DAP
\end{tabular}

Fonte: Quadro elaborado pela própria autora (2014) 


\subsubsection{Exemplo da aplicação dos estudos por área do MVC}

O relatório dos resultados das pesquisas brasileiras quando usam o MVC são muito diversificados e, em muitos casos, não permitem a avaliação da validade dos conteúdos. Os quatro relatórios de estudos (artigos) escolhidos para representar cada área das pesquisas em valoração contingente são avaliados segundo os itens sugeridos no quadro3.6. Foram usados os seguintes códigos: Item Completo (IC); Item Incompleto (IIC); e Item Não Realizado (INR). Os estudos estão assim divididos: Estudo 1 - MVC 1; Estudo 2 - MVC 2; Estudo 3 - MVC 3; e Estudo 4 - MVC 4. Os autores que os representam estão no quadro do apêndice B.5 e os resultados expressos no Quadro 3.7.

Quadro 3.7 - Avaliação de relatório de estudos brasileiros do Método de Valoração Contingente

\begin{tabular}{|c|c|c|c|c|c|c|c|c|c|c|c|c|}
\hline \multirow{2}{*}{ Itens } & \multicolumn{3}{|c|}{ Estudo 1} & \multicolumn{3}{|c|}{ Estudo 2} & \multicolumn{3}{|c|}{ Estudo 3} & \multicolumn{3}{|c|}{ Estudo 4} \\
\hline & $\mathrm{IC}$ & IIC & INR & $\mathrm{IC}$ & IIC & INR & $\mathrm{IC}$ & IIC & INR & $\mathrm{IC}$ & IIC & INR \\
\hline A aplicação do estudo & $\mathrm{X}$ & & & $\mathrm{X}$ & & & $\mathrm{X}$ & & & $\mathrm{X}$ & & \\
\hline $\begin{array}{l}\text { A definição teórica do } \\
\text { valor }\end{array}$ & & $\mathrm{X}$ & & & $\mathrm{X}$ & & $\mathrm{X}$ & & & & $\mathrm{X}$ & \\
\hline O quadro amostral & & $\mathrm{X}$ & & & & $\mathrm{X}$ & $\mathrm{X}$ & & & & $\mathrm{X}$ & \\
\hline $\begin{array}{l}\text { Modo de pesquisa e } \\
\text { taxas de respostas }\end{array}$ & $\mathrm{X}$ & & & $\mathrm{X}$ & & & $\mathrm{X}$ & & & $\mathrm{X}$ & & \\
\hline $\begin{array}{l}\text { Descrição dado ativo } \\
\text { ambiental e cenário de } \\
\text { valorização da pesquisa }\end{array}$ & & $\mathrm{X}$ & & $\mathrm{X}$ & & & & $\mathrm{X}$ & & & $\mathrm{X}$ & \\
\hline $\begin{array}{l}\text { O formato de avaliação } \\
\text { contingente utilizado }\end{array}$ & $\mathrm{X}$ & & & & $\mathrm{X}$ & & & $\mathrm{X}$ & & $\mathrm{X}$ & & \\
\hline $\begin{array}{l}\text { Características } \\
\text { sociodemográficas dos } \\
\text { respondentes e uso do } \\
\text { recurso }\end{array}$ & & & $\mathrm{X}$ & & $\mathrm{X}$ & & $\mathrm{X}$ & & & & & $\mathrm{X}$ \\
\hline $\begin{array}{l}\text { Método de análise de } \\
\text { dados, incluindo o } \\
\text { tratamento de valores } \\
\text { \$0 e respostas de } \\
\text { protesto e a equação } \\
\text { de estimação }\end{array}$ & & & $\mathrm{X}$ & & & $X$ & & $\mathrm{X}$ & & $\mathrm{X}$ & & \\
\hline $\begin{array}{l}\text { Estimativas de } \\
\text { tendência central e } \\
\text { dispersão dos dados e } \\
\text { métodos utilizados } \\
\text { para o cálculo da DAP }\end{array}$ & & $\mathrm{X}$ & & & & $\mathrm{X}$ & $\mathrm{X}$ & & & $\mathrm{X}$ & & \\
\hline Total & $3 / 9$ & $4 / 9$ & $2 / 9$ & $3 / 9$ & $3 / 9$ & $3 / 9$ & $6 / 9$ & $3 / 9$ & $0 / 9$ & $5 / 9$ & $3 / 9$ & $1 / 9$ \\
\hline
\end{tabular}

Fonte: Quadro elaborado pela própria autora (2014) 
O Quadro 3.7 aponta que o artigo MVC 3 está mais próximo do que seria um relatório ideal para o MVC, aqui não inexiste um rigor estatístico a pontuação somente serve como norteador de itens certos, incompletos ou errados. Problemas recorrentes como quadro amostral inexistente e ou incompleto promovem o aviltamento da pesquisa, uma vez que não se pode fazer inferência dos resultados. A descrição do ativo e cenário de valorização incompletos leva a resultados errôneos no valor do ativo. As características sociodemográficas do respondente e uso do ativo inexistentes ou incompletos podem mascarar as respostas porque as expectativas de vida dos indivíduos e o meio em que estão inseridos, bem como seu grau de instrução, interferem, e muito, nos valores declarados na DAP. Conhecer os respondentes, com certeza, direciona melhor a pesquisa, levando-a a atender os diferentes interesses.

Quadro 3.8 - Sugestões de checklist detalhado para um relatório de pesquisa

\begin{tabular}{|c|c|c|}
\hline 1 & \multicolumn{2}{|l|}{ Aplicação do Estudo } \\
\hline 2 & \multicolumn{2}{|l|}{ Definição teórica do valor } \\
\hline \multirow{4}{*}{3} & \multirow{4}{*}{ Quadro amostral } & População \\
\hline & & Amostra \\
\hline & & Amostragem \\
\hline & & Fórmula usada \\
\hline 4 & \multicolumn{2}{|l|}{ Coleta de dados } \\
\hline 5 & \multicolumn{2}{|l|}{ Pré-teste e grupo focal } \\
\hline \multirow{4}{*}{6} & \multirow{4}{*}{ Do recurso } & Veículo de pagamento \\
\hline & & Cronograma de pagamento \\
\hline & & Entidade administrativa do recurso \\
\hline & & Informações sobre os bens/ serviços substitutos \\
\hline \multirow{2}{*}{7} & \multirow{2}{*}{ Cenário da pesquisa } & Real \\
\hline & & Hipotético \\
\hline \multirow{3}{*}{8} & \multirow{3}{*}{ Formato de avaliação contingente utilizado } & Informações dos entrevistados \\
\hline & & Informações auxiliares \\
\hline & & Informações de fronteira \\
\hline 9 & \multicolumn{2}{|c|}{ Caracterização sociodemográficas dos inquiridos e uso do recurso } \\
\hline \multirow{3}{*}{10} & \multirow{3}{*}{ Método de Análise de dados } & Resposta de protesto \\
\hline & & Resposta zero \\
\hline & & Equação de estimação \\
\hline 11 & \multicolumn{2}{|c|}{ Estimativas de tendência central e dispersão dos dados } \\
\hline 12 & \multicolumn{2}{|l|}{ Método do cálculo e da agregaçãoda DAP } \\
\hline
\end{tabular}

Fonte: Quadro elaborado pela própria autora (2014) 
O Quadro 3.8, apresenta uma lista para verificação de itens que não podem faltar para que os relatórios das pesquisas brasileiras sejam transformados em documentos para uso em políticas públicas ou uso judicial. Essa lista tem o intuito de uniformizar as informações necessárias ao uso MVC e dar mais visibilidade aos trabalhos científicos. Não existe a pretensão de criar um rigor formal nas pesquisas e inibir o poder criativo de cada pesquisador, mas fornecer meios para se verificar se as informações contidas nos relatórios conseguem aglutinar o maior número possível de informações. Nesse ponto já se pode extrair algumas conclusões que são apresentadas na próxima seção.

\subsection{COMENTÁRIOS CONCLUSIVOS}

No Brasil, quando se fala em valoração, tudo é novo. As avaliações ambientais, ora produzindo valores reducionistas, ora extrapolados, não obedecendo a uma inferência adequada, procuram sempre um meio termo, e essa busca leva ao confronto de métodos de valoração. Mas quando o debate está direcionado às perdas irreversíveis das potencialidades do ambiente é difícil ignorar todos os problemas enfrentados.

O MVC ainda não está sendo aplicado no Brasil conforme todas as diretrizes sugeridas pelo Painel NOAA. Entre os fatores que mais afetam a aplicação do método estão: vencer todos os vieses; a descrição do cenário; o uso de uma amostra realmente significativa e abrangente. No final de duas décadas de estudo, ainda sabemos pouco, avaliamos pouco e não adquirimos tradição suficiente para valorar produtos de não mercado com a eficiência desejada.

Os pesquisadores avançaram muito, mas a restrição do conhecimento aos interiores dos muros acadêmicos tem dificultado a cooptação de um valor real para o meio ambiente no processo VC. A sociedade deveria ser mais envolvida, expressando seu juízo de valor segundo suas preferências e utilidade. Porém isso só pode ocorrer se for bem informada da grandiosidade do ativo a ser valorado. Muitas vezes é convidada a fazê-lo, mas o entendimento sobre o bem ou serviço que valora é reduzido, porque outros bens e serviços estão também em jogo.

Observou-se que, quando o objeto de valoração está bem próximo da realidade do indivíduo e atua diretamente a favor ou contra seus interesses, o valor imputado é mais homogêneo, porque envolve um mesmo interesse. Contudo, se o ativo ambiental tem pouco significado, ou sua percepção está ofuscada pela complexidade e extensão do bem ou serviço, os indivíduos se omitem em valorar ou passar essa responsabilidade a outros que julgam ser mais qualificados. 
Os pesquisadores deveriam debater mais o tema, explicar melhor através de suas pesquisas os processos, suas experiências, usar a mídia a seu favor para que a população pudesse participar mais dos conhecimentos científicos e, só assim, ter condições de expressar um valor mais próximo da realidade. Assim, em termos práticos, na ausência de mercado dos quais possam derivar direta ou indiretamente valores de uso, faz-se isso quantificando o consentimento marginal para pagar ou aceitar, considerando respectivamente aquisição ou renúncia do bem avaliado.

Cada pergunta merece uma resposta. Se bem entendida, a resposta também será clara. Se mal interpretada, a resposta poderá apresentar a dúvida da pergunta. Para se responder com eficiência, precisa-se conhecer o tema. Para se perguntar, precisa-se conhecer o ambiente do interlocutor. Isso significa que o cenário que antecede a DAP deve ser bem projetado, claro, preciso e simples. Com raras exceções, as perguntas sobre a DAP feitas nos trabalhos de pesquisa no Brasil têm alcançado seus objetivos, porém o conhecimento para se responder é que ainda embaraça o momento da valoração. 


\section{CAPÍTULO 4}

\section{VÁRIOS CAMINHOS UM OBJETIVO: O MÉTODO CUSTOS DE VIAGEM}

\subsection{INTRODUÇÃO}

O Método Custos de Viagem (MCV) é usado para estimar o valor dos benefícios recreativos gerados pelos ecossistemas. Assume-se que o valor do sítio ou seus serviços recreativos se refletem no quanto as pessoas estão dispostas a pagar para ir e usufuir de um local de recreação e retornar às suas residências. Esse método utiliza o comportamento real e escolhas efetivas para inferir valores. Assim, as preferências dos indivíduos são reveladas por suas escolhas. O gasto total de uma visita consiste em diversos componentes: a taxa de admissão (quando houver), o custo monetário da viagem para o local de recreação, o custo de oportunidade do tempo da viagem, o custo de oportunidade do tempo gasto no local, os gastos realizados no local e o custo monetário da viagem de retorno à residência. $\mathrm{O}$ custo total de uma visita representaria a disposição marginal a pagar por ela.

A valoração econômica de bens ou serviços ambientais pode ser feita por meio da abordagem da preferência revelada no momento da compra de certos bens disponíveis no mercado, associada ao uso ou consumo do bem ambiental. Se esse bem é utilizado em atividades recreativas, gera fluxo de serviços mensuráveis pelos indivíduos. Cada visita a um lugar de recreação gera uma transação explícita ou implícita, na qual os custos totais da viagem se mostram como o preço que se paga para utilização dos serviços recreativos escolhidos.

$\mathrm{Na}$ busca da valoração do lazer proporcionado por áreas livres, o MCV utiliza o comportamento de consumo do mercado por meio de gastos relacionados à viagem, tais como passagens, despesas com alimentação ingressos, pequenos souvenires adquiridos como lembranças, combustível para deslocamento, desgastes de $\operatorname{carros}^{21}$ (quando for o caso). Enfim, é considerado todo o necessário para o consumo durante o período destinado à recreação. Além desses gastos, são analisadas outras variáveis como nível educacional, idade, renda, zona de moradia e outras características atitudinais que podem interferir no resultado final (HANLEY; SPASH, 1993).

A abordagem do MCV foi sugerida pela primeira vez para os EUA por Hotelling (1947). O serviço de Parques Nacionais solicitou dez especialistas em valoração que desenvolvessem

\footnotetext{
${ }^{21}$ Mokhtari e Hosseinifar (2013) publicaram recentemente trabalho usando depreciação do veículo quando avaliaram o parque urbano Noshirvani no norte do Irã.
} 
uma metodologia pela qual poderiam dar o valor aos parques que justificasse os gastos com sua manutenção. De todas as respostas que receberam, somente a de Hotelling foi baseado em princípios econométricos, um insight simples (CENTENO, 2000). Hoje, as análises econômicas de opções de lazer estão entre as mais avançadas modelagens micro econométricas do comportamento do consumidor.

Segundo Phaneuf e Smith (2005), a literatura sobre MCV passou por três fases. A primeira de Clawson (1959) e Trice e Wood (1958), que iniciaram os trabalhos com aplicações para modelo de demanda, estimado com dados zonais (taxas de visitas de agregados por zonas populacionais em diferentes distâncias dos locais de recreação), usando dados agregados, sem informações socioeconômicas dos envolvidos. Esse modelo é interpretado como de forma reduzida. Em 1966, Clawson e Knetsch introduziram formalmente escritos sobre florestas. Em 1971, Burt e Brewer estimaram um sistema de equações de demanda para recreação em um lago com os micro dados.

A segunda fase se inicia com a atenção direcionada aos custos do tempo de viagem, o papel dos locais alternativos, a distância percorrida pela viagem e o local de oportunidade de demanda por atributos de recreação. Um trabalho representativo dessa fase é o de Phaneuf e Smith (2005). Na terceira fase, chamada de contemporânea, foi introduzida a teoria da utilidade aleatória $^{22}$ num modelo, como um método teoricamente consistente para resolver o problema de escolha discreta e continua para um novo RUM (Random Utility Maximization), e usou-se também a descrição da paisagem como necessária ao referencial do local para uma melhor escolha do consumidor ao site. A primeira pesquisa nessa etapa foi a dissertação de Hanemam (1978) e, mais tarde, a de Bockstael, Hanemann e Strand (1987).

Este capítulo analisa o que tem sido escrito, no Brasil, no período de estudo. Ele está dividido em quatro partes, além da introdução e conclusão. A primeira (seção 4.2) apresenta as características gerais do método, seus aspectos históricos, vantagens e limitações, e exibe algumas aplicações recentes. A segunda (seção 4.3) se preocupa com o método enquanto norteador de uma pesquisa, o tipo de abordagem do método, a importância do local e da coleta de dados, além dos principais modelos econométricos utilizados. Na terceira parte (seção 4.4), apresenta-se o emprego do método no Brasil desde o histórico até aplicações recentes, com comentários sobre os locais de abrangência, sobre as Instituições de Ensino Superior (IES) responsáveis e sobre os principais estudos no Brasil. Na seção 4.5 são feitas as análises gerais

\footnotetext{
${ }^{22}$ Mais utilizado para múltiplos locais. Um modelo RUM considera a escolha discreta de um indivíduo de um local de recreação a partir de muitos locais possíveis em uma única ocasião de escolha (PARSONS, 2003, p. 270)
} 
e pontuais dos estudos brasileiros.

\subsection{O MCV FACILIDADES E DIFICULDADES}

Shammin (1999) afirma que numerosas aplicações do MCV existem nos EUA, Europa e Austrália. Nos EUA e Reino Unido, as agências governamentais têm utilizado esse método para valorar parques e florestas nacionais. Países em desenvolvimento como Quênia, Costa Rica, Madagascar e Tailândia também fazem uso do método, aplicando-o na valoração de parques, zoológicos e florestas.

A grande vantagem do MCV é captar os valores relacionados ao uso direto e do patrimônio (natural) e propiciar, por meio do valor obtido, políticas públicas para criação de parques, conservação e ampliação de áreas públicas (IAMTRAKEL; TEKNOMO; HOKAO, 2005). Conhecer os valores significa garantir que a variável ambiental tenha peso efetivo nas tomadas de decisões. Os benefícios diretos possíveis de serem valorados pelo MCV que os parques trazem para a sociedade são: manutenção da biodiversidade e dos processos ecológicos, oportunidades de recreação, ecoturismo, educação e pesquisas nas áreas conservadas, contemplação dos valores estéticos, espirituais, culturais, históricos e existenciais (KINKER, 2002).

Desenvolver bancos de dados relevantes e bem documentados para recreação é difícil e moroso, mas se o método for valoração custos de viagem sua despesa de execução é normalmente mais baixa, comparando-se a outros métodos. O MCV torna mais simples e direta a pergunta: Quanto você tem despendido e que tempo tem empregado ao visitar o parque natural? Esse método limita-se a utilizar uma informação real em situações reais.

A facilidade de aplicação é outra vantagem desse método. Não existe um mercado hipotético. As amostras são coletadas no local, após conhecimento total ou parcial do local, e os gastos com as viagens podem ser planejados e executados na íntegra. Se houver necessidade, podem ser efetuadas mudanças para que os gastos sejam ajustados aos orçamentos dos indivíduos. Por fim, é um método que tem boa aceitação, visto que é relativamente pouco controverso no meio acadêmico por reconhecer as mudanças constantes nas preferências dos consumidores. Pela facilidade de adaptação a novos modelos econométricos, propicia oportunidades para se compreender melhor as tomadas de decisões dos indivíduos (PHANEUF; SMITH, 2005).

A possibilidade de se estimar pelo MCV somente o valor de uso do local de recreação é um fator limitante. Não é possível calcular o valor de não uso (RANDALL, 1994). Há 
fundamentalmente duas opções de escolha para a variável, dependendo do número de visitas feitas a determinada zona ou visitas feitas por determinado indivíduo. A primeira opção é expressa por visitas per capta e a segunda é uma coleta de dados de visitas por ano e por indivíduo. Ambas podem apresentar resultados diferentes. Não há consenso sobre qual é a mais adequada.

As aplicações do método geralmente são restritas. Podem-se valorar locais de recreação e o tempo ${ }^{23}$. O método também é circunscrito a situações do local especificado. Isso dificulta a confiabilidade, caso a comprovação dos resultados seja necessária, pois os procedimentos, mesmo sendo idênticos, sofrerão alterações, já que as características locais e os visitantes envolvidos serão geralmente diferentes com o passar do tempo.

Existe a possibilidade de distorção na pesquisa quando há, para um mesmo sítio, visitantes que residem nas proximidades do local em análise, além de viajantes que se deslocam de longas distâncias. Ou seja, se o indivíduo é residente ou turista eventual. Koop e Smith (1993) garantem que a determinação de valor exato (ou aproximado) da parcela que significa a disposição a pagar do indivíduo pela conservação do ambiente é difícil de calcular, uma vez que é complexo separar os objetivos diretos e indiretos de uma viagem. Valorar cada uma delas separadamente é tarefa dificílima, considerando-se que os indivíduos têm preferências sui generis.

Estudos que envolvem vários locais exigem muito tempo por causa das dificuldades de análises e de recursos para alcançar a total compatibilidade entre os sites. Entre as dificuldades estão, por exemplo, caracterizar os locais e a população da qual a amostra é retirada, de forma a garantir que mudanças nos excedentes dos consumidores sejam apenas com base nas decisões dos respondentes (LIENHOOP; ANSMANN, 2011). As visitas imprevistas não valoram o local da mesma forma que as visitas propositadas. Assim, se uma viagem tem mais de uma finalidade, o valor do site pode ser superestimado. Seria necessário determinar um escore de importância das visitas para cada local, o que, na prática, é muito difícil.

Uma das principais críticas ao modelo é a falta de precisão no que diz respeito à informação sobre os custos das viagens. Os entrevistados geralmente se mostram relutantes em responder as perguntas sobre os gastos com acomodações, refeições e compras. Quando respondem às perguntas, é difícil atribuir uma parte do custo para a visita específica em estudo, uma vez que os entrevistados nem sempre passam o dia todo em um único local e podem

\footnotetext{
${ }^{23}$ Modelos de escolha discreta para valorar o tempo de viagem gasto por mulheres para coletar água em países em desenvolvimento (PEARCE, 1993).
} 
participar de múltiplas atividades (CENTENO, 2000).

A existência de locais alternativos afeta naturalmente a demanda, uma vez que a taxa de visita vai depender não apenas dos custos da viagem, mas também da possibilidade de escolher locais que forneçam ao consumidor o mesmo nível de utilidade porque os indivíduos escolhem entre os diversos locais aquele que satisfaça sua cesta de bens e demanda por locais que possam atender seus anseios de recreação.

O cálculo do custo da distância é uma variável concreta. No entanto, é preciso incluir outros gastos que nem sempre são lembrados, como depreciação dos veículos. Outro fator a ser observado é a viagem de curta distância, já que apresenta custos diferentes. O cálculo deve ser considerado separado dos demais porque poderá subestimar o valor. Assim obtém-se várias curvas de demanda para compor o valor final do ativo ambiental. Outra questão que merece atenção especial é a diferenciação entre visitantes em férias, que podem permanecer mais de um dia no local, e visitantes diários, que estão apenas de passagens pelo patrimônio natural. Quem fica mais dias tem gastos com alimentação, hospedagem e custo de oportunidade durante os dias de passeio (PHANEUF; SMITH, 2005).

Definir o custo de oportunidade do tempo ou o valor do tempo gasto na viagem pode ser problemático, uma vez que o tempo de transporte poderia ser usado de outra forma. O Custo de Oportunidade (CO) deve ser adicionado aos custos de viagem, ou o valor do site será subestimado. Pearce e Tuner (1995) destacam que o consumidor escolhe entre trabalho e lazer. Ao optar pelo lazer, a partir do tempo que nele despenda, declara sua disposição a pagar por aquele recurso. $\mathrm{O}$ indivíduo considera os custos de viagem e o valor do seu tempo e decide se deverá produzir e ser remunerado ou gastar o tempo em lazer. Portanto, o elemento crítico, nos custos de acesso, é o valor tempo.

Entrevistar visitantes no local inadequado pode induzir a um vies na amostragem. Por exemplo, se o visitante conhecer o site, o local for visitado antes, ele poderá ter uma opinião e, se for depois, poderá aprovar ou não o local e responder o questionário de acordo com seus sentimentos e falsear respostas.

Abordagens do padrão de custos de viagens fornecem informações sobre as condições atuais, mas não sobre ganhos ou perdas decorrentes de mudanças nas condições dos recursos. O MCV é limitado no seu âmbito de aplicação, pois exige a participação do usuário. Ele não pode ser usado para atribuir valores de não uso aos recursos. Não pode ser utilizado para avaliar os valores fora do local, ou seja, suportados pelo local. Sites que têm qualidades únicas valorizadas por não usuários serão subvalorizados (HANLEY; SPASH, 1993). O fator limitante da aplicação no local diz respeito ao fato de que o método captura apenas os valores de uso 
direto do patrimônio natural, ou seja, supõe-se que apenas os visitantes possuam unidades marginais positivas pelos bens ou serviços ambientais prestados pelo patrimônio.

Os procedimentos estatísticos utilizados podem afetar os resultados. Entre os problemas podem-se citar: a escolha da forma funcional utilizada para estimar a curva de demanda, a escolha do método de estimativa e a escolha das variáveis incluídas no modelo. Segundo Hanley e Spash (1995), Haab e Mac Conell (1995) e Parsons (2003), as variáveis podem ser censuradas e truncadas. Truncadas quando se consideram as visitas somente no local escolhido, não se permitindo avaliação por bens substitutos e apenas visitas no período da amostra. Isso pode levar a erro de estimativa, pois os respondentes inquiridos não podem responder pelas preferências de outros visitantes em outras épocas. Quanto aos dados censurados, os autores levam em consideração o fato de que menos de uma visita não pode ser observada e isso leva a uma estimativa de parâmetros de demanda inclinada.

\subsubsection{Aplicações do MCV e análises dos dados obtidos}

Existem várias maneiras de abordar problemas com o uso do MCV. Segundo Parsons (2003), um dos problemas pode ser uma abordagem simples de custo de viagem zonal, que estima o valor para serviços recreativos do site como um todo, enquanto o necessário é que se busque informações sobre o número de visitantes em cada zona com diferentes distâncias, porque os custos de viagem e o tempo aumentam com a distância.

As zonas podem ser definidas por círculos concêntricos em torno do local ou por divisões geográficas, com áreas metropolitanas ou municípios vizinhos. Com essas informações, o pesquisador pode calcular o número de visitas, construir a função demanda e estimar o excedente do consumidor ou benefícios econômicos para os serviços de lazer. A soma dos excedentes dos consumidores reflete o benefício global do local. Assim, a variável dependente é uma taxa de visitação resultante da razão do número de visitas efetuadas a partir de cada zona, pela população daquela zona, durante um período de tempo. Esse tipo de variação do método não deve ser utilizado para avaliar a mudança na qualidade de lazer local.

A abordagem por zona caracteriza-se pela hipótese de homogeneidade entre os indivíduos de uma mesma zona. Portanto podem-se estabelecer zonas de origem dos visitantes através da espacialização do custo de viagem do visitante. Esse modelo tem caído em desuso porque a estimativa da região pode tornar-se enviesada, uma vez que não considera que apenas uma pequena parte da população da zona mais distante participa da atividade. Brown et al. (1983) sugerem que para contornar o problema seja usado na variável dependente a frequência 
da vista em termos per capta.

Outra maneira de abordar o problema seria um approach do custo de viagem individual. Nesse caso, o levantamento deverá ser mais detalhado. A pesquisa é definida de acordo com o número de visitas feitas por visitante durante um dado período a um determinado local. $\mathrm{O}$ Método Custos de Viagem Individual (MCVI) requer mais coletas de dados, porém os resultados são mais precisos. A função de demanda para a média dos visitantes e a área do excedente também é da média dos consumidores. Com os dados adicionais é possível prever mudanças na qualidade do local. Para tanto, existe a necessidade de projetar duas curvas de demanda diferentes, uma para cada nível de qualidade. A área entre as curvas é a estimativa da variação do excedente do consumidor quanto às mudanças de qualidade. Um exemplo disso pode se dá quando o número de peixes em um rio diminui pela pesca predatória ou quando há interdição de uma praia por derramamento de óleo.

Ao aplicar o MCVI, dois problemas podem ocorrer. Um deles é a truncagem ${ }^{24}$, que pode ser resolvido através da estimativa da probabilidade máxima ${ }^{25}$. O outro problema é o tratamento da variável dependente discreta como se fosse contínua, o que provoca perda de objetividade na reportagem dos dados.

Uma abordagem de utilidade aleatória (Random Utility Maximization - RUM) também pode ser usada, mas é mais sofisticada e de mais elevado custo. Ela permite maior flexibilidade aos cálculos dos benefícios, é ideal para locais com bens substitutos próximos e é bem aceita quando se quer estimar características específicas ou mudanças de qualidade dos locais. Nesse tipo de abordagem, assume-se que as pessoas vão revelar sua preferência por um local a todos os outros possíveis. Os indivíduos fazem compensações entre a qualidade do site e o preço da viagem para o site. São exemplos: qualidade da água em rios e lagos e das vias de acesso. $\mathrm{O}$ modelo RUM também pode ser utilizado para avaliar o acesso a mais de um local simultaneamente. Um bom exemplo é quando existe a necessidade de fechar várias praias por poluição. Alguns trabalhos recentes podem ser citados como exemplos.

Lienhoop e Ansmann (2011), avaliaram os efeitos das mudanças nos níveis de água para recreio em um reservatório para controle de cheias nas montanhas ao sul da Alemanha Oriental. O reservatório Pöhl fornece água para uma indústria de mineração e é um local de lazer para a comunidade com passeios de barco, caminhadas e camping. Com o objetivo de evitar inundações, se propôs reduzir as águas do reservatório. O objetivo foi avaliar os custos que adviriam para os usuários recreacionistas. A amostra contou com 591 visitantes abordados nas

\footnotetext{
${ }^{24}$ Variáveis explicativas e dependentes não são observadas.

${ }^{25}$ Corrige as influências que surgem pelo uso da estimativa do MQO, (GARROD; WILLIS, 1999).
} 
praias, estacionamento e pedestre em caminhadas. Destes, 380 questionários foram validados. A modelagem utilizada foi Poisson e regressão binomial negativo ${ }^{26}$. Os resultados indicam que uma diminuição nos níveis da água dos reservatórios reduz o valor recreativo o que foi verificado para 1 metro, 3,5 metros e 5 metros.

Outro trabalho recente foi o de Conradie e Garcia (2012), realizado no extremo sul da África, que valorou as Agulhas Plain, uma planície costeira entre Hermanus e o estuário do Rio Breede. Ela abrange uma área de 335.335 hectares. O site oferece uma costa intocada com oportunidade de observar baleias, golfinhos, mergulho com tubarões em gaiolas, pesca esportiva e mergulho. Existe ainda uma excepcional biodiversidade vegetal. Um pequeno número de pessoas visita o local com bastante frequência. Em geral, os visitantes ficam 14 dias fora de casa e no mínimo cinco dias no local. A amostra foi de 370 indivíduos, com o modelo binomial negativo truncado por excesso de dispersão. O estudo estabeleceu um valor recreativo de $£ 167$ bilhões para o site como um todo.

Purwanto (2013) usou o MCV para determinar a contribuição que a indústria do turismo poderia gerar na renda de moradores em Banyuwangi, na Indonésia, e qual o impacto regional desse turismo. O local é formado por montanhas, praias e uma cratera vulcânica no monte Ijen. Existem vários locais que poderiam ser usados pelos turistas para recreação em família. A amostra foi de 300 respondentes. As principais variáveis do estudo foram: origem do visitante, gasto com transporte, documentação para viagem (turistas estrangeiros), acomodação e alimentação. Utilizou-se a regressão linear múltipla para determinar a equação de demanda. A renda regional bruta foi de US\$ 3.749 .054 milhões. A contribuição seria de 15,2\% da receita total da região.

O MCV deve descrever as trocas entre bens externos e os locais de recreação de interesse, e permitir mudanças quando as condições e qualidades do site sofrerem alterações. $\mathrm{O}$ modelo deve vincular de forma consistente características do local, tais como se há ou não congestionamento, belezas naturais singulares, presença de espaço especial para o lazer infantil, locais de fácil acesso para idosos, atividades diversas para esportistas entre outros.

Ao se reportar sobre o congestionamento, Freeman III (2003) diz que quando este ocorre, diminui a utilidade e, consequentemente, a DAP. O grau de aglomeração é um dos atributos que influenciam na qualidade dos serviços e é visto como uma externalidade negativa.

\footnotetext{
${ }^{26}$ Este modelo relaxa a suposição de que a variância é igual à média e permite uma modelagem mais flexível. O modelo binomial negativo apresenta a heterogeneidade dos dados que a distribuição de Poisson não revela, (HAAB; MCONNELL, 2003).
} 
Os usuários podem ter diferentes utilidades marginais a pagar para evitar o congestionamento. O MCV pode então ser usado para mostrar como melhorias da qualidade de um local, por exemplo, estradas, pode reduzir o congestionamento em outro local.

O processo que liga as percepções de qualidade do local antes e como eles são modificados explica o comportamento dos indivíduos. Substituições intertemporais podem ocorrer se houver interrupções de curto prazo do local, por exemplo, interrupção temporal de banhos no mar por poluição, suspensão da pesca no período de piracema, fechamento temporário da área de acampamento em períodos chuvosos sujeitos a enchentes.

Algumas vezes o local que será avaliado tem um único tipo de recreação; outras vezes apresenta múltiplos usos como natação, pesca, canoagem. O correto seria estimar uma função de demanda para cada tipo. Também existe a possibilidade de agrupar os dados por tipos semelhantes de atividades, por exemplo, passeio de barco, lancha e pedalinho. A agregação simplifica os dados, a coleta e a análise.

Atualmente nenhum modelo pode lidar com a longa lista de requisitos que um local pode apresentar. No entanto, a literatura tem feito impressionante progresso. Smith e Kaoru (1990) foram os primeiros a escrever sobre a questão dos efeitos do local em modelos de agregação RUM e medidas de avaliação. Estudos posteriores trabalharam diferentes estratégias de agregação e cálculos estatísticos. Parsons (2003) apresenta quatro modelos com variações, e Phaneuf e Smith (2005) exibem cinco abordagens para a modelagem da demanda por recreação. Viagens, preços e características do local são registrados como se fossem mercadorias para serem analisadas, tendo em vista seus efeitos de bem-estar nos indivíduos.

Para capturar os dados dos consumidores, um questionário deve, em primeiro lugar, estar intimamente ligado ao que se deseja analisar e ao modelo que será aplicado. Para Parsons (2003), o questionário é usualmente dividido em quatro partes: a) material introdutório, b) questões sobre a viagem, c) questões sobre outros passeios, e d) questões socioeconômicas da família.

A pesquisa pode pedir as seguintes informações: localização da casa do visitante, quantidade de visitas àquele local, duração da viagem, despesas da viagem, renda do indivíduo, características socioeconômicas do visitante. Também pode solicitar informações atitudinais, como outros locais visitados durante a mesma viagem, finalidade da viagem, percepções da qualidade do meio ambiente, locais alternativos que a pessoas poderiam visitar, saber se existe ou não experiência na atividade que pretende desempenhar no local de recreação. A preferência é para questões fechadas e curtas. 
A coleta de dados deve ser vista como um processo econômico que, segundo Phaneneuf e Smith (2004), são as limitações dos recursos do estudo e do tempo para examinar as respostas. Existe um consenso entre economistas de que as questões levantadas para a coleta de dados do Método de Valoração Contingente também se aplicam ao MCV. Para a coleta dos dados, existem dois tipos de abordagem: on-site e off-site. Se a coleta for no local, há a vantagem de atingir a população alvo diretamente e a desvantagem de as pessoas que não visitam o local não poderem responder o questionário. Isso implica imprecisão da estimativa. Não haverá interceptação do preço de estrangulamento para a função demanda, pois não terá zero viagens. O termo de erro implícito na equação será truncado. E isso provoca uma equação de demanda muito íngreme e a estimativa de bem-estar será tendenciosa. Outro problema é o local da aplicação, antes ou depois dos dias de estadia. O ideal seria após os respondentes conhecerem bem o local. Deve-se ter cuidado com a estratificação endógena por causa do viés de seleção. A segunda alternativa, a abordagem off-site, evita o viés de seleção, porém ela apresenta custo mais elevado, o mercado será mais extenso (HAAB; McCONNELL, 2003).

O destino e a finalidade da viagem precisam ser questionados. Poderá haver um único destino ou múltiplos propósitos. Nesse caso, a lógica de tratar custo da viagem como preço de uma viagem de lazer ou experiência de recreação torna-se tênue, não tendo como identificar o custo marginal da porção da viagem para recreação, a não ser que sejam colocadas restrições no modelo. ${ }^{27}$

\subsection{CONTORNANDO AS LIMITAÇÕES DO MCV EM 67 ANOS DE PESQUISA}

A limitação quanto ao uso exclusivo do MCV em áreas de recreação ao ar livre foi vencida e novos lugares foram valorados. Atualmente o MCV é empregado para valorar, além das áreas citadas, museus, cidades históricas e bens públicos culturais (GUIA, 2008). O método também foi utilizado para avaliar fluxo de serviços públicos e serviços destinados a recolher resíduos perigosos (ANEX, 1995).

Para Palmquist e Phaneuf (2010), muitas pesquisas empíricas assumem o tempo como fungível e isso afeta o modo como é usado. Um período de quatro horas permite ao consumidor diferentes possibilidades de uso, muito diferente de quatro blocos de uma hora. Assim, o valor marginal do tempo pode aumentar à medida que o tamanho do bloco de tempo aumenta. Essa

\footnotetext{
${ }^{27}$ Par múltiplos propósitos, ver Mendelsohn et al. (1992).
} 
descoberta tem implicações para a valoração de diferentes tipos de experiências de recreação. Pequenos blocos de tempo são suficientes para uma visita a um parque local e blocos maiores de tempo são exigidos para viagens a parques regionais. Portanto, precisa-se observar a frequência das visitas e o valor do tempo de forma diferenciada entre os pesquisados quando se quer estimar o preço de sombra do tempo.

Existe uma relação entre o custo de oportunidade do tempo em curto prazo e em longo prazo. Os resultados empíricos revelam que o valor de curto prazo de tempo varia de acordo com o tamanho do bloco de tempo, que pode resultar em gastos adicionais quando relacionados a despesas de viagens de lazer ao ar livre de um dia inteiro, já que existe a possibilidade de várias viagens para o mesmo local para realizar diferentes atividades.

Vários estudos sugerem que o cálculo do custo de oportunidade do tempo com recreação seja entre um terço e até um quinto da renda mensal do indivíduo. Malta, Costa e Costa (2008) afirmam que Cesário (1976) sugeriu o valor de um terço, Caulkins, Bishop e Bouwes (1986), um quarto. Mas Farré (2003) assevera que, na Espanha, usa-se de 10\% a 50\% do salário/hora de sua vida profissional. Para qualquer unidade de medida utilizada, se a utilidade marginal do tempo de trabalho é negativa, então a taxa de salário é uma superestimava do valor de escassez de tempo.

Ainda não há um consenso de que uma taxa de salário seja um bom argumento para calcular o custo de oportunidade do tempo, como foi realizado no trabalho de McConnell e Strand (1981), que aludem que a pesquisa sobre o tempo de transporte ao site seja medido com base na taxa de salários. Existem estudos, como os de Bockstael et al. (1987), que questionam o uso dessa taxa porque há trabalhadores que apresentam tempo flexível de trabalho e outros não. Assim, o cálculo do custo de oportunidade do tempo precisa ser diferenciado. Lew e Larson (2005) demostram que o preço sombra do tempo não precisa ser igual ao salário.

Sobre a aplicação do MCV com destinos múltiplos, Mendelsohn et al. (1992) propuseram um modelo que busca tratar cada combinação dos lugares visitados como se fosse um local adicional. Para cada uma das combinações e para cada local individual é gerada uma função demanda, que fará parte de um sistema de equações de curvas de demanda inversa. Porém, existem problemas com o método que é a possibilidade da existência de solução de canto. O modelo tobit é utilizado para resolver esse problema. Por outro lado é comum as pessoas utilizarem uma mesma viagem para visitar mais de um local de recreação. A alocação dos custos de uma viagem com múltiplos destinos, exclusivamente para examinar um site recreacional, enviesa a medida da demanda pelos benefícios desse local. Os custos da viagem, portanto, devem ser divididos entre os vários locais visitados - divisão não trivial. 
Locais alternativos com atributos comparáveis são avaliados como locais substitutos, mas eles são comumente ignorados na avaliação porque se torna dispendioso desenvolver em estudo simultâneo em todos os locais substitutos. Morey et al. (1995) tecem uma crítica ao modelo e afirmam que ele não é consistente com o comportamento de maximização da utilidade, pois não trata dados com um número significativo de indivíduos e que as pessoas não visitam todos os atrativos envolvidos. Além disso, apresenta uma limitação no que se refere ao do efeito renda na agregação do excedente do consumidor. Uma forma de amenizar o problema foi proposta por Garrod e Willis (1999), que pediram aos respondentes que, numa escala préestabelecida, revelem a contribuição de cada local em sua viagem ou o tempo que se dedicou a cada local visitado.

A aplicação do MCV com mais de um destino e propósito foi realizado por Loomis, Yorizane e Larson (2000) em pesquisa com turistas que queriam ver baleias na Costa Oeste dos EUA. Os resultados demostraram que a exclusão de indivíduos com mais de um destino não acarreta um resultado enviesado, mas subestima o valor do bem que pode ser de $20 \%$ a $70 \%$ maior, caso sejam inclusos os outros indivíduos.

Hanley e Spash (1993) apresentaram uma dúvida sobre o MCV quanto ao cálculo dos custos de viagem no que se refere à distância percorrida quando envolve o uso de meios de transporte diferenciados. Eles sugerem que os custos podem ser efetuados utilizando-se gastos com combustível ou gastos totais como depreciação, manutenção, seguro, pedágios, entre outros. Como os indivíduos podem utilizar os mais diversos tipos de transporte, seus custos também deverão ser distintos. Além disso, os custos também podem variar dependendo do modelo ou potência do veículo. Independentemente das dificuldades para o cálculo, o valor monetário precisa ser medido.

Já Carr e Mendelsohn (2003) observaram o problema sobre tempo e distância já que muitos dos visitantes vinham de uma viagem internacional e usavam como veículo o avião que era difícil correlacionar com a distância entre os muitos visitantes. Outro problema visto foi o custo do transporte afirmado pelos visitantes e o confronto de preços com as agências de viagens. A pesquisa usou o modelo tobit, logit, modelo log-linear e log-linear polinomial. Teve por objetivo medir o valor da grande barreira de corais na Austrália. O estudo concluiu que viagens internacionais tinham custos fixos muito elevados e que o custo por milha não foi constante. O valor de custos dos recifes variou de US\$ 700 a 1.600 milhões por ano, com um gasto de US\$ 350 a 800 por visita.

Sobre a validade do valor recreativo das Florestas Irlandesas, Mayor, Scott e Tol (2007) apresentaram um trabalho usando uma amostra de 1.202 entrevistas e priorizou um questionário 
para avaliar a distância percorrida até o local, modo de transporte e tempo disponível para lazer. O modelo utilizado foi o Poisson e Binomial Negativo para testar o excesso de dispersão. O valor do excedente do consumidor foi de $£ 2,40$ por adulto por viagem. A contribuição foi estabelecer uma taxa de acesso às florestas ${ }^{28}$.

Um trabalho que merece análise é o de Mokhtari e Hosseinifar (2013), porque usa o MCV para avaliar um parque urbano em Babol, no Irã. O parque Amirkola foi estimado em US\$ 90 mil em um dia e recebe até 90.000 pessoas por dia. Esse é um parque público e, se houvesse uma taxa para frequentá-lo, reduziria para 60.000 pessoas/dia. Entre as variáveis está a depreciação dos veículos que as pessoas usavam, trabalho inédito com essa variável (amostra para 120 questionários). Entre os resultados socioeconômicos, o que mais chama a atenção é que a amostra é composta por $92 \%$ de homens e $70 \%$ dos informantes têm baixo nível de estudo. A explicação apresentada é que o parque é frequentado por homens comuns e que, no Irã, é o chefe da família, do sexo masculino, que geralmente vai ao parque, em grupos de cinco ou mais pessoas do gênero masculino, não é comum passear com pessoas do gênero feminino. Quanto ao baixo nível de estudo a explicação percebida é por causa da renda média (US\$ 300) baixa e pouca capacitação profissional. Tanto o gênero quanto a instrução influenciaram o valor da DAP.

\subsection{O MÉTODO CUSTOS DE VIAGEM APLICADO NO BRASIL}

Aplicações do MCV ocorreram há 20 anos no Brasil. O primeiro trabalho data de 1993 e poucos trabalhos foram realizados aplicando esse método: apenas 47 trabalhos foram encontrados na nossa pesquisa.

O primeiro trabalho com o uso do MCV realizado no Brasil foi em 1993 para um Programa de Despoluição da Baía de Guanabara no Rio de Janeiro, apresentado ao Banco Interamericano de Desenvolvimento. ${ }^{29}$ A pesquisa faz parte do relatório de referência para solicitar empréstimo, pelo Governo do Estado, com o objetivo de despoluir e realizar o saneamento básico em toda Bacia da Baía de Guanabara. O MCV foi estimado em US\$ 0,01 por família ao mês - benefício da balneabilidade.

\footnotetext{
28 Este trabalho também fez comparação com o Método de Valoração Contingente.

${ }^{29}$ Este estudo fez parte do projeto de tese de Dubeux (1998). E pela data apresentada em Motta (1998), a primeira aplicação do método no Brasil foi em 1993 (Programa de Saneamento Básico da Bacia da Baía de Guanabara BR 072).
} 
Grasso et al. (1995) escrevem um trabalho em que comparam dois métodos: Avaliação Contingente e Avaliação de Custos de Viagem. Nele é valorado o ecossistema manguezal nas regiões de Cananéia e Bertioga, local de livre acesso, sob o domínio público. Pouco depois, em 1997, Mota foi responsável por uma pesquisa na área de uso público do Parque Nacional de Brasília- PNB, época em que era aluno de doutorado em Meio Ambiente e Desenvolvimento pela UnB. O método foi aplicado para estabelecer o valor econômico de uso de piscinas de água mineral. As principais informações foram sobre os gastos monetários e o tempo despendido na visitação. A amostra contou com 1.018 participantes $^{30}$ (SALGADO; NOGUEIRA, 2001).

No ano de 1998, cinco trabalhos são expostos: o Manual para valoração da economia de recursos ambientais, de Seroa da Motta (1998), que apresenta vários métodos de valoração entre eles o MCV, seus vieses e um o estudo de caso como aplicação do método; o trabalho de Casimiro (1998), sobre valoração monetária de benéficos ambientais, no qual apresenta o caso do turismo no litoral Cearense; o trabalho de Carolina Dubeux (1998), sobre a Despoluição da Baía de Guanabara, tese em que faz referência ao método e apresenta um quadro-resumo sobre aplicação do método no projeto e os valores encontrados; a pesquisa de Aguiar e Ortiz (1998), sobre uma aplicação de dois métodos MVC e MCV do Parque Nacional de Brasília (mimeo); e, por fim, o trabalho de Nogueira e Medeiros (1998) sobre valoração econômica em seus aspectos teóricos e operacionais.

O MCV é aplicado pela segunda vez no Parque Nacional de Brasília, em 1999, com o objetivo de valorar seu uso recreativo, agora pelo Centro Nacional de Pesquisa de Recursos Genéticos e Biotecnologia (CENARGEN/EMBRAPA), com uma amostra de 3.850 indivíduos. Outro trabalho do mesmo ano é o de Baldissera e Hochheim (1999) que avalia o Parque Municipal da Lagoa do Peri, em Florianópolis (SC), trabalho citado por Abreu, Silva e Silva Junior (2008).

Os trabalhos teóricos que abordam o método são apenas oito. O trabalho de Nogueira e Medeiros (1998), da UnB; Seroa da Mota (1998), publicado pelo Ministério do Meio Ambiente; Tavares, Ribeiro e Lanna (1999), publicado pela UFPEL; Nogueira, Medeiros e Arruda (2000), da UnB; Brandli (2006), da Universidade de Passo Fundo; Romeiro e Andrade (2009), da UNICAMP; Barreto (2013), da UFL; e Miquelito et al. (2014) da UFF.

Nenhum dos trabalhos teóricos se dedicaram a aprofundar os modelos de análise econométrica, suas implicações para a aplicação do questionário e os tipos de questões. Esses

\footnotetext{
${ }^{30}$ Dados apresentados em nota de rodapé número quatro, no trabalho Economia e Gestão de áreas protegidas: o caso do Parque Nacional de Brasília.
} 
comentários estão dispersos nos trabalhos empíricos. Existe, portanto, uma lacuna no Brasil de trabalhos teóricos que possam nortear os trabalhos empíricos brasileiros. Não existem livros publicados no Brasil que tratam especificamente desse assunto. Os trabalhos brasileiros apresentam, como fonte de pesquisa teórica, trabalhos escritos nos EUA e Europa.

Dos trabalhos empíricos pesquisados, $18 \%$ foram realizados no Estado de Goiás; $15 \%$, no Distrito Federal; 10 \%, em Santa Catarina; 8\%, no Espírito Santo, Mato Grosso do Sul e Rio de Janeiro e Minas Gerais; 5\% no Paraná e Bahia; e 3\% nos demais estados, como destacado no gráfico $4.1 .^{31}$

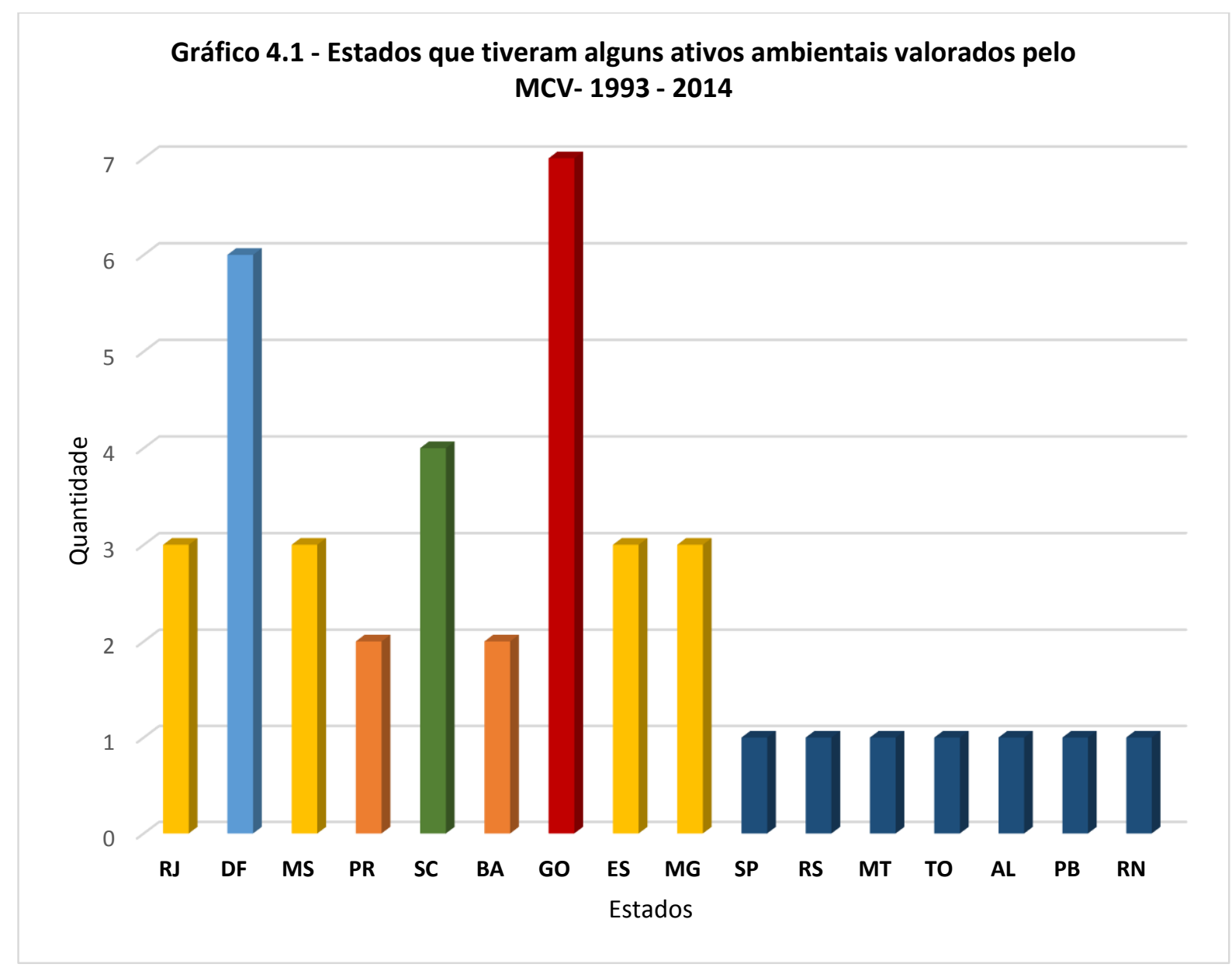

Fonte: Gráfico elaborado pela própria autora (2015), com base nas informações apresentadas no Apêndice B tabela B.1

As Instituições de Ensino que mais colaboraram com as pesquisas usando o MCV foram: UnB (36\%), UFRJ, UEG e UNOCHAPECÓ (4\%) e as demais instituições com $2 \%$ ver gráfico 4.2.

\footnotetext{
${ }^{31}$ As tabelas referentes aos gráficos deste capítulo estão no apêndice B
} 


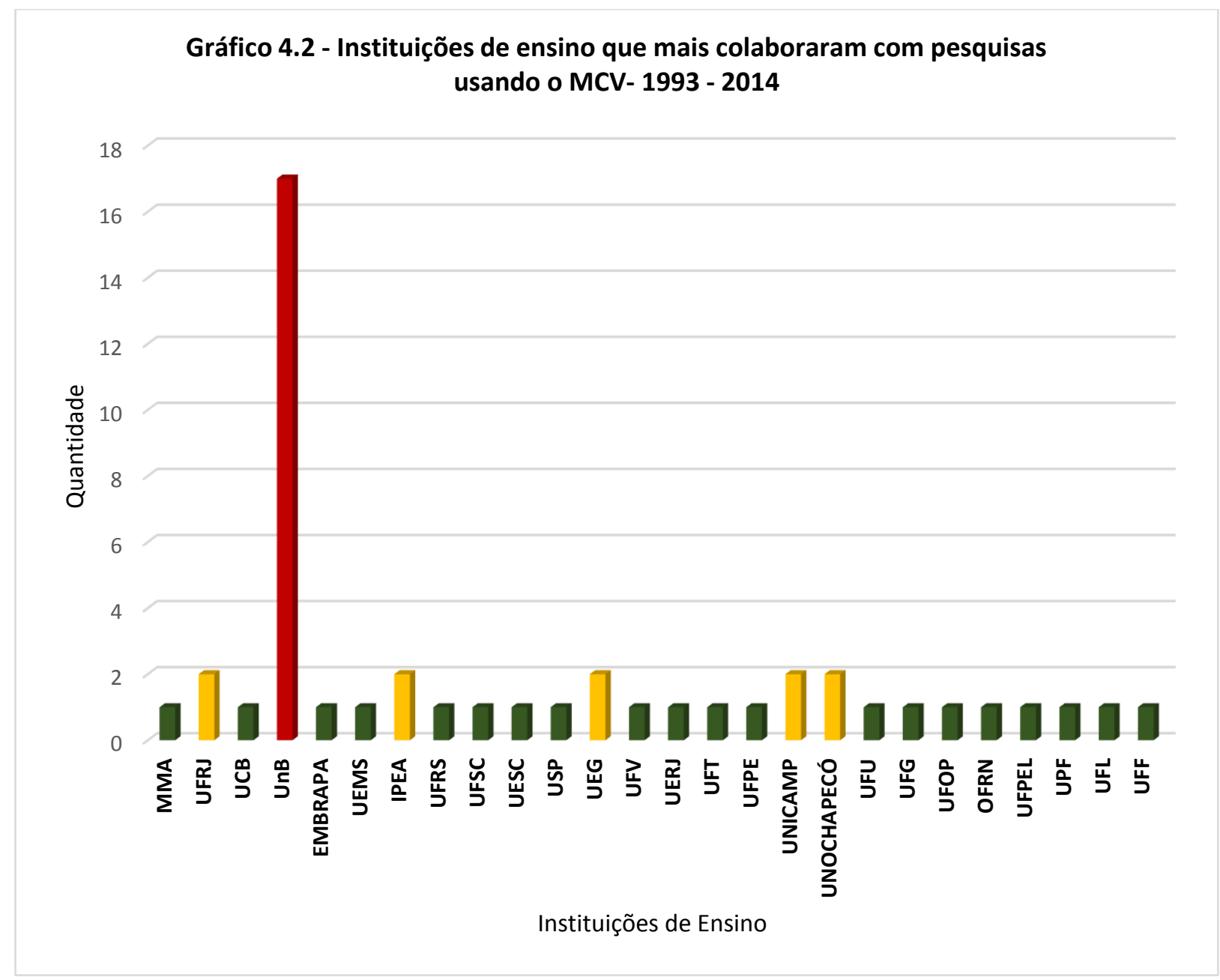

Fonte: Gráfico elaborado pela própria autora (2015), com base nas informações apresentadas no Apêndice B tabela B.2

No Gráfico 4.3, é exibida a quantidade de publicação por ano. Como se pode ver, o maior pico de publicação ocorrereu em 2008 e 2014. Nos anos de 1994, 1996, 2000, 2011 nada foi publicado a esse respeito. 


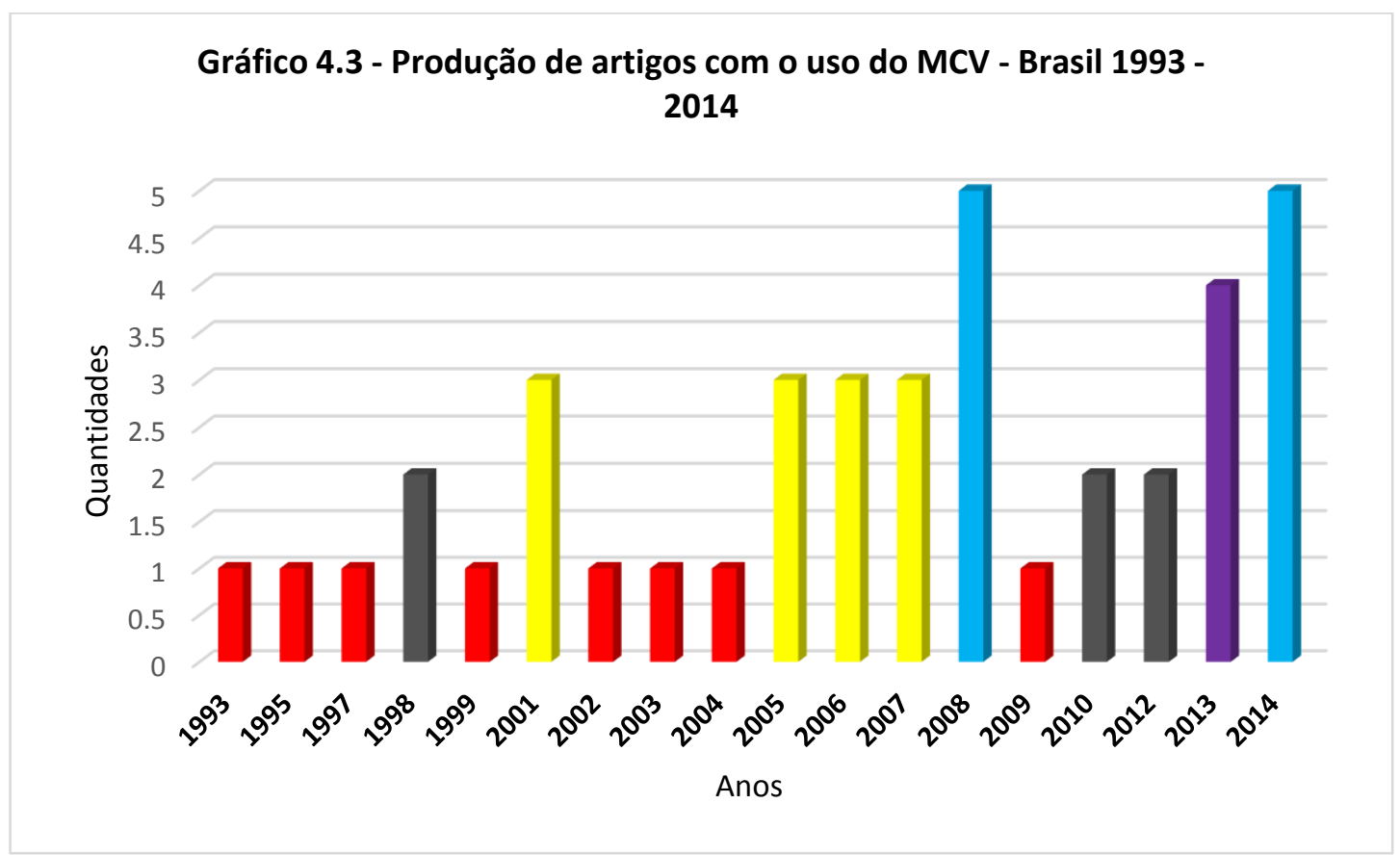

Fonte: Gráfico elaborado pela própria autora (2015), com base nas informações apresentadas no Apêndice B tabela B.3

O Apêndice $B_{1}$ apresenta somente os trabalhos empíricos publicados no Brasil (39), com os respectivos autores e datas de publicação. Desses trabalhos, 39\% externaram preocupação com a credibilidade de suas pesquisas segundo os critérios de avaliação da aplicação do MCV quanto à validade do construto tanto teórica quanto convergência, $36 \%$ se preocuparam com os critérios de construto teórico, e $25 \%$ se concentraram somente com o construto da convergência.

As pesquisas realizadas sobre os ativos de recreações no Brasil foram separadas por local de recreação para melhor compreensão dos dados. O primeiro grupo compreende os parques, divididos em nacionais ${ }^{32}$, estaduais e municipais. Juntos representam $36 \%$ das publicações. Existem no Brasil 69 parques nacionais, dos quais foram valorados pelo MCV apenas $8,7 \%$. Os parques estaduais somam 171, e 1,7\% foi valorado. Dos parques municipais, foram valorados apenas quatro, conforme apresentado no Quadro 4.1. Note-se que alguns parques foram valorados mais de uma vez, como o Parque Nacional de Brasília e o Parque Nacional da Chapada dos Veadeiros.

\footnotetext{
32 Os parques nacionais são uma categoria de unidade de conservação de proteção integral da natureza definida por lei. O objetivo é a preservação do ecossistema de relevância ecológica para possibilitar pesquisas científicas, recreação e turismo ecológico. São unidades de domínio público com visitação permitida, mas controlada pelo órgão administrativo. Os Parques Nacionais no Brasil são administrados pelo Instituto Chico Mendes de Conservação da Biodiversidade (ICMBio), uma autarquia vinculada ao Ministério do Meio Ambiente. Os parques estaduais são unidades de conservação regidas por legislação estadual específica e integram o Sistema Nacional de Unidades de Conservação da Natureza - SNUC, MMA (2014).
} 
Quadro 4.1 - Pesquisa em Parques Brasileiros que foram valorados pelo Método de Custo de Viagem - Brasil (1977-2014)

\begin{tabular}{|c|c|c|c|c|c|}
\hline \multicolumn{2}{|c|}{ Parques Nacionais } & \multicolumn{2}{|c|}{ Parques Estaduais } & \multicolumn{2}{|c|}{ Parques Municipais } \\
\hline $\begin{array}{l}\text { Nome do } \\
\text { parque / } \\
\text { Estado/Ano } \\
\text { de } \\
\text { publicação }\end{array}$ & Amostra/Valor & $\begin{array}{l}\text { Nome / } \\
\text { Estado }\end{array}$ & Valor & $\begin{array}{l}\text { Nome / } \\
\text { Estado }\end{array}$ & Valor \\
\hline $\begin{array}{l}\text { Parque } \\
\text { Nacional de } \\
\text { Brasília (DF) } \\
\text { - 1997, } 1999\end{array}$ & $\begin{array}{l}\text { Amostra: 1a } 3.347 \\
\text { e 2a } 1.018 \\
\text { Valor: } 1 \mathbf{a} \\
\text { US\$12,42 por } \\
\text { pessoa } \\
\text { 2a } \\
\text { US\$16.080.829,29 } \\
\text { anual }\end{array}$ & $\begin{array}{l}\text { Parque } \\
\text { Estadual de } \\
\text { Itaúna (ES) } \\
2006\end{array}$ & $\begin{array}{l}\text { Amostra: } 331 \\
\text { Valor: US\$ } \\
98,5 \text { milhões } \\
\text { por ano }\end{array}$ & $\begin{array}{l}\text { Parque } \\
\text { Natural do } \\
\text { Itajaí (SC) - } \\
2004\end{array}$ & $\begin{array}{l}\text { Amostra: } 53 \\
\text { Valor: US\$ } \\
985.727,22\end{array}$ \\
\hline $\begin{array}{l}\text { Parque } \\
\text { Nacional da } \\
\text { Chapada } \\
\text { dos } \\
\text { Veadeiros } \\
\text { (GO) - } 2006 \\
\text { e } 2013\end{array}$ & $\begin{array}{l}\text { Amostra: 1a } 389 \\
\text { 2a } 120 \\
\text { Valor: 1a US\$ } \\
3.401 .853,82 \\
\text { 2a US\$54,86 por } \\
\text { pessoa }\end{array}$ & $\begin{array}{l}\text { Parque das } \\
\text { Dunas e } \\
\text { Parque } \\
\text { Turístico } \\
\text { Ecológico } \\
\text { Dunas de } \\
\text { Jenipabu } \\
\text { (RN) -2014 } \\
\end{array}$ & $\begin{array}{l}\text { Amostra: } 567 \\
\text { Valor: US\$ } \\
47.296 .581,65 \\
\text { aa. } \\
\text { R\$ 27.619,18 } \\
\text { por ha }\end{array}$ & $\begin{array}{l}\text { Parque } \\
\text { Municipal do } \\
\text { Itiquira (GO) - } \\
2005\end{array}$ & $\begin{array}{l}\text { Amostra: } 810 \\
\text { Valor: US\$ } \\
321.308 .53\end{array}$ \\
\hline $\begin{array}{l}\text { Parque } \\
\text { Nacional da } \\
\text { Tijuca (RJ) - } \\
2008\end{array}$ & $\begin{array}{l}\text { Amostra: } 228 \\
\text { Valor: US\$ } \\
8.666 .966,98 \text { por } \\
\text { ano ou em média } \\
\text { US\$ } 24,08 \text { por } \\
\text { visitante }\end{array}$ & & & $\begin{array}{l}\text { Parque } \\
\text { Municipal das } \\
\text { Palmeiras } \\
\text { (SC) - } \\
2010\end{array}$ & $\begin{array}{l}\text { Amostra: } 84 \\
\text { - Valor: US\$ } \\
2.873,33 \text { por } \\
\text { ano }\end{array}$ \\
\hline $\begin{array}{l}\text { Parque } \\
\text { Nacional } \\
\text { Serra Geral } \\
\text { (RS/SC) - } \\
2008 \\
\end{array}$ & $\begin{array}{l}\text { Amostra: } 335 \\
\text { Valor: } \\
\text { US\$127milhões }\end{array}$ & & & $\begin{array}{l}\text { Parque } \\
\text { Municipal } \\
\text { Chapecó (SC) } \\
\text { - } 2013\end{array}$ & $\begin{array}{l}\text { Amostra: } 70 \\
\text { Valor: } \\
\text { US\$0,67 por } \\
\text { pessoa }\end{array}$ \\
\hline $\begin{array}{l}\text { Parque } \\
\text { Nacional do } \\
\text { Iguaçu (PR) - } \\
2001\end{array}$ & $\begin{array}{l}\text { Amostra: } 3.186 \\
\text { Valor: anual de } \\
\text { US\$ } 12 \text { milhões a } \\
\text { US\$ } 34 \text { milhões }\end{array}$ & & & & \\
\hline $\begin{array}{l}\text { Parque } \\
\text { Nacional da } \\
\text { Chapada } \\
\text { dos } \\
\text { Guimarães } \\
\text { (MT) - } 2005\end{array}$ & $\begin{array}{l}\text { Amostra: } 113 \\
\text { Valor: US\$ } \\
7.615 .204,54 \text { por } \\
\text { ano }\end{array}$ & & & & \\
\hline
\end{tabular}

Fonte: Quadro elaborado pela própria autora (2015) 
Dos trabalhos analisados, $42 \%$ tinham como objetivo confrontar o MCV com MVC, $10 \%$ analisar validade e confiabilidade, $41 \%$ calcular valor de uso e $17 \%$ estimar e avaliar a demanda turística. Quanto ao modelo econométrico utilizado, 50\% estimaram a equação de demanda pela regressão linear simples; 30\%, a regressão para múltiplos destinos; 10\%, a regressão linear logarítmica; e 10\%, apenas estatística descritiva e MQO. aplicaram questionário on-site, $83 \%$ e off-site $17 \%$. Somente $10 \%$ são trabalhos MCV zonal. Todos os trabalhos fizeram descrição criteriosa dos parques, apresentado a área, atrativos e qualidades (Ver Apêndice B.2 ).

No segundo grupo de pesquisas, foram separados 11 trabalhos que se dedicaram a abordar a recreação em rios, praias e balneário. Esse grupo representa $29 \%$ das publicações, que estão descritas no Quadro 4.2. Nesse grupo foi importante notar em que praias mais distantes os cálculos são feitos separados de praias urbanas, como foi o caso de citado por Fico e Valadares (2008). Nos demais estudos 27,3\% separaram as praias por zonas e 18,2\% coletaram dados off-site. Somente $18,2 \%$ escreveram trabalho sobre recuperação de praia em função da poluição.

\section{O terceiro grupo é formado pelos trabalhos que foram selecionados como outros} num total de 13 trabalhos. Foram incluídos nesse grupo porque existe uma multiplicidade de locais avaliados 35\%. Seguem alguns estudos desse grupo:

1) Jardim Botânico da Fundação Zoo-Botânica de Belo Horizonte, escrito por Mendonça et al. (2012), que coletou dados de 645 pessoas e obteve custo médio de viagem de US\$ 27,71;

2) O Santuário Vagafogo, em Pirenópolis (GO), elaborado por Sanches et al. (2013), que teve como objetivo pesquisar valor de uso. Ele considerou como transporte automóvel e avião. O custo médio por viagem variou de US\$26,09 a US\$392,98 por pessoa;

3) A Gruta do Maquiné, que foi valorada por Paula et al. (2008). O estudo contou com uma amostra de 298 pessoas e obteve um valor de US\$217,42- no agregado US\$7.751,90 - e os bens públicos culturais registrados; 


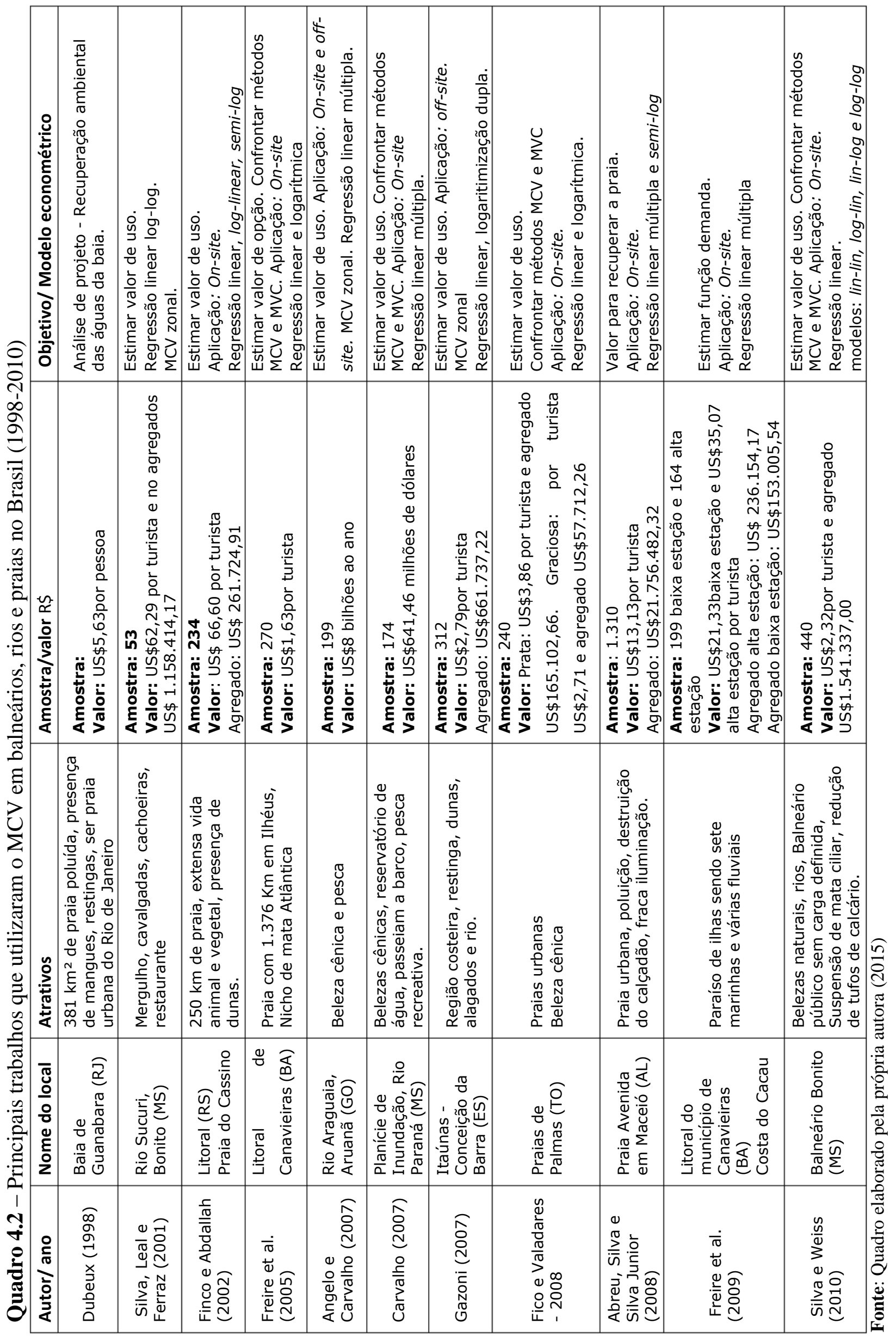


4) No trabalho de Marques (2012), os bens avaliados foram a Catedral de Brasília, a torre de TV e a Praça dos Três Poderes. A amostra foi de 1.906 pessoas. Foi empregado o Método Custos de Viagem zonal, individual e híbrida, e com multipropósitos. Foram escolhidos como transporte os três modais: ônibus, carro e avião. Obteve-se como valores: a) Catedral: de US\$10,74 a US\$247,79; torre de TV: US\$9,32 a US\$114,31; e Praças dos Três Poderes: de US $\$ 15,55$ a US $\$ 112,96$. Os resultados refletem o valor relacionado ao uso do bem por turistas brasileiros provenientes de outros Estados, não refletindo o valor relacionado ao custo de oportunidade do capital. "Os resultados sugerem que a abordagem individual se apresenta como a mais adequada, porque proporciona o menor valor de avaliação dos ativos culturais, revelando-se como alternativa mais conservadora" (MARQUES, 2012, p. 103).

5) Freire et al. (2013) valororaram a cidade de Cavalcante (GO), que possui uma área de preservação, o Parque Nacional da Chapada dos Veadeiros, considerado patrimônio mundial pela UNESCO. A região abriga animais e plantas do cerrado. A pesquisa foi realizada pelo Centro de Excelência em Turismo da UnB, com 374 pessoas, e chegou ao valor econômico de US\$2.161,46 por visitante.

6) O trabalho de Lopes (2014) objetivou aplicar uma métrica de valoração ambiental para a reserva ambiental da Chapada dos Veadeiros, com o intuito de verificar a percepção dos agentes públicos em utilizar as informações geradas pela contabilidade como forma de contribuir para ação/planejamento de políticas públicas no desenvolvimento sustentável da região. O MCV foi utilizado para calcular o valor dos bens ambientais que estão no território de Cavalcante. Com uma amostra de 354 questionários válidos, foi estimado o perfil dos turistas. Logo após, foram calculados os benefícios gerados pela visitação aos bens ambientais chegando a um valor médio aproximado por visitante de US\$2.195,84

7) Barcelos (2014) valorou o Santuário do Caraça, que é uma RPPN e possui muitos atrativos para recreação como cachoeiras, lagos e trilhas, e se cobra um valor para custear sua manutenção. O objetivo do trabalho foi obter o valor econômico recreativo/ano do Santuário do Caraça/MG. O MCV identificou a disposição máxima a pagar pelos visitantes do Santuário de US\$1.010,88 por individuo/ano e valor econômico total recreativo no valor de US\$6.712.423.852,07/ano.

8) E, por fim trabalho de Freire et al (2014) que valorou o Memorial Darcy Ribeiro localizado em Brasília, para aferir seu valor econômico e verificar quais os empecilhos encontrados na aplicação do método. A amostra contou com 72 respondentes e o valor encontrado foi de US\$2,27 por visitante ao patrimônio cultural. 
As análises mais detalhadas sobre os estudos brasileiros estão na seção seguinte, na qual serão vistos aspectos gerais como acuidade, confiabilidade dos estudos, seleção inadequada da amostra, instrumento de pesquisa e validade de conteúdo apresentados nos relatórios finais da pesquisa.

\subsection{ANÁLISES DE ESTUDOS BRASILEIROS DE VALORAÇÃO COM O MCV}

\subsubsection{Análises gerais das aplicações do MCV: pequenos erros, grandes problemas}

A acuidade com que é elaborada a pesquisa dá credibilidade ao trabalho. Duas etapas distintas precisam ser rigorosamente seguidas. A primeira é a técnica de amostragem, para que seja contemplado o maior número de pessoas no contexto pesquisado, visto que uma amostra tendenciosa provoca distorções ao resultado final. A segunda é a técnica utilizada para o cálculo da função demanda e, a partir dela, a estimativa do excedente do consumidor. Definir a melhor técnica, ou seja, o melhor ajuste econométrico ${ }^{33}$ garante um resultado crível. A confiabilidade dos resultados está intimamente ligada à precisão das estimativas, já que variações mínimas nos coeficientes do modelo tendem a gerar mudanças drásticas na estimativa do benefício liquido total.

O trabalho de Maia e Romero (2008) apresenta uma simulação que ilustra bem os problemas de seleção de amostra. Eles avaliaram o Parque Nacional da Serra Geral, usando o MCV zonal e, para conferir validade e confiabilidade aos dados, retiraram apenas um questionário da amostra de um visitante de São Joaquim da Barra. O respondente deste questionário era o único representante deste município, que, em valores expandidos, representava uma população de 109 habitantes, fazendo novo ajuste para a função demanda com as informações relativas aos 94 municípios restantes. A exclusão do questionário deste indivíduo tornou o ajuste $\log$-log mais significativo, porém foi suficiente para reduzir a estimativa do benefício em mais de um milhão de reais anuais, uma estimativa 3,5\% inferior à original.

Assim, recomenda-se a máxima cautela no critério de seleção da amostra e no tratamento dos dados. "Valores extremos tendem a afetar o resultado final [...] e a sugestão é que esses valores sejam agregados às localidades mais próximas, representando micro e mesorregiões geográficas" (MAIA; ROMEIRO, 2008, p. 121). O ideal seria utilizar amostras

\footnotetext{
${ }^{33}$ As formais funcionais mais comuns são linear, lin-log, log-lin e $\log$-log.
} 
maiores, porém isso pode comprometer o tempo e o custo da pesquisa.

\subsubsection{Análises pontuais dos vieses em estudos brasileiros para valoração ambiental no uso do $\mathrm{MCV}^{34}$}

\subsubsection{Seleção inadequada de uma amostra: um alerta teórico}

Uma boa amostra é essencial para que represente a população, foco das pesquisas. $\mathrm{O}$ MCV requer tamanho de amostra que efetivamente possa expressar a veleidade pela recreação. Como são variados os tipos de recreação desejados pelos indivíduos e geralmente os dados são esquadrinhados on site, o tamanho da amostra depende da frequência de visitação ao sítio a ser valorado, porém ela não pode ter pouca representatividade. Se o questionamento aos indivíduos for feito off site, a amostra deverá ter um escopo maior por causa da abrangência geográfica e da diversidade de pensamento e possibilidades de escolha para o lazer.

Para assegurar a representatividade do tamanho das amostras, devem ser usados testes de erro amostral, nos quais o erro de mensuração de uma amostra de tamanho $n$ e nível de confiança $\alpha$ apropriado sejam usados para uma população conhecida e finita. Quando não se conhece o valor do desvio padrão $(\sigma)$, a sugestão é a adoção de uma medida conservadora, assumindo-se o valor máximo do desvio padrão para uma variável dicotômica $(0,5)$. $\mathrm{O}$ parâmetro é o valor da tabela normal padronizada para $\alpha$ de probabilidade, no caso o intervalo de $95 \%$ de confiança $(1,96)$. Essas sugestões estão expressas nos mais diversificados tipos de literatura dedicados aos estudos de estatística.

Segundo Haab e McConnell (2003), além do tamanho adequado da amostra é necessário observar a) se o indivíduo escolhido para responder o questionário faz uso de seu tempo para visitar somente um ou vários destinos, com amplas possibilidades de maximizar sua utilidade/tempo e minimizar custos; b) se ao visitar determinado sítio irá se dedicar a um tipo de lazer ou a diversos tipos; c) qual o tipo de transporte é utilizado pelos indivíduos para chegar ao local. Todas essas questões devem ser levantadas para validar a amostra.

\footnotetext{
${ }^{34}$ Quanto se analisou o os trabalhos pelo MVC foram observados 4 trabalhos porque a amostra contava com 90 pesquisas. Os demais métodos serão analisados proporcionalmente a quantidade elegida.
} 


\subsubsection{Exemplos de trabalhos brasileiros publicados}

Foram escolhidos três trabalhos brasileiros, entre os já selecionados para análise de conteúdo quanto à escolha da população, tamanho da amostra e técnica de amostragem, para servir de ilustração. Os trabalhos selecionados obedeceram ao seguinte requisito representativo: um para os parques, outro para recreação em rios, praias, e balneário e um terceiro para os demais locais. Os trabalhos elegidos foram: Valoração do Parque Estadual de Itaúnas (ES), de Gazoni et al. (2006); Valoração econômica do litoral de Ilhéus (BA), de Freire, Guimarães Junior e Rodrigues (2005); e o trabalho de Mendonça et al. (2012) sobre a Valoração econômica do Jardim Botânico da Fundação Zoo-Botânica de Belo Horizonte (MG).

O trabalho de Gazoni et al. (2006) estimou o valor econômico do uso recreativo do Parque Estadual de Itaúnas (ES) por intermédio de uma abordagem psicográfica ${ }^{35}$ do MCV. A amostra contou com 311 questionários aplicados no interior do parque, de uma população anual de 32.240 indivíduos. Os resultados da pesquisa demostraram que o valor econômico total da utilidade recreativa do parque foi estimado em US\$52milhões/ano. No estudo de Gazoni et al. (2006) não há explicação sobre os caminhos percorridos para se chegar ao tamanho da amostra, nem há relatos sobre a técnica de amostragem selecionada. Também não há explicação sobre quantos e quais os dias foram escolhidos para seleção da amostra, em que época foi colhida a amostra - se alta ou baixa temporada, se ao longo de todo ano.

O trabalho de Freire, Guimarães Junior e Rodrigues (2005) teve por objetivo estimar a função demanda por turismo das praias no município de Ilhéus (BA), bem como o seu valor recreacional. Foram aplicados 270 questionários (um questionário por família) e validados somente 238, porque 32 questionários não apresentaram consistência para estimar a função demanda. O questionário foi aplicado no período de 28 de janeiro a 02 de fevereiro de 2004, na alta temporada local. A aplicação foi nas praias, numa extensão de $93 \mathrm{~km}$. O processo escolhido para a coleta de dados foi o não probabilístico simples, critério de exaustão ${ }^{36}$. Os valores encontrados foram de US\$151,71 por turista/dia. O valor do turismo por quilômetro de praia foi US\$ 1,68 por turista/dia.

O texto de Freire, Guimarães Junior e Rodrigues (2005) não revela como se chegou ao tamanho de uma amostra de 270; não há menção à população; também não é possível inferir se

\footnotetext{
${ }^{35}$ No verso do questionário aplicado por Gazoni et al (2006) tinha ilustrações do perfil psicográfico de turistas. Os pesquisados se auto classificaram segundo três características: Alocentricos, mesocentricos e psicocêntricos. O Objetivo era verificar qual dos perfis demandava mais transformações agressivas ao meio ambiente.

${ }^{36}$ São incluídos todos os indivíduos disponíveis.
} 
a retirada de 32 questionários interferiu no valor econômico calculado, se o valor ficou subestimado ou não. Outro problema encontrado diz respeito à busca por dados em somente uma época do ano; também não há referência de como se percorreu os $93 \mathrm{~km}$ na busca por respondentes ao questionário, ou se o questionário foi aplicado somente em uma praia, a mais frequentada por turistas. Isso impossibilitou conhecer o tipo de amostragem, apesar de o estudo explicar que foi por exaustão de dados.

Mendonça et al. (2012) estimaram valor econômico anual dos serviços ecossistêmicos prestados pelo Jardim Botânico da Fundação Zoo-Botânica de Belo Horizonte (MG) - JB/FZBBH. A população estimada de visitação é de 1.500 .000 pessoas ao ano. Os meses escolhidos foram de julho e agosto de 2011, de terça a domingo. Foram escolhidos dois pontos de visitação longe dos portões. A amostra foi composta por 645 indivíduos. O custo de viagem médio foi de US $\$ 27,71$, resultando num total anual de US\$56.797.784,77 para a função linear, US\$114,22 para o custo médio e US\$ 53.620.802,97anuais quando usada a função lin-log.

As explicações de Mendonça et al. (2012) para as entrevistas foram: a amostra deveria ser colhida em dois pontos bem distintos no site, um no início e outro no final. Coleta dos dados se deu em todos os dias da semana em que o JB/FZB-BH estivesse aberto para evitar viés de seleção. Foram descartados 84 questionários (13,02\% da amostra) por causa de informações insuficientes e da ocorrência de valores extremos (outliers) que poderiam limitar as estimativas. Pode-se inferir que o erro padrão foi menos de 5\%, que daria uma amostra de 400 indivíduos. Como foram entrevistados 645 e descartados 84, restaram ainda 561, número bem acima do mínimo no cálculo de uma amostra estatisticamente correta. Quanto à escolha dos indivíduos nada foi relatado.

\subsubsection{Instrumento da pesquisa}

Existe um consenso entre economistas de que as questões levantadas para a coleta de dados do Método Valoração Contingente também se aplicam ao MCV (PHANENEUF; SMITH, 2004). Partindo dessa premissa, serão avaliadas, nos três artigos, as questões que compõem o questionário e suas limitações. Na visão de Parsons (2003), o questionário deveria ser dividido em quatro partes: a) material introdutório, b) questões sobre a viagem, c) questões sobre outros passeios, d) questões socioeconômicas da família.

Gazoni et al. (2006) dividiram em quatro blocos o instrumento de pesquisa: identificação das origens, características socioeconômicas, perfil psicográfico e aspectos da viagem, incluindo a discriminação dos gastos. No primeiro bloco, descobriram que os 
visitantes, na sua maioria, vinham de MG, ES, SP, RJ, DF e BA, e uma pequena demanda de origem internacional. Para as características socioeconômicas, selecionaram renda, idade, anos de estudo. No terceiro, deram evidência para motivações da visita, sugestões de melhorias no local. No último bloco estão os gastos com deslocamento, custo de oportunidade do tempo e gastos totais com a viagem, dias de permanência, quantidade de vagens ao local.

Observa-se nos resultados apresentados no artigo que os turistas que realizam maiores gastos, tendem a realizar visitas com maiores frequências, porém permanecem por períodos menores. Nada é comentado sobre o transporte e a distância entre os locais de destino. Também não são feitos comentários sobre relações entre idade, renda e anos de estudo, apesar de haver uma equação de regressão linear por logaritmos. Há um amplo comentário, em percentuais, sobre o desejo de melhorias locais. Quanto aos gastos totais, apresenta-se em uma tabela dividindo-os em gastos realizados em Itaúnas, gastos com deslocamentos, gastos de oportunidade do tempo (que é calculado por meio da estimativa de renda/hora do visitante, que é relacionada com as horas totais da viagem (deslocamento e permanência) (GAZONI et al., 2006, p. 16, em nota de rodapé). Esse é o único gasto com explicação explicita.

Freire, Guimarães Junior e Rodrigues (2005) apresentam como variáveis independentes custos de viagem, custo de transporte, renda familiar, idade, sexo, grau de escolaridade, e tempo de permanência para estimar a equação de demanda. Outras variáveis qualitativas (dammies) também são mencionadas: se a viagem foi organizada por agência de viagens, casado, viaja sozinho, motivo da viagem recreio/lazer, visita a parentes/amigos. Os problemas apresentados quanto ao modelo de regressão foram: o sinal da variável composição do grupo não está de acordo com o esperado e o sinal da variável escolaridade não está de acordo com a literatura econômica. As variáveis sexo, estado civil e número de visitas a Ilhéus não influenciaram significativamente os resultados. Os autores optaram por valores ponderados das variáveis e procederam aos cálculos para a valoração.

As estimativas dos parâmetros da função demanda por turismo foram expressas em uma tabela, através dos coeficientes de regressão e teste $t$ de Student. Nada foi comentado quanto aos problemas apresentados. Não é citado o modelo de demanda, individual ou zonal. Os pesquisadores sugerem ao final que sejam feitos outros trabalhos com emprego de outras metodologias e que o trabalho não pode ser utilizado para projetar demanda anual porque foi usado somente um período de alta estação.

Mendonça et al. (2012) apresentam como questões avaliativas do modelo: sexo, origem dos entrevistados, escolaridade, frequência da vista ao local, motivos da vista, meio de transporte utilizado, tempo médio de viagem, tempo de permanência dentro do sítio em análise, 
renda média mensal. O modelo utilizado foi o de demanda individual. Os coeficientes se mostraram estatisticamente significantes. Houve restrição aos múltiplos destinos pela dificuldade encontrada de se entrevistar o público que apenas visitaram o JB/FZB-BH, em razão de não haver separação formal entre as diversas atrações e também pela proximidade das atrações e tendência natural do público em visitar várias áreas dento do complexo. E isso pode ter superestimado os valores. Outro problema encontrado se refere aos visitantes moradores da região metropolitana de Belo Horizonte.

\subsubsection{Relatórios dos estudos pelo MCV e a validade de conteúdo}

Os relatórios precisam ser bem detalhados porque, segundo Hanley e Spash (1993), a avaliação dos dados obtidos numa pesquisa com o uso MCV deveria ser aplicável a qualquer outro método.

Os relatórios dos resultados das pesquisas brasileiras que usam o $\mathrm{MCV}$ são diversificados e, em muitos casos, não permitem a avaliação da validade dos conteúdos. Os três relatórios de estudos escolhidos são avaliados segundo os itens comentados no texto de Boyle (2003), com adaptações. Esse quadro também foi utilizado no MVC porque muitos estudos apresentam o confronto entre as técnicas, portanto relatórios similares. Foi usado o seguinte código: Item Completo (IC), Item Incompleto (IIC), e Item Não Realizado (INR). Os estudos estão assim divididos: Estudo 1 - MCV 1; Estudo 2 - MCV 2; Estudo 3 - MCV 3 (ver Apêndice $\mathrm{B}$ quadro $\left.\mathrm{B}_{3}\right)$.

Como pode ser observado no Quadro 4.3, o relatório apresentado por MCV 3 foi o que mais se aproximou do ideal, por contemplar o maior número de itens. Uma pesquisa com itens incompletos ou não apresentados, como o item do quadro amostral, não inspira confiabilidade da pesquisa. O leitor não poderá verificar se a inferência estatística dos resultados procede.

A taxa de respostas precisa ser apresentada e estar completa. O não cumprimento desse item traz prejuízos ao se confrontar e relacionar as respostas. Se a taxa for alta, significa que uma grande quantidade de respondentes está de acordo ou não com uma determinada resposta, e uma pequena taxa às vezes retira o item do lugar de importância dado pelo pesquisador. 
Quadro 4.3 - Avaliação de relatório de estudos brasileiros

\begin{tabular}{|c|c|c|c|c|c|c|c|c|c|}
\hline \multirow{2}{*}{ Itens } & \multicolumn{3}{|c|}{ Estudo 1} & \multicolumn{3}{|c|}{ Estudo 2} & \multicolumn{3}{|c|}{ Estudo 3} \\
\hline & IC & IIC & INR & IC & IIC & $\begin{array}{c}\text { IN } \\
\mathrm{R}\end{array}$ & $\mathrm{IC}$ & IIC & INR \\
\hline A aplicação do estudo & $\mathbf{X}$ & & & $\mathbf{X}$ & & & $\mathbf{X}$ & & \\
\hline A definiç̧ão teórica do valor & & $\mathbf{X}$ & & & $\mathbf{X}$ & & $\mathbf{X}$ & & \\
\hline O quadro amostral & & & $\mathbf{X}$ & & $\mathbf{X}$ & & & $\mathbf{X}$ & \\
\hline $\begin{array}{l}\text { Modo de pesquisa e taxas de } \\
\text { respostas }\end{array}$ & & $\mathbf{X}$ & & $\mathbf{X}$ & & & $\mathbf{X}$ & & \\
\hline $\begin{array}{l}\text { Descrição dado ativo a ser } \\
\text { valorado. }\end{array}$ & $\mathbf{X}$ & & & $\mathbf{X}$ & & & $\mathbf{X}$ & & \\
\hline $\begin{array}{l}\text { O formato de avaliação por custo } \\
\text { de viagem utilizado }\end{array}$ & & $\mathbf{X}$ & & & $\mathbf{X}$ & & $\mathbf{X}$ & & \\
\hline $\begin{array}{l}\text { Características sociodemográficas } \\
\text { dos respondentes e uso do } \\
\text { recurso. }\end{array}$ & & $\mathbf{X}$ & & & $\mathbf{X}$ & & $\mathbf{X}$ & & \\
\hline $\begin{array}{l}\text { Método de análise de dados, } \\
\text { incluindo a equação de estimação }\end{array}$ & $\mathbf{X}$ & & & $\mathbf{X}$ & & & $\mathbf{X}$ & & \\
\hline $\begin{array}{l}\text { Estimativas de tendência central e } \\
\text { dispersão dos dados e métodos } \\
\text { utilizados para o cálculo do valor } \\
\text { do bem }\end{array}$ & $\mathbf{X}$ & & & $\mathbf{X}$ & & & $\mathbf{X}$ & & \\
\hline Total & $4 / 9$ & $4 / 9$ & $1 / 9$ & $5 / 9$ & $4 / 9$ & $0 / 9$ & $8 / 9$ & $1 / 9$ & $0 / 9$ \\
\hline
\end{tabular}

Fonte: Quadro elaborado pela própria autora (2014)

O formato da avaliação por custo de viagem utilizado pelo pesquisador deve ser claro e preciso. Numa ação cientifica/judicial é preciso informar como foram realizados os cálculos para que se possa proceder a conferencia dos dados.

Um checklist é sugerido no Quadro 4.4. O checklist deve ser adaptado ao relatório. Deve ser proposto somente com a finalidade de não faltar informações ao leitor e dar maior confiabilidade à pesquisa; não deve ser uma norma. Na seção seguinte são apresentados comentários conclusivos acerca dos trabalhos avaliados. 
Quadro 4.4 - Sugestões de checklist detalhado para um relatório de pesquisa com o uso de MCV.

\begin{tabular}{|c|c|c|c|}
\hline 1 & \multicolumn{3}{|l|}{ Aplicação do Estudo } \\
\hline 2 & \multicolumn{3}{|l|}{ Definição teórica do valor } \\
\hline \multirow{4}{*}{3} & \multirow{4}{*}{ Quadro amostral } & \multicolumn{2}{|l|}{ População } \\
\hline & & \multicolumn{2}{|l|}{ Amostra } \\
\hline & & \multicolumn{2}{|l|}{ Amostragem } \\
\hline & & \multicolumn{2}{|l|}{ Fórmula usada } \\
\hline \multirow{4}{*}{4} & \multirow{4}{*}{ Coleta de dados } & \multicolumn{2}{|l|}{ On site ou off site } \\
\hline & & \multicolumn{2}{|l|}{ Local da coleta } \\
\hline & & \multicolumn{2}{|l|}{ Individual ou zonal } \\
\hline & & \multicolumn{2}{|l|}{ Período da coleta } \\
\hline 5 & \multicolumn{3}{|l|}{ Pré-teste } \\
\hline \multirow{6}{*}{6} & \multirow{6}{*}{ Custos com a viagem } & \multirow{3}{*}{ Tipo de transporte } & Gastos com passagens \\
\hline & & & $\begin{array}{l}\text { Depreciação com o } \\
\text { veículo }\end{array}$ \\
\hline & & & $\begin{array}{l}\text { Gastos com } \\
\text { combustíveis }\end{array}$ \\
\hline & & \multicolumn{2}{|c|}{ Custo de oportunidade do tempo } \\
\hline & & \multicolumn{2}{|c|}{ Custo da alimentação } \\
\hline & & \multicolumn{2}{|l|}{ Suvenir } \\
\hline \multirow{2}{*}{7} & \multirow{2}{*}{ Destino da viagem } & \multicolumn{2}{|l|}{ Único } \\
\hline & & \multicolumn{2}{|l|}{ Múltiplos } \\
\hline \multirow{3}{*}{8} & \multirow{3}{*}{ Formato de avaliação utilizado } & \multicolumn{2}{|c|}{ Informações dos entrevistados } \\
\hline & & \multicolumn{2}{|c|}{ Informações auxiliares } \\
\hline & & \multicolumn{2}{|c|}{ Informações de fronteira } \\
\hline 9 & \multicolumn{3}{|c|}{$\begin{array}{l}\text { Caracterização sociodemográficas dos inquiridos e uso do recurso- frequência das } \\
\text { visitas, tipo de lazer }\end{array}$} \\
\hline \multirow{2}{*}{10} & \multirow{2}{*}{ Método de Análise de dados } & \multicolumn{2}{|c|}{ Método estatístico utilizado } \\
\hline & & Equação de estima & \\
\hline 11 & Estimativas de tendência central e di & ão dos dados & \\
\hline 12 & Método do cálculo do valor econômi & & \\
\hline
\end{tabular}

Fonte: Quadro elaborado pela própria autora (2014) 


\subsection{CONCLUSÕES}

Foram observados, nos trabalhos realizados no Brasil, diversos problemas na aplicação do Método Custos de Viagem. Entre eles, podem ser citados:

a) Grande variação nos resultados obtidos para valoração de um mesmo bem ambiental. A variação vai sempre existir porque é quase impossível repetir o survey com a mesma amostra, porém o que não deveria ocorrer é uma grande variação, como a que ocorreu nos trabalhos que valoraram o Parque Nacional de Brasília. Essa variação foi analisada por Aiache (2003).

b) Alguns locais que foram valorados coexistiam inevitavelmente com mais de um destino, mas estes foram ignorados no tratamento dos dados para o cálculo da equação de demanda, que deveria ser uma para cada destino ou ter os custos de viagens proporcionalmente divididos pela distância do local de lazer.

c) Problemas com a definição de custo de oportunidade do tempo e amostras não representativas também ocorreram nos trabalhos realizados no Brasil. Alguns trabalhos não apresentam teste de validade do construto e convergência, excetuando, é claro, aqueles que estavam sendo aplicados pela primeira vez. Entretanto, seriam necessárias comparações com outros trabalhos da mesma magnitude.

d) Outro problema é a data (momento) da coleta de dados. Alguns estudos usaram somente o período de alta temporada, o que pode ter superestimado o valor. Outros usaram períodos de baixa temporada, o que subestimou o valor. A sugestão é que o período de coleta seja de um ano para abranger diferentes períodos e estimar um valor mais fidedigno.

A aplicação do método sofre influência dos objetivos traçados pelos pesquisadores. Isso é inconteste, porém os objetivos em cada pesquisa devem ser bem claros para que possa servir para validar outros estudos. Muitos pesquisadores não são categóricos ao afirmarem sobre o valor estimado em suas pesquisas. Isso ocorre porque houve variações nos dados quanto ao tratamento dispensado ao método ou porque as peculiaridades enfrentadas em cada local de pesquisa foram difíceis de serem contornados.

É importante que a informação prestada sobre o valor do ativo ambiental reflita a realidade do ambiente natural analisado, para que os gestores públicos, de posse da informação, possam tomar decisões com vistas a promover bens e serviços que aumentem o bem-estar das 
pessoas. Por isso um survey elaborado com cuidado, uma amostra representativa e teste de hipóteses adequados do questionário, bem como minimização dos vieses inerentes do método, se fazem necessários.

Um problema observado em todo Brasil diz respeito à quantidade de Instituições de Ensino Superior (IES) que se dedicam a pesquisa. Menos de 10 IES trabalham sistematicamente com a área ambiental. Dentre elas, poucas se preocupam em trabalhar com valoração ambiental, menos ainda com o Método Custos de Viagem. Um método para ser aperfeiçoado requer tempo, dedicação à pesquisa e aplicação contínua. 


\section{CAPÍtULO 5 \\ O PRAZER, A ESCOLHA, O CONSUMO E A QUALIDADE DE VIDA: O MÉTODO DOS PREÇOS HEDÔNICOS}

\subsection{INTRODUÇÃO}

O método de precificação hedônica (MPH) é usado para estimar valores econômicos debens, serviços ou ativos ambientais que são afetados diretamente pelos preços de mercados de bens complementares. Ele pode ser usado para estimar os benefícios econômicos ou os custos associados com a qualidade ambiental ou amenidades do meio ambiente. Embora o MPH possa ser usado para cálculo de valor para bens ambientais, ele não captura o valor econômico total, somente o valor de uso direto e, em algumas situações, certos componentes do valor de usos indiretos. Por meio do MPH podemos obter apenas o valor de amenidades e nunca o componente de não uso (existência) do VET.

O MPH, também denominado método de preço implícito, constitui-se num dos métodos de valoração econômica mais antigos. A data de referência é 1928, quando Waugh (1928) publicou sobre fatores qualitativos que influenciam os preços dos vegetais, apresentando como referência a cor, o tamanho da haste e uniformidade dos brotos de aspargos em Boston $^{37}$. Seu objetivo era informar aos produtores o valor que os consumidores davam ao produto. Já Court (1941) notou que os preços hedônicos poderiam ser usados para melhorar as construções de índices de preços. Griliches (1961), dando continuidade aos estudos de Court, efetuou regressões similares, com o objetivo de descobrir as preferências dos consumidores referentes aos vários opcionais disponíveis em automóveis. Somente em 1967, Ridkere Henming perceberam a possibilidade de estimar o impacto das alterações do ambiente nos valores de propriedades residenciais ${ }^{38}$.

Em 1966, Lancaster propôs uma nova abordagem, na qual os bens são valorizados de acordo com os atributos que carregam. O autor explicita que a curva de utilidade pode se defrontar com o consumo de um bem diferenciado. Mas foi Rosen (1974) quem, pela primeira

\footnotetext{
${ }^{37}$ Este parágrafo é fortemente baseado no texto de Freeman III (1993).

${ }^{38}$ Amazonas (2010, p. 67) cita em seu trabalho que Taylor, em 1916, foi um dos precursores no uso do método. Ele estudou a dispersão da qualidade sobre o mercado de algodão e as diferenças de preços relacionadas, mas não estabeleceu ligações entre essas diferenças e as características do algodão dentro da análise estatística.
} 
vez, colocou os modelos hedônicos em um contexto de mercado, relacionando a função hedônica à função utilidade e à função de produção, e determinando as condições sob as quais o modelo pode ser identificado e estimado. Em 1976, Laad e Suannunt modificam a ideia de qualidade do produto para qualidade por características dos produtos (HANLEY; SPASH, 1993).

Este capítulo está dividido em três partes, além desta introdução e da conclusão. A primeira (seção 5.2) apresenta as características conceituais e operacionais básicas, os percalços e as proficuidades do MPH. Na seção (5.3), destaca-se o emprego do método. Inicialmente apresentamos algumas aplicações recentes em diferentes países. Em seguida, é apresentado um levantamento mais abrangente sobre as aplicações no Brasil. Aqui realizamos um levantamento histórico das aplicações do MPH a partir dos anos de 1987 quando se intensificou o uso do método com variáveis ambientais ao modelo e ressaltamos as mais recentes, com ênfase nos objetivos dos exercícios de valoração realizados A ênfase foi dada nos seguintes aspectos: locais de abrangência, instituições responsáveis, variáveis ambientais incluídas ao modelo e tipos de ajustes econométricos utilizados. A terceira seção (5.4) analisa o tratamento dado pelos estudos brasileiros com MPH em termos de três aspectos considerados cruciais para a confiabilidade dos valores estimados com a sua aplicação. Os três aspectos aqui destacados são: a) a seleção de uma amostra; b) a caracterização do objeto valorado; e c) o relatório de pesquisa e a validade de conteúdo.

\subsection{CARACTERÍSTICAS, PERCALÇOS E PROFICUIDADES DO MPH}

O MPH baseia-se na identificação de atributos ambientais que podem ser capturados no preço de mercado de um bem composto privado. Requer o estabelecimento de uma relação, denominada de função de preços hedônicos, entre o conjunto de atributos que compõem o bem privado analisado e seu respectivo preço de mercado. Esse método captura os valores de uso direto, indireto e de opção. E pode fornecer boas estimativas se a característica de interesse for de fácil percepção (PEARCE; TUNER, 1990). É, assim, um método de avaliação de preferência revelada, que usa mercado substituto para precificar bens ambientais.

O mercado imobiliário é o substituto mais comumente usado, dependendo de informações fornecidas pelas famílias quando fazem suas decisões de localização. As pessoas sentem prazer em viver em bons lugares. Quando a demanda por terra e habitação aumenta, o 
preço da habitação aumenta. Os preços das habitações mais elevados revelam o quanto as pessoas estão dispostas a pagar pelas amenidades em lugares agradáveis (GUNDMEDA, 2005).

Existem duas fases bem distintas para aplicação do MPH em que devem ser respondidas duas questões: a) Quais as principais características do produto valorado? (Resposta para a fase 1). b) Qual a forma matemática da relação preço atributo que melhor se adequa? (Resposta para a fase 2). Na primeira fase, é necessário coletar os dados sobre o mercado de imóveis por um período de tempo e estabelecer quais as características serão mais apropriadas. ${ }^{39} \mathrm{Na}$ segunda fase, é feita avaliação estatística, através de uma regressão de Mínimos Quadrados Ordinários (MQO), e deve-se gerar uma função preço hedônica. Supõe-se que a utilidade de cada indivíduo seja uma função das quantidades consumidas de um conjunto de bens, e que exista um vetor de características, que inclui todos os atributos da casa e de sua vizinhança. Como a teoria trata de estabelecer os valores das características para o comprador, não é necessário modelar o lado da oferta. Contudo pressupõe-se que o mercado está em equilíbrio (FREEMAN III, 1993).

No Quadro 5.1, estão apresentadas as aplicações do MPH que podem ser categorizadas em três pontos, segundo Gundimeda (2005): 1) Estudos de salários - conforto; 2) Preços das habitações; 3) Avaliação de riscos para a saúde que refletem em diferenças de salários.

Quadro 5.1 - Aplicações do Método do Preço Hedônico (MPH)

\begin{tabular}{|l|l|}
\hline Estudos Salários - conforto & $\begin{array}{l}\text { Usa informações sobre preço dos imóveis } \\
\text { e os salários que as pessoas gastam para } \\
\text { pagar por amenidades ambientais. }\end{array}$ \\
\hline Preços da habitação & $\begin{array}{l}\text { Usa informação sobre os preços dos bens } \\
\text { imobiliários para valorizar as amenidades } \\
\text { ambientais. }\end{array}$ \\
\hline Estudos salariais/ Valor de risco para a & $\begin{array}{l}\text { Usa informações sobre o risco à saúde e a } \\
\text { disposição em pagar para evitá-los. Estas } \\
\text { informações estatísticas são usadas para } \\
\text { "valorizaro risco para a vida". }\end{array}$ \\
\hline
\end{tabular}

Fonte: Quadro adaptado do texto de Gundimeda (2005)

\footnotetext{
${ }^{39}$ No entanto, o número de características não pode ser muito grande, pois quando de análise dos dados com o suo de regressão múltipla pode gerar problemas de multicolinearidade (AGUIERRI, 1997). Detalhes a seguir.
} 


\subsubsection{Escolha das variáveis e finalidades}

O MPH descreve um equilíbrio competitivo em um plano de divisão $n$, no qual comprador e vendedor se alocam. O bem heterogêneo é composto de $n$ características e cada consumidor adquire apenas uma unidade do bem. Freeman III (1993) afirma que as residências correspondem a uma classe de produtos que são diferenciados por características como: estruturais, implantação de políticas públicas e qualidade ambiental. Esses detalhes se encontram registrados no Quadro 5.2, elaborado com base em Freeman III (1979), Gundimeda (2005) e Amazonas (2010).

Quadro 5.2 - Características detalhadas das propriedades residenciais

\begin{tabular}{|c|c|}
\hline Características & Detalhamento \\
\hline Estrutural & $\begin{array}{l}\text { Características estruturais do imóvel: quantidade de } \mathrm{m}^{2} \text {; áreas comuns; } \\
\text { terraço; } \mathrm{n}^{\circ} \text { de quartos, banheiros e cômodos; existência de garagens; } \\
\text { idade do imóvel; jardins; } \mathrm{n}^{\circ} \text { de elevadores; tipo de residência. }\end{array}$ \\
\hline Locais & $\begin{array}{l}\text { Características relacionadas às vizinhanças: existência de comércio; } \\
\text { quantidade e qualidade das escolas; proximidade de centros } \\
\text { comerciais; acesso a serviços públicos; taxa de criminalidade, } \\
\text { desemprego e proporção da composição étnica; acessibilidade às vias } \\
\text { de acesso. }\end{array}$ \\
\hline $\begin{array}{l}\text { Qualidade } \\
\text { Ambiental }\end{array}$ & $\begin{array}{l}\text { Vetor de características ambientais adjacentes ao imóvel: qualidade do } \\
\text { ar e da água; nível de ruídos; proximidade de áreas verdes e sítios } \\
\text { naturais; proximidade de rio, lago ou mar. }\end{array}$ \\
\hline
\end{tabular}

Fonte: Freeman III (1979), Gundimeda (2005) e Amazonas (2010)

O número e a quantidade de variáveis arroladas dependem de cada pesquisa. O importante é que sejam relevantes e em número finito. Também é importante que possam separar os efeitos dos vários atributos de um bem, de maneira que ao mudar seu nível afete a utilidade individual (GARROD; WILLIS, 1999). 


\subsubsection{A função de preços hedônicos e os problemas econométricos}

Em geral, a forma funcional da equação de preços hedônicos é desconhecida, e a escolha torna-se um aspecto importante de investigação da pesquisa. Deve-se buscar aquela que produz o melhor ajuste a partir de uma regressão entre os preços dos imóveis observados e as caraterísticas desses imóveis. A escolha é arbitrária e podem ser lineares e não lineares (ver Quadro 5.3). As mais utilizadas são: linear, exponencial, potência, logarítmica, recíproca, quadrática, logística e de interação, segundo Angelo, Fouto e Lupee (2008).

Quadro 5.3 - Formas funcionais mais frequentes

\begin{tabular}{|c|c|c|c|}
\hline \multirow{9}{*}{ 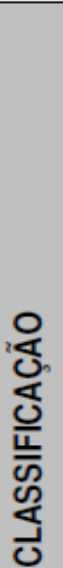 } & \multirow[b]{2}{*}{ 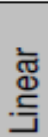 } & Função & Forma Funcional \\
\hline & & Linear & $p=\beta_{0}+\sum \beta_{k} x_{k}$ \\
\hline & \multirow{7}{*}{ 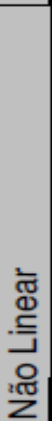 } & Exponencial & $\mathrm{p}=\beta_{0} \mathrm{II} \exp \left(\beta_{\mathrm{k}} \mathrm{x}_{\mathrm{k}}\right)$ \\
\hline & & Potência & $\mathrm{p}=\beta_{0} \mathrm{II}\left(\mathrm{x}_{\mathrm{k}}\right)_{\mathrm{k}}$ \\
\hline & & Logarítmica & $\mathrm{p}=\beta_{0}+\sum \beta_{\mathrm{k}} \ln \mathrm{x}_{\mathrm{k}}$ \\
\hline & & Recíproca & $\mathrm{p}=\beta_{0}+\sum \beta_{\mathrm{k}}\left(1 / \mathrm{x}_{\mathrm{k}}\right)$ \\
\hline & & Quadrática & $\mathrm{p}=\beta_{0}+\sum \beta_{\mathrm{k}} \mathrm{x}_{\mathrm{k}}+\sum \beta_{\mathrm{k}+1} \mathrm{x}_{\mathrm{k}}{ }^{2}$ \\
\hline & & Logística & $\ln [p / 1-p]=\beta_{0}+\sum \beta_{k} x_{k}$ \\
\hline & & Interação & $\mathrm{p}=\beta_{0}+\sum \beta_{\mathrm{k}} \mathrm{x}_{\mathrm{k}}+\sum \beta_{\mathrm{k}+1} \mathrm{x}_{\mathrm{k}} \mathrm{z}$ \\
\hline
\end{tabular}

Fonte: Amazonas (2010), baseado em Angelo, Fouto e Lupee (2008)

Essas formas funcionais de regressões frequentemente esbarram no problema de multicolinearidade e autocorrelação espacial dos resíduos. Haab e McConnel (2003) citam também outros problemas econométricos que surgem quando se inclui um atributo único de uma instalação de poluentes, mas se excluem outros atributos relevantes, o que torna menos pronunciado os efeitos da poluição.

A partir da década de 1980, alguns trabalhos adotaram a transformação Box-Cox. Sua principal vantagem consiste em permitir que os dados revelem a melhor forma funcional, definida pelos parâmetros de transformação estimados através da máxima verossimilhança. Os resíduos gerados são homocedásticos e simétricos (ANDERSSON, 1997). Entretanto o método se revela incapaz de atestar consistentemente a significância dos coeficientes estimados. Outra desvantagem é gerar resultados não intuitivos (BOWEN et al., 2001), pois se se adotar uma forma linear, o preço hedônico marginal passa ser uma constante. 
As análises dos dados, depois de gerados os resultados econométricas, podem ser feitas de duas formas: diagonal ou temporal. Na análise diagonal, considera-se determinado número de imóveis em um tempo determinado e, na análise diagonal temporal, estuda-se como varia o preço de determinado imóvel, ao variar a qualidade de algum atributo ambiental nas áreas adjacentes ao imóvel (OYARZUN, 1997). A estimativa da curva de demanda (Ver capítulo 2) pelo recurso ambiental é dada pelo emprego dos preços marginais, calculados a partir da função hedônica, em uma estimativa da função de disposição marginal a pagar (HANLEY; SPASH, 1993).

\subsubsection{Limitações e vieses relevantes}

Em teoria, o MPH pode ser aplicado a qualquer bem composto privado, cujos atributos sejam complementares a bens ou serviços ambientais. Porém, na prática, a sua aplicação mais comum e frequente tem sido na valoração econômica de atributos ambientais com base na variação de preços dos bens imóveis e de salários. Essa é uma técnica amplamente aceita principalmente porque o modelo combina decisões discretas e contínuas, (PALMQUIST, 2005).

Para Motta (1998, p. 39), o método é recomendável somente nos seguintes casos: a) quando existir alta correlação entre a variável ambiental e preço da propriedade; b) quando for possível avaliar se todos os atributos que influenciam o preço de equilíbrio no mercado de propriedades que, em análise, podem ser captados; e c) quando as hipóteses adotadas para o cálculo do excedente do consumidor podem ser realistas.

Um dos primeiros problemas enfrentados por pesquisadores é a escolha das variáveis independentes. Isso porque, no processo de seleção, pode ocorrer tanto multicolinearidade quanto omissão de variáveis que podem influenciar nos coeficientes e produzir estimativas imprecisas (PEARCE; TURNER, 1990).

Outros problemas que deverão ser enfrentados são: a) quanto à composição da amostra - as pessoas escolhidas podem não ter informações claras a respeito do que lhes é perguntado e vieses de resposta levam a subestimar os valores; b) implicações inerentes ao modelo econométrico relacionado com a heterocedasticidade, autocorrelação dos erros correlacionados a períodos anteriores, não normalidade (distribuído normalmente em torno da média). Além disso, a forma funcional escolhida, quando inadequada, pode comprometer a consistência e 
eficiência das regressões (PALMQUIST, 2005). No quadro 5.4, pode-se perceber várias outras limitações e vieses do MPH.

Quadro 5.4 - Limitações e vieses do MPH

Capacidade de percepção - Nem sempre, ao expressar a sua disposição a pagar, os indivíduos sabem os benefícios ou custos ambientais plenamente disponíveis.

Assimetria de informação - O método supõe que exista informação plena entre indivíduos para avaliar todas as opções de compra e que exista liberdade de compra das propriedades em todo mercado, o que na realidade não ocorre.

Omissão de variáveis - A qualidade dos dados afeta sensivelmente a qualidade das estimativas.

Problemas econométricos - Nem sempre é fácil identificar a forma funcional que melhor se ajusta aos dados.

Incapacidade - Não captura os valores de não uso ou de existência.

Dificuldade de percepção - Se o atributo ambiental for difícil de perceber, sua alteração não refletirá sua importância no preço hedônico.

Dificuldade de estimação - Dificuldade de diferenciar entre o valor do imóvel e o valor do solo da área, o que afeta a função preço hedônico.

Segmentação do mercado - O mercado pode se segmentar em intervalo de preço, histórico das localidades e composição étnica.

Variação nos modelos de residências - É necessário assumir que existe uma grande variedade de modelos residenciais disponíveis, de tal forma que cada casa está em equilíbrio.

Dificuldades de capturar certos fatores - A influência de outros fatores como mudanças em hábitos de consumo, peculiaridades inerentes a cada tipo de bem numa determinada cesta de bens similares dificilmente serão capturados.

Resultados inconclusivos - A equação estimada tem o potencial de apresentar coeficientes e sinais mistos.

Multicolinearidade - As variáveis independes inclusas na equação de preços hedônicos, podem estar intimamente relacionadas umas com as outras.

Características esperadas - Os atuais níveis de qualidade ambiental assumidos podem influenciar os preços das casas, mas o inverso também pode ocorrer.

Estimativas tendenciosas - Quando se quer evitar ou reduzir riscos, com informações de baixa qualidade.

Vinculação - Dependência no uso de base de dados detalhados.

Mobilidade - Na ausência de mobilidade e com custos de transação proibitivos, as pessoas não têm o poder de eleição e os preços dos bens de mercado não refletem a mudança produzida.

Fonte: Pearce e Turner (1995), Oyarzun (1997), Hanley e Spash (1999), Lezcano (2004), Palmquist (2005) e Riviera (2007) 


\subsection{APLICAÇÕES DO MPH: HISTÓRICO E ESTUDOS RECENTES}

\subsubsection{Estudos recentes do MPH: as publicações estrangeiras}

Muitos estudos ajudaram a aperfeiçoar o MPH. Entre eles estão: Brown e Rosen (1982), Epple (1987) e Bartik (1987). Esses apontaram problemas nas estimativas da curva de oferta e na curva de demanda quando se usavam o modelo de equações simultâneas. O grande problema reside quando se utiliza o preço implícito de cada atributo como variável dependente e as caraterísticas dos bens dos consumidores e/ou dos produtores como variáveis independentes. A grande ajuda encontrada para resolver esses problemas veio das sugestões de se usar o locus do mercado coletado de maneira segmentada e do fato de que as preferências dos consumidores deveriam permanecer constantes. Palmquist (1984) estimou a demanda por atributos e imóveis para sete cidades norte-americanas e considerou cada atributo um mercado distinto, resolvendo a contenda.

Entre a metade dos anos 1970 a 1980, um boom de trabalhos foi apresentado à comunidade científica sobre valoração monetária de non-market - não transacionados no mercado - tendo como variáveis unidades residenciais e as características locacionais ou ambientais. Na experiência norte-americana, há uma variedade de trabalhos que adaptaram o MPH ao contexto do objeto de estudo meio ambiente. Borba (1992) destacou entre eles: a qualidade do ar, nos trabalhos de Anderson e Crocker (1971) e Smith (1978); usina elétrica a carvão, para o texto de Blomquist (1974); usina nuclear, para o escrito de Glamble e Downing (1982); aterro sanitário, nas pesquisas de Tacoma (1986) e Zeiss e Atwater (1989).

$\mathrm{Na}$ Europa, há uma crescente demanda por áreas verdes, embora não haja um conhecimento preciso sobre o papel desempenhado por espaços verdes na qualidade de vida urbana, apesar de que benefícios são reconhecidos sobre a saúde humana, tanto física quanto psicológica. Os custos do fornecimento de florestas urbanas podem ser calculados, mas os benefícios são mais difíceis. Pesquisas quantitativas sobre os espaços verdes urbanos na Europa têm sido limitadas. Até o ano 2000, somente 200 estudos existiam sobre valoração para bens ambientais, com poucos exemplos para valoração usando MPH (TYRVÄINEN; MIETTINEM, 2000). 
A pesquisa de Tyrväinen e Miettinem (2000) procurou preencher essa lacuna avaliando o uso da terra urbana e as amenidades ambientais no distrito de Salo na Finlândia. De acordo com suas estimativas, à medida que as residências se distanciam das florestas urbanas, a cada um km, o preço das casas diminui em 5,9\%. Moradias com vistas para as florestas tem, em média preços $4,9 \%$ mais elevados.

Utilizando o MPH, Hasler et al. (2002) estimaram a disposição a pagar dos proprietários das residências por amenidades ambientais como florestas e vista para lagos na Dinamarca. Como resposta à pesquisa, verificou-se que o valor da residência seria de 13 a $24 \%$ maior que o preço médio de uma habitação que não tem esse atributo. Se a distância aumenta em 1\%, o valor é reduzido em $0,04 \%$.

As amenidades ambientais também foram estimadas por Gibbons, Mourato e Resende (2014) em toda Inglaterra. Foi a maior amostra até hoje. Os autores analisaram um milhão de transações imobiliárias e compararam seus dados com os obtidos em estudos na Grã-Bretanha, Escócia e País de Gales. As variáveis ambientais foram: cobertura do solo, áreas naturais, água doce, pântanos, planícies de inundações, montanhas, pastagens, florestas, jardins residenciais, entre outros. Para casas que tinham jardins, o aumento foi em 1\%; casas próximas aos Parques Nacionais, $4,85 \%$; florestas, $0,12 \%$; com o solo descoberto, o valor caiu em $0,38 \%$; em relação à distância de rios, o valor decresce a cada quilômetro em $0,39 \%$; entre outros resultados.

O cinturão verde de Viena, na Áustria, é responsável pela regulação do microclima, filtragem de ar, retenção de água e sequestro de carbono, contenção da expansão física da área urbana, além da preservação da biodiversidade daquele local. O valor implícito do cinturão verde foi o motivo do estudo de Herath, Choumert e Maier (2014), que foi capitalizado nos preços de apartamentos para a cidade de Viena. A amostra analisada foi de 1.651 apartamentos, nos quais que foram coletados os dados para a formação da equação preço hedônico. O período de coleta foi de dezembro de 2009 a março de 2010. Os pesquisadores utilizaram o modelo semi-log e demostraram que, a cada $1 \%$ de aumento em distância do cinturão, o valor dos apartamentos diminuía em 0,04 a $0,15 \%$. Concluem o trabalho afirmando que amenidades verdes são normalmente examinadas em ambientes não espaciais, e que análise espacial pode validar os resultados de análises não espaciais num contexto empírico ${ }^{40}$.

\footnotetext{
${ }^{40}$ No corpo do trabalho, vários estudos sobre amenidades verdes que impactam positivamente os imóveis são citados. Entre eles estão: Kadish e Netusil (2012), Sander e Haight (2012), Pantit et al. (2013), e Melichar e Kaprova (2013).
} 
Outro estudo que usou o MPH para mercado imobiliário e variáveis ambientais foi o de Cebula (2010). A cidade avaliada é Savannah na Geórgia/EUA. É uma cidade histórica considerada como patrimônio nacional. Na avaliação, o autor buscou saber qual o valor das residências, caso estivessem de frente para parques, praças, lagos. Como resultado, verificou que a casa aumenta em $17 \%$ seu valor, dependendo da distância. Também expôs que, se a casa usa tijolos na construção, esse valor aumenta em $24 \% .{ }^{41}$.

\subsubsection{O MPH e suas aplicações no Brasil}

\subsubsection{Breve histórico no Brasil}

No Brasil, os primeiros trabalhos com o MPH remontam à década de 1980. O pioneiro foi o de Oliveira et al. (1987), publicado na Revista DAE, em São Paulo. Trata-se de um artigo sobre avaliação econômica do programa de esgoto sanitário da região metropolitana de São Paulo (1986), co-financiado pelo Banco Interamericano de Desenvolvimento (BID). Nele destaca-se o MPH como forma indireta de quantificar a disposição a pagar. As variáveis independentes usadas foram: existência de banca de jornal, bares, metrô, igrejas, policiamento na rua, rede pública de esgoto, pavimentação das ruas, gás encanado, telefone residencial, quantidade de banheiros, quartos e sala. No trabalho, não há explicação sobre o método, nem referências a trabalhos sobre o assunto. Contudo, recomenda seu uso para projetos de análise benefício/custo para o setor de saneamento básico.

Uma amostra composta por cinquenta dados de lotes urbanos, situados nos bairros de Casa Forte, Torre e Ipetinga em Recife (PE), foi analisada por Dantas e Cordeiro (1987). Esses lotes eram utilizados pelo extinto Banco Nacional da Habitação (BNH) para avaliação de diversas glebas a serem adquiridas para implantação do Projeto Recife - Programa da Revitalização da Capibaribe - Subprograma Áreas Vazias. Nesse trabalho, os autores fizeram uma regressão hedônica, porém não explicaram nem interpretaram os resultados econômicos. Segundo Aguirre e Faria (1997), o estudo de Dantas e Cordeiro (1987) é o primeiro trabalho brasileiro utilizando o MPH.

\footnotetext{
${ }^{41}$ Nos EUA, existem muitos trabalhos que usam o MPH. Gibbons, Mouro e Resende (2014) citam pelo menos dez trabalhos recentes.
} 
Aguirre e Faria (1997) avaliam, em seu estudo, imóveis relacionados com o estudo de viabilidade econômica do Programa de Canalização de Córregos, Implantação de Vias e Recuperação Ambiental e Social de Fundos de Vales (PROCAV 11), na cidade de São Paulo, elaborado pela prefeitura da cidade no período de 1993 a 1994. A amostra analisada foi de 1.514 casos. O método foi o Box-Cox e a regressão por máxima verossimilhança. A principal variável da regressão hedônica foi se o imóvel sofria inundação, o coeficiente apresentou-se negativo e estatisticamente significante. Concluiu que a medida que os imóveis sofriam inundações, menores seriam os preços dos alugueis. Terminam afirmando que o MPH pode ser usado para avaliar os benefícios associados a projetos de investimentos que visem eliminar as enchentes em áreas urbanas de São Paulo.

Na década de 1990, dez trabalhos foram publicados, sendo três teóricos e sete empíricos. Porém, no que se refere às variáveis ambientais, foram publicados apenas dois. O destaque dessa década recaiu sobre os trabalhos teóricos que vieram para explicitar o assunto e clarificar os passos que deveriam ser seguidos pelos pesquisadores que se aventurassem nesse então novo modelo de valoração. Os trabalhos que inseriram a variável ambiental como requisito de valoração são: Nogueira e Medeiros (1998), Motta (1998), Tavares, Ribeiro e Lanna (1999) ${ }^{42}$.

Uma revisão sobre o MPH é apresentada por Tavares, Ribeiro e Lanna (1999). Eles asseveram que o método era "bastante comum" quando aplicado ao setor imobiliário. Declaram também que o MPH era mais aplicado para avaliar prejuízos ambientais do que benefícios como: proximidade de lixões, barulho de aeroportos, alagamentos. Os pesquisadores apresentam como limitações do método a fragilidade da capacidade de percepção dos indivíduos quanto ao bem estimado, e os requisitos estatísticos usados.

No apêndice C, Quadros C.1 e C.2 estão elencados todos os trabalhos. Em C.1 as produções teóricas e em C.2 os trabalhos empíricos. Serão analisados, nesta pesquisa, somente os trabalhos empíricos, do Brasil, que usaram como variável independente aspectos relacionados ao meio ambiente a partir do ano de 1987. Essa escolha se deu em razão do fato de que, em décadas passadas, pouco ou quase nada foi escrito a esse respeito. No Brasil, diversos trabalhos têm sido escritos usando o MPH, em especial em casos como:

\footnotetext{
${ }^{42}$ No primeiro trabalho, Nogueira e Medeiros (1998) explicam o método e suas limitações, e sugere o uso da função hedônica para cada seguimento de mercado, evitando assim vieses nos resultados. Usaram como referência os trabalhos de Freeman III (1993) e Pearce (1993). O trabalho de Motta (1998) é um manual de valoração em que, ao se reportar ao MPH, conceitua-o, apresentando sua fundamentação teórica, vieses estimativos e recomendações para uso. O trabalho é apresentado para ilustrar um estudo de caso sobre florestas urbanas na GrãBretanha.
} 
comercialização de celulares, veículos automotores, computadores, produção de vinhos, pêssego, taxa de criminalidade, doenças e acidentes de trabalho, prêmios pagos por usar o avião. Além, é claro, do uso específico para o setor imobiliário que evade aos objetivos deste trabalho. No gráfico 5.1 apresenta os trabalhos (teóricos e empíricos) publicados no Brasil com o uso do MPH desde de 1987.

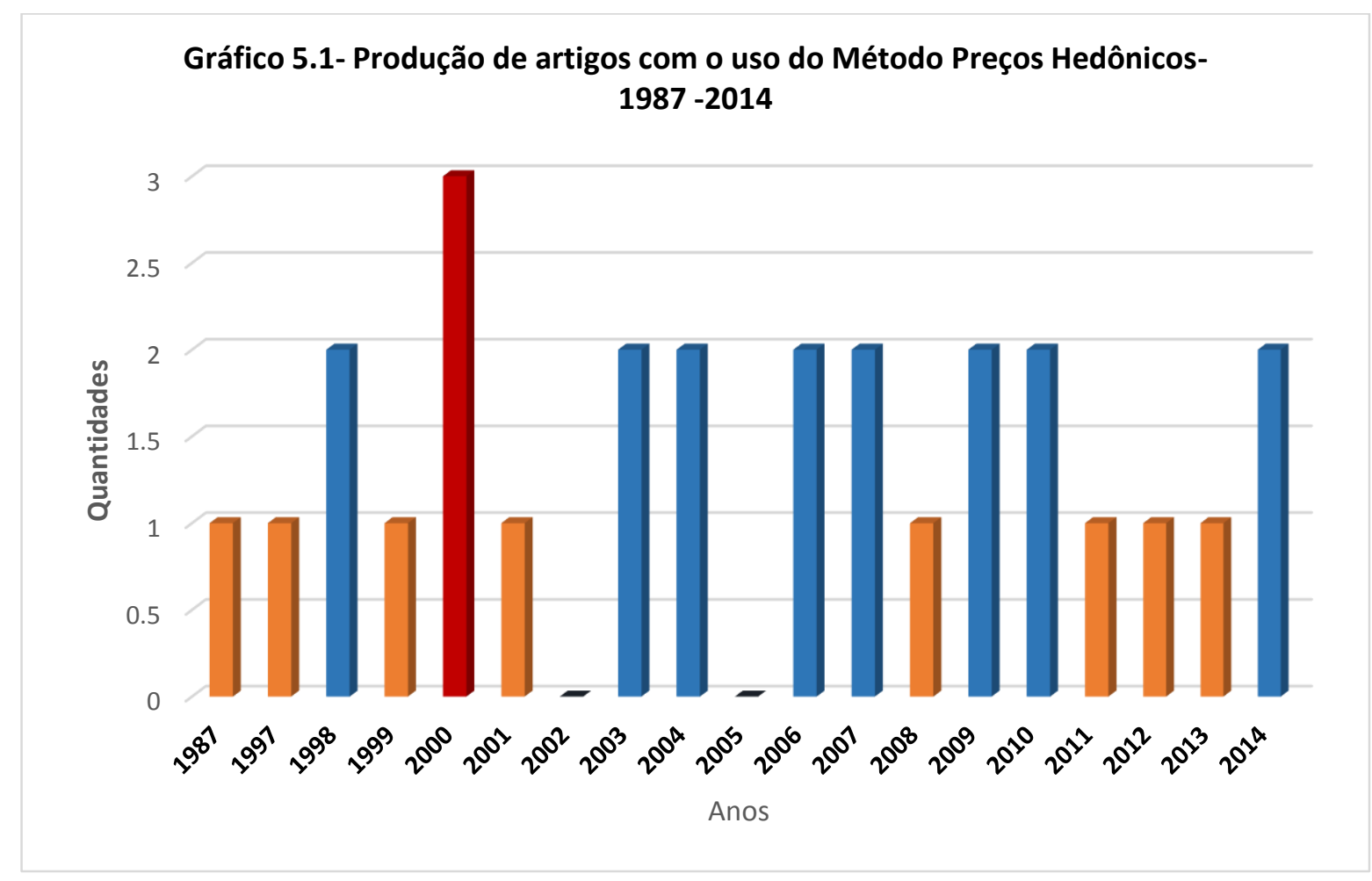

Fonte: Gráfico elaborado pela autora (2015), com base nas informações apresentadas no Apêndice C, tabela C.1

\subsubsection{Locais de abrangência e instituições responsáveis}

No Brasil, textos sobre o MPH começaram a ser escritos há 27 anos. O primeiro trabalho data de 1987. Muitos trabalhos já foram escritos no país, mas não o suficiente para dizer que já dominamos a técnica completamente. Foram encontrados na pesquisa 70 trabalhos.

Os trabalhos teóricos que abordam o método são apenas onze: o trabalho de Nogueira e Medeiros (1998), da UnB; Seroa da Mota (1998), publicado pelo Ministério do Meio Ambiente; Tavares; Ribeiro e Lanna (1999), publicada pela UFPEL; Nogueira; Medeiros e Arruda (2000), da UnB; Eustáchio e Távora Junior (2000), da UFRJ; Negrine Neto (2003), do Instituto de 
Economia Agrícola; Brandli (2006), da Universidade de Passo Fundo; Romeiro e Andrade (2009), da UNICAMP; Falco et al. (2010), da PUC-Rio; Barreto (2012), da UFL; e Miquelito et al. (2014) da UFF. Todos os trabalhos discorrem sobre o assunto rapidamente, exceto os de Nogueira e Medeiros (1998) e Seroa da Mota (1998), já comentados.

Dos trabalhos empíricos elegidos (70), apenas 17 foram selecionados. A seleção teve como base os trabalhos que apresentavam variáveis ambientais entre as qualidades dos vetores adjacentes ao imóvel. Os trabalhos analisados podem assim ser classificados:

a) Saneamento: Oliveira et al. (1987), Aguirre e Faria (1997), Faria et al. (2008);

b) Áres verdes dos imóveis: Batalhone (2000), Hochheim e Uberti (2001), Albuquerque, Melo e Souza (2007), Nascimento (2009).

c) Urbanização: Hermann (2003), Laera (2006), Lezcano (2004), Amazonas (2010), Santarlacci (2013), Rabêlo Neto et al. (2014), Azevedo (2014);

d) Erosão em meio rural: Campos, Cirino e Andrade (2004); e) Transporte público: Andrade e Maia (2007); f) Segurança: Borba (2011), ver gráfico 5.2.

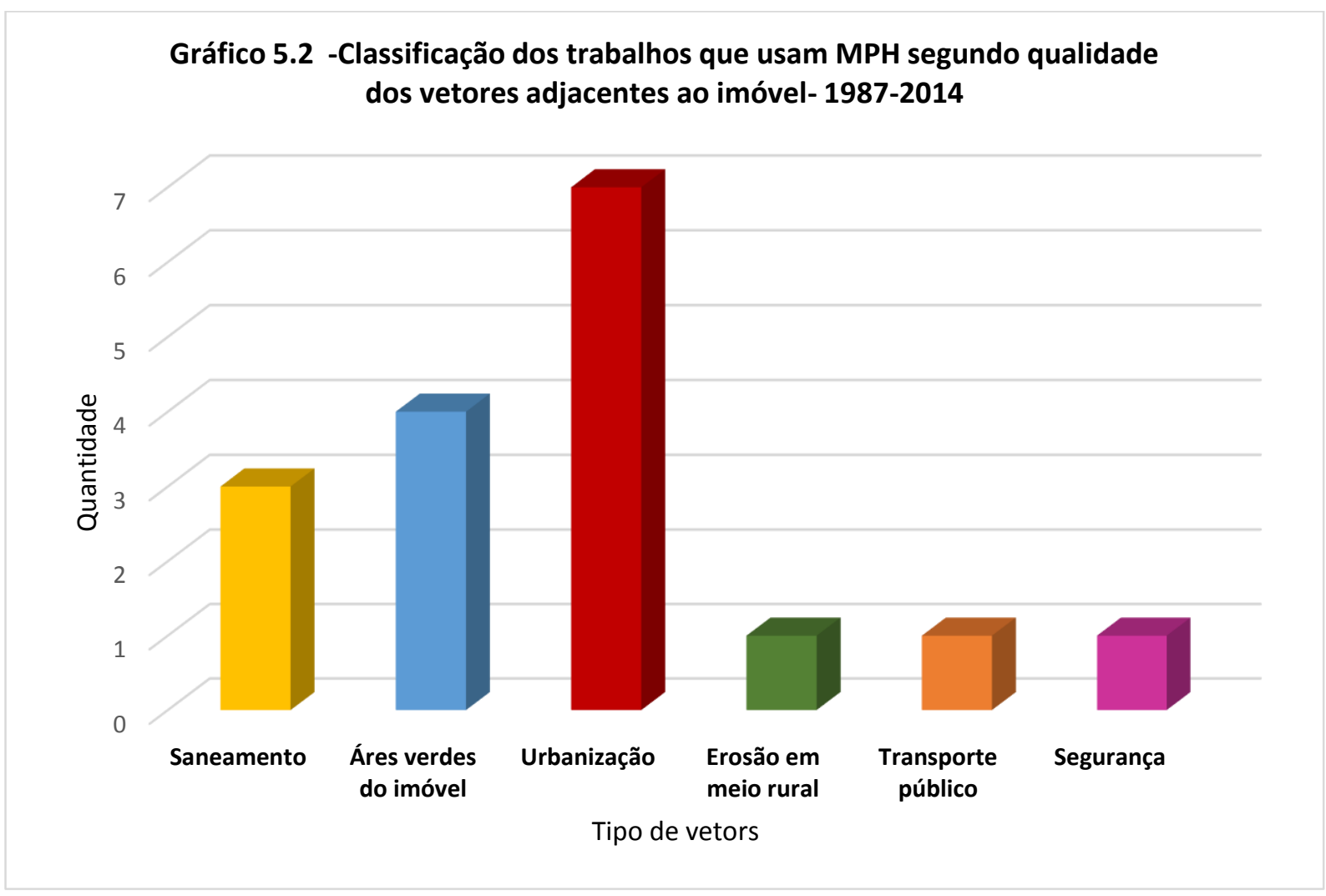

Fonte: Gráfico elaborado pela autora (2015), com base nas informações apresentadas no Apêndice C, tabela C.2 
Desses, $19 \%$ foram realizados no estado do São Paulo e Distrito Federal; 13\%, em Pernambuco, Rio de Janeiro e Santa Catariana; e 6\%, em Goiás, Ceará, Rio Grande do Norte e Paraná. Nos demais Estados, nada foi publicado, veja gráfico 5.3.

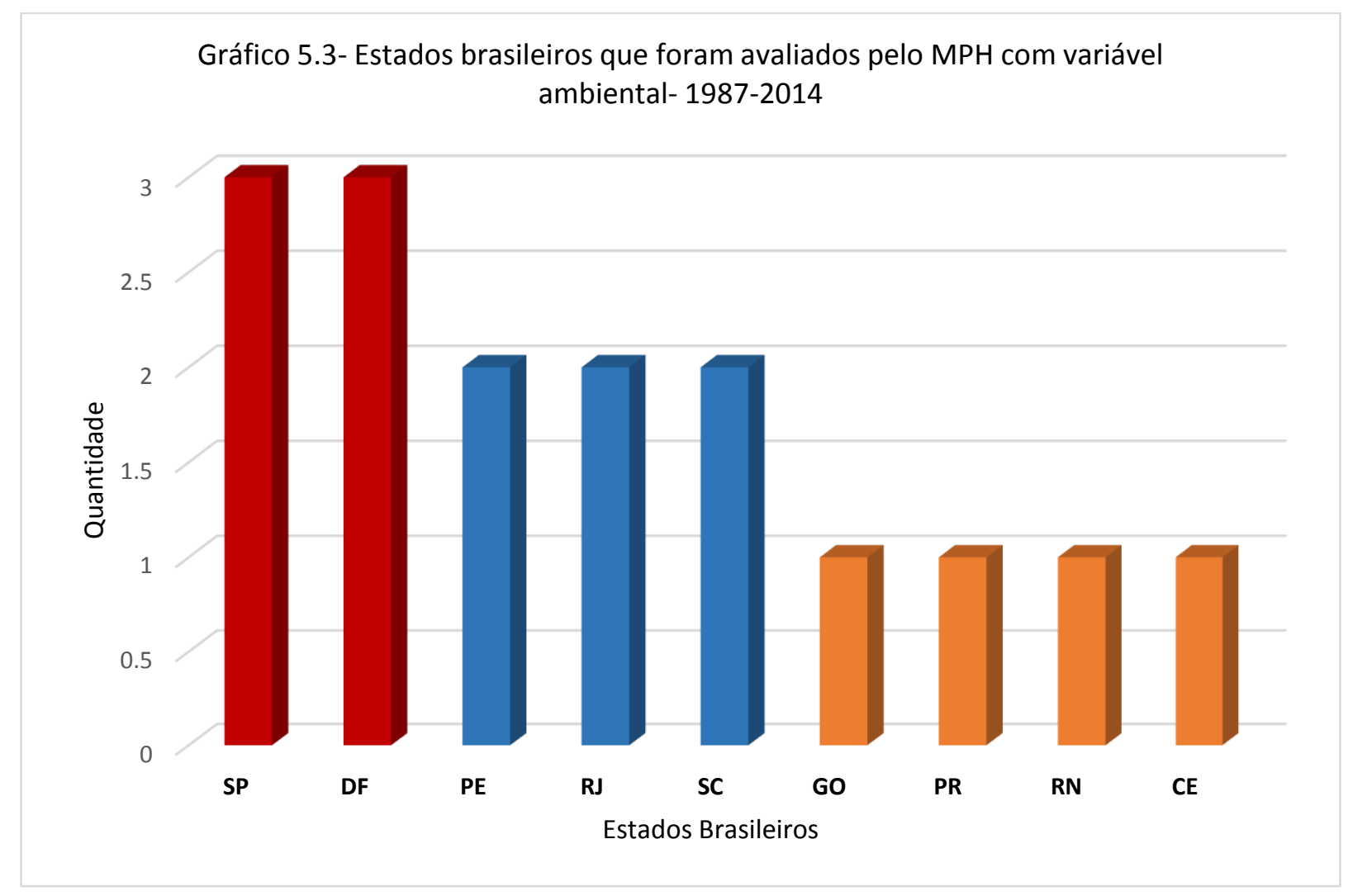

Fonte: Gráfico elaborado pela autora (2015), com base nas informações apresentadas no Apêndice C, tabela C.3

As Instituições de ensino que mais colaboraram com as pesquisas usando o MPH foram: UnB, com 25\%; UFPE, com 19\% (Ver gráfico 3). Além dessas, temos uma pesquisa da Arquitetura, Engenharia e Construção LTDA. - SEDNA; e uma da SABESP, (ver gráfico 5.4) 


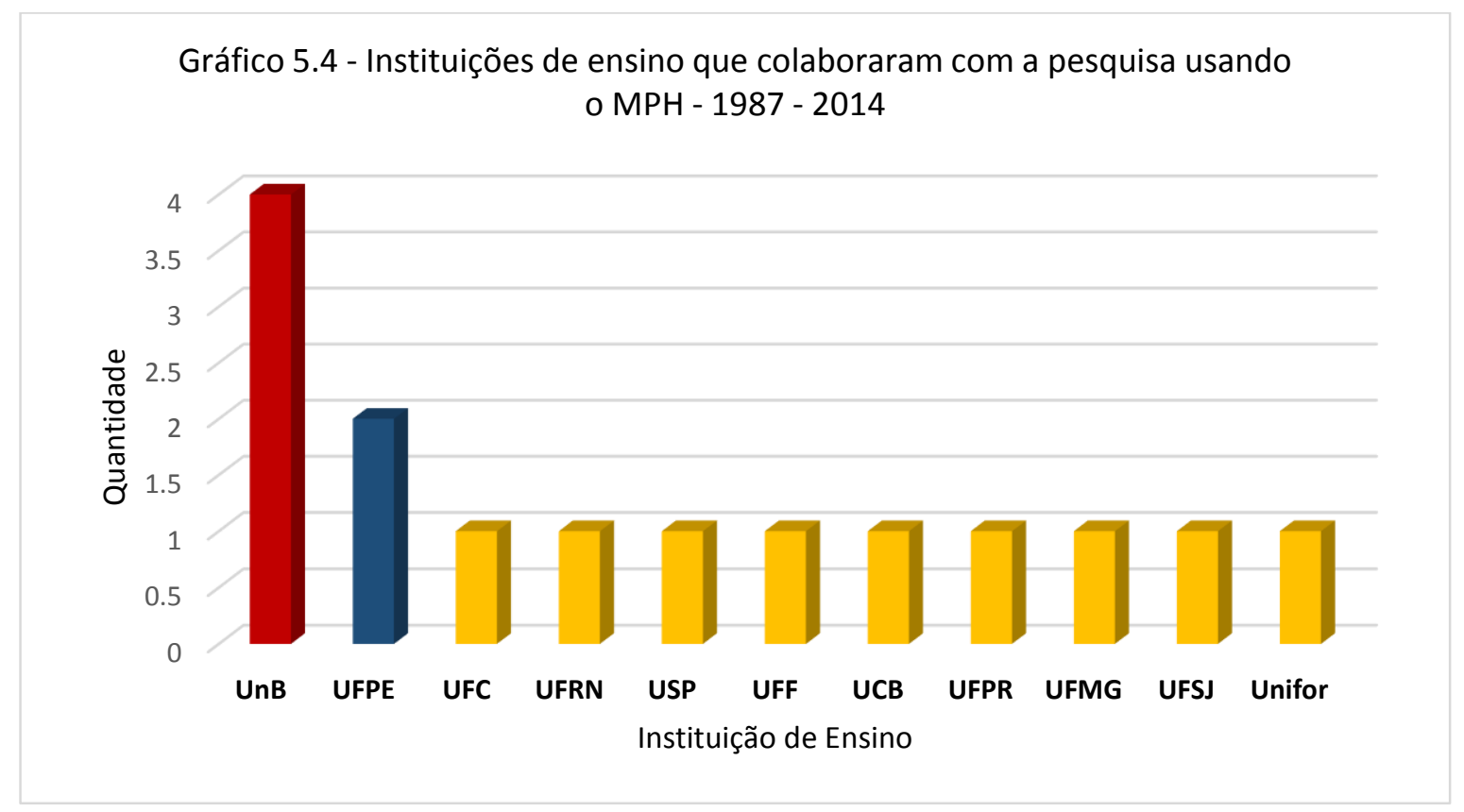

Fonte: Gráfico elaborado pela autora (2015), com base nas informações apresentadas no Apêndice C, tabela C.4

\subsubsection{Aspectos quantitativos dos estudos empíricos brasileiros}

Esses estudos foram selecionados por apresentarem variáveis ambientais relevantes no corpo do trabalho. Todos garantem que o preço dos imóveis residenciais varia para mais ou para menos (vetor benéfico ou não) quando se relaciona um vetor de características ambientais adjacentes ao imóvel. No quadro 5.5 são apresentadas as caraterísticas que influenciaram nos resultados. Em cada trabalho, poder-se-ia apresentar mais de uma variável.

Quadro 5.5 - Características ambientais inclusas nos trabalhos no Brasil (1997-2014)

\begin{tabular}{|l|l|}
\hline Variáveis & Frequência \\
\hline Áreas verdes urbanas, florestas. & 9 \\
\hline Poluição sonora, beleza cênica. & 4 \\
\hline Poluição de ar e mau cheiro & 2 \\
\hline Qualidade da água, alagamentos e presença de corpos d'agua. & 4 \\
\hline Erosão de solo, área degradada. & 1 \\
\hline
\end{tabular}

Fonte: Quadro elaborado pela própria autora (2015) 
Quanto aos modelos econométricos usados, os que produziram melhor ajuste de dados foram: a) linear, para $74 \%$ das pesquisas; b) logarítmica, 20\%; e 6\%, semi-log e box-cos linear. Os trabalhos fizeram simulações com mais de três tipos de formas funcionais (54\%) e elegeram uma que melhor obtivesse dados significativos para as variáveis. Sobre as análises da influência das variáveis ambientais, 54\% separaram um item para os comentários ou teceram explicações na conclusão dos trabalhos.

\subsection{ANÁLISES DE ESTUDOS BRASILEIROS DE VALORAÇÃO COM O MPH}

\subsubsection{Análises gerais das aplicações do MPH}

Ao abordarem os vieses a serem superados, 26,67\% dos trabalhos teceram comentários sobre como foram contornadas as dificuldades. Os vieses mais recorrentes foram multicolinearidade, homocedasticidades, normalidade dos resíduos e autocorrelação dos dados, segmentação de mercado e variação nos modelos residenciais.

Das 16 limitações apresentadas no Quadro 5.1, somente quatro (4) delas foram comentadas, sendo que duas delas em apenas um trabalho, o de Amazonas (2010). Aqui fica uma dúvida: omissão nos resultados e comentários ou desconhecimento profundo teórico sobre as limitações do MPH, já que não houve nenhuma das limitações elencadas no Quadro 5.1.

Dos estudos analisados, 34\% dos pesquisadores eram formados em Engenharia, $20 \%$ em Economia e os 54\% em outras graduações como Arquitetura, Biologia, Agronomia, Administração e Direito. As análises econométricas feitas em $50 \%$ das pesquisas são bem detalhadas e os comentários pertinentes. Os outros $50 \%$ somente fizeram alusão aos números obtidos ou colocaram em uma tabela sem comentários significativos. Essas omissões quanto às explicações econométricas podem ter ocorrido por falta de conhecimento aprofundado em Econometria, uma vez que esse conteúdo não é abordado nos diversos cursos e essa realidade pode ser observada nos artigos. A formação acadêmica dos autores influencia na forma como resultados dos artigos são expressos.

Quanto tamanho das amostras, 47,06\% calcularam com menos de 400 casos. Segundo Gebbons, Mourato e Resende (2014), amostras de pequenas dimensões podem trazer problemas de percepção na construção das análises, das características ambientais, apesar dos preços das casas continuarem a serem perceptíveis. Eles sugerem amostras maiores, mas afirmam que a representatividade ainda é uma questão em aberto. Assim sendo será dedicado uma seção sobre esse item, porque não só o tamanho mas também a seleção da amostra pode provocar vieses 
aos resultados e foram selecionados dois trabalhos brasileiros para exemplificar melhor esse contexto.

\subsubsection{Seleção inadequada de uma amostra}

Dois trabalhos brasileiros - entre os já selecionados para análise de conteúdo quanto à escolha da população, tamanho da amostra e técnica de amostragem - foram selecionados para a ilustração: a) Modelo de regressão para estimar o diferencial de preços das terras agrícolas com e sem erosão em Lagoa Dourada (MG) pelo MPH, de Campos, Cirino e Andrade (2014), e b) Ativo ambiental e preço de imóveis em Recife: um estudo exploratório a partir da utilização do método dos preços hedônicos de Albuquerque, de Melo e Souza (2007).

O trabalho de Campos, Cirino e Andrade (2004) estima, por meio de um estudo de caso, o impacto do processo erosivo sobre os preços das terras agrícolas de Lagoa Dourada (MG), tendo por hipótese que quanto maior e mais severa for a erosão, menor a produtividade do solo e consequentemente menor o preço da terra, por causa dos custos de produção elevados. $\mathrm{O}$ grupo de pesquisa Meio Ambiente e Desenvolvimento Regional da Universidade Federal São João Del Rei aplicou 49 questionários a produtores rurais de Lagoa Dourada.

O tamanho da população não foi informado e o tamanho da amostra foi definido pelas tabelas estatísticas de determinação de amostra de população finita. A técnica de amostragem não foi identificada. $\mathrm{O}$ trabalho apresenta dois comentários sobre a amostra. $\mathrm{O}$ primeiro discute o coeficiente de determinação $\left(\mathrm{R}^{2}\right)$ do modelo, que mede o grau de ajuste dos pontos à reta de regressão estimada, que foi da ordem de $25 \%$. Os autores afirmaram ser este um valor baixo, e que poderia ser aumentado se a amostra fosse maior. Os problemas sobre o número de variáveis (7) na composição do modelo são descartados. O segundo comentário explora a significância estatística e econômica de duas variáveis sugeridas na metodologia: área erodida e presença de rios e córregos na propriedade. Os autores, novamente, atribuem as imperfeições do modelo a uma amostra insuficiente para representar toda a população.

Os autores afirmaram ter usado a estatística para obtenção do número da amostra, porém não informaram o erro estatístico, que, segundo dados de censo publicado pelo IBGE (2010), para um efetivo de 1.538 propriedades, seria de aproximadamente $15 \%$. Assim, na escolha da amostra para representar todo o município seria necessária a escolha de uma técnica de amostragem expressiva. Por exemplo, por conglomerado, o território poderia ser dividido em setores e as mais diversas propriedades rurais seriam consultadas. Um erro aceitável seria de 
5\% e o número da amostra de 309 propriedades, sendo bem mais significativa. Faltou acuidade na obtenção dos dados.

O trabalho de Albuquerque, Melo e Souza (2007) explora a influência do ativo ambiental no preço do imóvel em Recife (PE). A hipótese testada foi que existe uma relação positiva entre preço dos imóveis e sua proximidade com os recursos naturais. Recife possui 94 bairros. 25 foram selecionados e a amostra foi de 443 imóveis. Foram escolhidos os bairros que tinham pelo menos um imóvel a venda e que também apresentasse renda média superior a US\$ 314,18 , uma vez que a propensão dos indivíduos a pagar pela existência do atributo ambiental é captada no valor do imóvel. Os dados da renda foram obtidos no site oficial da prefeitura e os dados imóveis, na Associação das Empresas do Mercado Imobiliário de Pernambuco (ADEMI). As variáveis permeiam entre os dados do imóvel até variáveis ambientais sobre a proximidade de corpos d'água e áreas verdes.

No modelo proposto, as pessoas pesquisadas estavam dispostas a pagar um valor de US\$16.773,73 a mais sobre o preço do imóvel para morar próximo às áreas verdes e US\$11.586,64 a mais no preço do imóvel próximo a corpos hídricos. A amostra é compatível aos dados, pois incorporou todos os imóveis à venda no período de janeiro a março de 2007. E o recorte sobre a renda dos bairros teve como explicação que pessoas com renda muito baixa estão fundamentalmente preocupadas com as condições mínimas de sobrevivência. Geralmente, quando a pessoa tem alimentação e moradia precárias, não há recursos adicionais para a obtenção de outros bens.

Os autores usaram o modelo linear generalizado e excluíram o bairro Jaqueira porque esse bairro apresenta a maior renda média da cidade. Os imóveis nesse bairro têm preço relativamente baixo em termos absolutos em relação à renda. Os imóveis são do tipo studio de pequeno porte e de luxo. Sua variável não era significativa ao modelo, influenciando de forma negativa em relação à renda. Portanto, a amostra final contou com 24 bairros. Nenhuma outra informação consta no texto sobre a amostra. Percebe-se, no trabalho de Albuquerque, Melo e Souza (2007), que a população e amostra estão bem delineadas. E as explicações de inclusão e exclusão são pertinentes à proposta do trabalho.

\subsubsection{Instrumento da pesquisa: a caracterização do objeto valorado}

O MPH é muito sensível à quantidade e qualidade dos dados. Para estimar os preços com o uso da função hedônica para um determinado mercado é necessário que haja uma boa 
seleção das características das propriedades. No entanto, o número de características não pode ser muito grande, porque pode gerar problemas de multicolinearidade (AGUIERRI, 1997). Esse número, também não pode ser muito pequeno porque não representaria adequadamente todo o cenário.

Um cenário incompleto leva a uma valoração irreal. O número de variáveis para compor um cenário adequado não é definido pela quantidade, mas pela abrangência estrutural das características essenciais relacionadas aos atributos estruturais, locacionais e ambientais colocados à disposição dos moradores. A aderência do modelo depende do tamanho da amostra e do perfil do imóvel idealizado e analisado pelos respondentes. Nesse contexto, Hanley e Spash (1999) destacam que a omissão de variáveis pode levar a estimativas tendenciosas para coeficientes e preços implícitos de variável que têm efeito significativo no preço, correlacionadas na equação hedônica e que foram omitidas da função.

O trabalho de Campos, Cirino e Andrade (2004) descreve o cenário com poucas variáveis. São apresentadas apenas sete: áreas erodidas, áreas da propriedade, distância da rodovia pavimentada, quantidade de benfeitorias em unidades e em metros, rios e córregos na propriedade como variável dummy e renda bruta da propriedade.

O trabalho de Albuquerque, Melo e Souza (2007) apresentou 13 variáveis: preço dos imóveis, área total da residência, idade da residência, número de quartos, imóvel com garagem, quantidade e apartamentos por andar, número de banheiros, distância entre bairro e o centro, renda do bairro, proximidade de corpos d'água e áreas verdes, além de seis variáveis denominadas RPA relacionadas à localização do imóvel, que é distante das áreas verdes e corpos hídricos. O estudo não faz levantamento algum sobre criminalidade local, presença de escolas, comércio próximo, e outras facilidades diárias perseguidas pelas famílias.

A escolha das variáveis é uma questão de sensibilidade do pesquisador e varia de trabalho para trabalho, porque está relacionada ao objeto de estudo, no caso a região em que está inserido, o tipo dos imóveis, a variável ambiental inserida para análise. Deve-se lembrar que quanto melhor for a descrição do cenário maior a chance de se ter um valor real para o ativo.

\subsubsection{Relatórios dos estudos pelo MPH e a validade de conteúdo}

O relatório de pesquisa precisa comunicar de forma clara os objetivos, as informações e detalhes sobre todos os passos alçados na valoração dos ativos ambientais para que seja um 
documento que valide o conteúdo e as estimativas de valor acertadas. O Quadro 5.6 apresenta os itens que Boyle (2003) e Taylor (2003) consideraram como imprescindíveis.

Quadro 5.6 - Itens indispensáveis a um relatório de Pesquisa - MVC

\begin{tabular}{|rl|}
\hline \multicolumn{1}{|c|}{ Itens do relatório de pesquisa } \\
\hline 1. & A aplicação do estudo \\
\hline 2. & A definição teórica do valor \\
\hline 3. & O quadro amostral- população amostra e técnica de amostragem \\
\hline 4. & Modo de pesquisa e taxas de respostas \\
\hline 5. & Descrição da variáveis do modelo e cenário de valorização \\
\hline 6. & Método de estimação da equação de demanda para o mercado \\
\hline 7. & Análise quantitativa e qualitativa das variáveis \\
\hline 8. & Instrumentos de ajustes utilizados \\
\hline
\end{tabular}

Fonte: Quadro elaborado a partir dos trabalhos de Boyle (2003) e Taylor (2003)

Os relatórios dos resultados das pesquisas brasileiras que usam o MPH são muito diversificados e, em muitos casos, não permitem a avaliação da validade dos conteúdos. Os dois relatórios de estudos (artigos) escolhidos para representar as pesquisas sobre valoração preços hedônicos são avaliados segundo os itens discutidos no texto de Boyle (2003) e Taylor (2003). Foi usado o seguinte código: Item completo - IC; Item incompleto - IIC e Item Não Realizado - INR. Os estudos estão assim divididos: Estudo 1) MPH 1 e Estudo 2) MPH 2. Os autores que os representam estão no quadro do apêndice D.3, e os resultados estão expressos no Quadro 5.7. 
Quadro 5.7 - Avaliação de relatório de estudos brasileiros

\begin{tabular}{|l|c|c|c|c|c|c|}
\hline \multirow{2}{*}{ Itens } & \multicolumn{3}{|c|}{ Estudo 1 } & \multicolumn{3}{c|}{ Estudo 2 } \\
\cline { 2 - 7 } & IC & IIC & INR & IC & IIC & INR \\
\hline Aplicação do estudo & $\mathbf{X}$ & & & $\mathbf{X}$ & & \\
\hline Definição Teórica do valor & $\mathbf{X}$ & & & $\mathbf{X}$ & & \\
\hline População & & & $\mathbf{X}$ & $\mathbf{X}$ & & \\
\hline Amostra & & & $\mathbf{X}$ & & $\mathbf{X}$ & \\
\hline Amostragem & & $\mathbf{X}$ & & $\mathbf{X}$ & & \\
\hline Boa descrição das variáveis & $\mathbf{X}$ & & & $\mathbf{X}$ & & \\
\hline Equação de demanda & $\mathbf{X}$ & & & $\mathbf{X}$ & & \\
\hline Taxa de respostas & & $\mathbf{X}$ & & $\mathbf{X}$ & & \\
\hline Cenário & $\mathbf{X}$ & & & & $\mathbf{X}$ & \\
\hline Análise quantitativa dos dados & $\mathbf{X}$ & & & & $\mathbf{X}$ & \\
\hline Análise qualitativa dos dados & $\mathbf{X}$ & & & $\mathbf{X}$ & & \\
\hline Instrumentos de ajustes & $\mathbf{X}$ & & & $\mathbf{X}$ & & \\
\hline Projeção do valor do bem ambiental & $\mathbf{8 / 1 3}$ & $\mathbf{3 / 1 3}$ & $\mathbf{2 / 1 3}$ & $\mathbf{1 0 / 1 3}$ & $\mathbf{3 / 1 3}$ & $\mathbf{0 / 1 3}$ \\
\hline Total & & & & & \\
\hline
\end{tabular}

Fonte: Quadro elaborado pela própria autora (2015)

Os resultados do Quadro 5.7 apontam que o artigo do estudo de MPH 2 está bem próximo do que seria um relatório ideal para o MPH. O quadro amostral traçado com minúcias e um cenário bem delineado levará a uma equação de demanda mais próxima à realidade da pesquisa e valores mais confiáveis. A necessidade de um bom relatório de pesquisa proporciona aos pesquisadores validade de construto e de conteúdo, e fomenta comparações com novas pesquisas, proporcionando avanço e aprimoramento das técnicas utilizadas e corrigindo pequenas deformações.

Em contrapartida, a não apresentação dos dados populacionais inviabiliza ao leitor fazer inferências sobre o trabalho. A apresentação de resultados incompletos sobre a amostra e amostragem para uma análise científica ou judicial promove o descrédito da pesquisa. O leitor precisa conhecer a maneira como a amostra foi coletada. É através da técnica de amostragem que decisões relevantes a respeito do valor calculado podem ser tomadas, seja para cobrar por um dano provocado em um ativo ambiental, seja para promover melhorias no ambiente. 
Sobre as descrições das variáveis, elas deverão ser o mais realista possível e ricas em detalhes. A presença da variável ambiental é muito importante para os trabalhos de valoração atualmente, porque um ambiente conservado faz parte da cesta de consumo dos indivíduos, ora usado para purificar o ar e águas, ora para promover bem-estar no modus vivendi do homem. A presença de atributos ambientais poderá alterar valores hedônicos significativamente. Somente $22 \%$ de todos os trabalhos de valoração apresentaram essa variável no processo. É pouco, mas é importante ressaltar que uma forte relação entre bem-estar e meio ambiente conservado data menos de um século.

Quadro 5.8 - Sugestões de checklist detalhado para um relatório de pesquisa com o uso de $\mathrm{MPH}$

\begin{tabular}{|c|c|c|}
\hline 1 & \multicolumn{2}{|l|}{ Aplicação do Estudo } \\
\hline 2 & \multicolumn{2}{|l|}{ Definição teórica do valor } \\
\hline \multirow{4}{*}{3} & \multirow{4}{*}{ Quadro amostral } & População \\
\hline & & Amostra \\
\hline & & Amostragem \\
\hline & & Fórmula usada \\
\hline \multirow{4}{*}{4} & \multirow{4}{*}{ Coleta de dados } & Descrição das variáveis \\
\hline & & Local da coleta \\
\hline & & Individual ou grupal \\
\hline & & Período da coleta \\
\hline 5 & \multicolumn{2}{|l|}{ Pré-teste } \\
\hline \multirow{2}{*}{6} & \multirow{2}{*}{ Apresentação do local } & Vaiáveis qualitativas do local \\
\hline & & Variáveis quantitativas do local \\
\hline \multirow{3}{*}{7} & \multirow{3}{*}{ Formato de avaliação utilizado } & Informações dos entrevistados \\
\hline & & Informações auxiliares \\
\hline & & Informações de fronteira \\
\hline 8 & \multicolumn{2}{|c|}{ Caracterização sociodemográficas dos inquiridos } \\
\hline \multirow{3}{*}{9} & \multirow{3}{*}{ Método de Análise de dados } & Método estatístico utilizado \\
\hline & & Equação de demanda estimada \\
\hline & & Explicação dos resultados econométricos \\
\hline 10 & \multicolumn{2}{|c|}{ Estimativas de tendência central e dispersão dos dados } \\
\hline 11 & \multicolumn{2}{|l|}{ Instrumentos de ajustes } \\
\hline 12 & \multicolumn{2}{|c|}{ Método do cálculo do valor econômico } \\
\hline 13 & \multicolumn{2}{|c|}{ Projeção do valor do bem ambiental } \\
\hline
\end{tabular}

Fonte: Quadro elaborado pela própria autora (2015) 
O Quadro 5.8 poderá ser usado como checklist para futuros relatórios de pesquisa. Não é intenção criar um aspecto formal, impedindo a criatividade dos pesquisadores; é somente uma maneira de verificar se todas as informações necessárias estão contempladas nos textos.

\subsection{COMENTÁRIOS CONCLUSIVOS}

De uma maneira geral, de acordo com as preferências individuais, para se estimar os valores dos bens ou produtos, utiliza-se do preço que aparece no mercado existente. Caso contrário, pode se recorrer a valores indiretos que se aproximariam ao preço do bem. Nas análises empíricas, os pesquisadores frequentemente usam variáveis independentes adicionais, como os deslocadores da equação para capturar os fatores que estariam afetando o preço. A premissa básica do MPH é que o preço de um bem comercializado está relacionado com as características, ou serviços que presta. Os preços das habitações na área indicam uma correlação entre a proximidade com a área preservada e a valorização dos imóveis.

A abordagem de preços hedônicos foi utilizada no Brasil para estimar o valor de bens associados à proximidade de residências a áreas verdes, parques, jardins e outros ativos naturais. Os problemas ambientais como: proximidade a ruídos, poluição de ar e água também podem influenciar negativamente no preço, evidenciando assim, a correlação entre o preço do imóvel e o valor do ambiente em que está inserido. O MPH é sensível às várias mudanças ocorridas nos ativos ambientais. As pessoas escolhidas para compor a amostra e inqueridas podem apontar vieses nas respostas desde que ocorra assimetria de informação entre o que se deseja e o que se apresenta como realidade. Uma amostra inadequada pode além de não representar a população levar a subestimação ou superestimação de valores.

Os trabalhos brasileiros analisados apontam para a necessidade de aprofundamento no uso do método. As críticas recaem sobre o tamanho escolhido para a amostra, o tipo de variáveis utilizadas, o modelo econométrico, as análises superficiais dos resultados, e omissões de qualidades adjacentes aos imóveis, entre outras. O principal agente motivador dessas dificuldades ainda é a carência de trabalhos teóricos que explicitem ao leitor/pesquisador as deficiências e vantagens do MPH, bem como entraves que poderiam desqualificar uma pesquisa. Não existem livros publicados no Brasil que tratam especificamente desse assunto. Os trabalhos brasileiros apresentam, como fonte de pesquisa teórica, trabalhos escritos nos EUA e Europa, e tentam relacionar com alguns trabalhos já realizados no Brasil. Os trabalhos teóricos poderiam apresentar estudos de casos brasileiros e estrangeiros, com riquezas de detalhes para que, através de outras experiências, pudéssemos criar nosso próprio banco de dados. 


\section{CAPÍTULO 6}

\section{UMA AVALIAÇÃO GERAL DA EXPERIÊNCIA BRASILEIRA}

\subsection{INTRODUÇÃO}

A prática de uso de métodos e procedimentos de valoração ambiental no Brasil teve início na década de 1980. As primeiras experiências foram com o MPH em 1987, MCV em 1993 e MVC em 1995. Os trabalhos teóricos iniciam-se com Motta (1997). Concomitantemente as IES também iniciaram o processo de pós-graduação strito sensu direcionado com a preocupação ambiental. Novos pesquisadores se formaram direcionando pesquisas na qual a variável meio ambiente pudesse estar incluída. Uma das consequências dessa consolidação foi a aplicação de métodos de valoração já experimentados em outros países. Hoje em todas as regiões brasileiras existem ativos ambientais valorados.

Os pesquisadores brasileiros ainda constroem os pilares de suas pesquisas baseados em autores estrangeiros porque poucos são os livros, norteadores teóricos, escritos no Brasil e que contenham experiências brasileiras com exemplos. O aporte que se faz uso são artigos publicados em revistas científicas, além de dissertações e teses de algumas IES que procuram desenvolver trabalhos de pesquisa nessa área (em especial, UnB, UFRJ, UFMT, UFOP, UFSC), espalhadas pelas cinco regiões brasileiras.

O método de valoração mais utilizado no Brasil em pesquisas relacionadas ao meio ambiente é o MVC. Sua grande utilização se faz pela facilidade (aparente) em ajustar o que as pessoas proclamam como valor a um bem ou serviço ambiental e produzir um valor único que as represente. Além disso, ele é o único que pode calcular o valor de existência dos ativos ambientais. Não obstante, o MVC pode apresentar muitos vieses e o pesquisador atento procura contorna-los segundo seu objeto de estudo. Os outros métodos também usados estão ligados a bens específicos como: lazer (MCV) e estruturas urbanas (MPH) e não estão isentos de desafios metodológicos. Nesse capítulo fazemos uma síntese dos principais resultados e das contribuições de nossa investigação. Além dessa introdução, a seção (6.2) aglutina assuntos e pensadores mais utilizados. A seção (6.3) quantifica os motivos de valoração e regionaliza a aplicação dos métodos de valoração. 


\subsection{OS AUTORES E SUAS OBRAS: O QUE DIZEM AS REFERÊNCIAS}

Em relação aos estudos observou-se uma frequência na repetição de obras citados pelos autores nos três métodos, tanto para obras internacionais quanto nacionais. Para obras internacionais observou-se as frequências dos autores clássicos. Não foram considerados artigos recentes as obras utilizadas na comparação dos resultados.

Para o MVC os autores internacionais mais citados estão representados no gráfico 6.1: Pearce (1993) com 26\% dos trabalhos, Freeman III (1979) $19 \%$ e Bateman e Turner(1993) com 15\%. Quando o método usado era MCV (gráfico 6.1b) os autores mais utilizados foram: Pearce (1993) com 28\% dos trabalhos, Hanley e Spash (1993) e Pearce e Turner (1990). No MPH (gráfico 6.1 c) foram Hanley e Spash (1993) com 37\% e Garrod e Willis (1999) com 33\%. Observa-se a importante obra de Hanley e Spash (1993) influenciando os três métodos $(82,9 \%)$ mas, também, não se pode negar a importância da obra de Pearce (1993) (26,12\%), entre outros.

Entre os temas de valoração econômica mais citados desses autores foram escolhidos por pesquisadores brasileiros: formas de pagamento, técnicas de valoração, medidas de valoração, embasamento teórico da DAP, aplicabilidade do MVC e MCV, operacionalização do MVC, importância da valoração, procedimentos econométricos de valoração, modelagem da curva de demanda aplicada a recursos naturais. Existem muitas "citações de citação" - apud - nos textos percebe-se que a leitura em língua estrangeira ainda é uma barreira para o entendimento e aprofundamento teórico. Em textos mais recentes de 2012 a 2014 essa prática tem sido evitada.

Os autores nacionais mais citados foram: para o MVC (gráfico 6.2a) Motta (1997) 26\%; Nogueira; Medeiros e Arruda (2000) com 16\% das pesquisas, seguidos por May; Lustosa e Vinha 14\%; e Nogueira e Medeiros (1998) com 12\%. Para o MCV (gráfico 6.2b) tem-se: Motta (1997) 44\%; Romeiro e Maia (2003) 29\%; e Ortiz; Motta e Ferraz (2000) 27\%. E para o MPH (gráfico 6.2c), Motta (1997) 44\%; Contador (1981) 32\% e Hermann (2003) 24\%.

Os assuntos pertinentes aos autores brasileiros são: dificuldades dos métodos, formação dos preços dos recursos naturais, tipos de métodos, relação entre taxa de visitação e custo de viagem, validade e confiabilidade de modelos, limitações e vantagens dos métodos, externalidade ambientais, cálculo usando os métodos de função demanda, avaliação ecossistêmica. 
Gráfico 6.1- Trabalhos Internacionais mais citados no Brasil- MVC, MCV e MPH

Gráfico 6.1 a - Autores internacionais mais citados em trabalhos brasileiros com o uso do MVC - 1999 - 2014

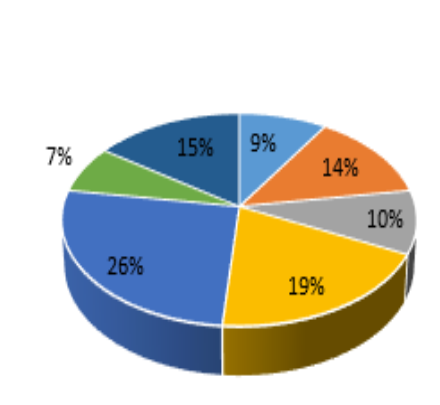

- Freeman III (1979)

- Pearce (1993)
Gráfico 6.1 b - Autores internacionais mais citados em trabalhos brasileiros com o uso do MCV -1993 2014

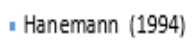

- Hanemann (1994)

- Mitchell e Carson (1993)

" Pearce e Turner (1990)

- Hanleye Spash (1999)

- Bateman e Turner (1993)

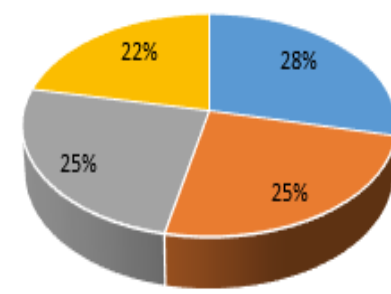

- Pearce (1995)

- Hanley e Spash (1993)

- Pearce e Turner (1990)

- Haab e McConnell (2003)

Gráfico $6.1 \mathrm{c}$ - Autores internacionais mais citados em trabalhos brasileiros com o uso do MPH -1987 - 2014

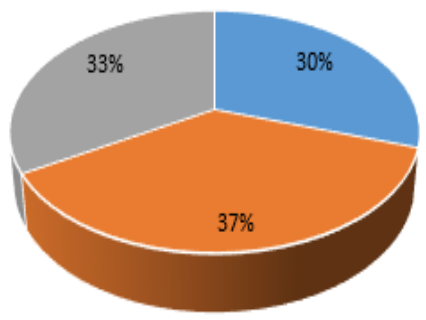

1 Palmquist (1984)

- Hanley e Spash (1993)

" Garrod Willis (1999)

Fonte: Gráfico elaborado pela autora (2015), com base nos capítulos 3, 4 e 5, e os dados colocados no Apêndice D tabela D.1

Essa análise tem como procedência verificar se a influência das ideias e os procedimentos em trabalhos feitos no Brasil segue uma determinada tendência. Perseguindo essa preocupação verificou-se a frequência com que os trabalhos no Brasil usam como modelo outros autores brasileiros e constatou-se que segundo o Google Acadêmico: May; Lustosa e Vinha (2003) com a obra Economia do Meio ambiente: Teoria e Prática foi citado 271 vezes; Motta (1997) com a obra Manual de Valoração Econômica dos Recursos Ambientais foi citado como referência 250 vezes, publicado pelo MMA; e Nogueira; Medeiros e Arruda (2000) com o artigo Valoração Econômica do Meio Ambiente: Ciência ou Empirismo? foi citado 68 vezes. O trabalho em comum para os três modelos foi o de Motta (1997) publicado pelo IPEA/ MMA e PNUD, deste modo, vê-se a grande responsabilidade do autor em nortear trabalhos no Brasil. 
Gráfico 6.2- Trabalhos nacionais mais citados no Brasil- MVC, MCV e MPH

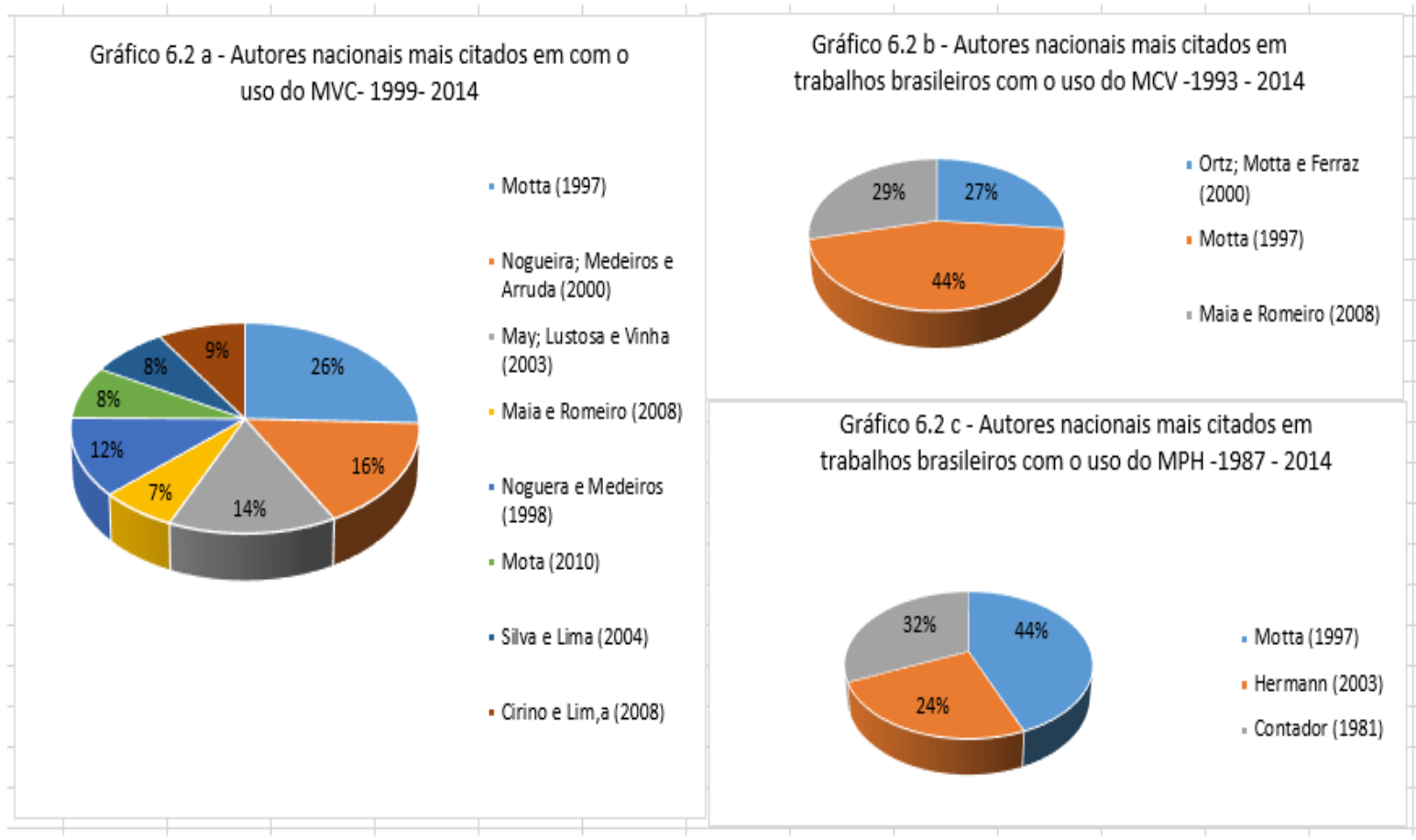

Fonte: Gráfico elaborado pela autora (2015), com base nos capítulos 3, 4 e 5 e os dados colocados no Apêndice D tabela D.2

Em relação a essa influência em termos de referências citadas, é interessante destacar que segundo Bentes et al. $(2014)^{43}$ se nos trabalhos a serem escritos os autores seguirem o "Manual de Valoração Econômica dos Recurso Ambientais" de Motta (1997) na sua integra, suas estimativas de VET e do valor da DAP sempre serão subestimados, uma vez que Motta (1997) considera somente quatro variáveis que são: número dos entrevistados dispostos a pagar; total da amostra; população total da área de estudo e valor médio da DAP. Eles também afirmam que os valores não representam adequadamente a realidade porque excluem varáveis importantes no contexto da análise.

\subsection{RESULTADOS DE VALORAÇÃO AMBIENTAL NO BRASIL}

\subsubsection{Motivos de valoração e fontes de financiamento}

Nesta tese foram pesquisados 143 trabalhos empíricos e 30 trabalhos teóricos sobre os três métodos de valoração da função demanda. Em análise minuciosa em nota de rodapé,

\footnotetext{
${ }^{43}$ Autores do artigo Valoração econômica da jusante da barragem de Tucuruí da UFRA e UFV.
} 
resumo, introdução, conclusão e agradecimentos pode-se notar que somente 20 trabalhos publicados como artigos citam as fontes financiadoras. As mais comuns são: Coordenação de Aperfeiçoamento de Pessoal de Nível Superior- CAPES, Conselho Nacional de Desenvolvimento Científico e Tecnológico - CNPq, Fundação de Amparo a Pesquisa do Estado de São Paulo -FAPESP, Fundação de Amparo à Pesquisa do Estado de Minas Gerais FAPEMIG, Instituto de Pesquisa Econômica Aplicada - IPEA, e Banco Interamericano de Desenvolvimento -BID. Aqui não estão relacionadas as teses e dissertações.

Duas considerações devem ser feitas a respeito dessa situação. A primeira é que trabalhos de tal abrangência não são financiados para sua realização. Segundo, os autores estão esquecendo de citar fonte financiadora. Se primeira hipótese for verdadeira, a situação é inquietante, porque pesquisas de valoração tendem ser muito dispendiosas e isso pode significar que para os gestores dos estados brasileiros a conservação de seus ativos naturais e o meio ambiente em geral não são importantes, pode ser relegado a um segundo plano. Se for a segunda, demostra descaso com o agente financiador.

Outro resultado interessante é relacionado com ao uso dos resultados e dos valores calculados pelos métodos de valoração ambiental. Somente 28 trabalhos $(23,28 \%)$ explicaram qual o emprego dos resultados. Os motivos com maior recorrência foram o de financiar projetos para saneamento (25\%) e subsidiar políticas públicas para conservação dos ativos (22\%), requalificação ambiental urbana, captação de recursos financeiros para a entidade e cobranças de taxas (14\%); e verificar a condução da política pública municipal e estadual (11\%) (ver gráfico 6.3). Os demais trabalhos $76,72 \%$ valoraram os ativos ambientais em práticas acadêmicas para suas IES. Em todos os trabalhos são elencados os objetivos de valoração, porém, esses objetivos visam aprimoramento das técnicas utilizadas. Seria muito útil que bancos de dados pudessem ser criados e mantidos para consulta pública tanto para projetos públicos quanto privados. 


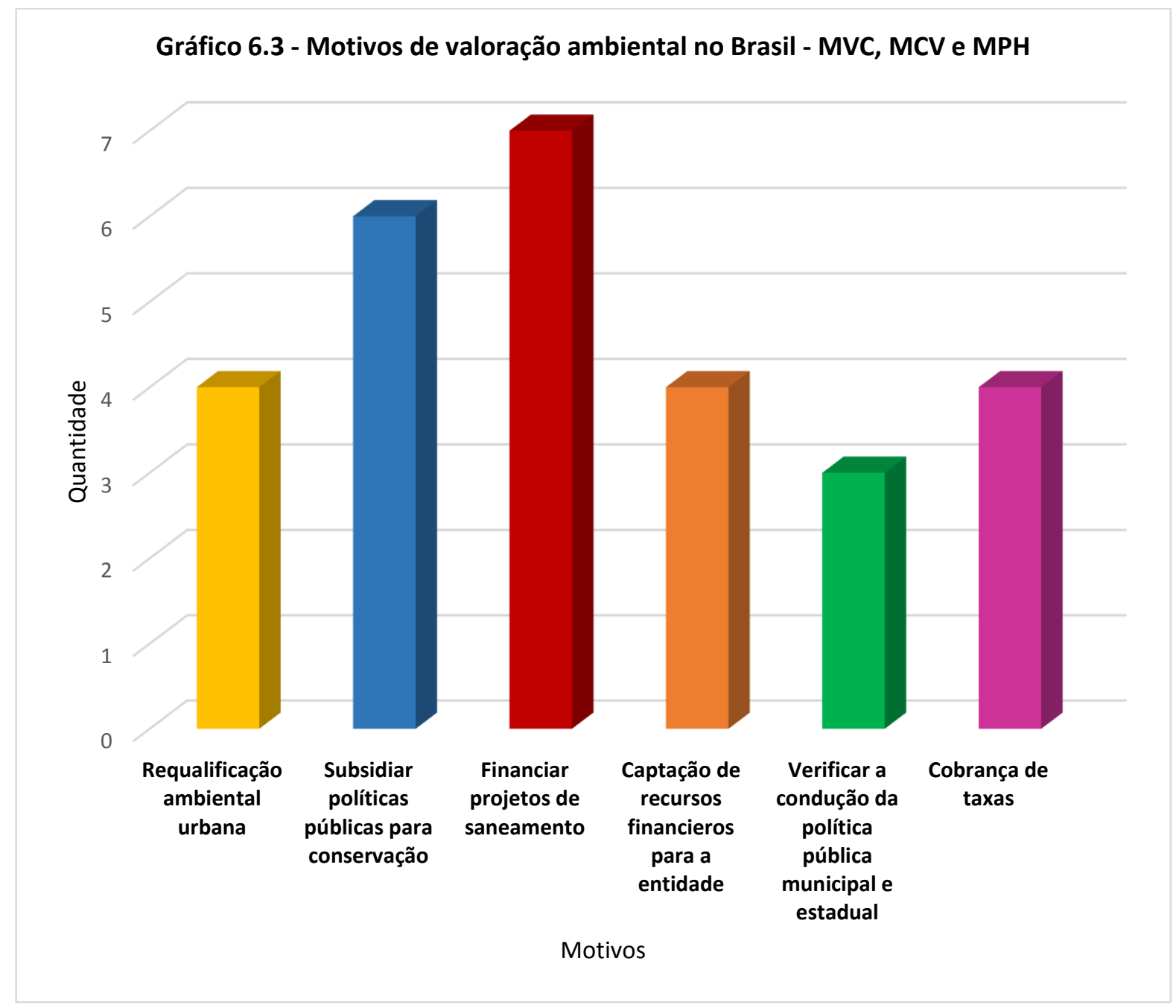

Fonte: Gráfico elaborado pela autora (2015), com base nos capítulos 3, 4 e 5 e os dados colocados no Apêndice D tabela D.3

Das IES do Brasil as que destacam por participar com o maior número de trabalhos estão: a UnB (DF) com 57\% dos trabalhos; UFRJ (RJ) com 10\%; UNOCHAPECÓ (SC) com 8\%; UFU (MG) com 7\%; e UFSC (SC), UFOP (MG) e UFMT (MT) com 6\%. A liderança se apresenta, portanto, com a região do Centro- Oeste com $63 \%$ das pesquisas realizadas no Brasil, seguida da região Sul com 14\% e Sudeste com 13\%, (Ver gráfico 6.4). 


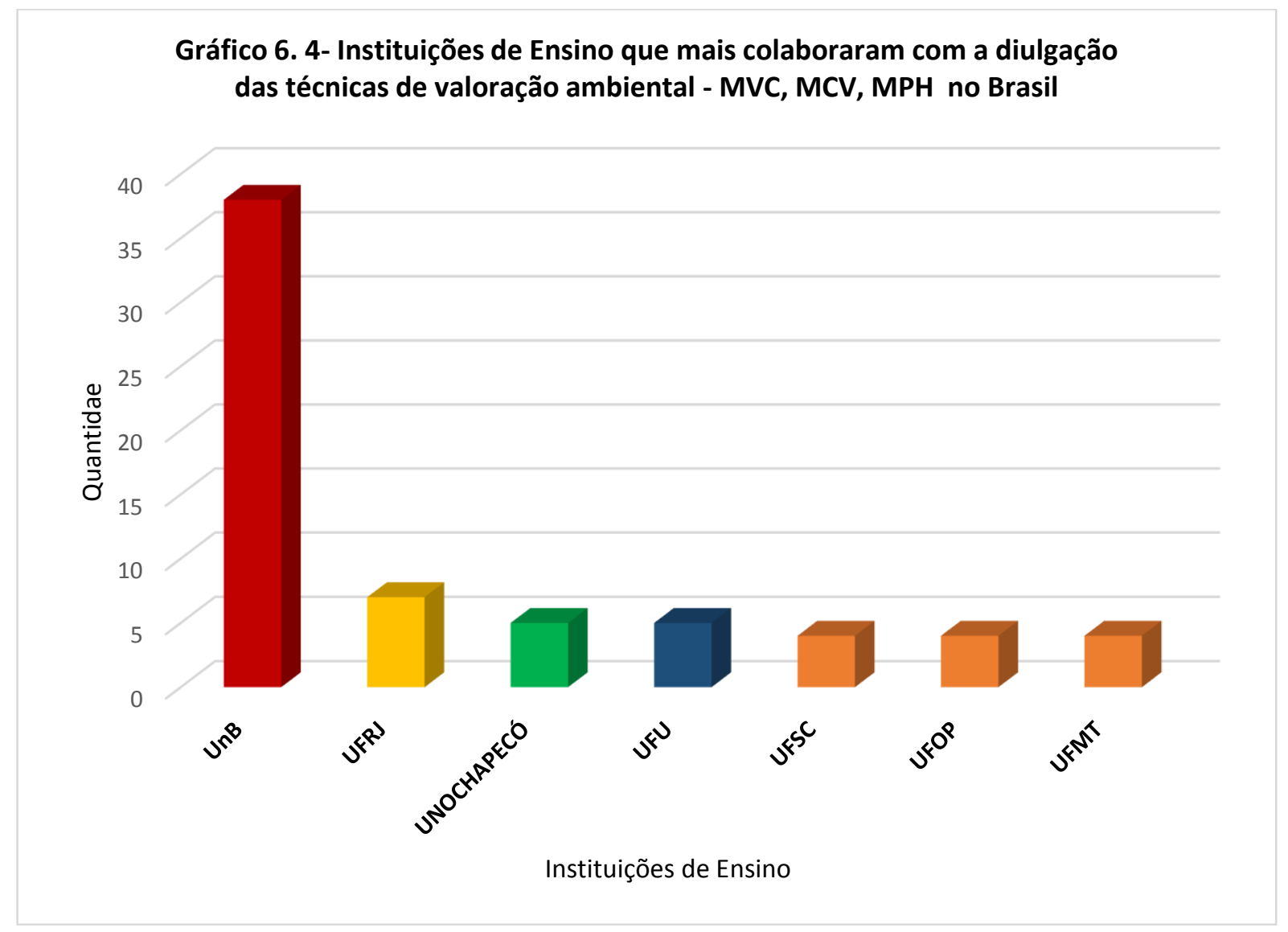

Fonte: Gráfico elaborado pela autora (2015), com base nos capítulos 3, 4 e 5 e os dados colocados no Apêndice D tabela D.4

\subsubsection{Panorama da valoração ambiental por região no Brasil}

No Brasil poucos são os ativos ambientais que passaram pelo processo de valoração. A Região Centro-Oeste é a que possui o maior número de ativos valorados (44 trabalhos) e desta o Distrito Federal se apresenta com $46 \%$ dos trabalhos. O método mais utlilizado foi o de MVC com 52,27\% seguido do MCV (38,64\%) e MPH (9,09\%), (ver gráfico 6.5). 
Gráfico 6.5- Visão geral de trabalhos escritos sobre ativos ambientais na Região Centro-Oeste do Brasil

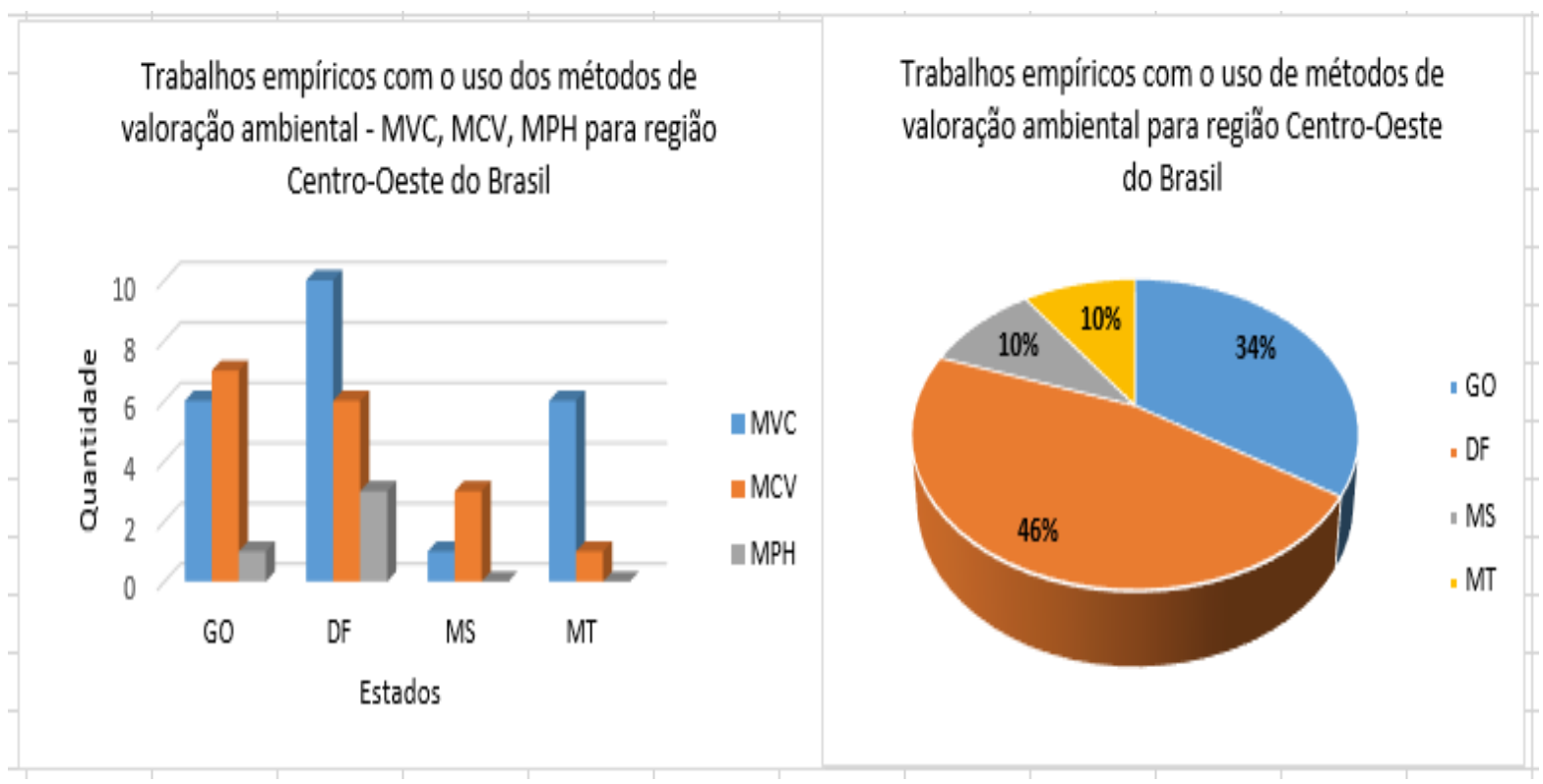

Fonte: Gráfico elaborado pela autora (2015), com base nos capítulos 3, 4 e 5 e os dados colocados no Apêndice D tabela D.5

A região Sudeste segue a região Centro-Oeste com 39 trabalhos. Os estados de São Paulo e Minas Gerais apresentam cada um 36\% dos trabalhos, (ver gráfico 6.6). Nessa região também está concentrado o maior número de ativos valorados pelo MPH.O método mais utilizado na região é o de valoração contingente com 61,54\%, seguido por MCV $(25,64 \%)$ e MPH (12,82\%). 
Gráfico 6.6- Visão geral de trabalhos escritos sobre ativos ambientais na Região Sudeste do Brasil

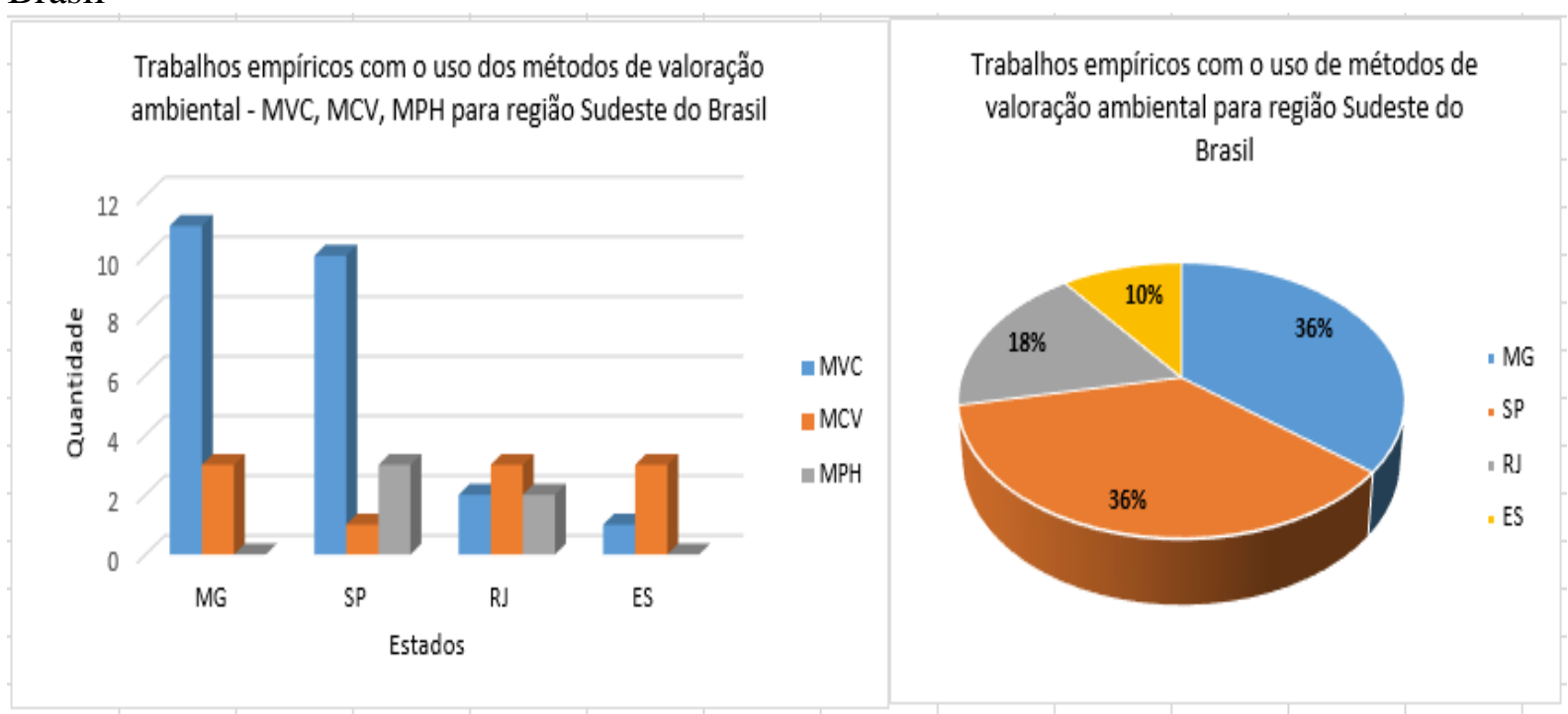

Fonte: Gráfico elaborado pela autora (2015), com base nos capítulos 3, 4 e 5 e os dados colocados no Apêndice D tabela D.6

A região Sul tem 26 trabalhos de valoração. O estado do Rio Grande Do Sul tem 54\% dos trabalhos de valoração e todos os estados possuem ativos valorados pelos três métodos. O MVC tem 61,54\% dos trabalhos; o MCV 26,92\% e o MPH 12,82\%, (Ver gráfico 6.7).

Gráfico 6.7 - Visão geral de trabalhos escritos sobre ativos ambientais na Região Sul do Brasil

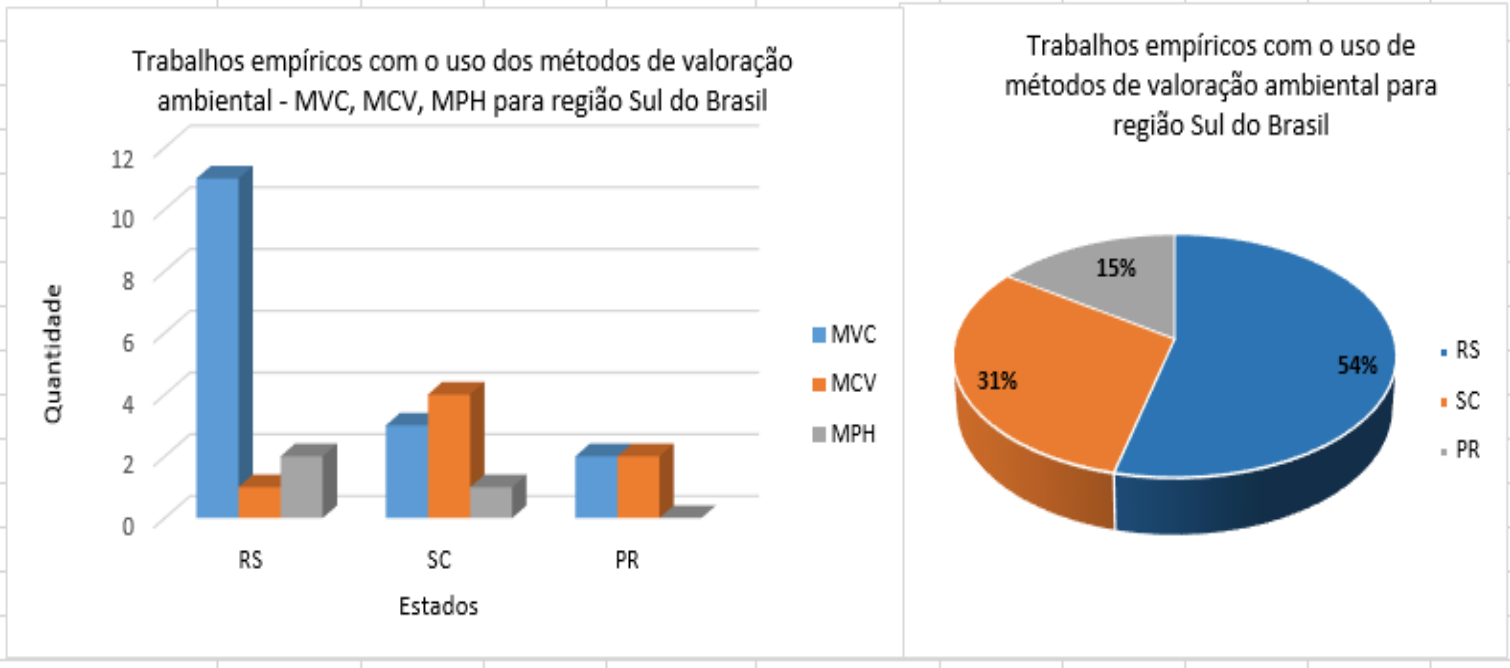

Fonte: Gráfico elaborado pela autora (2015), com base nos capítulos 3, 4 e 5 e os dados colocados no Apêndice D tabela D.7

A região Nordeste participa com 21 ativos valorados em seus diversos Estados. E o 
Ceará é o que possui o maior números de ativos com $29 \%$ dos trabalhos de valoração. Somente a Paraíba fez uso dos três métodos, apesar do MVC ter sido usado pelos pesquisadores com maior frequência (66,67\%). O MPH 19,05\%, e o MCV foi utilizado 14,92\% (ver gráfico 6.8).

Gráfico 6.8- Visão geral de trabalhos escritos sobre ativos ambientais na Região Noreste do Brasil

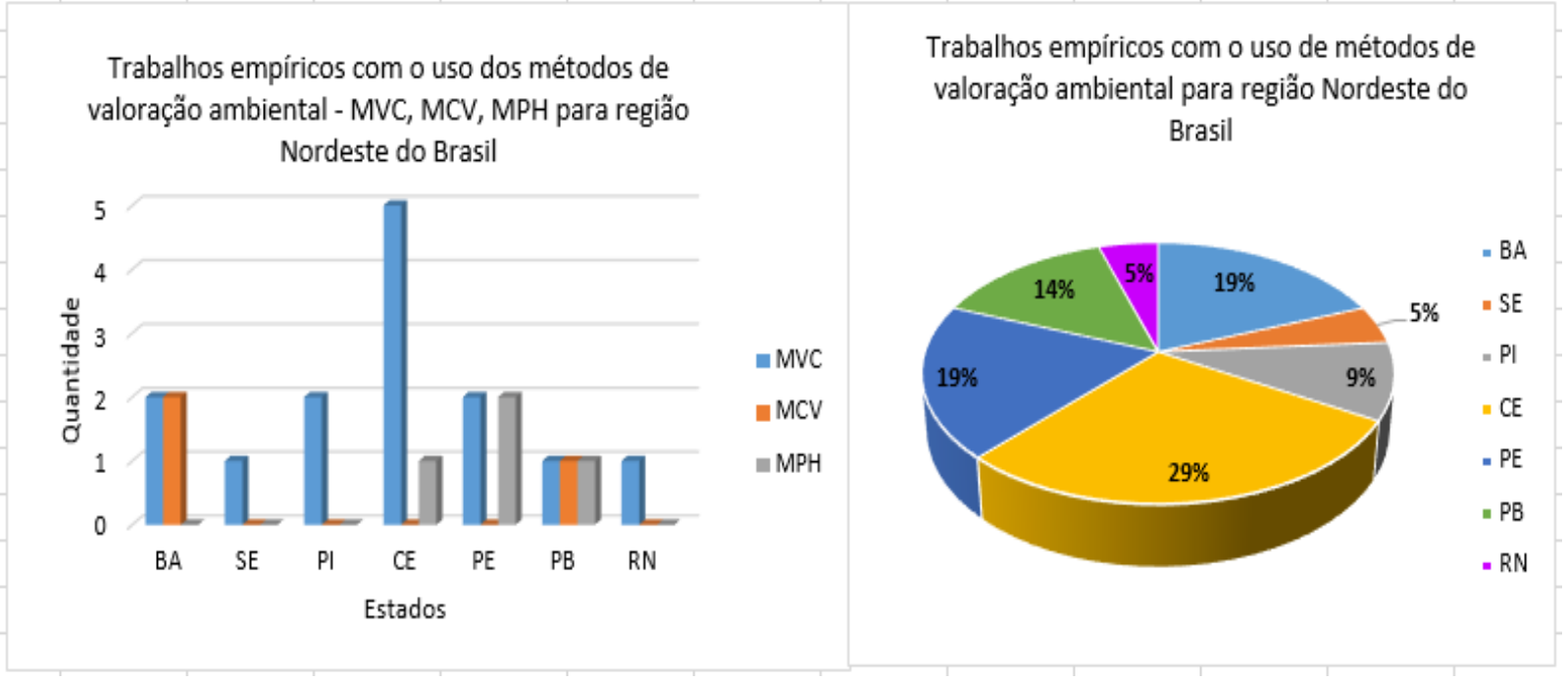

Fonte: Gráfico elaborado pela autora (2015), com base nos capítulos 3, 4 e 5 e os dados colocados no Apêndice D tabela D.8

A Região Norte é a que tem o menor número de trabalhos escritos sobre a valoração de seus ativos ambientais. Não possui trabalho que use o MPH. O MCV só foi utilizado duas vezes (7,69\%). O MVC registrou 92,31\% dos trabalhos. O Estado do Tocantins é o que participa com o maior número de ativos valorados, com 31\%, (Ver gráfico 6.9).

Gráfico 6.9- Visão geral de trabalhos escritos sobre ativos ambientais na Região Norte do Brasil

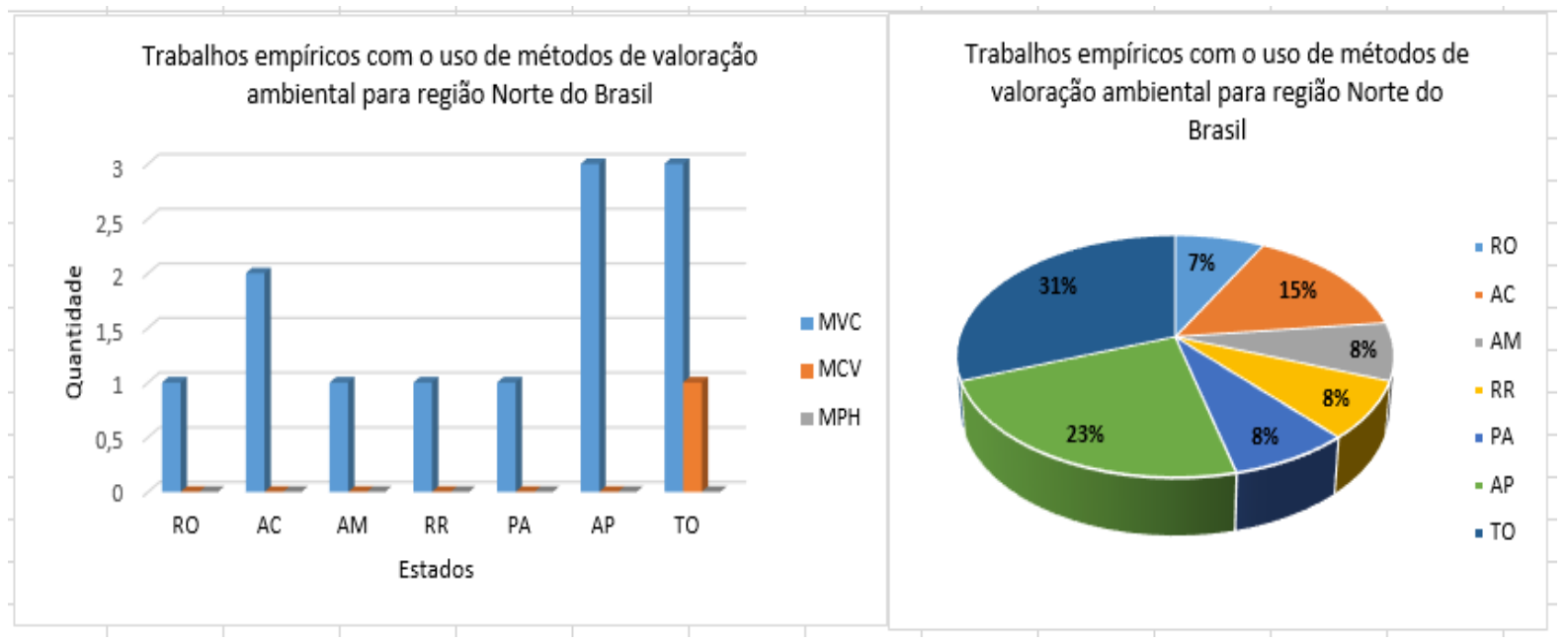

Fonte: Gráfico elaborado pela autora (2015), com base nos capítulos 3, 4 e 5 e os dados colocados no apêndice D tabela D.9 
No Brasil a publicação de trabalhos na área de valoração ambiental tem sido ascendente porém, moderado. Existe um aumento tímido na última décadas de 3,8\% ao ano (ver gráfico 6.10). Essa tendência se deve aos esforços da IES em todo o Brasil, iniciado pelas PósGraduações Stricto sensu principalmente na UFRJ, onde se iniciou todo o processo, UnB e UFSC.

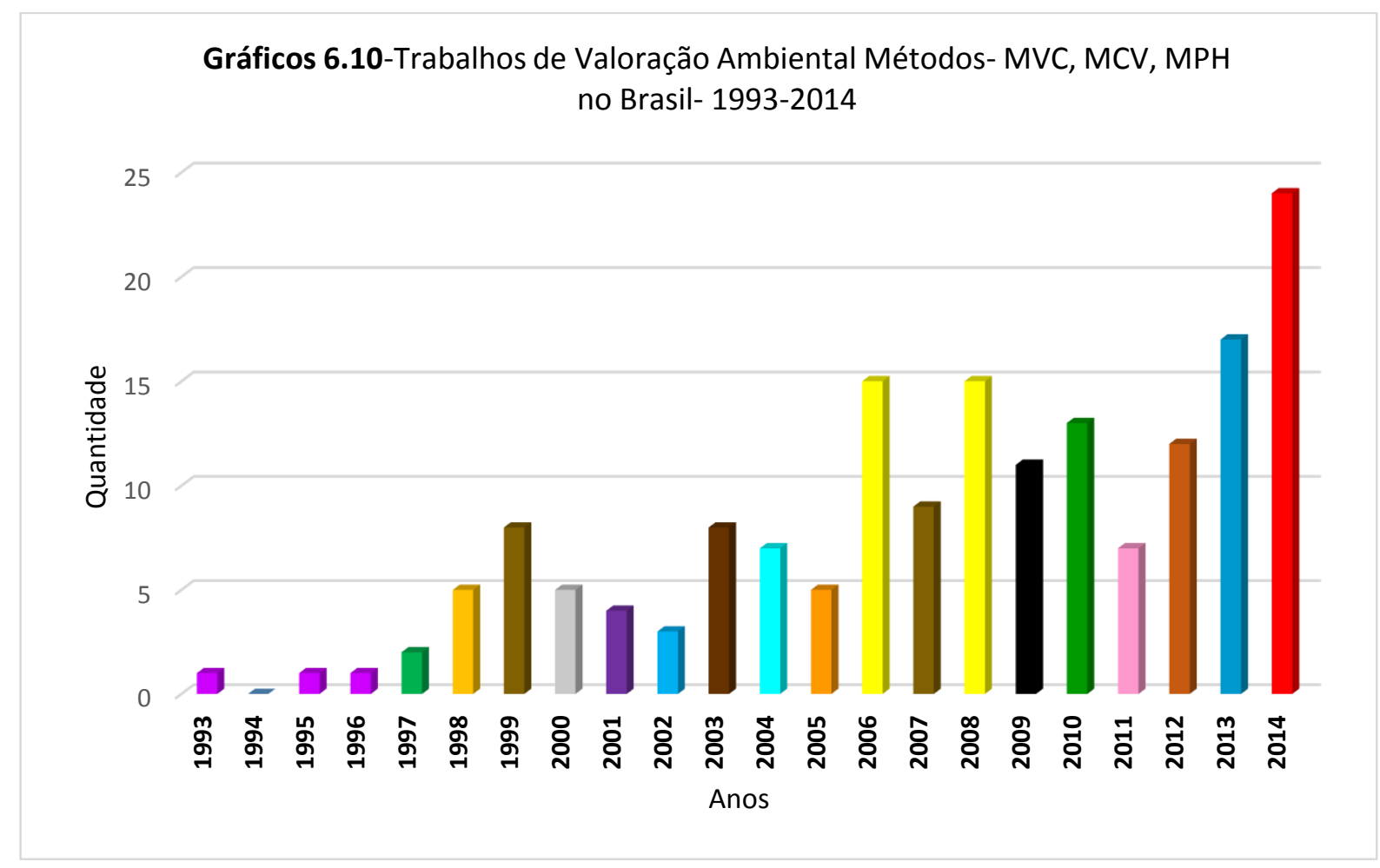

Fonte: Gráfico elaborado pela autora (2015), com base nos capítulos 3, 4 e 5 e os dados colocados no Apêndice D tabela D.10

Os poucos trabalhos teóricos escritos (48) que falam sobre os métodos de Função Demanda apresenta um aprofundamento relativo. Não existe uma discussão sistêmica sobre o assunto e muitos repetem de o mesmo assunto sem no entanto se preocupar em clarificar os pontos fundamentais para uma boa relação entre teoria e prática. O trabalhos foram sistematizados por ano e método, sem no entanto retirar os trabalhos que repetiam (18) por que, poucos falavam somente de um método. No gráfico 6.11 pode-se verificar que os anos de 2001, 2002, 2004 e 2011 nada foi publicado. O máximo de trabalhos publicados por ano (1999, 2008 e 2012) foram três, todos sobre o MVC. Dos Métodos publicados o MCV é o que tem menos estudos. 


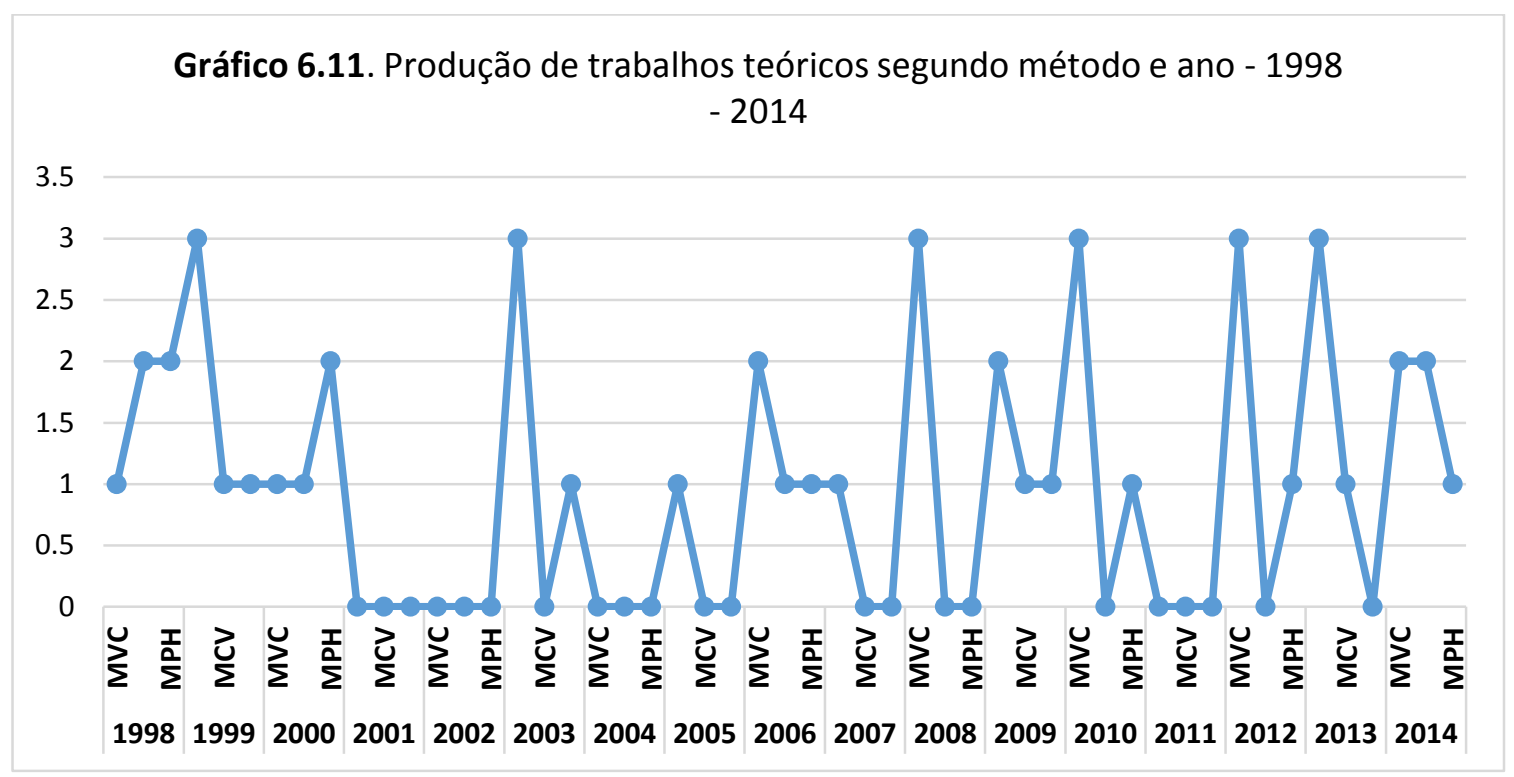

Fonte: Gráfico elaborado pela autora (2015), com base nos capítulos 3, 4 e 5. Os dados estão na tabela D.11, Apêndice D.

Os anos de maior produção intelectual teórica sobre os métodos de função demanda foram 1998, 1999, e 2014. As instituições de ensino que mais colaboraram para a difusão dos métodos foram a UnB (23\%) UFPEL, UFF e UFRJ (8,3\%), Ver gráfico 6. 12.

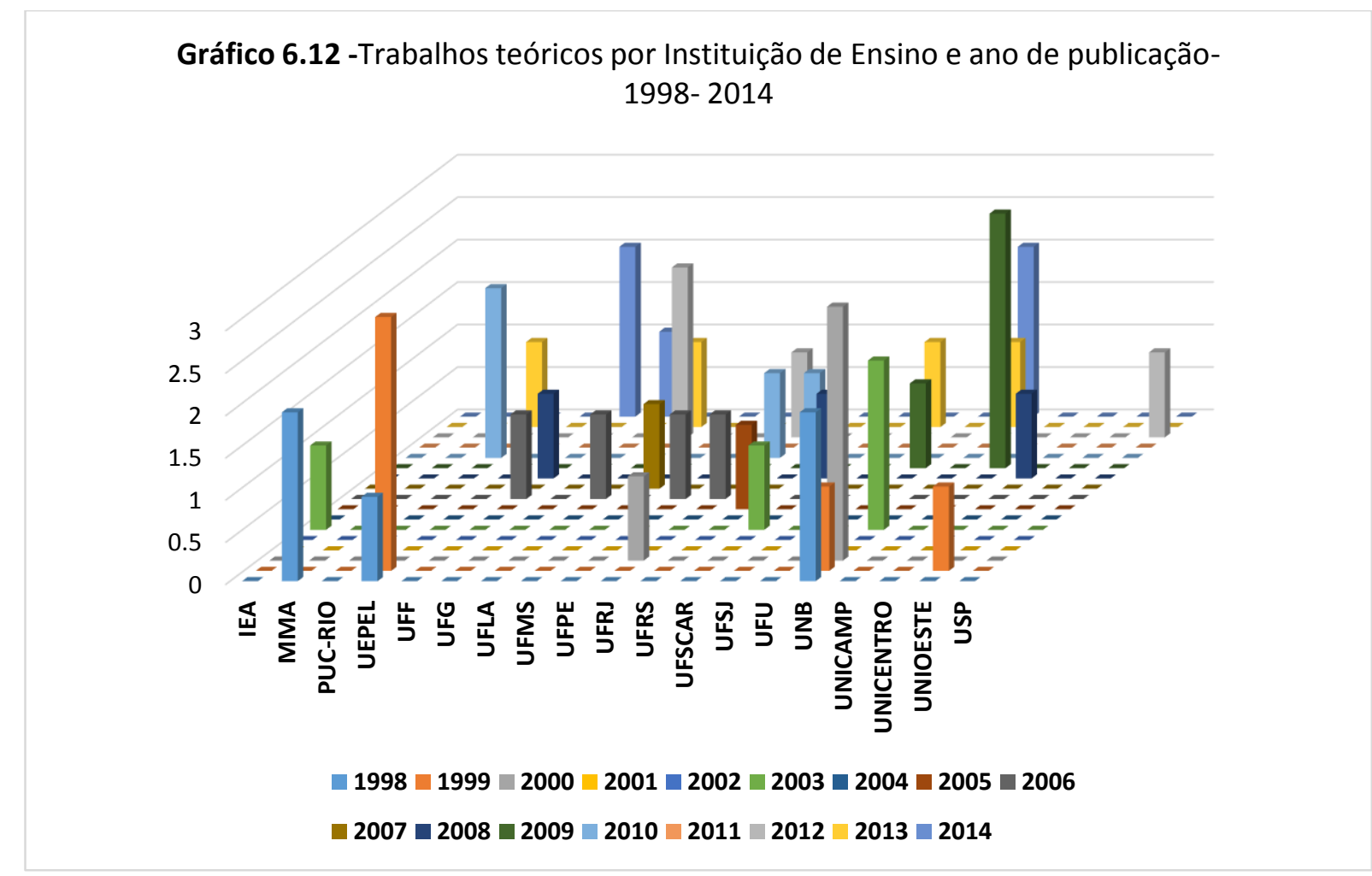

Fonte: Gráfico elaborado pela autora (2015), com base nos capítulos 3, 4 e 5. Os dados estão na tabela D. 12, Apêndice D. 
A produção por regiões e ano estão expressas no gráfico 6.13. Observa-se que a região sudeste é a mais participativa com 45,8\% dos trabalhos teóricos e a região Centro -oeste com $35,4 \%$. A região nordeste apresenta $2,2 \%$ e a Norte não tem nenhum trabalho teórico escrito.

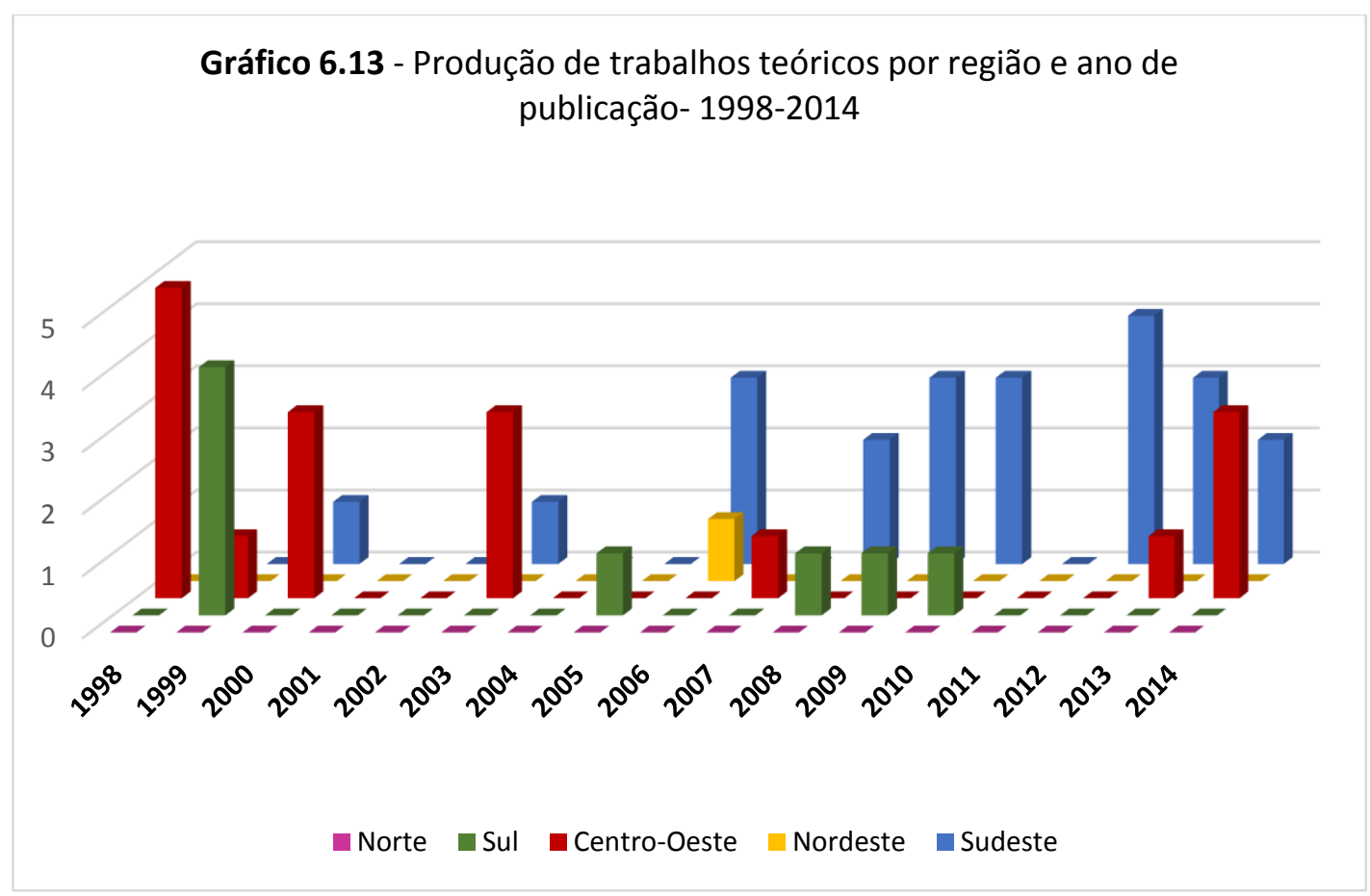

Fonte: Gráfico elaborado pela autora (2015), com base nos capítulos 3, 4 e 5. Os dados estão na tabela D.13 Apêndice D

Existe uma dependência entre os tipos de bens valorados, o método utilizado e os objetivos de pesquisa. No quadro 6.1 são apresentados os principais métodos de valoração por região segundo a utilização dos três métodos de função demanda. A região Centro -Oeste é a que apresenta o maior números de trabalhos $(30,48 \%)$ e a região Norte a menor $(9,1 \%)$. Esta constatação incita o pensamento sobre a responsabilidade da IES para a formação de profissionais que possam proceder pesquisas de valoração ambiental em suas regiões de origem. Esses novos pesquisadores precisam ser capacitados pelas IES para atuarem como multiplicadores técnicos e científicos. Uma outra forma de minimizar o problema da região Norte seria ampliar o escopo de atuação de profissionais de outras regiões para auxiliarem no processo de valoração. Porém, ainda teríamos muitos problemas a solucionar por causa da extensão territorial das regiões e a quantidade de ativos para serem valorados. 
Tabela 6.1 - Quantidade de Trabalhos empíricos por métodos e por regiões no Brasil 1993-2014

\begin{tabular}{l|cccccc|c}
\hline & \multicolumn{5}{|c|}{ Regiões } & \\
\cline { 2 - 6 } Método & Cento-Oeste & Sul & Norte & Nordeste & Sudeste & Total \\
\hline MVC & 23 & 16 & 12 & 14 & 24 & $\mathbf{8 9}$ \\
MCV & 17 & 7 & 1 & 3 & 10 & $\mathbf{3 8}$ \\
MPH & 4 & 3 & 0 & 4 & 5 & $\mathbf{1 6}$ \\
Total & $\mathbf{4 4}$ & $\mathbf{2 6}$ & $\mathbf{1 3}$ & $\mathbf{2 1}$ & $\mathbf{3 9}$ & $\mathbf{1 4 3}$ \\
\hline
\end{tabular}

Fonte: Tabela elaborada pela autora (2015), com base nos capítulos 3, 4 e 5

A tabela 6.2 apresenta os principais tipos de bens valorados no Brasil e pode-se verificar que os pesquisadores brasileiros apresentam criatividade, mesmo que tímida, para a escolha dos bens. Além dos parques $(41,26 \%)$, áreas verdes urbanas $(7,69 \%)$, praias $(6,99 \%)$ e recursos hídricos $(18,88 \%)$, comuns a quase todos os países, estamos valorando estradas, avenidas, gasodutos e feiras. Se conseguirmos aprimorar o uso dos métodos muito mais se poderá realizar em todas as áreas.

O processo de valorar pode parecer simples a quem ensaia os primeiros passo, mas aplicações concretas exigem imaginação e criatividade na determinação de o que e como perguntar aos entrevistados. O desenvolvimento de questões que induzam os entrevistados revelarem suas preferências em relação ao tributo meio ambiente também requer experiência e perspicácia do pesquisador. No Brasil percebe-se a imaginação criadora nos diversos trabalhos analisados, principalmente nos trabalhos dos autores que já utilizaram as técnicas mais de uma vez, pois é no momento da aplicação do método que se faz perceber a inúmeras dificuldades a serem superadas. Uma forma de superar dificuldades na aplicação dos questionários é a utilização do teste piloto que oportuniza readequação das questões a realidades do público alvo. Poucos são os pesquisadores que fazem uso da técnica em seus trabalhos de pesquisa, menos de $30 \%$, e isso pode gerar pequenos defeitos que podem produzir grandes distorções na DAP. Evitá-los permite o aprimoramento do método e obter um valor que realmente exprime o valor do ativo ambiental em análise. 
Tabela 6.2 - Número de trabalhos empíricos sobre os métodos de valoração MVC, MCV e MPH por tipos de bens e por regiões no Brasil -1993-2014

\begin{tabular}{|c|c|c|c|c|c|c|}
\hline \multirow[b]{2}{*}{ Tipos de bens } & \multicolumn{5}{|c|}{ Regiões } & \multirow[b]{2}{*}{ Total } \\
\hline & Cento-Oeste & Sul & Norte & Nordeste & Sudeste & \\
\hline APA & 2 & - & - & - & 3 & 5 \\
\hline APP & 1 & - & - & - & 1 & 2 \\
\hline $\mathrm{Ar}$ & - & - & 1 & 1 & 3 & 5 \\
\hline Áreas verdes urbanas & 2 & 3 & 2 & 2 & 2 & 11 \\
\hline Ativos culturais & 1 & - & - & - & - & 1 \\
\hline Avenida & - & - & - & 1 & - & 1 \\
\hline Câmpus Universitário & 2 & - & - & - & - & 2 \\
\hline Cidade & 1 & - & - & - & - & 1 \\
\hline Estradas & 1 & - & - & - & - & 1 \\
\hline Feiras & 1 & 1 & - & - & - & 2 \\
\hline Gasoduto & - & - & - & - & 1 & 1 \\
\hline Grutas & - & - & - & - & 3 & 3 \\
\hline Horto florestal & 1 & - & - & - & - & 1 \\
\hline Jardim botânico & - & - & - & 1 & 1 & 2 \\
\hline Jardim zoológico & 1 & - & - & - & - & 1 \\
\hline Lixo & - & - & 1 & 1 & 1 & 3 \\
\hline Mangues & - & - & - & - & 1 & 1 \\
\hline Museus & - & - & - & - & 1 & 1 \\
\hline Parques & 23 & 14 & 3 & 8 & 11 & 59 \\
\hline Praias & 0 & 1 & 4 & 2 & 3 & 10 \\
\hline Recursos hídricos & 7 & 6 & 2 & 4 & 8 & 27 \\
\hline Terras agrícolas & 1 & 1 & - & - & - & 2 \\
\hline Transporte público & - & - & - & 1 & - & 1 \\
\hline Total & 44 & 26 & 13 & 21 & 39 & 143 \\
\hline
\end{tabular}

Fonte: Tabela elaborada pela autora (2015), com base nos capítulos 3, 4 e 5 .

Os maiores problemas com aplicação dos métodos de valoração analisados nessa pesquisa foram: amostras inadequadas, instrumentos de pesquisa e os relatórios de pesquisa. Quanto às amostras inadequadas percebeu-se em análise aos três métodos que as pesquisas, em sua maioria, usam fórmulas estatísticas para os cálculos do valor da amostra, porém no descarte de questionários a quantidade é altera e não contempla o rigor do método utilizado. Outro problema para o descarte de questionários é que ao se eliminar algum questionário poderia também excluir uma dada região a qual ele representa e a amostra torna-se não representativa a população selecionada. No que se refere aos instrumentos da pesquisa, a apresentação dos cenários hipotéticos é, por vezes, incompleta, características essenciais dos ativos não podem ser negligenciadas, o que leva a uma valoração irreal. A expansão da DAP para a população nesse caso aumenta a distância entre o valor real e o valor informado. Isso traz prejuízo em 
casos de processos judiciais e criação de políticas públicas para conservação e manutenção dos ativos.

Os relatórios de pesquisas procuram contemplar o maior número possível de informações que o pesquisador acha apropriado divulgar, por falta de uma uniformidade destinada aos resultados, às vezes se torna difícil uma análise mais acurada dos resultados, e muitas informações úteis se perdem impedindo que se possa avançar em novas pesquisas. Um método só pode ser aprimorado quando conhecemos os caminhos que foram percorridos, erros e acertos, fazem parte da pesquisa e deveriam ser divulgados para que em futuras pesquisa os vieses possam ser superados. 


\section{CONSIDERAÇÕES FINAIS}

Concluir um trabalho é sempre difícil porque percebemos que estamos apenas iniciando um infinito processo de indagações e de estudos em busca de respostas. E se o assunto é valoração econômica do meio ambiente temos mais dúvidas que assertivas, por ser um tema relativamente novo, com muitos detalhes a serem observados e principalmente por necessitar de pesquisa de campo incorporando comportamento de consumidores para que o resultado final realmente expresse a vontade de uma população.

Valoração ambiental são métodos propostos para que as pessoas possam perceber através de um valor de mercado que o meio ambiente faz parte do contexto da vida e que uma vez espoliado, erodido, poluído e desrespeitado em sua forma traz mais prejuízos que ganho ao homem de hoje e do futuro. Muitas foram as tentativas de aperfeiçoamento dos métodos e diversas classificações foram utilizadas, por isso uma métrica para realizar sua equivalência foram apresentadas. Sabemos que com o aprofundamento das pesquisas outras denominações irão surgir, então aqui apresentamos apenas o impulso inicial deixando em aberto possíveis formas de completar esse quebra-cabeça.

O rigor teórico no qual é pautado os métodos de valoração ambiental foram reapresentados com o intuito de relembrar quão importante é a ligação da base teórica com a parte técnica dos métodos.

Os métodos de função demanda oportunizam aos indivíduos se posicionarem, exprimirem seus desejos contribuindo com uma classificação de valor do bem e/ou serviço ambiental em seu contexto através de valores monetários. Os métodos aqui estudados dependem diretamente das escolhas dos indivíduos (MVC) ou indiretamente através dos bens e serviços complementares (MCV e MPH). Assim, a base teórica do comportamento do consumidor precisou ser comentada para que pudéssemos perceber todas as nuances pelas quais passa essa escolha individual que agregada representa a vontade de uma comunidade. Ao valorar um ativo ambiental, novamente me posiciono e repito, dar valor a um bem e/ou serviço ambiental não é um trabalho meramente mecânico. O pesquisador deverá ter sensibilidade e conhecimento para extrair a verdadeira DAP ou DAC dos indivíduos (consumidores).

Nessa tese foram catalogados e analissdos195 trabalhos dos diferentes métodos, sendo 146 empíricos e 49 teóricos com algumas repetições. Os motivos das repetições foram: mesma publicação com títulos diferentes, dissertação e artigos com o mesmo título ou títulos próximos, mas com o mesmo banco de dados, o mesmo artigo com datas diferentes e por último mais de 
um método no mesmo artigo. Retiradas as repetições tivemos 173 artigos ao todo sendo 143 empíricos e 30 teóricos. Portanto a tese contém um abrangente banco de dados para futuras pesquisas.

O título sugestivo do terceiro capítulo precisa ser completado num futuro como bem sugeriu uma professora da banca: quem pergunta o que quer, a qualquer pessoa, de qualquer maneira, obtém o que não quer, e isso foi comprovado no capítulo. Através dos relatos de quem ousou valorar ativos através do MVC sem observar as diretrizes. Esse método é relativamente novo em sua aplicação no Brasil e muito temos que aprender. Sabemos que muitas são as diretrizes sugeridas pelo Painel NOAA, porém ignoramos ou esquecemos anos de pesquisa e regras básicas da aplicação do método. Os resultados desta desatenção tornam os resultados imprecisos e até duvidosos.

Dos últimos 15 anos foram catalogados 106 publicações resultados de estudos sobre o MVC, divididos em trabalhos teóricos (16) e empíricos (90). Os trabalhos empíricos foram subdivididos em quatro áreas de conhecimento devido suas diferentes especificidades. $\mathrm{O}$ montante de publicações se deve ao desempenho das IES em todo Brasil. Os pesquisadores são de diferentes áreas do conhecimento sendo que a maioria pertence às áreas das engenharias e ciências sociais aplicadas.

Nesses estudos analisados detectou-se falhas como: o não uso da pesquisa piloto para verificação de compreensão do questionário pelos indivíduos(consumidores) escolhidos para compor a amostra; falhas em detalhar os procedimentos da pesquisa para que se pudesse, se preciso for, enredar pelo mesmo caminho; os números afirmados das questões dos questionários(ora muito grandes ora pequenos demais) não podiam ser comprovados através da leitura das pesquisas; a não observação das diretrizes dos método; e, ainda não conseguimos contornar alguns vieses como o da: informação, escopo, instrumento, veículo de pagamento e de protesto, esse último muito difícil de realizar pela situação econômica e política do País.

No que se refere a agregação das DAPs pequenos erros nos leva a grandes distorções de valores. Alguns trabalhos não se preocuparam com a qualidade (quem vai responder) e quantidade (quantos vão efetivamente responder) da amostra. Ao se traçar objetivos de pesquisas os responsáveis assumem uma responsabilidade de alcança-los. Isso não significa obter apenas uma resposta, significa que poderemos estar traçando destinos de pessoas e ambientes que se quer conhecemos. Ao se valorar um ativo ambiental no Brasil estamos emitindo pareceres a destinos conforme nossa visão, em percebermos quão grande é nossa responsabilidade sobre a vida de outros seres. Assim, repito o que é a DAP sozinha? Não é nada. Ela faz parte de um processo de valoração, e muito mais pode-se obter nesse processo 
além das informações das pessoas (consumidores), estamos apresentando a opinião de uma comunidade em relação ao seu espaço.

Sobre o Método Custos de Viagem, foram analisados 47 trabalhos dos quais 39 são empíricos se destinam em valorar parques, praias e rios. E, 8 teóricos todos artigos pois, não existem livros sobre esse assunto publicado no Brasil. Quanto aos aspectos gerais os mesmos problemas apresentados nos trabalhos sobre MVC também foram exibidos em trabalhos que usaram esse método, portanto não vou me delongar a esse respeito. Problemas quanto ao uso específico do MCV foram destacados: locais que coexistiam com mais de um destino foram ignorados; alguns trabalhos não foram criteriosos com o uso da definição de custo de oportunidade do tempo e o cálculo ficou inadequado. A aplicação do questionário foi realizada em momentos impróprios (somente em alta temporada ou em baixa temporada) o que interferiu nos resultados.

Uma peculiaridade deste método foram os locais de aplicação em relação aos diferentes ativos valorados no Brasil, percebeu-se que temos consciência da importância de nosso patrimônio cultural e ambiental, isso significa que precisamos nos especializar para atingirmos o maior número possível de ativos. Existem regiões como a Norte que somente um trabalho a representa e isso é preocupante porque aquilo que não tem valor não é valorizado pela sociedade contemporânea.

O último dos métodos de função demanda analisado foi o MPH, 11 teóricos e 17 empíricos. Dos teóricos todos são artigos. Existem inúmeros trabalhos ligados ao MPH porém poucos são os que incluem a variável ambiental. Dos trabalhos elegidos se destacam aqueles que apresentaram vetores adjacentes ao imóvel relacionados com saneamento, urbanização, transporte e erosão. A análise da variável ambiental ou inexiste nos trabalhos ou são pouco comentados. Novamente percebeu-se problemas com amostra, técnica de amostragem e relatórios de pesquisa. No que se refere ao método o problema detectado são as omissões de variáveis que caracterizam os imóveis e áreas adjacentes, como o método é muito sensível a quantidade e qualidade dos dados essas omissões provocam estimativas tendenciosas. Um cenário incompleto induz a um valor irreal.

O Brasil ainda é carente em publicações a respeito do uso dos métodos de função demanda e isso induz os pesquisadores a procurar na literatura estrangeira subsídios teóricos que os apõem em suas pesquisas. Os autores teóricos mais consultados são Pearce (1993), Freeman III (1979, 2003), Hanley e Spash (1993). Existem, também, os autores nacionais que firam consultados frequentemente como: Motta (1997, 1998), Nogueira; Medeiros e Arruda 
(2000), Romeiro e Maia (2003). Ressalta-se assim uma tendência na busca por conhecimento e uma responsabilidade muito grande de poucos autores em nortear trabalhos brasileiros.

A região norte por exemplo, poucos foram as iniciativas de valoração, em contrapartida nas regiões Sudeste e Centro-Oeste pode-se verificar a concentração de esforços por apresentar uma gama de trabalhos com o uso dos três tipos de métodos aqui apresentados. Nesse momento gostaria de apresentar um apelo aos formuladores de políticas públicas em reforçar a ideia de formação de profissionais capacitados em valoração do meio ambiente na Região Norte. Poderíamos ter uma linha de crédito direcionada às instituições de ensino para capacitar mão de obra em Economia do Meio Ambiente, com uma linha de pesquisa direcionada a valoração ambiental. É bem verdade que a amostra colhida nessa tese ainda poderá ser acrescentados outros trabalhos, diversos foram os motivos de não escolha entre eles o não acesso a pesquisa porque não há uma uniformidade de termos para procura on-line ou a dissertação e tese estavam indisponíveis por meio eletrônico. Também não foi pretensão do trabalho analisar todos os trabalhos, apenas uma amostra que os representassem.

Observou-se, também, que existem pesquisas com rico embasamento teórico, detalhadas, criativas, inovadoras e de grande relevância cientifica para nosso banco de dados. Todas essas qualidades não foram sistematicamente apontadas (ponto frágil da pesquisa) porque fugiam aos escopo desse trabalho, mas deixo aqui a oportunidade de novos trabalhos em levantar as grandes verdades dos trabalhos escritos por brasileiros sobre o Brasil e tenho certeza que muito iremos nos surpreender com os esforços até aqui apresentados por antigos e novos pesquisadores.

Um ponto forte dessa tese é apresentado no final dos capítulos três, quatro e cinco em forma de um check list para que futuros pesquisadores possam se embasar no momento de realizar trabalhos empíricos sobre os três métodos de valoração MVC, MCV e MPH. Também fica a sugestão para aqueles pesquisadores que se dedicam escrever sobre trabalhos teóricos sobre valoração ambiental, que seus trabalhos sejam mais detalhados nos diversos aspectos do método para que possamos ter uma literatura mais aprofundada e que possíveis dúvidas possam ser dirimidas ao longo do processo de valoração ambiental. 


\section{REFERÊNCIAS}

ABAD, M. C. E. Valoração econômica do meio ambiente: o método de valoração contingente no Brasil. 2002. 137 f. Dissertação (Mestrado em Economia e Gestão Econômica do Meio Ambiente) - Centro de Estudos em Economia, Meio Ambiente e Agricultura, Universidade de Brasília, 2002.

ABREU, E. A. P. de; SILVA, A. G. da. Valoração Econômica: aplicação do método do custo de viagem para a Praia da Avenida em Maceió. FAPEAL. Anais... do XXXVI Encontro Nacional de Economia- ANPEC, Niterói, RJ. 2008.

ADAMS, C. et al. Valoração Economia do parque Estadual Morro do Diabo (SP). Páginas \& Letras Editora Gráfica: São Paulo, 2003. 23 p.

ACTON, J. P. Evaluating public progress to save lives: the case of heart attacks. Rand Research Report R-73-02. RAND Corporation, Santa Monica, CA. 1973.

AGUIAR, A. L.; ORTIZ, R. A. Estudo de Valoração Econômica do Parque Nacional de Brasília: Métodos da Valoração Contingente e do Custo de Viagem. Brasília (mimeo), 1998.

AGUIRRE, A.; FARIA, D. M. C. P. A utilização de "preços hedônicos" na avaliação social de projetos. Revista Brasileira de Economia, v. 51, n. 3, p. 391-411, set. 1997.

AIACHE, R. R. Uso de instrumentos econômicos para valoração de parques nacionais: os casos do Parque Nacional de Brasília e do Parque Nacional do Iguaçu. 2003. 146 f. Dissertação (Mestrado em Gestão Econômica do Meio Ambiente) - Universidade de Brasília, Brasília, 2003.

AHEARN, M. C.; BOYLE, K. C.; HELLERSTEIN, D. R. Designing a CV study to estimate the benefits of the CRP on grassland bird populations. In: ALBERINI, A.; KAHN, J. R. (Ed.). Handbook on Contingent Valuation. Northampton: Edward Elgar Publishing, 2006. p. 204-231.

ALBERINI, A.; BOYLE, K. J.; WELSH, M. P. Analysis of contingent valuation data with multiple bids and bids response options allowing respondents to express uncertainty. Journal of Environmental Economics and Management. 2003.

ALBUQUERQUE, E. E.; MELO, A. S.S.de A.; SOUZA, H. R. de. Ativo ambiental e preço de imóvel em Recife: um estudo exploratório a partir da utilização o método dos preços hedônicos. 2007. Disponível em: 〈www.ecoeco.org.br>. Acesso em: 10 abr. 2014.

ALMEIDA, A. N. Et al. Disposição a pagar pela preservação e melhoria do Parque olhos D'Agua- DF. Anais... V Congesso Brasileiro da Gestão Ambiental. Belo Horizonte - $24^{a} 27$ de nov., 2014.

ALVES FILHO, M. V.; VALADARES, M. B. Valoração econômica: Os métodos de custo de Viagem e de valoração contingente aplicado às praias de Palmas-TO. SOBER, 2008. 
AMAZONAS, L. V. F. Métodos de preços hedônicos e a valoração de áreas verdes urbanas: Parque Vaca Brava em Goiânia-Goiás. Brasília, 2010. 142 p. Dissertação (Mestrado em Gestão Econômica do Programa de Pós-Graduação em Economia, Administração, Contabilidade e Ciência da Informação e Documentação) - Universidade de Brasília, Brasília, 2010.

AMAZONAS, M.DE C. Valor ambiental em um perspectiva heterodoxa institucionalecológica. Economia e Sociedade, Campinas, v. 18, n. 1, p. 183-212, abr. 2009.

AMIRAN, E. Y.; HAGEN, D. A. The Scope Trials: Variation in Sensitivity to Scope and WTP with Directionally Bounded Utility Functions. Journal of Environmental Economics and Management, v. 59, n. 3, p. 293-301, 2010.

ANDERSSON, D. E. Hedonic Prices end center accessibility: conceptual foundations and na Empirical Hedonic study of the Market for consominium housing in Singapure: National Taiwan University, 1997.

ANDRADE, M. O.; MAIA, M. L. A. Aplicação do modelo dos preços hedônicos para avaliação da influência da acessibilidade ao transporte público sobre o preço da terra urbana. In: XXI ANPET - Congresso Nacional de Pesquisa e Ensino em Transportes, Rio de Janeiro, Brasil. Panorama Nacional da Pesquisa em Transportes, 2007.

ANEX, R. P. A. Travel-cost method of evaluating household hazerdous waste disposal services. Jornnal fo Environmental Management, v. 45, p. 189-198. 1995.

ANGELO, C. F. de; FOUTO, N. M. M. D.; LUPEE, M. R. Segmentação de mercado e preçoscasos: automóveis, vinhos, computadores, locações comerciais e imóveis residências. São Paulo: Saint Paul Editora, 2008.

ANGELO, P. G.; CARVALHO, A. R. Valor recreativo do Rio Araguaia, região de Aruanã, estimado pelo método do custo de vigem. Acta Sci. Biol. Sci., Maringá, v. 29, n. 4, p. 421-428, 2007.

ARAUJO, A. B. A. Disposição a pagar pela recuperação/preservação do Rio Apodi-Mossoró. Mossoró, 2014. 83 f. Dissertação (Mestrado em Meio Ambiente, Tecnologia e Sociedade da Universidade Federal rural do Semi-Árido.) Mossoró, 2014.

ARAÚJO, A. F. V. de; RAMOS, F. S. A Influência das Observações não Representativas e dos Votos de Protesto na Avaliação de Ativos Ambientais: o método de avaliação contingente Revista Econômica do Nordeste, Fortaleza, v. 36, n. 4, out.-dez. 2005.

ARAÚJO, A. F. V. Valoração ambiental; uma aplicação do modelo logit a avaliação monetária do Jardim Botânico da cidade de João Pessoa. UFPE. 2002.

ARAUJO, H. R.Valoração dos serviços ambientais da gruta do Salitre, Diamantina, Minas Gerais, Brasil. Ouro preto, 2014. 72f. Dissertação (Sustentabilidade Socio economica ambiental da Universidade Federal de Ouro Preto) Ouro Preto, 2014. 
AZEVEDO, N. G. Benefícios econômicos agregados às propriedades urbans pelas paisagens naturais. Natal, 2014. 55 f. Dissertação (Mestrado em Desenvolvimento e Meio Ambiente da Universidade Federal do Rio Grande do Norte. PRODEMA). Natal, 2014.

BARCELOS, T. S. Valoração econômica do Santuário do Caraça em Minas Gerais/ Br. Ouro Preto, 2014.136 f. Dissertação (Sustentabilidade socioeconômica Ambiental da Universidade de Ouro Preto). Ouro Preto, 2014.

BARBIER, E. B. Valuing ecosystene servicies as productive inputs. Economic Policy, n. 22, p. 177-229, 2007.

BARBISAN A. O.; PANDOLFO, A.; REINEHR, R. Técnica de valoração econômica de ações de requalificação do meio ambiente: aplicação em área degradada. Revista Engenharia, v. 14, n. 1, p. 119-128, jan./mar., 2009 .

BARTIK, T. J.; SMITH, V. K. Urban Amenities and Public Policy. In: MILLS, E. S. (Ed.). Handbook of Regional and Urban Economics. Amsterdam: Elsevier, 1987.

BARRETO, M. E. A valoração econômica como instrumento de gestão ambiental aplicável à compensação ambiental: o caso do parque estadual do Ibitipoca- MG. Ambito Juridico n. 111, ano XVI, mar. 2013.

BATAlHONE, S. A. Uma Abordagem Empírica sobre o Método de Preços Hedônicos e o Valor dos Imóveis Residenciais. 2000. Dissertação (Mestrado em Economia) - Departamento de economia, Universidade de Brasília, Brasília, 2000.

BATEMAN, I. J.; TURNER, R. T. Valuation of the environment methods and tecniques: the contingente value method. In: TURNER, R.T. Sustainable environmental economics and management principle and pratice. Belhaven Press, New York, 1992.

BATISTA, B. M. F. Valoração econômica do campus da UFMT- Cuiabá como área de lazer e recreação. Cuiabá, 2014. Dissertação (Ciências Florestais e Ambientais da Universidade Federal do Mato Grosso). Cuiabá, 2014.

BARZEV, R. Guía metodológica de valoración económica de bienes, servicios e impactos ambientales: vprredor biológico mesoamericano. Série técnica 04, CCAD - PNUD/GEF, 2002.

BELLUZZO JR., W. Valoração de bens públicos: o método de valoração contingente. 1995. 151 p. Dissertação (Mestrado em Economia) - Universidade de São Paulo, São Paulo, 1995.

BELLUZZO JR., W. Avaliação contingente para valoração de projetos de conservação e melhoria dos recursos hídricos. Pesquisa e Planejamento Econômico, Rio de Janeiro, v. 29, n. 1, p.113-136, 1999.

BENETEZ, R. M. Impactos das preferencias ambientais sobre os resultados dos métodos de análise de valoração ambiental- Rating e Ranking contingente. 2005. 179 f. Tese (Doutorado em Economia) - Universidade Federal do Rio Grande do Sul, Porto Alegre, 2005.

BENTES, E. S. et al. Valoração econômica da jusante da barrage de Tucuruí. Revista de Política Agrícola.MAPA, Ano XXIII, n. 4, out./nov./dez., 2014 
BEM, J. S. de; GIACOMINE, N. M. R. O uso do método de valoração contingente para uma cesta de bens culturais no município de Canos, rio grande do Sul. Revista do Museu e Arquivo Histórico LaSalle. Mouseio, n. 10. Jul./dez., 2011.

BERNARD, C. T. da S.; NOGUEIRA, J. M.; CRUZ NETO, C. C. Valoração de nada e precificação de tudo? A herança maldita das valorações dos serviços ecossistêmicos de R. Costanza. Sociedade Brasileira de Economia Ecológica, 2015.

BISHOP, R.C.; HEBERLEIN,T.A. 'Measuring values of extra market goods', American Journal of Agricultural Economics, v.61, p. 926-930, 1979.

BLAKEMORE, F., \& WILLIAMS, A. British tourists' valuation of a Turkish beach using contingent valuation and travel cost methods. Journal of Coastal Research, v. 24, n. 6, 2008.

BOCATO JR, F. C.; CUNHA, A. C. aplicação do método de avaliação contingente para a estimativa do valor de uso da área de proteção ambiental da Fazendinha- APAFAZ, Macapá, amazônio - BR. Revista Geomae Campo Mourão, Pr. V.4, n.1, 2013.

BOCKSTAEL, N.; et al. Measuring the Benefits of Water Quality Improvements Using Recreation Demand Models. Draft Report Presented to the US Environmental Protection Agency under Cooperative Agreement, Washington, 1987.

BOFF, L. Saber cuidar: ética do humano. Petrópolis: Vozes, 1999.

BORBA, R. A. V. Um modelo para avaliação dos efeitos do impacto ambiental no valor imobiliário e sua aplicação com o estudo de caso da Usina de Compostagem de Lixo da Vila Leopoldina. São Paulo, 1992. 72 p. Dissertação (Mestrado em Engenharia Civil) - Escola Politécnica da Universidade de São Paulo, Universidade de São Paulo, São Paulo, 1992.

BORBA, R. A. V. Segurança como variável na metodologia do preço hedônico. $11^{\mathrm{a}}$ conferência Internacional da LARES- Latin merican Real Estate Society, Centro Brasileiro Britânico, São Paulo, p.14-16, set. 2011.

BORJA, O.R.P. Ecoturismo responsável: valoração econômica de bens e serviços ambientais. Revista Brasileira de Ecoturismo. São Paulo, v. 4, n. 3, p. 345-360, 2011.

BOTÊLHO, A. F. Método Custo de Viagem na Valoração do Parque Municipal do Itiquira. Dissertação (Mestrado em Gestão Econômica do Meio Ambiente) - Faculdade de Economia, Administração, Contabilidade e Ciências da Informação e Documentação (FACE), Departamento de Economia, Universidade de Brasília, Brasília, 2005.

BOYLE, K. J. Contingent valuation in practice. In: CHAMP, P. A.; BOYLE, K.J.;BROWN,T.C. (EDs.) Series Editor Ian J. Bateman.Boston : Kluwer Academic Publishers.p.111-170, 2003.

BUZIN, E.J.W.K. et al. Análise da disposição a pagar por produto agrícola a ser oferecido ao Mercado. Revista Agrarian Academy Centro Cientifico Conhecer. v.1,n.1, 2014. 
BOWEN, H.R. The interpretation of voting in the allocation of economic resources. Quarterly Journal of Economics, v. 58, p. 27-48, 1943.

BOWEN, W.; et al.. Theoretical and empirical considerations regarding space in hedonic housing price model applications. Growth and Change, v. 32, n. 4, p. 466-490, 2001.

BRAGA, P.L.S.; ABADALLAH, P.R.; OLIVEIRA, C. R. de. Valoração econômica do parque Nacional da Lagoa do Peixe, RS. Instituições, Eficiência, Gestão e Contratos no Sistema Agroindustrial - SOBER. Ribeirão Preto: Editora da USP, 2005. v. 1.

BRANDLI, E. N.; et al. Análise das vantagens e limitações dos métodos de valoração de recursos ambientais: Método do custo de viagem, método de valoração contingente e método de preços hedônicos. XIII SIMP, Bauru, SP. 6 a 8 de nov. 2006.

BROWN, W. G. et al. Using individual observations to estimate recreation demand functions: a caution. American Journal of Agricultural Economics, v. 65, n. 1, p. 154-157, 1983.

BROWN, J.N.; ROSEN, H. S. On the estimation of structural hedonic price models. Econometrica, n. 50, p. 765-768, 1982.

BRENT, R.J. Applied cost-benefit analysis Cheltenham: Edwuard Elgar, 1997.

BRUGNARO, C. Valuing riparian forests restoration: a CVM application in Corumbatai river basin. Revista de Economia e Sociologia Rural, v. 48, n. 3, p. 507-520, 2010.

CAMARGO, P.L.T. Valoração ambiental da área da Serrinha (Parque Estdual do Itacolomi) Mariana/MG. Ouro Preto, 2014. 111f. Dissertação (Sustentabilidade Socioeconomica e ambiental da Universidade de Ouro Preto) Ouro preto, 2014.

CAMERON, T.A. 'A new paradigm for valuing non-market goods using referendumdata: maximum likelihood estimation by censored logistic regression', Journal of Environmental Economics and Management, v.15, p. 355-379, 1988.

CAMERON, T.A.; M.D. JAMES . 'Efficient estimation methods for 'closed-ended' contingent valuation surveys', Review of Economics and Statistics, v.69, p. 269 - 276,1987.

CAMPOS, E. M. G.; CIRINO, J. F.; ANDRADE, D. C. Modelo de regressão para estimar o diferencial de preços das terras agrícolas com e sem erosão em Lagoa dourada (MG) pelo Método dos Preços Hedônicos. XXXVI SBPO-O impacto da Pesquisa Operacional nas novas Tendências Multidisciplinares. São João Del Rei (MG). 23-26 nov. 2004.

CARNEIRO, D. Q. Caracteristicas econômicas do valor de uso e de não uso de parques sobre dunas. 2014, 71f. Dissertação (Mestrado em Desenvolvimento e Meio Ambiente do programa regional de pós-graduação da Universidade do Rio Grande do Norte) .Natal, 2014.

CARSON, R. T. Contingent Valuation: A Pratical alternative when prices are not available. Journal of Economic Perpectives. v. 26, n. 4, p. 27-42, 2012.

CARSON, R. T.; J. LOUVIERE A common nomenclature for stated preference elicitation approaches, Environmental and Resource Economics, v.49, n. 4, p.539-559, 2011. 
CARSON, R.T.; T. GROVES. Incentive and informational properties of preference questions', Environmental and Resource Economics, v.37, p. 181-210, 2007.

CARSON, R.T.; HANEMANN, W. M. Contingent valuation'. In: MÄLER, K. G.; VINCENT, J. R. (Ed.). Handbook of Environmental Economics. Amsterdam: Elsevier, 2005.

CARVALHO, A.R. Abordagem ecológico-econômica para estimar o valor do fragmento de uma planície de inundação no Brasil (Estado do Mato Grosso do Sul). Brasil J. Biologia, v. 67, n. 4, p. 663-671, 2007.

CARVALHO, D.R. O parque nacional da Chapada Diamantina: Valor econômico da Paisagem centrada no sujeito e no Espaço. GeoNordeste, n. 2, 2009.

CARR, L. MENDELSOHN, R. Valuing Coral Reefs: A Travel Cost Analysis of the Great Barrier Reef. Royal Swedish Academy of Sciences, Ambio, v. 32, n. 5, aug. 2003.

CARRAMASCHI, E.C; CORDEIRO NETO, O.M.; NOGUEIRA, J.M. O preço da água para irrigação: um estudo comparativo de dois métodos de valoração econômica- Contingente e dose resposta. Caderno de Ciência \& Tecnologia, Brasília, v. 17, n. 3, p. 59-81, set./dez. 2000.

CARRERA-FERNANDEZ, J. Curso básico de microeconomia. Salvador: EDUFBA, 2009.

CASTRO, J.D.B. Valor econômico dos parques de Anápolis/GO: Uma plicação do métodod de Valoração Contingente. Anais da Jornada de Pesquisa, Pós-Graduação e Extensão da UnUCSEH. Anápolis. Anais... V.1, n.1, 2014.

CASTRO, J.D.B.; CASTRO, M.C.G. Parqes municipais em avaliação: uma aplicação do método de valoração contingente para o municipio de Anápolis/GO. $3^{\circ}$ coloquio Iberoamericaano- Paisagem Cultural, Patrimônio e projeto. Anais... Belo Horizonte, 15 a 17 de setembro,2014.

CASTRO, J.D.B.; NOGUEIRA, J. M. Valoração econômica de bens públicos: usos e abusos da valoração contingnete no Brasil. Anais da Sociedade Brasileira de Economia Adiministração e Sociologia Rural. Goiânia. Anais...52 Congresso da SOBER. 27 a 30 de Jul.,2014.

CASTRO, J.D.B.; NOGUEIRA, J. M.Vários caminhos um objetivo: o Método Custo de Viagem. Anais da Sociedade Brasileira de Economia Adiministração e Sociologia Rural. Goiânia. Anais...52 $2^{\circ}$ Congresso da SOBER. 27 a 30 de Jul.,2014.

CAULKINS, P. P.; BISHOP, R. C.; BOUWES, N. The Travel Cost Model for Lake Recreation: A Comparison of Two Methods for Incorporating Site Quality and Substitution Effects. American Journal of Agricultural Economics, v. 68, n. 2, p. 291-97, may 1986.

CEBUlA, R. J. The Hedonic Pricing Model Applied to the Housing Market of the City of Savannah and Its Savannah Historic Landmark District. the Review of Regional Studies, v. 39, n. 1, p. 9-22, 2009. 
CENTENO A. B. O método do custo de viagem aplicado na valoração do histórico e patrimônio cultural da Região de Castilha- Leon, Espanha. $40^{\circ}$ Congresso de Associação europeia de Ciência Regional. Barcelona, 2000.

CINTRA, L. D.; CASTRO, J.D.B. Valoração contingente do parquet da Liberdade em Anápolis Anais da Jornada de Pesquisa, Pós-Graduação e Extensão da UnUCSEH. Anápolis. Anais... V.1, n.1, 2014.

CIRINO, J. F.; LIMA, J. E. Valoração contingente da área de Proteção ambiental APA- São José -MG: um estudo de caso. Revista Economia e Sociologia Rural, v. 46, n. 3, jul./set. 2008.

CONRADIE, B.; GARCIA, M. Na estimate of the recreational of the Agulhas Plain, South Africa, with special reference to the value of plant biodiversity.Sajems v.16, n. 2, 2013.

CONTADOR, Cláudio Roberto. Avaliação social de projetos. 3 Ed. São Paulo: Atlas, 301 p., 1981.

CORBETI, C.M.C.; ALVIN, A.M.;DIAS, D.V.. Valoração econômica dos recursos hídricos da região de Pelotas. Revista Acadêmica da FACE, Porto Alegre, v. 21, n.1, p. 85-96, jan./jun. 2013.

CORREAA, M. A.; ALMEIDA, F. P. Disposição à pagar pelo uso do Parque Municipal Victório Siquieroli no município de Uberlância (MG). V congress Brasileiro de Gestão Ambiental. Belo Horizonte. Anais do IBEAS, 24 a 27 de nov. 2014.

COSTA, D. M. B. A valoração econômica como ferramenta para compensação de derramamento de petróleo. 2012. Dissertação (Mestrado Planejamento Energético) - COPPE, Universidade Federal do Rio de Janeiro, Rio de Janeiro, 2012.

COURT, L. M. Entrepreneurial and Consumer Demand Theories for Commodities Spectra. Econometrica, v. 9, n. 1, 1939, p.135-162.

DANTAS, R. A.; CORDEIRO, G. M. Uma nova metodologia para a avaliação de imóveis utilizando modelos lineares generalizados. Revista Brasileira de Estatística, v. 49, p. 27-46, 1988.

DAVIDSON, J. D. Forecasting traffic on STOL. Operations Research Quarterly. v. 24, p. 561$569,1973$.

DAVID, J.; RICHARDS, M., Economics and Participatory Forest Management: A Case of Inappropriate Precision or Untapped Potential? Forest Policy and Environment Group, ODI, London, 1998.

DAVIS, R. K. Recreação planejamento como um problema econômico. Jornous Nat. Recursos, v. 3, p. 239, 1963.

DE FRIES, R.; PAGIOLA, S. (Coord.). Analytical Approaches for Assessing Ecosystem Condition and Human Well-being. In: HASSAN, R.; SHOLES, R.; ASH, N. (Ed.). Ecosystems and Human Well-being. Estados Unidos da América: Island Press, 2005. p. 37-71. (Ecosystems and Human Well-being: Current State and Trends, v. 1). 
DIAMOND, P. A.; HAUSMAN, J.A. Contingent Valuation: Is Some Number. Journal of Economic Perspectives, v. 8, n. 4, p. 45-64, 1994.

DOMICIANO, C.S.; RIBEIRO, F.L.; DOMICIANO, F.S. Análise do perfil socioeconômico e os custos de viagem dos visitantes do Parque Nacional da Chapada dos Veadeiros (PNCV) uma contribuição ao desenvolvimento da comunidade de seu entorno. X Congresso Nacional de Meio Ambiente de poços de Caldas. Instituto Federal, 2013.

DUBEUX, C. B. S. A Valoração Econômica como instrumento de Gestão Ambiental - O Caso da Despoluição da Baía de Guanabara. 1998. Dissertação (Mestrado) - Universidade Federal do Rio de Janeiro, Rio de Janeiro, 1998.

EPPLE, D. Hedonic Prices and Implicit Markets: Estimating Demand and Supply Functions for Differentiated Products. Journal of Political Economy, v. 87, n. 1, p.59-80, 1987.

EUSTÁCHIO, J. A. V.; TÁVORA JUNIOR, J. L. Metodologias de avaliação de ativos ambientais: uma comparação entre medidas. Disponível em: <http://www.ecoeco. unicamp.br/ecoeco.> Acesso em: abril. 2014.

FACCO, J.; JACOSKI, C. A. Conjugação de métodos de valoração aplicados a um parque ambiental - Estudos com o Ecoparque Chapecó- SC. Holos Environment, v. 13, n. 1, p. $112-$ $121,2013$.

FALCO, G. P. et al. A gestão socioambiental à luz das técnicas de valoração econômica do ambiente: uma análise do valor de uso indireto e do valor de existência. VII SEGeT-Simpósio de Excelência em Gestão e Tecnologia, 2010.

FARIA, R. C. de et al. Uma aplicação do método de preços hedônicos no setor de saneamento: projeto de São Bento do Sul - SC. Planejamento e Políticas Públicas, n. 31, jun. 2008.

FARIA, R. C.; NOGUEIRA, J. M. Métodos de valoração contingente: aspectos teóricos e testes empíricos. Anais do 52a Reunião Anual da SBPC, de 9-14 jul. 2000.

FARIA, R. C.; NOGUEIRA, J. M. Método de Valoração contingente: Aspectos Teóricos e Testes empíricos. Cadernos para Discussão, série NEPAMA, Brasília, n. 4, 1998.

FARRÉ, M. J. valor de uso recreativo de los espacios naturales protegidos.Una aplicación de los métodos de valoración contingente y del coste del viaje. Estudios de Economia Aplicada, v. 21, n. 2, p. 297-320, 2003.

FERNANDES, R.N. Efeitos da queimada de cana de açúcar sobre o bem estar das famílias: uma aplicação do método de avaliação contingente. São Pualo: USP, 2008.

FERNANDES, R. N.; KUWAHARA, M. Y. O valor econômico dos recursos hídricos no uso turístico: o exemplo de Brotas. Jovens pesquisadores v.3, n.1, jan./jun., 2006.

FINCO, M. V. A.; ABDALLAH, P. R. Valoração Econômica do Meio Ambiente: O Método do Custo de Viagem Aplicado ao Litoral do Rio Grande do Sul. Teoria e Evidência Econômica, v. 10 , n.18, maio 2002 . 
FINCO, M.V. A.; VALADARES, M. B. Valoração econômica: ao método do custo de viagem e de valoração contingente aplicados às parias de Palmas/TO. Revista de Economia e Sociologia Rural, 2008.

FREEMAN III, A. M. The benefits of environmental improvement. Baltimore: John Hopkings University Press, 1979.

FREEMAN III, A. M. The Measurement of Environmental and Resource Values: Theory and Methods. 2. ed. Washington, D.C.: Resources for the Future, 2003.

FREIRE, C. R. F.; et al. Valor de uso e valor de opção do litoral do município de Canavieiras, Estado da Bahia (Brasil). Observatório de la Economia Latinoamericana, n. 117, 2009.

FREIRE, C.R.F. et al. Valoração econômica do litoral do município de Ilhéus- Estado da Bahia. XLIII Congresso da SOBER. Sociedade Brasileira de Economia e Sociologia Rural. Ribeirão preto, 24-27 jul. 2005.

FREIRE, F. DE S. et al. Aplicação do método do custo de viagem na valoração de bens ambientais: um estudo de caso na cidade e Cavalcante-GO. XIII Congresso internacional de custo- OTOC- Gestão pelos custos em caminho em tempos de crise. Alfândega do Porto, Portugal. 18 abr. 2013.

FREIRE, F. DE S. et al. Quanto vale o Beijodromo? XXI Congresso Brasileiro de Custos. Anais... Natal, RN. 17 a 19 de nov. de 2014.

FREITAS, K.A.A. et al. Valoração econômica dos benefícios ambientais percebidos pela população da bacia do Educandos provenientes do PROSAMIM. Acta Amazônica, v. 40, n.3, p. 509-514, 2010.

FREITAS, E. A. S. F.; PEREIR, B.D.; MAIA,J.C.S. Valoração contingente de ativos ambientais na suinocultura: Um estudo de caso no município de Diamantino-MT. Cuiabá: UFMT, 2004. 167p.

FREITAS, E. A. S. F.; PEREIRA, B. D.; MAIA, J. C. de S. Valoração contingente de ativos ambientais na suinocultura: um estudo de caso no município de Diamantino/MT. Sociedade Brasileira de Economia Administração e Sociologia Rural. Anais... XLII congresso nacional da SOBER, Cuiabá/MT, 2004.

FONTENELLE, M. A função ambiental da propriedade e unidades de conservação. Revista da Faculdade de Direito de Campos, ano II, n. 2. Campos dos Goytacazes, 2001.

FONTENELE, R.E.S. Determinação da tarifa de reuso da água no distrito industrial de Fortaleza sob a ótica do custo marginal de longo prazo e do método de Avaliação Contingente. Organização Rural \& Agroindustria, Larvas. V.9,n.2, p. 175- 188, 2007.

FORGIARINI, F. R.; SILVEIRA, G. L. da; CRUZ, J. C. Cobrança pelo Uso da Água e Comitês de Bacia: estudo de caso da Bacia Hidrografica do Rio Santa Maria/ RS. Anais do XVII Simpósio Brasileiro de Recursos Hídricos, São Paulo, 2007. 
GARROD, G.; WILLIS, K. G. Economic Valuation of the Environment - Methods and Case Studies. Cheltenham: Edward Elgar, 1999, p. 55-81.

GARROD, G.; WILLIS, K. G.Contingent valuation tchiques: a review of their unbiasedness, efficiency, and consistency. Countryside change working. Paper séie n.ao Newcastle upon Tyne UK: University of Newcastle upon Tyne., 1990.

GAZONI, J. L.; MOTA, J. R.; BRASILEIRO, I. L. G.; CARVALHO, A. X. Y. Valoração Econômica do Parque Estadual de Itaúnas (ES). Brasília, IPEA, 2006. Texto para Discussão n. 1238 .

GAZONI, J. L. Viagem aos comuns: valoração econômica da utilidade turística dos recursos ambientais de Itaúna, Conceição da Barra/ ES. Turismo, Visão e Ação, v. 9, n. 3, p. 305-324 set./dez. 2007.

GEOFFREY, A. J.; PHILIP, J. R. Advanced Microeconomic Theory. 3. ed. Harlow: Pearson, 2011.

GIBBONS, S.; MOURATO, S.; RESENDE, G. M. The amenity value of English nature: a hedonic price approach. Environmental and Resource Economics, v. 57, n. 2, p. 175-196, 2014.

GRASSO, M. et al. aplicações de técnicas de avaliação econômica ao Ecossistema manguezal. In: MAY, P. H. (Org.). Economia Ecológica: aplicações no Brasil. Rio de Janeiro: Campus, 1995.

GRILICHES, Z. Hedonic Price Indexes for Automobiles: An Econometric Analysis of Quality Change, The Price Statistics of the Federal Government, General Series, n. 73, p. 137-196, 1961.

GONÇALVES, M. et al. Estimativas da tarifa econômica a ser cobrada no mercado de água rural londrinense: valoração contingente. A Economia em Revista, v. 19, n. 2, dez. 2011.

GONÇALVES, R. S. et al. O uso do método de Valoração Contingente para mensurar o passivo ambiental causado pelo lixo urbano: um estudo de caso em Carlos Chagas, MG. $49^{\circ}$ Congresso da sociedade Brsileira de Economia Administração e Sociologia Rural. Belo Horizonte MG. 24 a 27 de jul. 2011.

GUIA, A. T. B. A Valoração econômica de Bens Culturais: Uma aplicação a monumentos da cidade de Tomar. Dissertação (Mestrado em Economia das Organizações) - Programa de Mestrado em Economia das Organizações da Universidade de Trás-os-Montes e Alto Douro. Portugal, Vila Real, 2008.

GULLO, M.C.R. Valoração econômica dos recursos naturais: Uma aplicação para o setor industrial de Caxias do Sul. Porto Alegre: UFRGS, 2010.

GUNDMEDA, H. Hedonic Price Method: a concept note. Madras School of Economics, Chennai, v. 15, p. 2009, 2005. 
HAAB, T.C. et al. From Hopeless to curious? Thoughts on Hausman's Dubious to Hopeless critique of Contingent Valuation. Department of Economics Appalachian State University. n. 113, mar. 2013.

HAAB, T. C.; MCCONNELL, K. E. Valuing Environmental and natural resources: the econometrics of non-market valuation. Cheltenham: Edward Elgar, 2003.

HAMMACK, J. AND G.M. BROWN, Jr. Waterfowl and wetlands: toward bioeconomic analysis. Baltimore MD: Johns Hopkins University Press.1974

HANEMANN, W. M. A Methodological and Empirical Study of the Recreation Benefits from Water Quality Improvement. Ph.D. Dissertation (Doctorate in Economics) - Harvard University, 1978.

HANEMANN, W.M.; J.B. LOOMIS AND B.J ; KANNINEN. Statistical efficiency of doublebounded dichotomous choice contingent valuation. American Journal of Agricultural Economics, v.73, p.1255-1263, 1991.

HANLEY, N. R. SPASH, C. L. Cost-Benefit Analysis and the Environment. Cheltenham: Edward Elgar, 1993.

HANLEY, N. C.; SPASH, C. L. Cost Benefit Analysis and the Environment. Cheltenham: Edward Elgar, 1999.

HANLEY, N.; SHOGREN, J. F. WHITE, B. Environmental Economics: In Theory and Practic. Oxford: Oxford University Press, 1997.

HANLEY, N.; SHOGREN, J.A.; WHITE, B. Environmental Economics: In Theory and Practice. Hampshire: Palgrave Macmillan, 2002.

HASHIMURA, L.DE M. M. Uso e abusos do método de valoração contingente no Brasil: vieses em sua aplicação.63f. Monografia (Gradução em Ciêncis Econômicas) - Universidade de Brasília, Brasília, 2008

HASLER, B. et al. The recreational values of forest, lake and nature restoration - Valuation of nature goods the hedonic price method. 2002.

HAUSMAN, J. Contingent Valuation: Prom dubious to hopeless. Journal of Economic Perspectives. v. 26, n. 4 p. 43-56, 2012.

HENDERSON, B. L. R.; et al. Valoração ambiental do Parque Estadual do Urtiga na Região metropolitan de Belém/PA. Centro Cientifico Conhecer. Enciclopédia Biosfera, v.10, n.18, 2014.

HERATH, S. CHOUMERT, J. MAIER, G. The value of the greenbelt in Vienna: a spatial hedonic analysis. Etudes et Documents CERDI n. 2 Jan. 2014.

HERMANN, B. M. Estimando o preço implícito de amenidades urbanas: evidências para o município de São Paulo. 2003. 74 f. Dissertação (Mestrado em Economia). FEA-USP, São Paulo, 2003. 
HERRIGES, J. et al., What are the consequences of consequentiality? Journal of Environmental Economics \& Management. n. 59. p. 67-81, 2010.

HICKS, J. R. The generalize Theory of Consumer's surplus. Review of Economic Studies, v. , p. $68-73,1945$.

HILDEBRAND, E.; GRAÇA, L.R.; HOEFLICH, V.A. Valoração contingente na avaliação econômica de áreas verdes urbanas. Floresta, v. 31, n. 1, p. 121-132, 2002.

HOCHHEIM, N.; UBERTI, M. S. Uso de variáveis ambientais na avaliação de imóveis urbanos: uma contribuição à valoração ambiental. XI Congresso Brasileiro de Engenharia de Avaliações e Perícias - XI COBREAP, Universidade Federal de Santa Catariana, Florianópolis, 2001.

HOTELLING, H. [1947]: "Letter to the National Park Service," Reprinted in An Economic Study of the Monetary Evaluation of Recreation in the National Parks [1949]. U.S. Department of the Interior, National Park Service and Recreational Planning Division, Washington, DC.

HUFSCHMIDT, M. M.; et al. A. Environment, natural systems, and development: an economic valuation guide. Baltimore: Johns Hopkins University Press, 1983.

IAMTRAKEL, P.; TEKNOMO, K.; HOKAO, K. Public park valuation using travel cost method. Proceedings of the Eastern Asia society for Transportation studies, v. 5, p. 1249-1264, 2005.

JACOBSEN, J.B.; HANLEY, N. Are There Income Effects on Global Willingness to Pay for Biodiversity Conservation? Environ Resource Econ., n. 43, p.137-160, 2009.

JAMES, L. D.; LEE, R. R. Economics of Water Resources Planning. New York: McGraw-Hill, 1971.

JÕAO, C.G.; BAASCH, S.S.N. A valoração do meio ambiente, um estudo de caso: O parque do Rio Vermelho- Florianópolis-SC. $19^{\circ}$ congresso Brasileiro de Engenharia Sanitária e ambiental. 2012.

JONHSTON, R. J. Is Hypothetical Bias Universal? Validating Contingent Valuation Responses Using a Binding Public Referendum. Journal of Environmental Economics and Management .v. 52, n. 1, p. 469-481, 2006.

JONES-LEE, M.W. The Value of Life: An Economic Analysis. Chicago: University of Chicago Press, 1976.

JUSTOS, W. R.; RODRIGUES, C.P.B. Valoração econômica do Parque Ecológico eStadual do Sítio Fundão, Crato/CE. Revista de Politica Agrícola. Ano XXIII. n.1. jan./fev./mar., 2014.

KLING, C. L.; PHANEUF, D. J.; nnAO, J., From Exxon to BP: Has Some Number Become Better than No Number? Journal of Economic Perspectives, v. 26, n. 4, p. 3-26, 2012. 
KINKER, S. Ecoturismo e conservação da natureza em parques nacionais. Campinas: Papirus, 2002. (Coleção turismo).

KOPP, R. J.; SMITH, V. K. (Ed.). Valuing Natural Assets: The Economics of Natural Resource Damage Assessment, Washington, D.C.: Resources for the Future, 1993, p. 131-133.

KWAK, S.; YOO, S.; KIM, C. Measuring the Willingness to Pay for Tap Water Quality Improvements: Results of a Contingent Valuation Survey in Pusan. Journal Water, n. 5, v. 4, p.1638-1652, 2013.

LAERA, L. H. N. Valoração econômica da arborização - A valoração dos serviços ambientais para a eficiência e manutenção do recursos ambiental urbano. 2006. 131 p. Dissertação (Mestrado em Ciência Ambiental) - Programa de Pós-Graduação em Ciência Ambiental, Universidade Federal Fluminense, Niteroi, 2006.

LANCASTER, K. A new approach to consumer teory. Journal of Politiacal Economy. v. 74, p.132-157, 1966.

LEITE, D.C.; JACOSKI, C.A. Comportamento do usuário na valoração contingente e custo de viagem- O caso do Parque das Palmeiras em Chapecó, SC, Brasil. Revista Ambiente \& Água, v. 5, n. 2, p. 226-235, 2010.

LEW, K.L., LARSON, D. M. Accounting for to chaotic shadow value softimein discrete-choice creation demand models. Journal of Environmental Economics and Management, v. 50, p. 341$361,2005$.

LEZCANO, L. M. Analise do efeito do rico de cheia no valor de imóveis pelo Método Preço Hedônico. Dissertação (Mestrado em Engenharia de Recursos Hídricos e Ambiental) Universidade Federal do Paraná, Curitiba, 2004.

LIENHOOP, N.; ANSMANN, T. Valuing water level changes in reservoirs using two stated preference approaches: Na exploration of validity. Germany Ecological Economics, v. 70, p. 1250-1258, 2011.

LIMA, E. L. Curso de Análise. 11.ed. Rio de Janeiro: IMPA, 2011. v. 2.

LOPES, F. J. Métrica de valoração ambiental: Uma percepção da Gestão pública no município de Cavalcante. Brasília.2014,102 f. Dissertação (Universidade de Brasília. Faculdade de Economia, Administração e Ciências Contábeis e Atuariais - FACE. Programa Multiinstitucional e Inter-Regional de Pós-Graduação em Ciências Contábeis (UnB/UFPB/UFRN). Brasília, 2014.

LOPES, R. C. ; CASTRO, J.D.B. Valoração econômica de recursos ambientais: um estudo sobre o parquet da Matinha. Anápolis/GO. Anais da Jornada de Pesquisa, Pós-Graduação e Extensão da UnUCSEH. Anápolis. Anais... V.1, n.1, 2014.

LOOMIS, J.; YORIZANE, S.; LARSON, D. Testing significance of multi-destination and multi-purpose trip effects in a travel cost method demand model for whale watching trips. Agricultural and Resource Economics Review, v. 29, n. 2, p. 183-191, 2000. 
LOURENÇO, L. F. Valoração ambiental da qualidade do ar como ferramenta na gestão de saúde pública: Estudo de caso com os controladors de tráfico. São Paulo: Senac, 2012.

LOUVIERE, J.J. Predicting the evaluation of real stimulus objects from an abstract evaluation of their attributes: the case of trout streams. Journal of Applied Psychology, n. 59, p. 572-577, 1974.

LUCENA, L.F.L.; TÁVORA JÚNIOR, J. L. A importância da redução do lixo para a qualidade ambiental em Recife- PE - uma análise por valoração contingente. ANPEC 2006.

MACHADO, F. H. Valoração econômica dos Recursos hídricos da bacia hidrográfica do Ribeirão do Feijão-São Carlos (SP), 2011

MAC-KNIGHT, V. Aplicação do método de valoração contingente para estimar o altruísmo paternalístico na valoração de morbidade em crianças devida a poluição do ar em São Paulo. 2008.124 f. Dissertação (Mestrado em Engenharia) - Universidade Federal do Rio do Janeiro, COPPE, RIO DE JANEIRO, 2008.

MAIA, A. G.; ROMEIRO, A. R. Validade e confiabilidade do método de custo de viagem: um estudo aplicado ao Parque Nacional da Serra Geral. Econ. Aplicada, v. 12, n.1, p. 103-123, 2008.

MAIA, H. G.; ROMEIRO, A. R.; REYDON, B. P. Valoração de recursos ambientaisMetodologias e recomendações. Texto para discussão. IE/UNICAMO. n. 116, mar. 2004.

MALDONADO, A. D. R. M. Métodos de valoração econômica ambiental e danos ambientais causados pela bovinocultura de corte. 2006. Dissertação (Mestrado em Agronegócios) Universidade Federal de Mato Grosso do Sul. Campo Grande. 2006.

MALTA, R. R.; COSTA, N. M. C. da; COSTA, V. C. da. Valoração dos serviços recreativos e ecoturísiticos em uma unidade de conservação - o caso do Parque Nacional da Tijuca (Rio de Janeiro- RJ) - Brasil. Programa de Pós-graduação em Geografia - PPGO- UERJ, 2008.

MARSHALl, A.(1920) Princípio de economia política. São Paulo: Abril cultural, 1982. v.1. (Os Economistas).

MARQUES, M. de M. Mensuração de ativos culturais: uma aplicação do método do custo de viagem em bens públicos culturais do Distrito Federal. 2012.127f. Dissertação (Ciências Contábeis ao Programa Multiinstitucional e Inter-Regional de Pós-Graduação em Ciências Contábeis) Universidade de Brasília, Universidade Federal da Paraíba e Universidade Federal do Rio Grande do Norte, Brasília 2012.

MATOS, A. et al. Análise crítica dos métodos de valoração econômica dos bens e recursos ambientais. VIII coloque Ibérico de Estudios Rurales. Cáceres, 2010.

MATOS, A.D.M.de. Valoração ambiental de áreas de preservação permanente da Micro bacia do Ribeirão São Bartolomeu no Município de Viçosa, MG. Sociedade de Investigação Florestal, Revista Árvore, v. 31, n. 2, p. 347-353, 2007. 
MATTOS, A. D. M. Valoração ambiental de áreas de preservação permanente da microbacia do Ribeirão São Bartolomeu no Município de Viçosa, MG. 2006. 91f. Tese (Doutorado em Ciência Florestal) - Universidade Federal de Viçosa, Viçosa-MG, 2006.

MATTOS, K. A valoração econômica do meio ambiente dentro do contexto do desenvolvimento sustentável. Revista Gestão Industrial, v., n. 2, p. 248-259, 2005.

MAYOR, K.; SCOTT, S.; TOL, R. S. J. Comparing the travel cost method and the contingente valuation method. Na application of convergent validity theory to the recreational value of Irish forests. The Economic and Social Research Institute Dublin. Working Paper, n. 190, apr. 2007.

MÁXIMO, P. S.; SILVA, M. L.; MÁXIMO, M. S. Valoração de contingente pelas modelagens logit e Análise multivariada: um estudo de caso da disposição a aceitar compensação dos cafeicultores vinculados ao pro-café de viçosa- SP. SIF - Revista Árvore. Viçosa (MG), v. 33, n. 6, p. 1149-1157, 2009.

MAY, P. H.; VEIGA NETO, F. C.; POZO, O. V. C. Valoração econômica da biodiversidade: estudos de caso no Brasil. [Brasília]: Ministério do Meio Ambiente, Secretaria de Biodiversidade e Florestas, fev. 2000.

MAY, P. H.; LUSTOSA, M. C.; VINHA, V. da. Economia do meio ambiente: teoria e prática. Elsevier, 2003.

MENGER, C. Princípios de Economia Política. São Paulo: Nova Cultural, 1988.

MILLENNIUM ECOSYSTEM ASSESSMENT - MEA. Conceptual Framework. In: HASSAN, R.; SHOLES, R.; ASH, N. (Ed.). Ecosystems and Human Well-being. Estados Unidos da América Island Press, 2005. p. 25-36. (Ecosystems and Human Well-being: Current State and Trends, v. 1).

MITCHELL, R.C.; CARSON, R.T. Using Surveys to Value Public Goods: The Contingent Valuation Method. Washington: Resources for the Future. 1989.

MCCONNELL, K. E.; STRAND.I.E. Measuring the cost of Time in Recreation Demand Analysis. American Journal of Agricultural Economics. v. 63, p. 153-156, 1981.

MENDELSOHN, R. et al. Measuring recreation values with multiple destination trips. American Journal of Agricultural Economics, v. 74, n. 4, p. 926-933, 1992.

MENDELSOHN, R..; et al. Measuring Recreation Values with Multiple-Destination Trips. American Journal of Agricultural Economics, v.74, p.926-933.1992.

MENDONÇA, M. P. et al. Valoração econômica do Jardim Botânico da Fundação ZooBotânica de Belo Horizonte, Minas Gerais. Instituto de Economia. Universidade federal de Uberlândia, 2012.

MIQUELITO, A.C. et al. A valoração econômica como ferramenta para compensação de acidentes ambientais: o caso dos acidentes ocorridos na região sudeste do Brasil (2006-2012). Anais do X Congresso Nacional de Excelência em Gestão.8 e 9 de ago de 2014. Anais... Rio de Janeiro, 2014 
MONTEIRO, J. M.; ARAUJO, E. de L.; AMORIM, E. L. C. Valuation of the Aroeira (Myracrodruon urundeuva allemão) perspective on conservation. Acta Botânica, Brasília, v. 26, n. 1, p. 125- 132, 2014.

MOKHTARI, R.; HOSSEINIFAR, S. M. Economic and social value of recreational facilities in urban áreas by using travel cost method ( Case study: Amirkola Urban Park, Mazandaran Province, Iran). Europen Online. Journal of Natural and Social Sciences, 2013.

MORAES, M. R. Avaliação contingente dos benefícios econômicos locais da cobertura arbórea urbana do município de Palmas- TO. Dissertação (Mestrado em Desenvolvimento Regional) - Programa de Mestrado em Desenvolvimento Regional, Universidade Federal do Tocantins, Palmas, 2010.

MORAES, O. J. Economia Ambiental: Instrumentos econômicos para o desenvolvimento sustentável. São Paulo: Centauro, 2009.

MORAES, M. R.; ARAUJO, F. V.; PAIXÃO, A.N. Valoração econômica da cobertura arbórea na cidade de Palmas -TO a partir do Método de Avaliação Contingente. V ENCONTRO DA SOBER NE/XI SEMANA DE ECONOMIA DA URCA. 25/11/2010.

MORGADO, R. C. et al. Valoração ambiental do Parque Ecológico de Usos múltiplos Águas Claras - DF: Analisando a disposição a pagar dos usuários. Revistas de Estudos Ambientais. v.13, n. 2, p. 6-17, jul./dez. 2011.

MORRISON, M. Aggregation Biases in Stated Preference Studies. Australian Economic Papers. v. 39, n. 2, p. 215-30, 2000.

MOREY, E.et al. Revised Report and Rebuttal: Assessment of Damages to Anglers and Other Recreators from Injuries to the Upper Clark Fork River Basin, Report prepared by Hagler Bailly Consulting for the State of Montana, Natural Resource Damage Litigation Program, October $18,1995$.

MOTA, J. A. Travel Cost Method: Uma Alternativa de Análise da Demanda por Ativos Ambientais. Estudos Empresariais, Brasília: Universidade Católica de Brasília, Ano 2, n. 3, set./dez., 1997.

MOTTA, J. A. O valor da natureza: economia e política dos recursos naturais. Rio de Janeiro: Garamond, 2001.

MOTA, J. A. et al. Demanda Contingente por água no Distrito Federal do Brasil. Revista de La Red Iberoamericana de Econômica Ecológica. v. 15, p. 31-42, 2010.

MOTA, J.A. et al. A valoração da biodiversidade: conceitos e concepções metodológicas. In: MAY, P. H. (Org.). Economia do meio ambiente: Teoria e prática. 2. ed. Rio de Janeiro: Elsevier, 2010.

MOTTA, R. S. da. Valoração e precificação dos recursos ambientais para uma economia verde. In: Economia Verde: Desafios e Oportunidade. IPEA, Rio de Janeiro, 2011. 
MOTTA, R. S. da. Economia ambiental. Rio de Janeiro: FGV, 2006.

MOTTA, R. S. da. Manual para Valoração Econômica de Recursos Ambientais. Brasília: Ministério do Meio Ambiente, dos Recursos Hídricos e da Amazônia Legal, 1997, 216 p.

MOTTA, R. S. da. Manual para Valoração Econômica de Recursos Ambientais. Brasília: Ministério do Meio Ambiente, dos Recursos Hídricos e da Amazônia Legal, 1998, 216 p.

MOTTA, R.SS da.Valoração e precificação dos recursos ambientais para uma economia verde. Rio de Janeiro: IPEA, 2011.

MOTTA. R. S DA; ORTIZ, R. A. Análise do custo benefício do museu da Imagem e Som do rio de Janeiro. Revista de Economia Contemporânea, Rio de Janeiro, v. 17, n. 1, Jan./apr., 2013.

MUELLER, C. C. Os economistas e as relações entre o Sistema econômico e o meio ambiente. Brasília: Editora da Universidade de Brasília: Finatec, 2007.

MÜLLER, V.R. Valoração ambiental do parque Nacional da Chapada dos Veadeiros, através do método do Custo de viagem. Anais da 58 ${ }^{\mathrm{a}}$ Reunião Anual da SBPC- Florianópolis, SC. Jul. 2006.

NASCIMENTO, J. A. R. do. Níveis de Renda e DAPs: Evidências de Correlação via função preço hedônico. Dissertação. 77 p. (Mestrado em Gestão Econômica do Meio Ambiente) Universidade de Brasília, Brasília, 2009.

NEGRINE NETO, A. Preços Hedônicos. Informações Econômicas. SP, v. 33, n.12, dez. 2003.

NOGUEIRA, J. M.; MEDEIROS, M. A. A.de. Valoração Econômica do Meio Ambiente: Aspectos Teóricos e Operacionais. 50a. Reunião Anual da Sociedade Brasileira para o Progresso da Ciência (SBPC). Natal, jul. 1998.

NOGUEIRA, J.M., MEDEIROS, M. A.A., ARRUDA, F.S.T. Valoração econômica do Meio Ambiente: Ciência ou Empirismo? Brasília: Cadernos de Ciência e Tecnologia, v. 17, n. 2, p. 81-115, mai/ago. 2000.

NUNES, P.A.L.D.; VAN DEN BERGH, J.C.J.M. Economic valuation of biodiversity: sense or nonsense? Ecological Economics, n. 39, p. 203-222, 2001

OBARA, A. T. Valoração Econômica de unidade e conservação. O MVC: Estudo de caso: Estação ecológica de Jataí (Luiz Antônio SP). 1999.122 f. Tese (Doutorado em Ecologia e Recursos Naturais) - Centro de Ciências Biológicas e da Saúde, Universidade Federal de São Carlos, São Carlos, 1999.

OLIVEIRA FILHA, R. C.; MONTEIRO, M.S.L. Ecoturismo no parque Nacional Serra da Capivara: Trata-se de uma prática sustentável? Turismo em Análise, v. 20, n. 2, ago. 2009.

OLIVEIRA, C. R.; TOUGUINHA, C. C. Valoração ambiental do Saco da Mangueira: uma inovação ao método contingente. In: Encontro bienal da sociedade brasileira de economia ecológica, 5, 2004, Caxias do Sul. Anais... Caxias do Sul: [s.n], 2004, 1 CD ROM. 
OLIVEIRA, H. S. et al. Aplicação da metodologia dos preços hedônicos na avaliação de projetos de Saneamento. Revista DAE, São Paulo, v.47, n. 149, jun./set. 1987.

OLIVEIRA JUNIOR, A. F. de. Valoração econômica da fundação ambiental de suporte relacionada às atividades de turismo, Brotas, SP. 2003. $277 \mathrm{f}$. Tese (Ecologia e recursos naturais) - Centro de Ciências Biológicas e da Saúde, Universidade Federal de São Carlos, São Carlos, São Paulo, 2003.

OLIVEIRA, R. G. O excedente do consumidor. FEARP. São Paulo: USP. 2012.

OLIVEIRA, W. R. Disposição a pagar pelo ensino na universiadade pública federal: uma aplicação da valoração contingente no curso de Ciências Contábeis da Universide de Brasília. Brasília, 2014. 90f. Dissertação (Mestrado em Ciências Contábeis da Universidade de Brasília) Brasília, 2014.

ORTIZ, R. Valoração Econômica Ambiental. In: MAY, P; LUSTOSA, M; VINHA, V. (Org.). Economia do Meio Ambiente: Teoria e Prática. Rio de Janeiro: Elsevier, 2003. p. 81-100.

ORTIZ, R. A.; MOTTA, R. S. da; FERRAZ, C. Estimando o Valor Ambiental do Parque Nacional do Iguaçu: Uma Aplicação do Método de Custo de Viagem, Texto para Discussão do IPEA, nº 777, Rio de Janeiro, IPEA, 2001.

ORTIZ, R. A.; MOTTA, R. S. da; FERRAZ, C. Estimando o Valor Ambiental do Parque Nacional do Iguaçu: Uma Aplicação do Método de Custo de Viagem. Projeto Treinamento e Elaboração de Estudos de Análise Econômica para Valoração da Biodiversidade do PROBIO/MMA. IPEA, Textos para Discussão n. 777, Rio de Janeiro, jan. 2000, 26 p.

OYARZUN, Diego Azqueta. Valoración Económica de la Calidad Ambiental. Madrid: McGraw-Hill/Interamericana de España, 1997, 299 p.

PALMQUIST, R. B. Estimating The Demand for The Characteristics of Housing. The Review of Economics and Statistics, v. 64, n. 3, 1984, p. 394-404.

PALMQUIST, R. B. Property Value Models. In: MÄLER, K.-G.; VINCENT, J. R. (Ed.). Handbook of environmental economics. Elsevier, 2005. v.2

PALMQUIST, R.B.; PHANEUF, D. J. Short run constraints and the increasing marginal value of time in recreations. Environ Resource Econ., v. 46, p. 19-41, 2010.

PARSONS, G. R. The travel cost model. In: CHAMP, P. A.; BOYLE, K.; BROWN, T. C. A Primer on nonmarket valuation: The Economics of Non-Market goods and resources. Norwell, MA: Kluwer Academic Publishers, 2003.

PAULA, D. P.; SILVA, M. A. C.; MORIERA, F. A. F. Práticas sustentáveis: A percepção dos servidores e alunos de uma instituição de ensino superior. Revista Caminhos de Geogafia. v.15, n. 51, set. 2014. p. 95-107.

PAULA, Z. R. et al. Valoração econômica da gruta do Maquiné em Cordisburgo- MG: uma aplicação do método do custo de viagem. Sociedade Brasileira de Economia, Administração e Sociologia Rural. XLVI congresso da SOBER. Rio Branco- Acre, 20 a 23 de julho de 2008. 
PEARCE, D. W. e TURNER, R. K. Economics of Natural Resources and The Environment. Baltimore: Johns Hopkins University Press, 1990. 378 p.

PEARCE, D. W.; TURNER, R. K. Economía de los Recursos Naturales y del Medio Ambiente. Madri, Espanha: Celeste Ediciones, 1995.

PEARCE, D. W .Valuing biological diversity: issues and overview. In: (Eds) OECD. Valuation of biodiversity benefits: Selected studies. OECD: Paris, 2001.

PEARCE, D. W. Economic values and the natural world. Massachusetts: The MIT, 1993. 129 p.

PEARCE, D. W.; MORAN, D. O valor económico da biodiversidade. Trad. S. da Costa Raimundo. Lisboa, Portugal: Instituto Piaget, 1994.

PERMAN, R. et al. Pollution control: instruments. In: Natural Resource \& Environmental Economics. London: Longman, 1996.

PERMAN, R. et al. Natural resource and Environmental Economics. 4. ed. England; Addison Wesley is an imprint of Pearson. p. 411-454.2011.

PHANEUF, D. J.; SMITH, V. K. Recreation demand models. Handbook of environmental economics, v. 2, p. 671-761, 2005.

PINDYCK, R. S.; RUBINFELD, D. L. Microeconomia. 7. ed. São Paulo: Pearson, 2010.

PIZAIA, M.G. Proposta metodológica para a cobrança pelo uso da água bruta rural no Estado do Paraná: Valoração contingente. XII Encontro Regional de Economia- ANPEC 11- 13 de ago. Anais...Porto Alegre-RS. 2010.

POE, G. L.; BISHOP, R. C. Valuing the Incremental Benefits of Groundwater Protection when Exposure Levels are Known. Environmental and Resource Economics, v. 13, n. 3, p. 347-373, 1999.

POE, G. Valuation of groundwater quality using a contingent valuation-damage function approach. Water Resources Research, v. 34, n. 12, p. 3627-3633, 1998.

POMPERMAYER, R. S. Valoração econômica do serviço ambiental de proteção da qualidade hídrica. 2012. Tese (Doutorado em Ciências Florestais) - Programa de Pós-Graduação em Ciências Florestais, Departamento de Engenharia Florestal, Faculdade de Tecnologia, Universidade de Brasília, Brasília, 2012.

PONTES, M.R. Valoração contingente de um projeto de recuperação da qualidade das águaso caso do córrego limoeiro em Presidente prudente-SP. UFSC, 2009.

POVOA, B. B.; TOSTA, M. C. R. Valoração contingente do gasoduto Cacimbas-Catu na reserva da biosfera da Mata Atlântica em São Mateus/ ES. XXXI Encontro Nacional de Engenharia de Produção- Inovação tecnológica e propriedade intelectual: desafios da 
engenharia e produção na consolidação do Brasil no Cenário Econômico Mundial. Belo Horizonte, MG 04-07 de out. 2011.

PUGAS, M. A. R. Valoração contingente de unidades de conservação: avaliando s DAP espontânea e induzida da população de Rondonópolis (MT) pelo horto Florestal. 2006.130 f. Dissertação (Mestrado em Gestão Econômica do Meio Ambiente) - Universidade de Brasília, Brasília, 2006.

PURWANTO, J. M. Valuasi eknomi ekowisata dengan model travel cost dan Dampaknya Terhadao usaha Kecil Pariwisata. JKM, Revista Gestão e empreendedorismo v. 15, n. 1, mar. 2013.

RABÊLO NETO, A. et al. Valoração econômica de projetos de requalificação dos métodos de avaliação contingnete e preços Hedônicos. Revista Desenvolvimento em questão. Editora Unijuí. ano 12. n.28. p. 104-143out./dez., 2014.

RAMOS, F. de S. Qualidade do meio ambiente e falhas de mercado. Revista Análise Econômica, ano 14, p. 39-51, mar./set.1996.

RANDALL, A. A Difficulty with the Travel Cost Method. Land Economics, v.70, n.1, p. 8896, 1994.

RESENDE, F. DE M. et al. Valoração econômica do Parque Nacional da Serrado Cipó (MG): uma aplicação do Método Contingente. Associação Nacional dos Centros de Pós-Graduação em Economia. ANPEC. 2013. Disponível em: 〈www.anpec.org.br〉. Acesso em: out. 2014.

RIDKER, Ronald G.; HENNING, John A. The determinants of residential property values with special reference to air pollution. The Review of Economics and Statistics, p. 246-257, 1967.

RIVIERA, E. B. B. de R. Preços hedônicos: teoria e aplicação no setor imobiliário na cidade de São Paulo (1995-2004). Revista Jovens Pesquisadores, ano IV, n. 7, jul./dez. 2007.

RODRIGUES, T.L.; FARIA, R.C. Disposição a pagar pelo uso da água na produção de hortaliças do Distrito Federal. Cadernos de Ciência \& Tecnologia, Brasília, v. 25, n. 1/3, p. 6583. Jan./dez. 2008.

RODRIGUES, W.; NOGUEIRA, J.M.; CARVALHO, E. Avaliação econômica dos danos ambientais causados pela implantação da Usina Hidrelétrica Luiz Eduardo Magualhães: uma aplicação do método de valoração contingente. Informe Gepec, v. 13, n. 1, jan./jun. 2009.

RODRIGUES, W.; SANTANA, W.C. Análise de sistemas de gestão de resíduos sólidos urbanos: O caso da coleta de Lixo seletiva em Palmas, TO. URBE. Revista Brasileira de Gestão Urbana, v. 4, n. 2, p. 299-312, jul./dez. 2012.

ROMEIROS, A.; ANDRADE, D.C. Valoração econômica-ecológica de recursos naturais. Gestion y Ambiente, v. 12, n. 3, p. 21 -36, ago./dez. 2009.

ROMEIRO, A ., MAIA, A G. Valorando o conforto ambiental: atitudes e comportamento na disposição a pagar. Economia Aplicada, v. 7, p. 819-844, 2003. 
ROSA, T.; GAMA, C.; DIA, L. Método de valoração econômica ambiental e sua aplicação no Parque Municipal das Mangabeiras. Trabalho de conclusão de curso de aperfeiçoamento em Engenharia Ambiental Integrada do IETEC. Belo Horizonte, 2012.

ROSEN, S. Hedonic Price and Implicit Markets: Product differentiation in Pure Campetition. Journal of Political Economy, v. 82, p. 34-55, 1974.

ROSSAROLLA, F.; SILVEIRA, G.L.; Cruz, J.C. Gestão dos Recursos hídricos e cobrança pelo uso da água: Visão da Sociedade da Bacia Hidrográfica do Rio Santa Maria - RS. Revista Brasileira de Recursos hídricos. v. 12, n. 2, p. 123- 133, abr./jun. 2007.

SAHAMMIN, R. Application of the travel cost method (TCM): A case study of environmental valuation of Dhaka zoological garden. IUCN- EUA, 1999.

SAMPLES, K.C.; DIXON, J.A.; GOWEN, M.M. Information discloure and endangered species valuation. Land Economics, v. 62, n. 3, p. 306-312, 1986.

SANTARLACCI, A. DE S. Externalidades positivas geradas pelo Parque Olhos D’Água ao mercado imobiliário por meio de índices hedônicos. 2013. 72 p. Dissertação (Mestrado em Ciências Florestais) - Universidade de Brasília, Brasília, 2013.

SANTOS, D.R. et al. Mensuração da disposição a pagar para recuperação do córrego dos Indios: uma aplicação do MVC. Revista Brasileira de Ciencias Ambientais. n.25 set.2012

SANTOS, L. J. M. Proposta de Métrica de valoração ambiental para reservas legais e áreas de preservação permanente. Ribeirão Preto, 2013. Dissertação (Faculdade de Economia, Administração e Contabilidade de Ribeirão preto. Universidade de São Paulo) Ribeirão Preto, 2013.

SALGADO, G. S. M.; NOGUEIRA, J. M. Economia e gestão de áreas protegidas: o caso do Parque Nacional de Brasília In: $4^{\circ}$ Encontro da Sociedade Brasileira de Economia Ecológica, 2001. Belém - Pará: PIEBT - UFPA- FADESP, 2001. v. 1 p. 25-56.

SHAKESPEARE, W. The Tragedy of Hamlet. Prince of Denmark. Primeiro Fólio, 1623.

SAMUELSON, P. The pure theory of public expenditures. Review of Economics and Statistics, n. 36, p. 387-389, 1954.

SANCHES, K. L. et al. Indicadores de valor de uso para fins de valoração econômica do Santuário de vida silvestre Vagafogo em Pirenópolis (GO). Enciclopédia Biosfera, Centro Cientifico Conhecer, Goiânia, v. 9, n. 17, p. 3566, 2013.

SERRA, M.A. et al. A valoração contingente com ferramenta de economia aplicada a conservação ambiental: $\mathrm{O}$ caso da estrada Parque Pantanal. Planejamento e políticas públicas, n. 27, jun./dez. 2004.

SILVA, J. L.; BACARJI, A. G.; RODRIGUES, P. C. valoração ambiental de áreas de preservação permanente (app's): um estudo de caso no bairro jardim Universitário, Cuiabá, Mato Grosso. III Congresso Brasileiro de Gestão ambiental. Anais... v. 3, Goiânia, 2012. 
SILVA, L. F.; LEAL, V. T.; FERRAZ, M. Valoração econômica de recursos naturais como subsídio ao planejamento eco turístico: um estudo de caso na Nascente do Rio SucuriBonito/MS. V Encontro Nacional da ECOECO. Caxias do Sul-RS, 2001.

SILVA, L. F.; WEISS, J. Valoração Econômica de benefícios ambientais como suporte a formulação de Políticas públicas: Um estudo de caso no Balneário Municipal de Bonito MS.IX Encontro Nacional da Sociedade Brasileira de Economia Ecológica -ECOECO, 2010.

SILVA, R. G.; FERNANDES, E. A.; LÍRIO, V. S. Aplicação da Teoria dos Jogos ao Método de valoração contingente. Revista Economia: Análise e Perspectiva Econômica. Rio VerdeGoiás, p.7-14, 2003.

SILVA, R. G da. D. S. Disposição a Pagar para Evitar Danos à Saúde Oriundos das Queimadas: uma aplicação do método de valoração contingente no Estado do Acre. 2005. 120 p. Tese (Doutorado em Economia Aplicada) - Universidade Federal de Viçosa, Viçosa, 2005.

SILVA, R. G.; LIMA, E. J. Avaliação econômica da poluição do ar na Amazônia Ocidental: Um estudo de caso do Estado do Acre. REC. Rio de Janeiro, v. 44, n. 2, p. 157-178, abr./jun. 2006.

SILVA, R. G. LIMA, J. E. Valoração contingente do parque Chico Mendes: uma aplicação probabilística do método Referendum com Bidding games. Revista de Sociologia Rural v.42. n. 4 out./dec., 2004.

SILVA, T. C. et al. Valoração econômica ambiental de coleta seletiva no bairro Aldeota Fortaleza- CE. X Congresso Nacional de Meio Ambiente de Poços de Caldas Instituto Federal Sul de Minas Gerais, 2013.

SILVEIRA, V. C. Valoração econômica e percepção ambiental da Área de Proteção Ambiental Estadual Cachoeira das Andorinhas - Sub-Bacia do Rio das Velhas-MG. 154f. Dissertação (Mestrado em Engenharia Ambiental) - Programa de Pós-graduação em Engenharia Ambiental, Universidade Federal de Ouro Preto, Ouro Preto, 2011.

SILVEIRA, V. C.; CIRINO, J. F.; PRADO FILHO, J. F. Valoração Econômica da área de proteção ambiental estadual da Cachoeira das Andorinhas- MG. Revista Árvore, Viçosa, MG, v. 37, n. 2, p. 257-266, 2013.

SMITH, V. Kerry; KAORU, Yoshiaki. Signals or noise? Explaining the variation in recreation benefit estimates. American Journal of Agricultural Economics, v. 72, n. 2, p. 419-433, 1990.

SIMON, C.P.; BLUME, L. Matemática para economistas. Porto Alegre: Bookman, 2004.

SINGER, P. Curso de Introdução à Economia Política. 17. ed. Rio de Janeiro: Forense Universitária, 2004.

SOSNOSKI, L.;SILVA,F.G.; MORAES, G. I. Valoração de um recurso natural- Estimação do valor de uso do parquet Saint'Hilaire, Viamão, RS. $7^{\circ}$ Encontro de Economia Gaúcho. 15 a 16 de maio, 2014. 
SOUSA, A. B. et al. Valoração ambiental de Olhos d'água da Chuva em Palmeira do Piauí (PI). Scientia Plena, v. 8, n. 4, 2012.

SOUZA, G.B.S.; MOTA, J.A. Valoração Econômica de áreas de recreação: o caso do Parque metropolitano de Pituaçu- Salvador, BA. Revista de Economia, UFPR, v. 32. n. 1, 2006.

SOUZA, L. A. C. et al. Aplicação do método de avalição contingente através da técnica de disposição a pagar numa unidade de conservação do municipio de Cuiabá- MT. V Congresso Brasileiro de Gestão Ambiental. Anais ...Belo Horizonte. 24 a 27 de nov. 2014.

SOUZA, R.F.P; SILVA JUNIOR, A.G. Valoração Econômica ambiental: O caso do Rio Paraibuna, Juiz de Fora- MG ANPEC - 2006.

SOUZA, T.B.; CUNHA, E. B. Valoração econômica ambiental: uma estimativa do valor de uso e valor de não uso do Rio Amazonas no litoral da capital Amapaense. Revista Meio-Ambienta e Sustentabilidade, v. 3, n. 2. Jun./dez., p. 265-285, 2013.

SOUZA, R. S. de. Entendendo a questão ambiental: temas de economia, política e gestão do meio ambiente. Santa Cruz do Sul, RS. Edunisc, 2000.

STAMPE, M.Z.; TOCCHETTO, D.G.; FLORISSI, S. Utilizando a metodologia de valoração contingente para estimar os benefícios gerado aos usuários pela feira do livro de Porto Alegre. ANPEC, 2008.

STAVINS, R. N. Economics of environment selected readings.5.ed.Havard University. New York, Norton \& company, 2005.

SUKHDEV, P. T. The Economics of Ecosystems and Biodiversity: Mainstreaming the Economics of Nature: A synthesis of the approach, conclusions and recommendations of TEEB, 2010 .

TAFURI, A. C. Valoração ambiental do Parque Estadual do Itacolomi, Ouro Preto, Minas Gerais. 2008. 158 f. Dissertação (Mestrado em Saneamento, Meio Ambiente e Recursos Hídricos) - Universidade Federal de Minas Gerais, Belo Horizonte, 2008.

TAKAYAMA, A. Analytical methods in economics. The University of Michigan Press, 1993.

TAVARES, V.E.Q.; RIBEIRO, M.M.R.; LANNA, A.E.L. Valoração monetária de bens e serviços ambientais: Revisão do estado da arte sob a ótica da gestão das águas. Revista Brasileira de Recursos Hídricos, v. 6, n. 3, jul./set. p. 97-116, 1999.

TAYLOR, L. O. The hedonic Method. In: CHAMP, P.; BOYLE, K. Brown, T. A primer on nonmarket valuation. London: Kluwer Academic Publishers, 2003.

TEISL, M. F.ET AL.Test-Retest Reliability of contingent valuation with independent sample pretest and post-test control groups. American journal of Agricultural Economics n.77, v. 3, p, $339-259,1995$.

TURNER, K. T. et al. Valuing nature: lessons learned and future research directions. Ecological Economics. n. 46, p. 493-510, 2003. 
TYRVÄINEN, L.; MUITTINEN, A. Property Prices and Urban Forest Amenities. Journal of Environmental Economics and Management, n. 39, p. 205-223, 2000.

VAN DEN BERGH, J. C. J. M. Ecological Economics: Themes, approaches, and differences with environmental economics. Tinbergen Institute discussion Paper. Department of Spatial Economics. Amsterdam: Free University, 2000.

VASCONCELOS, P.G. Método de valoração contingente: sobre a validade de preferências, cenários e agregação.2012.108 f. Dissertação (Mestrado em Gestão Econômica do Meio Ambiente) - Universidade de Brasília, Brasília, 2012.

VASCONCELOS, C. S. Aplicação do método de valoração contingente no Parque Municipal do Itiquira em Formosa-GO. Brasília, 2014. 109f. Dissertação (Mestrado em desenvolviemnto Sustentável. Centro de Desenvolvimento Sustentável. Universidade de Brasília, Brasília, 2014.

VARIAN, H. R. Microeconomia: princípios básicos. 5. ed. Rio de Janeiro: Campus, 2000.

VIANA, J. F. C. et al. Valoração ambiental do parque ecológico e de uso múltiplo olhos d'água como subsídio à sua concessão. 2006. IX Encontro Nacional da ECOECO Políticas Públicas e Perspectiva da Economia Ecológica Brasília. Brasília, out. 2011.

VIANA, M.O.L. Medidas monetárias da variação no bem-estar.In: VI Encontro Nacional de Economia Ecológica. 6.ed. 2005, Brasília. Anais ... Brasilia: ECOECO, 2005. P. 1-11.

VOLANOVA, S.R.F.; CHICORRO, J.F.; ARRUDA, C.A.S. Disposição a pagar pelo uso de unidades de conservação urbanas: Parque da Cidade Mãe Bonifácea, Cuiabá- MT. Interações Campo Grande, v. 11, n. 1, jan./jun. 2010.

VOSSLER, C. A.; DOYON, M. RONDEAU, D. Truth in consequentiality: Theory and field evidence on discrete choice experiments. American Economics Journal: Microeconomics, v. 4, n. 4, p.145-171, 2012.

VOSSLER, C.; POE, G. Consequentiality and contingent values: An emerging paradigm, in: The International Handbook on Non-Market Environmental Valuation, ed. Jeff Bennett. Northampton, MA: Edward Elgar, 2011.

VOSSLER, C.; EVANS, M. Bridging the gap between the field and the lab: Environmental goods, policy maker input, and consequentiality. Journal of Environmental Economics and Management. n. 58. p. 338-345, 2009.

WAUGH, F. V. Quality Factors Influencing Vegetable Prices. Journal of Farm Economics, v. 10, p. 185-96, 1928. 


\section{APÊNDICE A}

Quadro A.1- Quantidade de trabalhos empíricos que usaram o Método de Valoração Contingente por Estado Brasileiro

\begin{tabular}{|l|r|l|r|l|r|l|r|l|r|}
\hline Estado & Quant. & Estado & Quant. & Estado & Quant. & Estado & Quant. & Estado & Quant. \\
\hline AC & 2 & CE & 5 & MG & 11 & PE & 2 & RS & 11 \\
\hline AM & 1 & DF & 10 & MS & 1 & PI & 2 & SC & 3 \\
\hline AP & 3 & ES & 1 & MT & 6 & PR & 3 & SE & 1 \\
\hline BA & 2 & GO & 6 & PA & 1 & RJ & 2 & SP & 10 \\
\hline RR & 1 & TO & 3 & PB & 1 & & & RN & 2 \\
\hline
\end{tabular}

Fonte: Quadro elaborado pela própria autora (2015)

Quadro A.2 - Número de publicações sobre o método de valoração contingente (1998-2014)

(Continua)

\begin{tabular}{|c|c|c|c|c|c|}
\hline \multirow[b]{2}{*}{ Instituições } & \multicolumn{4}{|c|}{ Áreas de conhecimento } & \multirow[b]{2}{*}{ TOTAL } \\
\hline & Tradicional & $\begin{array}{l}\text { Recursos } \\
\text { hídricos }\end{array}$ & $\begin{array}{l}\text { Patrimônio } \\
\text { histórico cultural }\end{array}$ & $\begin{array}{ll}\text { Impactos } & \text { sobre } \\
\text { a } & \text { saúde } \\
\text { humana. } & \\
\end{array}$ & \\
\hline IFECT-MT & 1 & - & - & - & 1 \\
\hline IPEA & 1 & 1 & - & - & 2 \\
\hline MACKENZIE & - & 1 & - & - & 1 \\
\hline SENAC & - & - & - & 1 & 1 \\
\hline PUCRS & 1 & 1 & - & - & 2 \\
\hline UCB & 1 & 1 & - & - & 2 \\
\hline UFCG & - & - & - & 1 & 1 \\
\hline UEL-PR & - & 1 & - & - & 1 \\
\hline UERJ & - & - & 1 & - & 1 \\
\hline UESB & - & - & 1 & - & 1 \\
\hline UESC & 1 & - & - & - & 1 \\
\hline UFA & 1 & - & - & - & 1 \\
\hline UEG & 4 & - & - & - & 4 \\
\hline UFAC & - & 1 & - & 1 & 2 \\
\hline UFAM & - & 1 & - & - & 1 \\
\hline UFAP & - & 1 & - & - & 1 \\
\hline UFCE & - & - & - & 1 & 1 \\
\hline UFCG & - & - & - & 1 & 1 \\
\hline UFERSA & - & 1 & - & - & 1 \\
\hline UFF & - & 1 & - & - & 1 \\
\hline
\end{tabular}




\begin{tabular}{|c|c|c|c|c|c|}
\hline \multirow[b]{2}{*}{ Instituições } & \multicolumn{4}{|c|}{ Áreas de conhecimento } & \multirow[b]{2}{*}{ TOTAL } \\
\hline & Tradicional & $\begin{array}{l}\text { Recursos } \\
\text { hídricos }\end{array}$ & $\begin{array}{l}\text { Patrimônio } \\
\text { histórico cultural }\end{array}$ & $\begin{array}{ll}\text { Impactos } & \text { sobre } \\
\text { a } & \text { saúde } \\
\text { humana. } & \\
\end{array}$ & \\
\hline UFIT & - & 1 & - & - & 1 \\
\hline UFMG & 1 & - & - & - & 1 \\
\hline UFMT & 3 & - & - & 2 & 5 \\
\hline UFOP & 1 & 2 & 1 & - & 4 \\
\hline UFPA & 1 & - & - & - & 1 \\
\hline UFPE & 1 & - & 1 & - & 2 \\
\hline UFPI & - & 2 & 1 & - & 3 \\
\hline UFPR & 1 & - & - & 2 & 3 \\
\hline UFRG & 1 & - & 1 & - & 2 \\
\hline UFRJ & - & - & - & 1 & 1 \\
\hline UFRN & 1 & - & - & - & 1 \\
\hline UFRPE & 1 & - & - & - & 1 \\
\hline UFRS & 3 & - & - & 1 & 4 \\
\hline UFRR & 1 & - & - & - & 1 \\
\hline UFSC & 3 & - & - & 1 & 4 \\
\hline UFES & 1 & - & - & - & 1 \\
\hline UFSM & - & 1 & - & - & 1 \\
\hline UFT & 2 & - & - & - & 2 \\
\hline UFV & 3 & 1 & 1 & - & 5 \\
\hline UFVA & - & - & - & 1 & 1 \\
\hline UFVJM & - & 1 & - & 1 & 2 \\
\hline UFU & 1 & - & - & - & 1 \\
\hline UnB & 4 & 2 & - & 1 & 7 \\
\hline UNIFAP & 1 & - & - & - & 1 \\
\hline UNIFOR & - & 1 & - & 1 & 2 \\
\hline Unochapecó- SC & 1 & 1 & 1 & - & 3 \\
\hline USP & - & 1 & - & 1 & 2 \\
\hline UU & 1 & - & - & - & 1 \\
\hline TOTAL & 42 & 23 & 8 & 17 & 90 \\
\hline
\end{tabular}

Fonte: Quadro elaborado pela própria autora (2015) 
Quadro A.3 - Valores atribuídos aos Bens e/ou serviços ambientais pelo MVC no Brasil - 1998-2014

(Continua)

\begin{tabular}{|c|c|c|c|}
\hline $\begin{array}{l}\text { LOCAL, AUTOR E } \\
\text { DATA }\end{array}$ & ATRIBUTO VALORADO & $\begin{array}{l}\text { POPULAÇÃO } \\
\text { E AMOSTRA }\end{array}$ & $\begin{array}{l}\text { VALORES } \\
\text { ESTIMADOS } \\
\text { (US\$) }\end{array}$ \\
\hline $\begin{array}{l}\text { Jardim zoológico } \\
\text { de Brasília - Faria e } \\
\text { Nogueira (1998) }\end{array}$ & $\begin{array}{l}\text { DAP dos visitantes do Jardim } \\
\text { Zoológico para preservar }\end{array}$ & $\begin{array}{l}\text { Amostra } \\
1.044\end{array}$ & $\begin{array}{l}\text { DAP mínima 2,26 } \\
\text { Máxima 33,16 } \\
\text { Mínimo } 180,94 \text { e } \\
\text { Máxima } 18,35\end{array}$ \\
\hline $\begin{array}{l}\text { Bacia hídrica do } \\
\text { Alto Tietê - } \\
\text { Belluzzo Junior } \\
(1999)\end{array}$ & $\begin{array}{l}\text { DAP da população do Alto Tietê } \\
\text { pra implantação de projeto de } \\
\text { conservação }\end{array}$ & Amostra 720 & $\begin{array}{l}\text { DAP sem vês } 0,67 \\
\text { Com viés 2,01 por } \\
\text { pessoa }\end{array}$ \\
\hline $\begin{array}{lrr}\text { Estação } & \text { ecológica } \\
\text { Jataí de } & \text { Luiz } \\
\text { Antônio } & - & \text { Obara } \\
(1999) & & \\
\end{array}$ & $\begin{array}{l}\text { DAP da população do Município } \\
\text { de Luiz Antônio pela manutenção } \\
\text { da UC }\end{array}$ & $\begin{array}{l}\text { População - } \\
1.897 \\
\text { Amostra } \\
100\end{array}$ & 27 \\
\hline $\begin{array}{lr}\text { Córrego da } \\
\text { Rocinha } \\
\text { Carramaschi; } \\
\text { Cordeiro Neto e } \\
\text { Nogueira (2000) }\end{array}$ & ural por $\mathrm{m}^{3} \mathrm{de}$ & Amostra - 57 & $\begin{array}{l}0,0309 \\
0,0304 \text { por } \mathrm{m}^{3}\end{array}$ \\
\hline $\begin{array}{l}\text { Jardim botânico de } \\
\text { João Pessoa - } \\
\text { Araújo (2002) }\end{array}$ & essoa & $\begin{array}{l}\text { População } \\
140.903 \\
\text { Amostra } \\
502\end{array}$ & $\begin{array}{l}\text { DAP } \quad \text { Mínimo } \\
2.649,64 \text { milhões } \\
\text { aa } \\
\text { Máximo } 4.615,72 \\
\text { milhões aa }\end{array}$ \\
\hline $\begin{array}{l}\text { Área verde urbana } \\
\text { de Curitiba - } \\
\text { Hidelbrand, Graça } \\
\text { e Hoeflich (2002) }\end{array}$ & $\begin{array}{l}\text { DAP das Pessoas visitantes nas } \\
\text { áreas verdes pelos benéficos } \\
\text { gerados }\end{array}$ & $\begin{array}{l}\text { População - } \\
2.000 \\
\text { Amostra -94 }\end{array}$ & $\begin{array}{l}\text { DAP média } 0,71 \\
\text { por pessoa } \\
10.683,57\end{array}$ \\
\hline $\begin{array}{l}\text { Parque Estadual do } \\
\text { Morro do Diabo, } \\
\text { Adams et al. } \\
(2003)\end{array}$ & $\begin{array}{l}\text { DAP da população da cidade de } \\
\text { São Paulo pelo valor de } \\
\text { existência da UV }\end{array}$ & $\begin{array}{l}\text { População } \\
40.417 \\
\text { Amostra } \\
200\end{array}$ & $\begin{array}{l}\text { DAP } \\
2.478 .259,00 / \text { ano }\end{array}$ \\
\hline Lagoa do Peixe /RS & $\begin{array}{l}\text { DAP da Populaçãodomunicípio } \\
\text { Mostarda, São José e Tavares }\end{array}$ & Amostra 130 & $\begin{array}{l}\text { DAP média } 2,78 \\
\text { por pessoa ao ano }\end{array}$ \\
\hline $\begin{array}{l}\text { Rio Meia Ponte - } \\
\text { Silva, Fernandes } \\
\text { Lirio (2003) }\end{array}$ & $\begin{array}{l}\text { DAP dos consumidores de } \\
\text { hortaliças para conservação do } \\
\text { rio }\end{array}$ & stra -505 & $\begin{array}{ll}\text { DAP 2,21 } & \text { sem } \\
\text { consciência } & \\
\text { ecológica. } & \\
3,05 & \text { com } \\
\text { consciência } & \\
\end{array}$ \\
\hline $\begin{array}{l}\text { Parque Chico } \\
\text { Mendes - Silva e } \\
\text { Lima }(2004),\end{array}$ & $\begin{array}{l}\text { DAP população Rio Branco para } \\
\text { conservação do parque }\end{array}$ & Amostra -256 & $\begin{array}{l}\text { DAP 2,61 por } \\
\text { pessoa }\end{array}$ \\
\hline $\begin{array}{l}\text { Ativos ambientais: } \\
\text { ar - } \quad \text { Freitas; } \\
\text { Pereira e } \text { Maia } \\
(2004)\end{array}$ & $\begin{array}{l}\text { DAP das pessoas de Diamantino } \\
\text { pela melhoria da qualidade do ar }\end{array}$ & $\begin{array}{l}\text { População } \\
18.457 \\
\text { Amostra } \\
338\end{array}$ & $\begin{array}{l}\text { DAP } 0,, 61 \text { por } \\
\text { pessoa } \\
134.223,50 \text { aa }\end{array}$ \\
\hline $\begin{array}{l}\text { Enseada Saco da } \\
\text { Mangueira } \\
\text { Oliveira e Toguinha } \\
\text { (2004) }\end{array}$ & $\begin{array}{l}\text { DAP da população da Cidade Rio } \\
\text { Grande para conservação }\end{array}$ & $\begin{array}{l}\text { População - } \\
187.000 \\
\text { Amostra - } \\
115\end{array}$ & $2.650 .176,00$ \\
\hline $\begin{array}{l}\text { Estrada Parque - } \\
\text { Serra et al. (2004), }\end{array}$ & $\begin{array}{l}\text { DAP das pessoas que acessam a } \\
\text { estrada pra implantação de } \\
\text { sistema de acesso melhor }\end{array}$ & Amostra -143 & $\begin{array}{l}1,72 \text { a } 3,10 \text { por } \\
\text { pessoa }\end{array}$ \\
\hline
\end{tabular}




\begin{tabular}{|c|c|c|c|}
\hline $\begin{array}{l}\text { LOCAL, AUTOR E } \\
\text { DATA }\end{array}$ & ATRIBUTO VALORADO & $\begin{array}{l}\text { POPULAÇÃO } \\
\text { E AMOSTRA }\end{array}$ & $\begin{array}{l}\text { VALORES } \\
\text { ESTIMADOS } \\
\text { (US\$) }\end{array}$ \\
\hline $\begin{array}{l}\text { Parque Nacional } \\
\text { Lagoa do Peixe - } \\
\text { Braga. Abadallah e } \\
\text { Oliveira (2005) }\end{array}$ & $\begin{array}{l}\text { DAP da população dos municípios } \\
\text { Mostarda, São José do Norte e } \\
\text { Távora para manutenção do } \\
\text { parque }\end{array}$ & $\begin{array}{l}\text { Amostra } \\
130\end{array}$ & 3,25 por pessoa \\
\hline $\begin{array}{ll}\text { Praia Brava e } \\
\text { Balneário } \\
\text { Camboriú } & - \\
\text { Benetez }(2005), & \\
\end{array}$ & $\begin{array}{l}\text { DAP dos frequentadores para } \\
\text { preservar o ambiente }\end{array}$ & Amostra -399 & $\begin{array}{l}\text { DAP Mínima 0,81 } \\
\text { Máxima } 20,45\end{array}$ \\
\hline $\begin{array}{l}\text { Parque } \\
\text { Metropolitano de } \\
\text { Pituaçu - Souza e } \\
\text { Mota (2006) }\end{array}$ & $\begin{array}{l}\text { DAP dos visitantes para manter } \\
\text { as funções do parque }\end{array}$ & Amostra -395 & $\begin{array}{l}3,49 \text { mensal } \\
1.033 .051,96 \text { aa }\end{array}$ \\
\hline $\begin{array}{l}\text { Parque Ecológico e } \\
\text { de Uso Múltiplo } \\
\text { Olhos D’agua - } \\
\text { Viana (2006) }\end{array}$ & $\begin{array}{l}\text { DAP a população circunvizinha do } \\
\text { parque para melhorias e } \\
\text { manutenção do parque }\end{array}$ & $\begin{array}{l}\text { Amostra } \\
203\end{array}$ & $\begin{array}{l}\text { Dap } 1,48 \text { por } \\
\text { pessoa }\end{array}$ \\
\hline $\begin{array}{l}\text { Horto Florestal de } \\
\text { Rondonópolis } \\
\text { Pulgas (2006) }\end{array}$ & $\begin{array}{l}\text { DAP da população de } \\
\text { Rondonópolis para preservação }\end{array}$ & $\begin{array}{l}\text { População } \\
40.775 \\
\text { Amostra } \\
381\end{array}$ & $\begin{array}{l}\text { DAP induzida } 2,11 \\
\text { DAP espontânea } \\
4,45 \text { por pessoa }\end{array}$ \\
\hline $\begin{array}{lr}\text { Micro bacia } & \text { do } \\
\text { Ribeirão } & \text { São } \\
\text { Bartolomeu } & - \\
\text { Matos (2006) } & \\
\end{array}$ & $\begin{array}{l}\text { DAP da população e viçosa para } \\
\text { recuperar e preservar o Ribeirão }\end{array}$ & $\begin{array}{l}\text { População } \\
71.624 \\
\text { Amostra } \\
280\end{array}$ & $\begin{array}{l}12,64 \text { ao mês } \\
1.746 .012,69 \text { aa }\end{array}$ \\
\hline $\begin{array}{l}\text { Reciclagem Lucena } \\
\text { e Távora Junior } \\
(2006)\end{array}$ & $\begin{array}{l}\text { DAP da população de Recife, } \\
\text { Jaboatão dos Guararapes pra } \\
\text { implantação ode reciclagem de } \\
\text { lixo }\end{array}$ & $\begin{array}{l}\text { População - } \\
2.053 .428 \\
\text { Amostra - } \\
498\end{array}$ & $\begin{array}{l}\text { DAP média } 22,77 \\
46.765 .825,21\end{array}$ \\
\hline $\begin{array}{l}\text { Queimadas } \\
\text { qualidade do ar } \\
\text { Silva e Lima } \\
(2006) ;\end{array}$ & $\begin{array}{l}\text { DAP da população de Rio Branco } \\
\text { pela qualidade do ar }\end{array}$ & $\begin{array}{l}\text { Amostra } \\
249\end{array}$ & $\begin{array}{l}10,24 \\
19.694 .286,13\end{array}$ \\
\hline $\begin{array}{l}\text { Recursos hídricos } \\
\text { de Brotas - } \\
\text { Fernandes e } \\
\text { Kuwahara (2006). }\end{array}$ & $\begin{array}{l}\text { DAP da população de Brotas para } \\
\text { preservar recursos hídricos locais }\end{array}$ & Amostra - 74 & $\begin{array}{l}11,29 \quad \text { aa } \\
\text { individual } \\
795.550,35 \text { aa }\end{array}$ \\
\hline $\begin{array}{l}\text { Rio Paraibuna - } \\
\text { Souza e Silva } \\
\text { Junior (2006) }\end{array}$ & $\begin{array}{l}\text { DAP da população de Juiz de Fora } \\
\text { para despoluir o rio }\end{array}$ & Amostra 400 & 2,26 por pessoa \\
\hline $\begin{array}{l}\text { APP Do Ribeirão } \\
\text { São Bartolomeu - } \\
\text { Matos et al. (2007) }\end{array}$ & $\begin{array}{l}\text { DAP população de viçosa para } \\
\text { preservação do Ribeirão }\end{array}$ & $\begin{array}{l}\text { População } \\
71.624 \\
\text { Amostra } \\
280\end{array}$ & $\begin{array}{l}14,65 \text { ao mês } \\
1.893,76 \text { aa }\end{array}$ \\
\hline $\begin{array}{l}\text { Reuso de águas } \\
\text { industriais em } \\
\text { fortaleza - Silva e } \\
\text { Fontenele (2007) }\end{array}$ & $\begin{array}{l}\text { DAP do DIF pelos diversos usos } \\
\text { de água }\end{array}$ & $\begin{array}{l}\text { População - } \\
70 \\
\text { Amostra -70 }\end{array}$ & $\begin{array}{l}\text { Mínimo } \quad 0,22 \\
\text { Máximo } 0,30 \text { por } \\
\mathrm{m}^{3} \text { de água }\end{array}$ \\
\hline $\begin{array}{l}\text { Reusuo de água do } \\
\text { distrito industrila } \\
\text { de Fortaleza - } \\
\text { Fontenele (2007) }\end{array}$ & $\begin{array}{l}\text { DAP do DIF pelos diversos usos } \\
\text { de água }\end{array}$ & $\begin{array}{l}\text { População - } \\
70 \\
\text { Amostra -70 }\end{array}$ & $\begin{array}{l}\text { Mínimo } 0,22 \\
\text { Máximo } 0,30 \text { por } \\
m^{3} \text { de água }\end{array}$ \\
\hline $\begin{array}{l}\text { Rio Santa Maria - } \\
\text { Rossarolla; Silveira } \\
\text { e Cruz (2007) }\end{array}$ & $\begin{array}{l}\text { DAP da população de Santa Maria } \\
\text { para cobrança do uso dá água pra } \\
\text { irrigação do arroz }\end{array}$ & $\begin{array}{l}\text { População } \\
200.000 \\
\text { Amostra } \\
384\end{array}$ & $\begin{array}{l}\text { Não souberam } \\
\text { responder a DAP }\end{array}$ \\
\hline
\end{tabular}




\begin{tabular}{|c|c|c|c|}
\hline $\begin{array}{c}\text { LOCAL, AUTOR E } \\
\text { DATA }\end{array}$ & ATRIBUTO VALORADO & $\begin{array}{l}\text { POPULAÇÃO } \\
\text { E AMOSTRA }\end{array}$ & $\begin{array}{l}\text { VALORES } \\
\text { ESTIMADOS } \\
\text { (US\$) }\end{array}$ \\
\hline $\begin{array}{l}\text { Queimadas } \\
\text { qualidade do ar } \\
\text { Fernandez (2008), }\end{array}$ & $\begin{array}{l}\text { DAP das pessoas de Ribeirão } \\
\text { Preto pela qualidade do ar } \\
\text { antecipando a proibição das } \\
\text { queimadas da cana de açúcar }\end{array}$ & $\begin{array}{l}\text { População - } \\
\text { Amostra } \\
1.211\end{array}$ & $\begin{array}{l}\text { Modelo } 1-3,76 \\
\text { Modelo } 2-7,96 \\
\text { Modelo } 3-7,35 \\
\text { Modelo } 4-7,83 \\
\text { Modelo } 5-6,91\end{array}$ \\
\hline $\begin{array}{l}\text { Praia do Prata e } \\
\text { Graciosa - Alves } \\
\text { Filho e Valadares } \\
(2008)\end{array}$ & $\begin{array}{l}\text { DAP dos visitantes para preservar } \\
\text { a praia }\end{array}$ & Amostra -240 & $\begin{array}{l}3,86 \text { por pessoa } \\
66.461,49\end{array}$ \\
\hline $\begin{array}{l}\text { Feira do Livro - } \\
\text { Stampe; Tocchetto } \\
\text { e Florissi (2008) }\end{array}$ & $\begin{array}{l}\text { DAP dos visitantes da feira do } \\
\text { livro por ingresso na feira }\end{array}$ & $\begin{array}{l}\text { População - } \\
1,7 \text { milhões } \\
\text { Amostra - } \\
319\end{array}$ & 3,05 por pessoa \\
\hline $\begin{array}{l}\text { APA São } \begin{array}{l}\text { José } \\
\text { Cirino e } \\
(2008)\end{array} \\
\text { Lima }\end{array}$ & $\begin{array}{l}\text { DAP da população dos municípios } \\
\text { Tiradentes, Prados, Santa Cruz } \\
\text { de Minas, Coronel Chaves e São } \\
\text { João Del Rei para preservar o } \\
\text { parque }\end{array}$ & $\begin{array}{l}\text { População - } \\
31.162 \\
\text { Amostra } \\
518\end{array}$ & $\begin{array}{l}13,98 \text { por pessoa } \\
5.227 .174,19\end{array}$ \\
\hline $\begin{array}{lr}\text { Produtores } & \text { de } \\
\text { Hortaliças } & - \\
\text { Rodrigues e } & \text { Farias } \\
(2008), & \\
\end{array}$ & $\begin{array}{l}\text { DAP dos agricultores } \\
\text { manutenção das águas } \\
\text { agricultura }\end{array}$ & Amostra -81 & $0,016 \mathrm{~m}^{3}$ \\
\hline $\begin{array}{l}\text { Ativos ambientais } \\
\text { na suinocultura em } \\
\text { Damantino/MT } \\
\text { Freitas. Pereira e } \\
\text { Maia (2008) }\end{array}$ & DAP dapupulação & Amostra 330 & $\begin{array}{l}1,07 \text { mensal por } \\
\text { individuo }\end{array}$ \\
\hline $\begin{array}{l}\text { Valoração } \\
\text { ambiental do } \\
\text { Parque Estadual do } \\
\text { Itacolomi, Ouro } \\
\text { Preto/MG - Tafuri } \\
(2008)\end{array}$ & $\begin{array}{l}\text { DAP dos visitante e monitores do } \\
\text { parque }\end{array}$ & $\begin{array}{l}\text { População } \\
3.119 \\
\text { Amostra } 114\end{array}$ & $\begin{array}{l}\text { DAP anual } \\
1.221 .896,38\end{array}$ \\
\hline $\begin{array}{l}\text { Poluição do ar e } \\
\text { morbidade } \text { Mac- } \\
\text { Knight (2008) }\end{array}$ & $\begin{array}{l}\text { DAP das pessoas nos hospitais e } \\
\text { Pronto socorro das cidades São } \\
\text { Paulo, Ribeirão preto, Taubaté, } \\
\text { Presidente Prudente }\end{array}$ & $\begin{array}{l}\text { População - } \\
\text { Amostra } 205 \\
\text { e } 736\end{array}$ & $\begin{array}{l}99,55 \text { internados } \\
\text { em Hospitais } \\
58,89 \quad \text { pronto } \\
\text { socorro }\end{array}$ \\
\hline $\begin{array}{l}\text { Parque Nacional } \\
\text { Chapada } \\
\text { Diamantina } \\
\text { Carvalho (2009) }\end{array}$ & $\begin{array}{l}\text { DAP dos visitantes da Chapada } \\
\text { para conservar e recuperar }\end{array}$ & Amostra -400 & $\begin{array}{lcr}\text { DAP } & \text { média } \\
\text { Mínima } & 10,59 \text { e } \\
\text { Máxima } & 12,28\end{array}$ \\
\hline $\begin{array}{l}\text { Parque Nacional } \\
\text { Serra da Capivara } \\
\text { - Oliveira Filho e } \\
\text { Monteiro (2009) } \\
\end{array}$ & $\begin{array}{l}\text { DAP da população da cidade de } \\
\text { Coronel José dias e São } \\
\text { Raimundo pela preservação do } \\
\text { parque }\end{array}$ & $\begin{array}{l}\text { População - } \\
1175 \\
\text { Amostra - } \\
451\end{array}$ & $\begin{array}{l}\text { DAP mínima 3,09 } \\
\text { e DAP Máxima } \\
10,30\end{array}$ \\
\hline $\begin{array}{l}\text { Usina Hidroelétrica } \\
\text { Luiz Eduardo } \\
\text { Magalhães } \\
\text { Rodrigues; } \\
\text { Nogueira; } \\
\text { Carvalho (2009). } \\
\end{array}$ & $\begin{array}{l}\text { DAC população Porto Nacional } \\
\text { por danos causados pela Usina }\end{array}$ & $\begin{array}{l}\text { População - } \\
46.285 \\
\text { Amostra } \\
200\end{array}$ & $\begin{array}{l}\text { DAC média } 15,06 \\
8,34 \text { milhões aa }\end{array}$ \\
\hline $\begin{array}{l}\text { Córrego Limoeiro - } \\
\text { Pontes (2009) }\end{array}$ & $\begin{array}{l}\text { DAP da população de Presidente } \\
\text { Prudente para tratamento } \\
\text { sanitário }\end{array}$ & $\begin{array}{l}\text { Amostra } \\
257\end{array}$ & $\begin{array}{l}2,76 \text { cenário legal } \\
3,78 \text { cenário ideal }\end{array}$ \\
\hline $\begin{array}{ll}\text { Cafeicultores } & - \\
\text { Máximo; Silva e } \\
\text { Máximo (2009) }\end{array}$ & $\begin{array}{l}\text { DAP dos cafeicultores para } \\
\text { recuperar área de mata }\end{array}$ & $\begin{array}{l}\text { População - } \\
82\end{array}$ & $\begin{array}{l}\text { DAP pra } 70 \text { ha } \\
130.895,98\end{array}$ \\
\hline
\end{tabular}




\begin{tabular}{|c|c|c|c|}
\hline $\begin{array}{l}\text { LOCAL, AUTOR E } \\
\text { DATA }\end{array}$ & ATRIBUTO VALORADO & $\begin{array}{l}\text { POPULAÇÃO } \\
\text { E AMOSTRA }\end{array}$ & $\begin{array}{l}\text { VALORES } \\
\text { ESTIMADOS } \\
\text { (US\$) }\end{array}$ \\
\hline & & Amostra - 60 & \\
\hline $\begin{array}{l}\text { Bacia do Rio } \\
\text { Corumbataí } \\
\text { Barbisan (2009). }\end{array}$ & $\begin{array}{l}\text { DAP da população de Corumbataí } \\
\text { pra projeto de mata ciliar }\end{array}$ & $\begin{array}{l}\text { Amostra } \\
930\end{array}$ & $\begin{array}{l}1,05 \text { por pessoa } \\
14.1091,65 \text { aor } \\
\text { mês }\end{array}$ \\
\hline $\begin{array}{l}\text { Parque da Cidade } \\
\text { Mãe Bonifácea - } \\
\text { Volanova. (2010) }\end{array}$ & $\begin{array}{l}\text { DAP população de Cuiabá para } \\
\text { conservação do parque }\end{array}$ & $\begin{array}{l}\text { População - } \\
20 \text { mil } \\
\text { Amostra } \\
200\end{array}$ & $\begin{array}{l}0,17 \text { por pessoa } \\
12.416,16 \text { aa }\end{array}$ \\
\hline $\begin{array}{l}\text { Represa Dal Bó - } \\
\text { Gullo (2010). }\end{array}$ & $\begin{array}{l}\text { DAP da população de Caxias do } \\
\text { Sul preservar }\end{array}$ & $\begin{array}{l}\text { População - } \\
\text { Amostra - } \\
250\end{array}$ & 11,92 \\
\hline $\begin{array}{l}\text { Barragem Santa } \\
\text { Maria - Mota et al. } \\
(2010),\end{array}$ & $\begin{array}{l}\text { DAP da população Paranoá e } \\
\text { Brasília para captação de água } \\
\text { em área de conservação }\end{array}$ & $\begin{array}{l}\text { População - } \\
540.750 \\
\text { Amostra - } \\
400\end{array}$ & $\begin{array}{l}\text { 0,03 por } \mathrm{m}^{3} \\
\text { Paranoá } \\
0,02 \mathrm{~m}^{3} \text { Brasília }\end{array}$ \\
\hline $\begin{array}{lr}\text { Bacia } & \text { do } \\
\text { Educandos } & - \\
\text { Freitas et al. } \\
(2010)\end{array}$ & $\begin{array}{l}\text { DAP da população Bacia do } \\
\text { Educando para manutenção do } \\
\text { projeto }\end{array}$ & $\begin{array}{l}\text { Amostra } \\
1.070\end{array}$ & $\begin{array}{l}7,79 \text { por pessoa } \\
26.187 .153,71 \text { aa }\end{array}$ \\
\hline $\begin{array}{l}\text { Rio Passo Fundo - } \\
\text { Brugnaro (2010) }\end{array}$ & $\begin{array}{l}\text { DAP da população de } \\
\text { Fundo pra recuperar } \\
\text { degradadas áreas }\end{array}$ & $\begin{array}{ll}\text { População } & - \\
2.340 & \\
\text { Amostra } & - \\
150 & \\
\end{array}$ & $\begin{array}{l}\text { DAP } 11^{a} \\
\text { alternativa } 2,62 \mathrm{e} \\
2^{\mathrm{a}} \text { alternativa } \\
7,91\end{array}$ \\
\hline $\begin{array}{l}\text { Árvores em Palmas } \\
\text { - Moraes, Araújo e } \\
\text { Paixão (2010), }\end{array}$ & $\begin{array}{l}\text { DAP população de Palmas para } \\
\text { ter uma árvore em frente de casa } \\
\text { e cuidada }\end{array}$ & Amostra -410 & $\begin{array}{l}\text { Mínimo } 3,14 \text { e } \\
\text { Máximo } 4,13\end{array}$ \\
\hline $\begin{array}{lrl}\text { Ribeirão } & \text { Feijão } & - \\
\text { Machado (2011) }\end{array}$ & $\begin{array}{l}\text { DAP da população de Itajubá } \\
\text { para proteção dos recursos } \\
\text { hídricos }\end{array}$ & Amostra -280 & $\begin{array}{l}\text { 1,95 por pessoa } \\
519.384,56 \text { aa }\end{array}$ \\
\hline $\begin{array}{l}\text { Ribeirão } \\
\text { Cafezal/Rio Tibagi } \\
\text { - Pizaia (2011). }\end{array}$ & $\begin{array}{l}\text { DAP da população rural no } \\
\text { Paraná para cobrança de tarifa de } \\
\text { água pra agricultura }\end{array}$ & $\begin{array}{l}\text { População - } \\
4.112 \\
\text { Amostra - } 82\end{array}$ & $\begin{array}{l}14,67 \text { ao mês ou } \\
0,09 \text { por } \mathrm{m}^{3}\end{array}$ \\
\hline $\begin{array}{l}\text { Parque Ecológico e } \\
\text { de Usos Múltiplos } \\
\text { Águas Claras - } \\
\begin{array}{l}\text { Morgado et al. } \\
(2011)\end{array}\end{array}$ & $\begin{array}{l}\text { DAP da população de Aguas } \\
\text { Claras para manter e conservar o } \\
\text { parque }\end{array}$ & $\begin{array}{l}\text { População - } \\
60.000 \\
\text { Amostra } \\
276\end{array}$ & 7,36 ao mês \\
\hline $\begin{array}{l}\text { Gestores de } \\
\text { Agencia de Viagem } \\
\text { - Borja (2011) } \\
\end{array}$ & $\begin{array}{l}\text { DAP dos gestores de viagens pra } \\
\text { conservação das serras } \\
\text { Sergipanas }\end{array}$ & \begin{tabular}{|l|} 
População - \\
17 \\
Amostra -17 \\
\end{tabular} & 3,17 aa \\
\hline $\begin{array}{l}\text { Gasoduto de } \\
\text { Cacimbas - Povoa } \\
\text { e Tosta (2011) }\end{array}$ & $\begin{array}{l}\text { DAP da população de São Mateus } \\
\text { para diminuir o impacto } \\
\text { ambiental do gasoduto }\end{array}$ & $\begin{array}{l}\text { Amostra } \\
204\end{array}$ & 3,72 por pessoa \\
\hline $\begin{array}{l}\text { Passivo ambiental } \\
\text { causado pelo lixo } \\
\text { urbano, Carlos } \\
\text { Chagas/G } \\
\begin{array}{l}\text { Gonçalves et al } \\
(2011)\end{array} \\
\end{array}$ & $\begin{array}{l}\text { DAP da População de Carlos } \\
\text { Chagas }\end{array}$ & Amostra 272 & $\begin{array}{l}\text { DAP 9,72 por } \\
\text { pessoa } \\
\text { DAP total } \\
1.138 .348,51\end{array}$ \\
\hline $\begin{array}{l}\begin{array}{l}\text { Mercado de água } \\
\text { ruaral } \\
\text { Londrina/PR- em } \\
\text { Gonçalves et al. } \\
(2011)\end{array} \\
\end{array}$ & $\mathrm{DAF}$ & $\begin{array}{l}\text { População } \\
4.112 \\
\text { Amostra } 85\end{array}$ & $\begin{array}{lr}\text { DAP } & \text { por } \\
\text { residência } & 0,09 \\
\text { por } \mathrm{m}^{3} & \end{array}$ \\
\hline
\end{tabular}




\begin{tabular}{|c|c|c|c|}
\hline $\begin{array}{l}\text { LOCAL, AUTOR E } \\
\text { DATA }\end{array}$ & ATRIBUTO VALORADO & $\begin{array}{l}\text { POPULAÇÃO } \\
\text { E AMOSTRA }\end{array}$ & $\begin{array}{l}\text { VALORES } \\
\text { ESTIMADOS } \\
\text { (US\$) }\end{array}$ \\
\hline $\begin{array}{l}\text { Olhos d'agua da } \\
\text { Chuva - Souza et } \\
\text { al. (2012) }\end{array}$ & $\begin{array}{l}\text { DAP pelos moradores da Cidade } \\
\text { de Palmeiras para conservação } \\
\text { das águas }\end{array}$ & $\begin{array}{l}\text { População - } \\
5.586 \\
\text { Amostra - } 40\end{array}$ & 2,46 por pessoa \\
\hline $\begin{array}{l}\text { APP de Cuiabá - } \\
\text { Silva, Bacarji e } \\
\text { Rodrigues (2012) }\end{array}$ & $\begin{array}{l}\text { DAP pela população do bairro } \\
\text { Jardim Universitário para valorar } \\
\text { a APP }\end{array}$ & $\begin{array}{l}\text { População - } \\
\text { Amostra - } \\
100\end{array}$ & 4,92 por pessoa \\
\hline $\begin{array}{l}\text { Parque do Rio } \\
\text { Vermelho - João e } \\
\text { Baasch (2012) }\end{array}$ & $\begin{array}{l}\text { DAP visitante para preservar o } \\
\text { parque }\end{array}$ & $\begin{array}{l}\text { População - } \\
1500 \\
\text { Amostra } \\
100\end{array}$ & $\begin{array}{l}\text { DAP mínima } 1,72 \\
\text { DP máxima } 4,92 \\
\text { Por pessoa }\end{array}$ \\
\hline $\begin{array}{l}\text { Qualidade do ar } \\
\text { Lourenço et al. } \\
(2012)\end{array}$ & $\begin{array}{l}\text { DAP dos controladores de tráfego } \\
\text { São Paulo para melhorar a } \\
\text { qualidade do ar }\end{array}$ & $\begin{array}{l}\text { Amostra } \\
1.300\end{array}$ & 16,24 por pessoa \\
\hline $\begin{array}{l}\text { Árvore - Aroeira - } \\
\text { Monteiro, Araújo e } \\
\text { Amorim (2012) }\end{array}$ & $\begin{array}{l}\text { DAP dos visitantes da feira por } \\
\text { ingresso }\end{array}$ & $\begin{array}{l}\text { Amostra } \\
613\end{array}$ & $\begin{array}{l}\text { DAP média } 19,83 \\
\text { aa }\end{array}$ \\
\hline $\begin{array}{l}\text { Coleta seletiva de } \\
\text { Lixo - Rodrigues e } \\
\text { Santana (2012). }\end{array}$ & $\begin{array}{l}\text { DAP da população de Palmas para } \\
\text { implantação da coleta seletiva }\end{array}$ & $\begin{array}{l}\text { População } \\
40.435 \\
\text { Amostra } \\
615\end{array}$ & $\begin{array}{l}\text { DAP Residencial: } \\
\text { convencional } \\
9,95, \quad \text { seletiva } \\
11,75 \\
\text { DAP não } \\
\text { residencial: } \\
\text { convencional } \\
\begin{array}{l}12,59 \quad \text { seletiva } \\
13,06\end{array}\end{array}$ \\
\hline $\begin{array}{l}\text { Corrego dos Índios } \\
\text {, Malacacheta/MG } \\
\text { - Santos et al. } \\
(2012)\end{array}$ & $\begin{array}{l}\text { DAP da populaçãode Malacacheta } \\
\text { /MG }\end{array}$ & $\begin{array}{l}\text { População - } \\
18.181 \\
\text { Amostra } 280\end{array}$ & $\begin{array}{l}\text { DAP média } 21,18 \\
\text { por pessoa }\end{array}$ \\
\hline $\begin{array}{l}\text { APA Estadual da } \\
\text { cachoeira das } \\
\text { Andorinhas } \\
\text { Silveira; Cirino e } \\
\text { Prado Filho (2013) }\end{array}$ & $\begin{array}{l}\text { DAP da população de Ouro preto } \\
\text { pra melhorar e conservar a } \\
\text { qualidade ambiental }\end{array}$ & $\begin{array}{l}\text { Amostra } \\
723\end{array}$ & $\begin{array}{l}6,84 \text { por mês por } \\
\text { pessoa. } \\
461.105,83 \text { ao }\end{array}$ \\
\hline $\begin{array}{l}\text { Enseada Saco do } \\
\text { Laranjal - Corbeti; } \\
\text { Silveira et al. } \\
(2013)\end{array}$ & $\begin{array}{l}\text { DAP população de Pelotas/RS } \\
\text { para preservação }\end{array}$ & $\begin{array}{l}\text { População - } \\
339.934 \\
\text { Amostra - } \\
170\end{array}$ & $\begin{array}{l}11,65 \text { por pessoa } \\
3.634 .206,59\end{array}$ \\
\hline $\begin{array}{l}\text { Parque ambiental } \\
\text { de Chapecó- Facco } \\
\text { e Jacosdki (2013). }\end{array}$ & $\begin{array}{l}\text { DAP visitante para usufruir } \\
\text { estrutura do parque }\end{array}$ & $\begin{array}{l}\text { População - } \\
700 \\
\text { Amostra - } 70\end{array}$ & $\begin{array}{l}\text { DAP } 1,55 \text { por } \\
\text { pessoa }\end{array}$ \\
\hline 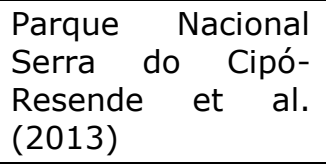 & $\begin{array}{l}\text { DAP dos visitantes pela } \\
\text { conservação dos ecossistemas do } \\
\text { Parque. }\end{array}$ & $\begin{array}{l}\text { Amostra -514 } \\
\text { População - } \\
100.000\end{array}$ & $\begin{array}{ll}\text { DAP } 3,17 & \text { por } \\
\text { pessoa } & \\
\text { DAP por ano } \\
317.544,99 & \end{array}$ \\
\hline $\begin{array}{l}\text { Museu som e } \\
\text { Imagem - Mota e } \\
\text { Ortiz (2013). }\end{array}$ & DAP de turistas por ingresso & $\begin{array}{l}\text { Amostra } \\
720\end{array}$ & $\begin{array}{l}\text { DAP Estrangeiros } \\
\text { média } 12,65 \text { a } \\
14,13 \\
\text { Nacionais } 10,37 \text { a } \\
11,60\end{array}$ \\
\hline $\begin{array}{l}\text { Orla da Cidade de } \\
\text { Macapá - Sousa e } \\
\text { Cunha (2013) }\end{array}$ & $\begin{array}{l}\text { DAP das pessoas a passeio na } \\
\text { orla de Macapá para valorar o Rio } \\
\text { Amazonas }\end{array}$ & Amostra - 60 & $3.111 .716 .095,44$ \\
\hline $\begin{array}{l}\text { Coleta seletiva, } \\
\text { Silva et al. (2013) }\end{array}$ & $\begin{array}{l}\text { DAP dos moradores de Aldeota } \\
\text { pelo serviço de coleta seletiva }\end{array}$ & $\begin{array}{l}\text { População - } \\
43.361 \\
\text { Amostra - } 30\end{array}$ & DAP média 16,73 \\
\hline
\end{tabular}




\begin{tabular}{|c|c|c|c|}
\hline $\begin{array}{l}\text { LOCAL, AUTOR E } \\
\text { DATA }\end{array}$ & ATRIBUTO VALORADO & $\begin{array}{l}\text { POPULAÇÃO } \\
\text { E AMOSTRA }\end{array}$ & $\begin{array}{c}\text { VALORES } \\
\text { ESTIMADOS } \\
\text { (US\$) }\end{array}$ \\
\hline $\begin{array}{l}\text { Fazendinha } \\
\text { APAFAZ- Macapá - } \\
\text { Bocato Junior; } \\
\text { Cunha (2013) }\end{array}$ & DAP dos visitantes & Amostra 148 & $\begin{array}{l}\text { DAP } 1,36 \text { ao mês. } \\
1.407 .064,07 \text { aa. }\end{array}$ \\
\hline $\begin{array}{l}\text { Recursos hídricos } \\
\text { da região de } \\
\text { Pelotas - Corbeti; } \\
\text { Alvim e rias } \\
(2013)\end{array}$ & População de Pelotas/RGS & $\begin{array}{l}\text { População } \\
339.934 \\
\text { Amostra :170 }\end{array}$ & $\begin{array}{l}\text { DAP } 70,96 \text { por } \\
\text { ano por pessoa } \\
\text { Valor anual } \\
3.634 .206,59\end{array}$ \\
\hline $\begin{array}{l}\text { Parque Estadual do } \\
\text { Itacolomi. Mariana } \\
\text { /MG. Camargo } \\
(2014)\end{array}$ & DAP dos visitantes & Amostra 128 & $\begin{array}{l}4,35 \text { ao mês. } \\
8.628 .931,12 \text { aa }\end{array}$ \\
\hline $\begin{array}{l}\text { Campus da UFMT. } \\
\text { Batista (2014) }\end{array}$ & $\begin{array}{l}\text { DAP dos visitantes da área de } \\
\text { lazer dos Campus da UFMT }\end{array}$ & $\begin{array}{l}\text { População - } \\
3.000 \\
\text { Amostra -295 }\end{array}$ & $\begin{array}{l}\text { DAP } 1,38 \text { ao mês } \\
1.429 .442,69 \text { aa }\end{array}$ \\
\hline $\begin{array}{l}\text { Parque Municipal } \\
\text { Victorino Siquieroli } \\
\text {-Uberlândia- MG. } \\
\text { Correia e Almeida ( } \\
\text { 2014) }\end{array}$ & DAP da comunidade local & $\begin{array}{l}\text { População } \\
1.214 \\
\text { Amostra } 40\end{array}$ & $\begin{array}{l}\text { DAP } 1,89 \text { por } \\
\text { pessoa ao } \\
\text { Total } 2.075,64 \text { aa }\end{array}$ \\
\hline $\begin{array}{lr}\begin{array}{l}\text { Parque } \\
\text { d'Agua- }\end{array} & \text { Olhos } \\
\text { Almeida } \\
\text { (2014) }\end{array}$ & DAP usuários do parque & Amostra 100 & $\begin{array}{l}\text { DAP } 7,12 \text { ao mês } \\
\text { por pessoa }\end{array}$ \\
\hline $\begin{array}{l}\text { Parque estadual } \\
\text { Urtiga- Belém / PA. } \\
\text { Honderson et al. } \\
(2014)\end{array}$ & DAP da população de Belém & $\begin{array}{l}\text { População } \\
1.393 .399 \\
\text { Amostra } 221\end{array}$ & DAP $4.710,97$ \\
\hline $\begin{array}{l}\text { Parque } \\
\text { Saint"Hilarire } \\
\text { Viamão/ RS. } \\
\text { Sosnoski; Silva e } \\
\text { Moraes (2014) } \\
\end{array}$ & $\begin{array}{l}\text { DAP frequentadores do parque e } \\
\text { moradores da RMPA }\end{array}$ & $\begin{array}{l}\text { População } 37 \\
\text { moradores do } \\
\text { parque }\end{array}$ & $\begin{array}{l}\text { DAP Total } 37.023 \\
\text { milhões }\end{array}$ \\
\hline $\begin{array}{l}\text { Parque municipal } \\
\text { de Anápolis/GO. } \\
\text { Castro e Castro } \\
(2014)\end{array}$ & DAP da população de Anápolis & $\begin{array}{l}\text { População } \\
361.991 \\
\text { Amostra } 400\end{array}$ & $\begin{array}{l}\text { DAP 2,32 por } \\
\text { pessoa }\end{array}$ \\
\hline $\begin{array}{l}\text { Parque Municipal } \\
\text { Maatinha - } \\
\text { Anápolis/GO Lopes } \\
\text { e Castro (2014) }\end{array}$ & $\begin{array}{l}\text { DAP dos frequentadores do } \\
\text { parque }\end{array}$ & Amostra 100 & $\begin{array}{l}\text { DAP ente } 0,90 \text { e } \\
1,35 \text { por pessoa } \\
\text { ao mês }\end{array}$ \\
\hline $\begin{array}{l}\text { Parque Municipal } \\
\text { Liberdade, } \\
\text { Anápolis/ GO. } \\
\text { Cintra e Castro } \\
(2014)\end{array}$ & $\begin{array}{l}\text { DAP dos frequentadores do } \\
\text { Parque }\end{array}$ & Amostra 100 & $\begin{array}{l}\text { DAP } 3,23 \text { por } \\
\text { pessoa ao mês }\end{array}$ \\
\hline $\begin{array}{ll}\text { Parques } & \text { em } \\
\text { Anápolis/ } & \text { GO. } \\
\text { Castro (2014) } & \\
\end{array}$ & $\begin{array}{l}\text { DAP dos frequentadores dos } \\
\text { quatro parques }\end{array}$ & Amostra 400 & $\begin{array}{l}\text { DAP 2,485,52 a } \\
12,50 \text { total } \\
296.291,81 \text { aa }\end{array}$ \\
\hline $\begin{array}{l}\text { Parque Municipal } \\
\text { Itiquira, Formosa / } \\
\text { GO. Vasconcelos } \\
(2014) \\
\end{array}$ & $\begin{array}{l}\text { DAP dos frequentadores do } \\
\text { Parque }\end{array}$ & Amostra 400 & $\begin{array}{ll}\text { DAP } 8,11 & \text { por } \\
\text { adulto.4,50 } & \text { por } \\
\text { crianças } & \end{array}$ \\
\hline $\begin{array}{l}\text { Unidade de } \\
\text { Conservação } \\
\text { Parque da Cidade }\end{array}$ & $\begin{array}{l}\text { DAP dos frequentadores do } \\
\text { Parque }\end{array}$ & $\begin{array}{l}\text { População } \\
20.000 \\
\text { Amostra } 20\end{array}$ & $\begin{array}{l}\text { DAP média de } \\
277,99\end{array}$ \\
\hline
\end{tabular}




\begin{tabular}{|c|c|c|c|}
\hline $\begin{array}{l}\text { LOCAL, AUTOR E } \\
\text { DATA }\end{array}$ & ATRIBUTO VALORADO & $\begin{array}{l}\text { POPULAÇÃO } \\
\text { E AMOSTRA }\end{array}$ & $\begin{array}{l}\text { VALORES } \\
\text { ESTIMADOS } \\
\text { (US\$) }\end{array}$ \\
\hline \multicolumn{4}{|l|}{$\begin{array}{l}\text { Mãe Bonifácia, em } \\
\text { Cuiabá/ MT. Souza } \\
\text { et al. (2014) }\end{array}$} \\
\hline $\begin{array}{lr}\text { Parques } & \text { sobre } \\
\text { Dunas, } & \text { Natal/RN } \\
\text { Carneiro } & (2014) \\
\end{array}$ & $\begin{array}{l}\text { DAP dos frequentadores e } \\
\text { Turistas dos Parques }\end{array}$ & Amostra 353 & $\begin{array}{l}\text { DAP } \\
47.215 .482,30 \text { ao } \\
\text { ano }\end{array}$ \\
\hline $\begin{array}{l}\text { Requalificação } \\
\text { urbana da } \\
\text { comunidade de } \\
\text { Belém /CE. Rebêlo } \\
\text { Neto et al. (2014) }\end{array}$ & DAP da população local & Amostra 147 & $\begin{array}{l}\text { DAP média } 4,96 \\
\text { por pessoa }\end{array}$ \\
\hline 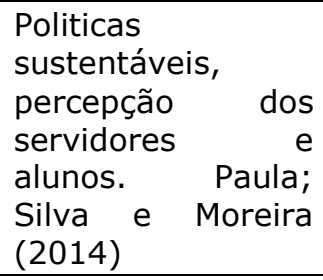 & $\begin{array}{l}\text { DAP dos alunos e servidores da } \\
\text { UEVA- UVA Sobral/CE }\end{array}$ & Amostra 60 & DAP 4,50 a 9,01 \\
\hline $\begin{array}{l}\text { Santuário } \\
\text { Caraça/MG. } \\
\text { Barcelos (2014) }\end{array}$ & DAP dos visitantes do santuário & Amostra 210 & $\begin{array}{l}\text { DAP } 4,50 \text { por } \\
\text { pessoa } \\
6.053 .066,46 \text { ao }\end{array}$ \\
\hline $\begin{array}{l}\text { Gruta do Salitre } \\
\text { Diamantina/MG. } \\
\text { Araújo (2014) }\end{array}$ & $\begin{array}{l}\text { DAP dos visitantes da Gruta e } \\
\text { moradores de Curralinho }\end{array}$ & Amostra 267 & $\begin{array}{l}\text { DAP } 3,51 \text { e total } \\
1.802 .207,74 \\
\text { para visitantes e } \\
\text { DAP } 2,92 \text { e total } \\
901.103,85 \text { dos } \\
\text { moradores }\end{array}$ \\
\hline $\begin{array}{l}\text { Ensino Público } \\
\text { federal } \text {-curso de } \\
\text { Ciências Contábeis } \\
\text { da UnB. Oliveira } \\
(2014)\end{array}$ & DAP dos alunos do Curso & $\begin{array}{l}\text { Amostra } \\
\text { open-ended } \\
290 \\
\text { Referendum - } \\
501\end{array}$ & $\begin{array}{l}\text { DAP } 270,33 \text { open- } \\
\text { ended e } 441,01 \\
\text { referendum }\end{array}$ \\
\hline $\begin{array}{l}\text { Memorial Darcy } \\
\text { Ribiero -Freire et } \\
\text { al. }(2014)\end{array}$ & DAP dos visitantes do Memorial & $\begin{array}{l}\text { População : } \\
915 \text { visitantes } \\
\text { anuais. } \\
\text { Amostra:72 }\end{array}$ & $\begin{array}{l}\text { DAP } 1,82 \text { por } \\
\text { pessoa }\end{array}$ \\
\hline $\begin{array}{l}\text { Recuperação e } \\
\text { Preservação do Rio } \\
\text { Apodi- Mossoró- } \\
\text { Araujo (2014) }\end{array}$ & $\begin{array}{l}\text { DAP da população ribieirinha e } \\
\text { população do município de } \\
\text { Mossoró }\end{array}$ & Amostra: 300 & $\begin{array}{l}\text { DAP 9,23 por } \\
\text { pessoa } \\
\text { Total anual } \\
28.785 .010,69\end{array}$ \\
\hline $\begin{array}{l}\text { Parque Ecológico } \\
\text { Estadual do Sítio } \\
\text { Fundão, Crato, CE } \\
\text { - Ribeiro justo e } \\
\text { Rodrigues (2014) }\end{array}$ & DAP dos visitantes do Parque & Amostra: 600 & $\begin{array}{l}\text { DAP } 1,05 \text { por } \\
\text { pessoa }\end{array}$ \\
\hline
\end{tabular}

(Conclusão)

Fonte: Quadro elaborado pela própria autora (2015) 
Quadro A.4- Trabalhos teóricos da valoração contingente no Brasil - 1999 -2014 (continua)

\begin{tabular}{|c|c|c|}
\hline Autor e ano & Nome do trabalho & Instituição \\
\hline Romeiro e Andrade (2009) & $\begin{array}{l}\text { Valoração econômica ecológica de recursos } \\
\text { naturais. }\end{array}$ & UNICAMP \\
\hline Aiache (2003) & $\begin{array}{l}\text { Parques Nacionais: uma avaliação de } \\
\text { métodos de valoração através dos casos do } \\
\text { Parque Nacional de Brasília e do Parque } \\
\text { Nacional do Iguaçu }\end{array}$ & UnB \\
\hline Amaral et al. (2009) & $\begin{array}{l}\text { Valoração econômica dos impactos } \\
\text { ambientais em cenários } \\
\text { hídrica na indústria }\end{array}$ & UFRJ \\
\hline Amazonas (2009) & $\begin{array}{l}\text { Valor ambiental em uma perspectiva } \\
\text { heterodoxa institucional- ecológica }\end{array}$ & UFU \\
\hline Barreto (2006) & $\begin{array}{l}\text { A valoração econômica como instrumento de } \\
\text { gestão ambiental aplicável a compensação } \\
\text { ambiental: o caso do parque estadual do } \\
\text { IBITIPOCA- MG }\end{array}$ & UFL \\
\hline Benitez (2005) & $\begin{array}{l}\text { Impactos das preferências ambientais sobre } \\
\text { os resultados dos métodos de análise } \\
\text { conjunta de valoração ambiental rating e } \\
\text { ranking contingente }\end{array}$ & UFRS \\
\hline Buzin et al (2014) & $\begin{array}{l}\text { Análise dadisposição a pagar por produtos } \\
\text { agrícolas a ser oberecido no mercado }\end{array}$ & UFG \\
\hline Camphora e May (2006) & $\begin{array}{l}\text { A valoração ambiental como ferramenta de } \\
\text { gestão em unidades de conservação: há } \\
\text { convergência de valores para o bioma? }\end{array}$ & UFRJ \\
\hline Castro e Nogueira (2014) & $\begin{array}{l}\text { Vakloração econômica de bens públicos: uso } \\
\text { e abusos da valoração contingente no Brasil. }\end{array}$ & UnB \\
\hline Cassimiro Filho (1999) & $\begin{array}{l}\text { Valoração Monetária de amenidades } \\
\text { Ambientais: Algumas considerações }\end{array}$ & UNIOESTE \\
\hline Falco et al. (2010) & $\begin{array}{l}\text { A gestão socioambiental à luz das técnicas de } \\
\text { valoração econômica do meio ambiente: uma } \\
\text { análise do valor de uso indireto e do valor de } \\
\text { existência }\end{array}$ & PUC-Rio \\
\hline Fonseca et al. (2013) & $\begin{array}{l}\text { A validade do método de contingencia como } \\
\text { valoração de bens e serviços ambientais }\end{array}$ & EFSJ \\
\hline Fonseca e Drummond (2003) & $\begin{array}{l}\text { Reflorestamento de manguezais e o valor de } \\
\text { resgate para o sequestro de carbono } \\
\text { atmosférico }\end{array}$ & UnB \\
\hline Freitas e Fracalanza (2012) & $\begin{array}{l}\text { A cobrança pelo uso da água como } \\
\text { instrumento de valoração ambiental da } \\
\text { política de recursos hídricos }\end{array}$ & USP \\
\hline Martins e Valêncio (2003) & $\begin{array}{l}\text { Valoração dos Recursos hídricos e impasse } \\
\text { sócio ambiental na Agricultura paulista: } \\
\text { alguns desafios para a gestão de políticas } \\
\text { públicas }\end{array}$ & UFSCAR \\
\hline $\begin{array}{l}\text { Matos; Ribeiro; Fernandes; } \\
\text { Cabo (2013) }\end{array}$ & $\begin{array}{l}\text { Análise crítica dos métodos de valoração } \\
\text { econômica dos bens ambientais }\end{array}$ & \\
\hline $\begin{array}{l}\text { May; Veiga Neto e Pozo } \\
\text { (1999) }\end{array}$ & $\begin{array}{l}\text { Valoração econômica da biodiversidade: } \\
\text { estudos de caso no Brasil }\end{array}$ & MMA \\
\hline Nogueira e Medeiros (1999) & $\begin{array}{l}\text { Quanto vale aquilo que não tem valor? Valor } \\
\text { de existência, economia e meio ambiente. }\end{array}$ & UnB \\
\hline
\end{tabular}




\begin{tabular}{|c|c|c|}
\hline Autor e ano & Nome do trabalho & Instituição \\
\hline $\begin{array}{l}\text { Nogueira; Medeiros e Arruda } \\
(2000)\end{array}$ & $\begin{array}{l}\text { Valoração econômica do meio ambiente: } \\
\text { Ciência ou empirismo? }\end{array}$ & UnB \\
\hline Paula et al. (2013) & $\begin{array}{l}\text { A gestão ambiental a luz das técnicas de } \\
\text { valoração econômica do meio ambiente: uma } \\
\text { análise do valor de uso indireto e do valor de } \\
\text { existência. }\end{array}$ & PUC - RIO \\
\hline Tavares e Ribeiro (1999) & $\begin{array}{l}\text { Valoração monetária de bens e serviços } \\
\text { ambientais: Revisão do Estado-da-arte sob } \\
\text { ótica da Gestão das águas. }\end{array}$ & UFPEL \\
\hline Sancho e Dain (2012) & $\begin{array}{l}\text { Avaliação em saúde e avaliação economia em } \\
\text { saúde: Introdução ao debate sobre seus } \\
\text { pontos de interseção }\end{array}$ & UFRJ \\
\hline Sancho e Vargens (2010) & $\begin{array}{l}\text { Avaliação economia em Saúde na esfera de } \\
\text { atenção local à saúde }\end{array}$ & UFRGS \\
\hline Silva (2008) & $\begin{array}{l}\text { Os micro fundamentos do método de } \\
\text { valoração contingente }\end{array}$ & UFAC \\
\hline Silva e Ferreira (2010) & $\begin{array}{l}\text { Um Estudo teórico sobre a contabilização dos } \\
\text { impactos ambientais no setor sucroalcooleiro }\end{array}$ & UFRJ \\
\hline Silva; Reis e Ferreira (2012) & Valor da natureza: a evolução desse conceito & UFLA \\
\hline Vasconcelos (2013) & $\begin{array}{l}\text { Método de valoração contingente: sobre a } \\
\text { validade de preferências, cenários e } \\
\text { agregação }\end{array}$ & UnB \\
\hline Venâncio e Kurtz (2008) & $\begin{array}{l}\text { Evolução da legislação sobre o Meio Ambiente } \\
\text { e o processo de valoração econômica da água } \\
\text { no Brasil }\end{array}$ & UNICENTRO \\
\hline Vouga (2008) & $\begin{array}{l}\text { Os leilões virtuais e a dimensão cultural da } \\
\text { formação do valor econômico }\end{array}$ & UFF \\
\hline Zago (2007) & $\begin{array}{l}\text { A valoração econômica da água - uma } \\
\text { reflexão sobre a legislação de gestão dos } \\
\text { recursos hídricos do Mato Grosso do Sul. }\end{array}$ & UFMS \\
\hline
\end{tabular}

(Conclusão)

Fonte: Quadro elaborado pela própria autora (2015)

Quadro A.5 - Trabalhos empíricos analisados que utilizaram o Método Valoração Contingente no Brasil

\begin{tabular}{|l|l|}
\hline Legenda & Autores \\
\hline MVC 1 & Barbsan (2009) \\
\hline MVC 2 & Bem e Giacomini (2011) \\
\hline MVC 3 & Silva e Lima (2006) \\
\hline MVC 4 & Viana et al. (2011) \\
\hline
\end{tabular}

Fonte: Quadro elaborado pela própria autora (2015) 
Apêndice A.6- Referente as tabelas dos gráficos do capítulo 3

Tabela A.1 - Referente ao Gráfico 3.1

Produção de trabalhos com o uso do MVC- Brasil 1999 -

2014

\begin{tabular}{cc}
\hline Anos & Quantidade \\
\hline 1998 & 1 \\
1999 & 6 \\
2000 & 2 \\
2001 & 0 \\
2002 & 2 \\
2003 & 5 \\
2004 & 4 \\
2005 & 2 \\
2006 & 10 \\
2007 & 4 \\
2008 & 9 \\
2009 & 8 \\
2010 & 9 \\
2011 & 6 \\
2012 & 9 \\
2013 & 12 \\
2014 & 17 \\
Total & 106 \\
\hline
\end{tabular}

Fonte: da pesquisa (2015)

Tabela A.2 - Referente ao gráfico 3.2

Áreas de conhecimento dos estudos empíricos - 1997- 2014

\begin{tabular}{lc}
\hline Áreas de conhecimento & Quantidade \\
\hline Conhecimento tradicional & 42 \\
Recursos hídricos & 23 \\
Patrimônio histórico cultural & 8 \\
Impactos sobre a saúde humana & 17 \\
Total & 90 \\
\hline
\end{tabular}

Fonte: da pesquisa (2015) 
Tabela A.3 Referente ao gráfico 3.4

Estados que tiveram ativos ambientais valorados pelo MVC- 1997-2014

\begin{tabular}{lc}
\hline Estado & Q \\
AC & 2 \\
AM & 1 \\
AP & 3 \\
BA & 2 \\
RO & 1 \\
CE & 5 \\
DF & 10 \\
ES & 1 \\
GO & 6 \\
TO & 3 \\
MG & 11 \\
MS & 1 \\
MT & 6 \\
PB & 1 \\
PA & 1 \\
PE & 1 \\
PI & 2 \\
PR & 2 \\
RJ & 3 \\
RS & 3 \\
SP & 11 \\
SC & 10 \\
SE & 3 \\
RN & 1 \\
Total & 2 \\
Fonte: Pagua & 90 \\
\hline
\end{tabular}

Fonte: da pesquisa (2015)

Tabela A.4 - Referente ao gráfico 3.5-

Subdivisão dos trabalhos da área Patrimônio histórico cultural- 2004 -2014

\begin{tabular}{lc}
\hline Áreas & Quantidade \\
\hline $\begin{array}{l}\text { Recuperação e preservação dos } \\
\text { ativos }\end{array}$ & 5 \\
Aumento da eficiência no uso do & \\
ativo e alerta para policy makers & 3 \\
Total & 7 \\
\hline
\end{tabular}

Fonte: da pesquisa (2015) 
Tabela A.5 -Referente ao gráfico 3.6

Subdivisão dos trabalhos da áreas de saúde humana - 2002- 2012

\begin{tabular}{lc}
\hline Áreas & Quantidade \\
\hline Reciclagem, coleta seletiva e lixo & 4 \\
Poluição de solo, ar e água & 7 \\
Benfícios do ativo para a saúde, recuperação, & \\
manutenção e policy makers & 6 \\
Total & 17 \\
\hline
\end{tabular}

Fonte: da pesquisa (2015)

Tabela A.6 - Referente ao gráfico 3.7

Subdivisão dos trabalhos da área de recursos hídricos - 1999- 2014

Área

Quantidade

Garantir o benefício de uso permanente, recuperação e manutenção

do ativo

Suscitar aporte financeiro por meio de políticas públicas

Total

Fonte: da pesquisa (2015)

Tabela A. 7- Referente ao gráfico 3.8

Subdivisão dos trabalhos da área de Conhecimento tradicional- 1998 2014

\begin{tabular}{lc}
\hline Área & Quantidade \\
\hline Requalificação do meio ambiente & 10 \\
Proteção e Conservação do ambiente & 25 \\
valorado & 7 \\
Captação de recursos & 42 \\
Total & \\
\hline
\end{tabular}

Fonte: da pesquisa (2015) 
Tabela A.8- Referente ao gráfico 3.9

Bens que causam impacto à saúde - 2002-2014

\begin{tabular}{lr}
\hline Opções & Quantidade \\
\hline Ciências Sociais Aplicadas & 2 \\
Engenharias & 9 \\
Ciências da Saúde & 5 \\
Com pesquisa piloto & 7 \\
Sem pesquisa piloto & 10 \\
Não usam modelo & 7 \\
MQO & 8 \\
Logit & 1 \\
Tobit & 1 \\
Open-ended & \\
Referendum c/follow-up & 9 \\
Referendum simples & 5 \\
\hline Fonte: da pesquisa (2015) & 3 \\
\hline
\end{tabular}

Fonte: da pesquisa (2015)

Tabela A.9 - Referente ao gráfico 3.10

Recursos hídricos - 1999 - 2014

\begin{tabular}{lr}
\hline Opções & Quantidade \\
\hline Ciências Sociais Aplicadas & 11 \\
Engenharias & 6 \\
Ciências Humanas & 4 \\
Ciências da Saúde & 2 \\
Com pesquisa piloto & 3 \\
Sem pesquisa piloto & 20 \\
Open-ended & \\
Referendum c/follow-up & 15 \\
Referendum simples & 3 \\
Jogos de Leilão & 2 \\
Não usam modelo & 2 \\
MQO & \\
Logit & 6 \\
Tobit & 6 \\
Logit e probit & 5 \\
\hline
\end{tabular}

Fonte: da pesquisa (2015) 
Tabela A.10 - Referente ao gráfico 3.11

Bens culturais e patrimônio histórico - 2004 - 2014

\begin{tabular}{ll}
\hline Opções & Quantidade \\
\hline Ciências Sociais Aplicadas & 4 \\
Ciências Humanas & 4 \\
Com pesquisa piloto & 2 \\
Sem pesquisa piloto & 6 \\
Open-ended & 2 \\
Referendum c/follow-up & 6 \\
Não usam modelo & \\
MQO & 4 \\
Logit & 1 \\
Logit e probit & 2 \\
Fonte: da pesquisa (2015) & 1 \\
\hline
\end{tabular}

Tabela A.11 - Referente ao gráfico 3.12

Bens Conhecimento tradicional

\begin{tabular}{ll}
\hline Opções & Quantidade \\
\hline Ciências Sociais Aplicadas & 23 \\
Ciências Humanas & 13 \\
Engenharias & 6 \\
Com pesquisa piloto & 16 \\
Sem pesquisa piloto & 26 \\
& \\
Open-ended & 8 \\
Referendum c/follow-up & 17 \\
Referendum simples & 17 \\
Não usam modelo & \\
MQO & 8 \\
Logit & 3 \\
Tobit & 6 \\
\hline
\end{tabular}

Fonte: da pesquisa (2015) 
Tabela A.12 - Referente ao gráfico 3.13

Vieses apresentado nos trabalhos sobre bens que causam impactos a saúde - 2002 - 2014

\begin{tabular}{lr}
\hline Opções & Quantidade \\
\hline Viés de protesto & 11 \\
Viés de informação & 3 \\
Não revelado & 3 \\
Total & 17 \\
\hline
\end{tabular}

Fonte: da pesquisa (2015)

Tabela A. 13 - Referente ao gráfico 3.14

Vieses apresentado nos trabalhos sobre bens culturais e patrimônio histórico - 2004 - 2014

\begin{tabular}{ll}
\hline Opções & Quantidade \\
\hline Viés de instrumento & 1 \\
Viés de protesto & 5 \\
Viés de escopo & 1 \\
Não revelado & 1 \\
Total & 8 \\
\hline
\end{tabular}

Fonte: da pesquisa (2015)

Tabela A.14 - Referente ao gráfico 3.15

Vieses apresentado nos trabalhos sobre recursos

hídricos - 1999- 2014

\begin{tabular}{lc}
\hline Opções & Quantidade de \\
\hline Viés de protesto & 10 \\
Viés de informação & 6 \\
Viés Veículo de pagamento & 1 \\
Viés hipotético & 2 \\
Vies do ponto inicial & 1 \\
Não revelado & 3 \\
Total & 23 \\
\hline Fonte: da pesquisa (2015)
\end{tabular}

Fonte: da pesquisa (2015) 
Tabela A.15 - Referente ao gráfico 3.16

Vieses apresentado nos trabalhos sobre conhecimento

tradicional - 1998 - 2014

\begin{tabular}{lr}
\hline Opções & Quantidade \\
\hline Viés do ponto inicial & 6 \\
Viés de veículo de & 1 \\
pagamento & 25 \\
Viés de protesto & \\
Viés de decisão de baixo & 1 \\
custo & 9 \\
Não revelado & 42 \\
Total & \\
\hline
\end{tabular}

Fonte: da pesquisa (2015) 


\section{APÊNDICE B}

Quadro B.1 - Trabalhos empíricos com o uso do MCV - Brasil - 1993-2014

(Continua)

\begin{tabular}{|c|c|c|c|c|c|}
\hline No & Ano & Autor & Título do trabalho & Estado & $\begin{array}{l}\text { Instituição } \\
\text { responsável }\end{array}$ \\
\hline 1 & 1993 & $\begin{array}{l}\text { Estado do Rio de } \\
\text { Janeiro }\end{array}$ & $\begin{array}{l}\text { Programa de Despoluição } \\
\text { da Baía de Guanabara no } \\
\text { Rio de Janeiro }\end{array}$ & RJ & $\begin{array}{l}\text { Estado do Rio de } \\
\text { Janeiro }\end{array}$ \\
\hline 2 & 1995 & Grasso et al. & $\begin{array}{l}\text { Aplicações de técnicas de } \\
\text { avaliação econômica ao } \\
\text { Ecossistema manguezal }\end{array}$ & $\mathrm{SP}$ & UFRJ \\
\hline 3 & 1997 & Mota & $\begin{array}{l}\text { Travel Cost Method: uma } \\
\text { alternativa de análise da } \\
\text { demanda por atrativos } \\
\text { ambientais }\end{array}$ & DF & UCB/UnB \\
\hline 4 & 1998 & Aguiar e Ortiz & 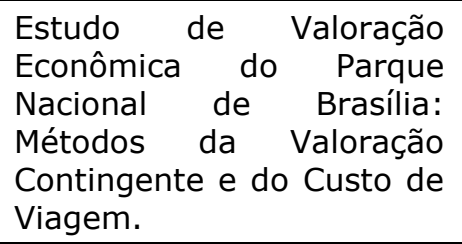 & DF & UnB \\
\hline 5 & 1998 & Dubeux & $\begin{array}{l}\text { A Valoração Econômica } \\
\text { como instrumento de } \\
\text { Gestão Ambiental - O Caso } \\
\text { da Despoluição da Baía de } \\
\text { Guanabara }\end{array}$ & RJ & UFRJ \\
\hline 6 & 1999 & CENARGEN/EMBRAPA & $\begin{array}{l}\text { Avaliação Sócio Econômica } \\
\text { do parque Nacional de } \\
\text { Brasília }\end{array}$ & DF & $\begin{array}{l}\text { CENARGEN/EMBRA } \\
\text { PA }\end{array}$ \\
\hline 7 & 2001 & Silva; Leal e Ferraz & $\begin{array}{l}\text { Valoração de recursos } \\
\text { naturais como subsídio aos } \\
\text { planejamento Eco turístico: } \\
\text { um estudo de caso na } \\
\text { Nascente do rio Sucuri- } \\
\text { Bonito/ MS }\end{array}$ & MS & UEMS \\
\hline 8 & 2001 & Salgado e Nogueira & $\begin{array}{l}\text { Economia e gestão de } \\
\text { áreas protegidas: o caso do } \\
\text { Parque Nacional de Brasília }\end{array}$ & DF & UnB \\
\hline 9 & 2001 & Ortiz; Motta e Ferraz & $\begin{array}{l}\text { Estimando o valor } \\
\text { ambiental do Parque } \\
\text { Nacional do Iguaçu: Uma } \\
\text { aplicação do método de } \\
\text { Custo de viagem }\end{array}$ & PR & IPEA \\
\hline 10 & 2002 & Finco e Abdallah & $\begin{array}{l}\text { Valoração econômica do } \\
\text { meio ambiente: O método } \\
\text { do Custo de Viagem } \\
\text { aplicado ao Litoral do rio } \\
\text { Grande do Sul }\end{array}$ & RS & UFRGS \\
\hline & & Aiache & $\begin{array}{l}\text { Parques Nacionais: uma } \\
\text { avaliação de métodos de } \\
\text { valoração através dos } \\
\text { casos do Parque Nacional }\end{array}$ & PR & UnB \\
\hline
\end{tabular}




\begin{tabular}{|c|c|c|c|c|c|}
\hline No & Ano & Autor & Título do trabalho & Estado & $\begin{array}{l}\text { Instituição } \\
\text { responsável }\end{array}$ \\
\hline 11 & 2003 & & $\begin{array}{l}\text { de Brasília e do Parque } \\
\text { Nacional do Iguaçu }\end{array}$ & & \\
\hline 12 & 2004 & Sebold e Silva & $\begin{array}{l}\text { Uma aplicação do método } \\
\text { dos custos de viagem para } \\
\text { valoração de um parque } \\
\text { ambiental }\end{array}$ & SC & UFSC \\
\hline 13 & 2005 & Freire et al. & $\begin{array}{l}\text { Valoração econômica do } \\
\text { litoral do Município de } \\
\text { Ilhéus - Estado da Bahia }\end{array}$ & $\mathrm{BA}$ & ESALQ/USP \\
\hline 14 & 2005 & Botêlho & $\begin{array}{l}\text { Método custo de viagem na } \\
\text { valoração do parque } \\
\text { municipal do Itiquira }\end{array}$ & $\mathrm{GO}$ & UnB \\
\hline 15 & 2005 & Fritsch & $\begin{array}{l}\text { Valoração econômica do } \\
\text { Parque Nacional da } \\
\text { Chapada dos Guimarães } \\
\text { utilizando o método de } \\
\text { custos de viagem }\end{array}$ & MT & UnB \\
\hline 16 & 2006 & Müller & $\begin{array}{l}\text { Valoração ambiental do } \\
\text { Parque Nacional da } \\
\text { Chapada dos Veadeiros } \\
\text { através do método do custo } \\
\text { de Viagem }\end{array}$ & GO & UnB \\
\hline 17 & 2006 & Gazoni & $\begin{array}{l}\text { Em busca de Marâ-Ey-Me: } \\
\text { Valoração econômica do } \\
\text { parque Estadual de Itaúna- } \\
\text { ES }\end{array}$ & ES & UnB \\
\hline 18 & 2006 & $\begin{array}{l}\text { Gazoni, Mota, } \\
\text { Brasileiro e Carvalho }\end{array}$ & $\begin{array}{l}\text { Valoração econômica do } \\
\text { Parque Estadual de Itaúna } \\
\text { (ES) }\end{array}$ & ES & IPEA \\
\hline 19 & 2007 & Gazoni & $\begin{array}{llr}\text { Viagem } & \text { aos comuns: } \\
\text { valoração } & \text { econômica da } \\
\text { utilidade } & \text { turística } & \text { dos } \\
\text { recursos } & \text { ambientais } & \text { de } \\
\text { Itaúna, } & \text { Conceição } & \text { da } \\
\text { Barra/ES } & & \end{array}$ & ES & UnB \\
\hline 20 & 2007 & Carvalho & $\begin{array}{l}\text { Abordagem ecológico- } \\
\text { econômica para estimar o } \\
\text { valor do fragmento de uma } \\
\text { planície de inundação no } \\
\text { Brasil - Mato Grosso do Sul. }\end{array}$ & MS & UEG \\
\hline 21 & 2007 & Angelo e Carvalho & $\begin{array}{lr}\text { Valor recreativo do } & \text { Rio } \\
\text { Araguaia, região } & \text { de } \\
\text { Aruanã, estimado pelo } \\
\text { método de custo de } \\
\text { viagem. }\end{array}$ & GO & UEG \\
\hline 22 & 2008 & Paula et al. & $\begin{array}{l}\text { Valoração Econômica da } \\
\text { Gruta do Maquiné em } \\
\text { Cordisburgo- MG: uma } \\
\text { aplicação do método do } \\
\text { Custo de Viagem }\end{array}$ & MG & UFV \\
\hline 23 & 2008 & $\begin{array}{l}\text { Malta; Costa N. e } \\
\text { Costa V }\end{array}$ & $\begin{array}{l}\text { Valoração econômica dos } \\
\text { serviços recreativos e eco } \\
\text { turísticos em uma unidade } \\
\text { de conservação - o caso do }\end{array}$ & RJ & UERJ \\
\hline
\end{tabular}




\begin{tabular}{|c|c|c|c|c|c|}
\hline No & Ano & Autor & Título do trabalho & Estado & $\begin{array}{l}\text { Instituição } \\
\text { responsável }\end{array}$ \\
\hline & & & $\begin{array}{l}\text { Parque Nacional da Tijuca } \\
\text { Rio de Janeiro/ RJ - Brasil }\end{array}$ & & \\
\hline 24 & 2008 & Fico e Valadares & $\begin{array}{l}\text { Valoração econômica: os } \\
\text { métodos do custo de } \\
\text { viagem e de valoração } \\
\text { contingente aplicados às } \\
\text { praias de Palmas/TO }\end{array}$ & TO & UFT \\
\hline 25 & 2008 & $\begin{array}{l}\text { Abreu; Silva e Silva } \\
\text { Junior-- }\end{array}$ & 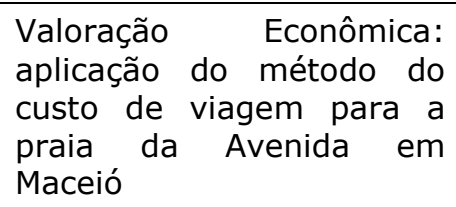 & AL & UFPE \\
\hline 26 & 2008 & Maia e Romeiro & $\begin{array}{l}\text { Validade e confiabilidade } \\
\text { do método de custo } \\
\text { Viagem: Um estudo } \\
\text { aplicado ao Parque } \\
\text { Nacional da Serra Geral }\end{array}$ & $\mathrm{SC}$ & UNICAMP \\
\hline 27 & 2009 & Freire et al. & $\begin{array}{l}\text { Valor de uso de opções do } \\
\text { litoral do município de } \\
\text { Canavieiras, Estado da } \\
\text { Bahia- Brasil }\end{array}$ & $\mathrm{BA}$ & UESC \\
\hline 28 & 2010 & Leite e Jacoski & $\begin{array}{l}\text { Comportamento do usuário } \\
\text { na valoração contingente e } \\
\text { custo de viagem - O caso } \\
\text { do Parque das Palmas em } \\
\text { Chapecó, SC, Brasil }\end{array}$ & SC & UNOCHAPECÓ \\
\hline 29 & 2010 & Silva e Weiss & $\begin{array}{llr}\text { Valoração Econômica de } & \text { de } \\
\text { benefícios ambientais como } \\
\text { suporte a formação de } \\
\text { políticas públicas: } & \text { Um } \\
\text { estudo de caso no } & \text { no } \\
\text { Balneário municipal de } \\
\text { Bonito- MS }\end{array}$ & MS & UnB \\
\hline 30 & 2012 & Mendonça et al. & $\begin{array}{l}\text { Valoração Econômica do } \\
\text { Jardim Botânico da } \\
\text { Fundação Zoo-Botânica de } \\
\text { Belo Horizonte, Minas } \\
\text { Gerais }\end{array}$ & MG & UFU \\
\hline 31 & 2012 & Marques & $\begin{array}{l}\text { Mensuração de Ativos } \\
\text { culturais: uma aplicação do } \\
\text { método do custo de viagem } \\
\text { em bens públicos culturais } \\
\text { do Distrito Federal }\end{array}$ & DF & UnB \\
\hline 32 & 2013 & Sanches et al. & $\begin{array}{l}\text { Indicadores de valor de uso } \\
\text { para fins de valoração } \\
\text { econômica do Santuário de } \\
\text { Vida Silvestre Vaga fogo } \\
\text { em Pirenópolis-Go }\end{array}$ & GO & UnB \\
\hline
\end{tabular}




\begin{tabular}{|c|c|c|c|c|c|}
\hline No & Ano & Autor & Título do trabalho & Estado & $\begin{array}{l}\text { Instituição } \\
\text { responsável }\end{array}$ \\
\hline 33 & 2013 & $\begin{array}{l}\text { Domiciano, Ribeiro e } \\
\text { Domiciano, F - }\end{array}$ & $\begin{array}{l}\text { Análise do perfil } \\
\text { socioeconômico e os custo } \\
\text { de viagem dos visitantes do } \\
\text { parque Nacional da } \\
\text { Chapada dos Veadeiros - } \\
\text { uma contribuição ao } \\
\text { desenvolvimento da } \\
\text { comunidade de seu entorno }\end{array}$ & GO & UFG \\
\hline 34 & 2013 & Facco, Jacosski & $\begin{array}{l}\text { Conjugação de métodos de } \\
\text { valoração aplicados a um } \\
\text { parque ambiental- Estudo } \\
\text { com o Eco parque Chapecó- } \\
\text { SC }\end{array}$ & SC & UNOCHAPECÓ \\
\hline 35 & 2013 & Freire et al. & $\begin{array}{l}\text { Aplicação do Método do } \\
\text { Custo de Viagem na } \\
\text { valoração de bens } \\
\text { ambientais: Um estudo de } \\
\text { caso na cidade de } \\
\text { Cavalcante-Go }\end{array}$ & GO & UnB \\
\hline 36 & 2014 & Freire et al. & Quanto vale o Beijódromo? & DF & UnB \\
\hline 37 & 2014 & Lopes & $\begin{array}{l}\text { Métrica de valoração } \\
\text { ambiental: uma percepção } \\
\text { da gestão pública no } \\
\text { município de Cavalcante }\end{array}$ & GO & UnB \\
\hline 38 & 2014 & Carneiro & $\begin{array}{l}\text { Caracterização econômica } \\
\text { do valor de uso e não uso } \\
\text { de Parques sobre Dunas }\end{array}$ & RN & UFRN \\
\hline 39 & 2014 & Barcelos & $\begin{array}{l}\text { Valoração Econômica do } \\
\text { Santuário do Caracas em } \\
\text { Minas Gerais/ BR }\end{array}$ & MG & UFOP \\
\hline
\end{tabular}

(Conclusão)

Fonte: Quadro elaborado pela própria autora (2015) 
Quadro B.2 - Caraterísticas e modelos utilizados para pesquisas com o uso do MCV

\begin{tabular}{|c|c|c|c|c|}
\hline $\mathbf{N}^{\mathbf{0}}$ & Nome do Parque & Características principais & Modelo utilizado & Objetivos \\
\hline 1 & $\begin{array}{l}\text { Parque Nacional de } \\
\text { Brasília - DF }\end{array}$ & $\begin{array}{l}\text { Área: } 1,5 \text { milhões de } \mathrm{m}^{2} \\
\text { Flora e fauna típicas do } \\
\text { cerrado, presença de rios }\end{array}$ & $\begin{array}{l}\text { Regressão linear } \\
\text { Coleta on-site }\end{array}$ & $\begin{array}{l}\text { Confronto de } \\
\text { métodos } \mathrm{MCV} \text { e } \\
\text { MVC }\end{array}$ \\
\hline 2 & $\begin{array}{lr}\text { Parque Nacional } & \text { da } \\
\text { Chapada } & \text { dos } \\
\text { Veadeiros - GO } & \end{array}$ & $\begin{array}{l}\text { Área:65.514 há } \\
\text { Cerrado intocado } \\
\text { reservas hídricas }\end{array}$ & $\begin{array}{l}\text { Regressão linear } \\
\text { Coleta on-site }\end{array}$ & $\begin{array}{l}\text { Estimar e avaliar } \\
\text { demanda } \\
\text { turística. }\end{array}$ \\
\hline 3 & $\begin{array}{l}\text { Parque Nacional da } \\
\text { Tijuca - RJ }\end{array}$ & $\begin{array}{l}\text { Área:3.953 há } \\
\text { Floresta de mata Atlântica, } \\
\text { trilhas, locais para } \\
\text { piquenique, playgrounds, } \\
\text { Museu, Restaurante, }\end{array}$ & $\begin{array}{l}\text { Coleta on-site } \\
\text { Uso de Estatística } \\
\text { descritiva }\end{array}$ & $\begin{array}{l}\text { Confronto de } \\
\text { métodos } \mathrm{MCV} \text { e } \\
\text { MVC }\end{array}$ \\
\hline 4 & $\begin{array}{l}\text { Parque Nacional Serra } \\
\text { Geral - RS/SC }\end{array}$ & $\begin{array}{l}\text { Área: } 17.300 h a \\
\text { Beleza cênica, canyons, } \\
\text { cachoeiras, Rica flora e } \\
\text { fauna ameaçadas. }\end{array}$ & $\begin{array}{l}\text { Regressão linear } \\
\text { lin-log, log-lin, } \\
\text { log-log } \\
\text { Múltiplos destinos } \\
\text { Coleta on-site }\end{array}$ & $\begin{array}{l}\text { Calcular valor de } \\
\text { uso }\end{array}$ \\
\hline 5 & $\begin{array}{l}\text { Parque Nacional do } \\
\text { Iguaçu - PR }\end{array}$ & $\begin{array}{l}\text { Área: } 185 \text { mil há } \\
\text { Rico acervo biológico, } \\
\text { conjunto de quedas- } \\
\text { d'água. }\end{array}$ & $\begin{array}{l}\text { Coleta on-site } \\
\text { Modelo Tobit } \\
\text { truncada e } \\
\text { endogenamente } \\
\text { estratificada }\end{array}$ & $\begin{array}{l}\text { Calcular valor de } \\
\text { uso }\end{array}$ \\
\hline 6 & $\begin{array}{lr}\text { Parque Nacional da } \\
\text { Chapada } & \text { dos } \\
\text { Guimarães - MT } & \end{array}$ & $\begin{array}{l}\text { Área: } 32.776,80 \text { há } \\
\text { Sitiorarqueológico, } \\
\text { monumentor histórico, } \\
\text { cabeceira de vários rios. }\end{array}$ & $\begin{array}{l}\text { on-site } \\
\text { lo } \\
\text { ssão linear }\end{array}$ & $\begin{array}{l}\text { Calcular valor de } \\
\text { uso }\end{array}$ \\
\hline 7 & $\begin{array}{l}\text { Parque Estadual de } \\
\text { Itaúnas - ES }\end{array}$ & $\begin{array}{l}\text { Área:3.481,2ha } \\
\text { Floresta de restinga, } \\
\text { alagados, dunas e } \\
\text { manguezais }\end{array}$ & $\begin{array}{l}\text { ssão linear } \\
\text { tmica } \\
\text { on-site }\end{array}$ & $\begin{array}{l}\text { Estimar e avaliar } \\
\text { demanda } \\
\text { turística. }\end{array}$ \\
\hline 8 & $\begin{array}{l}\text { Parque Natural do } \\
\text { Itajaí - SC }\end{array}$ & $\begin{array}{l}\text { Área:8ha } \\
\text { Água mineral, piscina } \\
\text { olímpica, pesque-pague, } \\
\text { restaurante, floresta e } \\
\text { faunas típicas }\end{array}$ & $\begin{array}{l}\text { Coleta off-site } \\
\text { Custo de viagem } \\
\text { zonal }\end{array}$ & $\begin{array}{l}\text { Calcular valor de } \\
\text { uso }\end{array}$ \\
\hline 9 & $\begin{array}{l}\text { Parque Municipal do } \\
\text { Itiquira (GO) }\end{array}$ & $\begin{array}{l}\text { Área:485.707ha } \\
\text { Cachoeiras, mata de } \\
\text { cerrado, nascentes de } \\
\text { água, corredeiras e } \\
\text { cascatas, canyon e área de } \\
\text { camping. }\end{array}$ & $\begin{array}{l}\text { Coleta on-site } \\
\text { Regressão linear } \\
\text { multivariada. } \\
\text { Múltiplos sites. }\end{array}$ & $\begin{array}{l}\text { Calcular valor de } \\
\text { uso }\end{array}$ \\
\hline 10 & $\begin{array}{l}\text { Parque Municipal das } \\
\text { Palmeiras - SC }\end{array}$ & $\begin{array}{l}\text { Área: } 14.000 \mathrm{~m}^{2} \\
\text { Atrativo natural frágil pela } \\
\text { expansão urbana, } \\
\text { palmeiras nativas área de } \\
\text { piquenique com quadras } \\
\text { esportivas }\end{array}$ & $\begin{array}{l}\text { Regressão linear } \\
\text { Coleta on-site e } \\
\text { off-site }\end{array}$ & $\begin{array}{l}\text { Confronto de } \\
\text { métodos MCV e } \\
\text { MVC }\end{array}$ \\
\hline 11 & $\begin{array}{l}\text { Parque Municipal } \\
\text { Chapecó - SC }\end{array}$ & $\begin{array}{l}\text { Área: } 43.000 \mathrm{~m}^{2} \\
\text { Árvores exóticas, e trilhas } \\
\text { para caminhadas. }\end{array}$ & $\begin{array}{l}\text { Regressão linear } \\
\text { Coleta on-site }\end{array}$ & $\begin{array}{l}\text { Confronto de } \\
\text { métodos MCV e } \\
\text { MVC }\end{array}$ \\
\hline 12 & $\begin{array}{l}\text { Parque Estadual das } \\
\text { Dunas - RN }\end{array}$ & $\begin{array}{l}\text { Área: } 1.172 \text { ha } \\
\text { Mata nativa e mata } \\
\text { Atlântica }\end{array}$ & $\begin{array}{l}\text { Regressão linear } \\
\text { Coleta on-site }\end{array}$ & $\begin{array}{l}\text { Confronto de } \\
\text { métodos MCV e } \\
\text { MVC }\end{array}$ \\
\hline 13 & $\begin{array}{l}\text { Parque } \\
\text { Ecológico } \\
\text { Jenipabu }\end{array}$ & $\begin{array}{l}\text { Área: ' } 800 \text { ha } \\
\text { Vegetação de restinga }\end{array}$ & $\begin{array}{l}\text { Regressão linear } \\
\text { Coleta on-site }\end{array}$ & $\begin{array}{l}\text { Confronto de } \\
\text { métodos MCV e } \\
\text { MVC }\end{array}$ \\
\hline
\end{tabular}

Fonte: Quadro elaborado pela própria autora (2015) 
Quadro B.3 - Trabalhos empíricos analisados que utilizaram do Método Custo de Viagem no Brasil

\begin{tabular}{|l|l|}
\hline Legenda & Autores \\
\hline MCV 1 & Gazoni et al. (2006) \\
\hline MCV 2 & Freire, Guimarães Junior e Rodrigues \\
& $(2005)$ \\
\hline MCV 3 & Mendonça et al. (2012) \\
\hline
\end{tabular}

Fonte: Quadro elaborado pela própria autora (2015)

\section{Apêndice B.4 Tabelas refrentes ao Capítulo 4}

Tabela B.1 - Referente ao gráfico 4.1

Estados que tiveram alguns ativos ambientais valorados pelo MCV- $1993-2014$

\begin{tabular}{lr} 
Estados & Quantidade \\
\hline RJ & 3 \\
DF & 6 \\
MS & 3 \\
PR & 2 \\
SC & 4 \\
BA & 2 \\
GO & 7 \\
ES & 3 \\
MG & 3 \\
SP & 1 \\
RS & 1 \\
MT & 1 \\
TO & 1 \\
AL & 1 \\
PB & 1 \\
RN & 1 \\
Total & 40 \\
\hline
\end{tabular}

Fonte: Tabela elaborada pela própria autora (2015) 
Tabela B.2- Referente ao gráfico 4.2

Instituições de ensino que mais colaboraram com pesquisas usando o MCV-1993 - 2014

\begin{tabular}{|c|c|}
\hline IES & Quantidade \\
\hline MMA & 1 \\
\hline UFRJ & 2 \\
\hline UCB & 1 \\
\hline UnB & 17 \\
\hline EMBRAPA & 1 \\
\hline UEMS & 1 \\
\hline IPEA & 2 \\
\hline UFRS & 1 \\
\hline UFSC & 1 \\
\hline UESC & 1 \\
\hline USP & 1 \\
\hline UEG & 2 \\
\hline UFV & 1 \\
\hline UERJ & 1 \\
\hline UFT & 1 \\
\hline UFPE & 1 \\
\hline UNICAMP & 2 \\
\hline UNOCHAPECÓ & 2 \\
\hline UFU & 1 \\
\hline UFG & 1 \\
\hline UFOP & 1 \\
\hline OFRN & 1 \\
\hline UFPEL & 1 \\
\hline UPF & 1 \\
\hline UFL & 1 \\
\hline UFF & 1 \\
\hline Total & 47 \\
\hline
\end{tabular}

Fonte: Tabela elaborada pela própria autora (2015) 
Tabela B.3- Referente ao gráfico 4.3

Produção de artigos com o uso do Método

Custo de Viagem - Brasil 1993 - 2014

\begin{tabular}{rr}
\hline Anos & Quantidades \\
\hline 1993 & 1 \\
1995 & 1 \\
1997 & 1 \\
1998 & 2 \\
1999 & 1 \\
2001 & 3 \\
2002 & 1 \\
2003 & 1 \\
2004 & 1 \\
2005 & 3 \\
2006 & 3 \\
2007 & 3 \\
2008 & 5 \\
2009 & 1 \\
2010 & 2 \\
2012 & 2 \\
2013 & 4 \\
2014 & 5 \\
Total & 40 \\
\hline
\end{tabular}

Fonte: Tabela elaborada pela própria autora (2015) 


\section{APÊNDICE C}

Quadro C.1 - Pesquisas Teóricas sobre Preços Hedônicos (1998-2014)

\begin{tabular}{|c|c|c|c|c|}
\hline $\mathrm{n}^{\mathrm{o}}$ & Ano & Autor e ano & Nome do trabalho & Instituição \\
\hline 1 & 1998 & Nogueira e Medeiros & $\begin{array}{l}\text { Quanto vale aquilo que não tem valor? Valor de } \\
\text { existência, economia e meio ambiente. }\end{array}$ & UnB \\
\hline 2 & 1998 & Motta & $\begin{array}{l}\text { Manual para valoração econômica de recursos } \\
\text { ambientais }\end{array}$ & MMA \\
\hline 3 & 1999 & $\begin{array}{l}\text { Tavares; Ribeiro e } \\
\text { Lanna }\end{array}$ & $\begin{array}{l}\text { Valoração monetária de bens e serviços ambientais: } \\
\text { Revisão do Estado-da-arte sob ótica da Gestão das } \\
\text { águas. }\end{array}$ & UFPEL \\
\hline 4 & 2000 & $\begin{array}{l}\text { Eustáchio e Távora } \\
\text { Junior }\end{array}$ & $\begin{array}{l}\text { Metodologias da avaliação de ativos ambientais: uma } \\
\text { comparação entre as medidas }\end{array}$ & UFRJ \\
\hline 5 & 2000 & $\begin{array}{l}\text { Nogueira; Medeiros e } \\
\text { Arruda }\end{array}$ & $\begin{array}{l}\text { Valoração econômica do meio ambiente: Ciência ou } \\
\text { empirismo? }\end{array}$ & UnB \\
\hline 6 & 2003 & Negri Neto & Preços Hedônicos & IEA \\
\hline 7 & 2006 & Brandli et al. & $\begin{array}{l}\text { Análise das vantagens e limitações dos método de } \\
\text { valoração de recursos ambientais: Método do custo de } \\
\text { Viagem, Método de valoração contingente e Método } \\
\text { de preços hedônicos }\end{array}$ & UFPE \\
\hline 8 & 2009 & Romeiro e Andrade & Valoração econômica ecológica de recursos naturais & UNICAMP \\
\hline 9 & 2010 & Falco et al. & $\begin{array}{l}\text { A gestão socioambiental à luz das técnicas de } \\
\text { valoração econômica do meio ambiente: uma análise } \\
\text { do valor de uso indireto e do valor de existência }\end{array}$ & PUC-Rio \\
\hline 10 & 2012 & Barreto & $\begin{array}{l}\text { A valoração econômica como instrumento de gestão } \\
\text { ambiental aplicável a compensação ambiental: o caso } \\
\text { do parque estadual do IBITIPOCA- MG }\end{array}$ & UFL \\
\hline 11 & 2014 & Miquelito et al. & $\begin{array}{l}\text { A valoração econômica como ferramenta para } \\
\text { compensação de acidentes ambientais: o caso dos } \\
\text { acidentes ocorridos na região sudeste do Brasil } \\
\text { (2006-2012) }\end{array}$ & UFF \\
\hline
\end{tabular}

Fonte: Quadro elaborado pela própria autora (2015) 
Quadro C.2 - Trabalhos Empíricos sobre Valoração com o uso do Método de Preços Hedônicos - Brasil (19872014)

(Continua)

\begin{tabular}{|c|c|c|c|c|c|c|}
\hline No & Ano & Autores & Título do trabalho & Estado & $\begin{array}{l}\text { Instituição } \\
\text { responsável }\end{array}$ & Amostra \\
\hline 1 & 1987 & Oliveira et al. & $\begin{array}{l}\text { Aplicação da metodologia dos } \\
\text { preços hedônicos na avaliação } \\
\text { de projetos de saneamento. }\end{array}$ & $\mathrm{SP}$ & SABESP & 2.010 \\
\hline 2 & 1997 & $\begin{array}{l}\text { Aguirre e } \\
\text { Faria }\end{array}$ & $\begin{array}{l}\text { Utilização de preços hedônicos } \\
\text { na avaliação social de projetos }\end{array}$ & SP & UFMG & 1.514 \\
\hline 3 & 2000 & Batalhone & $\begin{array}{l}\text { Valoração econômica: uma } \\
\text { abordagem empírica sobre o } \\
\text { método de preços hedônicos e o } \\
\text { valor dos imóveis residenciais }\end{array}$ & DF & UnB & 1.031 \\
\hline 4 & 2001 & $\begin{array}{l}\text { Hochheim e } \\
\text { Uberti }\end{array}$ & $\begin{array}{l}\text { Uso da variáveis na avaliação } \\
\text { de imóveis urbanos: uma } \\
\text { contribuição à valoração } \\
\text { ambiental }\end{array}$ & SC & UFSC & 88 \\
\hline 5 & 2003 & Hermann & $\begin{array}{l}\text { Estimando o preço implícito de } \\
\text { amenidades urbanas: } \\
\text { Evidências para o município de } \\
\text { são Paulo }\end{array}$ & SP & USP & 497 \\
\hline 6 & 2004 & Lezcano & $\begin{array}{l}\text { Análise do efeito do risco de } \\
\text { cheia no valor de imóveis pelo } \\
\text { método dos preços hedônicos }\end{array}$ & PR & UFPR & 159 \\
\hline 7 & 2004 & $\begin{array}{l}\text { Campos; } \\
\text { Cirino } \\
\text { Andrade }\end{array}$ & $\begin{array}{l}\text { Modelo de regressão para } \\
\text { estimar o diferencial de preços } \\
\text { das terras agrícolas com e sem } \\
\text { erosão em Lagoa Dourada- MG } \\
\text { pelo método dos Preços } \\
\text { Hedônicos. }\end{array}$ & MG & UFS] & 49 \\
\hline 8 & 2006 & Laera & $\begin{array}{l}\text { Valoração econômica da } \\
\text { arborização - a valoração dos } \\
\text { serviços ambientais para a } \\
\text { eficiência e manutenção do } \\
\text { recursos ambiental urbano }\end{array}$ & RJ & UFF & 2.297 \\
\hline 9 & 2007 & $\begin{array}{l}\text { Andrade e } \\
\text { Maia }\end{array}$ & $\begin{array}{l}\text { Aplicação do modelo dos preços } \\
\text { hedônicos para avaliação da } \\
\text { influência da acessibilidade ao } \\
\text { transporte público sobre o } \\
\text { preço da terra urbana }\end{array}$ & PE & UFPE & 110 \\
\hline 10 & 2007 & $\begin{array}{l}\text { Albuquerque } \\
; \quad \text { Melo e } \\
\text { Souza }\end{array}$ & $\begin{array}{l}\text { Ativo ambiental e preço de } \\
\text { imóveis em Recife: um estudo } \\
\text { exploratório a partir da } \\
\text { utilização do método dos preços } \\
\text { hedônicos }\end{array}$ & PE & UFPE & 443 \\
\hline 11 & 2008 & Faria et al. & $\begin{array}{l}\text { Uma aplicação do método de } \\
\text { preços hedônicos no setor } \\
\text { saneamento: o projeto de São } \\
\text { Bento do Sul-SC }\end{array}$ & SC & UCB & 390 \\
\hline 12 & 2009 & Nascimento & $\begin{array}{l}\text { Níveis de renda e DAPs: } \\
\text { Evidências de correlação via } \\
\text { função preço hedônico }\end{array}$ & DF & UnB & 294 \\
\hline 13 & 2010 & Amazonas & $\begin{array}{l}\text { Método de preços hedônicos e a } \\
\text { valoração de áreas verdes } \\
\text { urbanas: Parque Vaca Brava } \\
\text { em Goiânia- Goiás }\end{array}$ & GO & UnB & 11.532 \\
\hline
\end{tabular}




\begin{tabular}{|l|l|l|l|l|l|l|}
\hline No & Ano & Autores & Título do trabalho & Estado & $\begin{array}{l}\text { Instituição } \\
\text { responsável }\end{array}$ & Amostra \\
\hline 14 & 2011 & Borba & $\begin{array}{l}\text { Segurança como variável na } \\
\text { metodologia do preço Hedônico }\end{array}$ & RJ & SEDNA & 39 \\
\hline 15 & 2013 & Santarlacci & $\begin{array}{l}\text { Externalidades positivas } \\
\text { Geradas pelo Parque Olhos } \\
\text { D'água ao mercado imobiliário } \\
\text { por meio de índices hedônicos. }\end{array}$ & UnB & 826 \\
\hline 16 & 2014 & $\begin{array}{l}\text { Rabêlo Neto } \\
\text { et al. }\end{array}$ & $\begin{array}{l}\text { Valoração econômica de } \\
\text { projetos de requalificação } \\
\text { urbana: uma aplicação dos } \\
\text { métodos de avaliação } \\
\text { Contingente e Preços Hedônicos }\end{array}$ & UFC & 519 \\
\hline 17 & 2014 & Azevedo & $\begin{array}{l}\text { Benefícios à propriedades } \\
\text { agregados às paisagens } \\
\text { urbanas pelas } \\
\text { naturais }\end{array}$ & UFRN & 283 \\
\hline
\end{tabular}

(Conclusão)

Fonte: Quadro elaborado pela própria autora (2015)

Quadro C.3 - Trabalhos empíricos analisados que utilizaram do Método Preços Hedônicos no Brasil

\begin{tabular}{|l|l|}
\hline Legenda & Autores \\
\hline MPH 1 & Campos; Cirino e Andrade (2004) \\
\hline MPH 2 & Albuquerque; Melo e Souza (2007) \\
\hline
\end{tabular}

Quadro elaborado pela própria autora (2015) 


\section{Apêndice C.4 -Tabelas referentes aos gráficos do capítulo 5}

Tabela C.1- Referente ao gráfico 5.1

Produção de artigos com o uso do Método

Preços Hedônicos- 1987 -2014

\begin{tabular}{cc}
\hline Anos & Quantidade \\
\hline 1987 & 1 \\
1997 & 1 \\
1998 & 2 \\
1999 & 1 \\
2000 & 3 \\
2001 & 1 \\
2002 & 0 \\
2003 & 2 \\
2004 & 2 \\
2005 & 0 \\
2006 & 2 \\
2007 & 2 \\
2008 & 1 \\
2009 & 2 \\
2010 & 2 \\
2011 & 1 \\
2012 & 1 \\
2013 & 1 \\
2014 & 2 \\
Total & 27 \\
\hline
\end{tabular}

Fonte: Tabela elaborada pela própria autora (2015)

Tabela C.2- Referente ao gráfico 5.2

Classificação dos trabalhos que usam MPH segundo qualidade dos vetoresadjacentes ao imóvel- 1987-2014

Qualidade dos vetores Quantidade

\begin{tabular}{lc}
\hline Saneamento & 3 \\
Valor de imóveis & 4 \\
Urbanização & 7 \\
Erosão em meio rural & 1 \\
Transporte público & 1 \\
Segurança & 1 \\
Total & 17 \\
\hline
\end{tabular}

Fonte: Tabela elaborada pela própria autora (2015) 
Tabela C.3- Referente ao gráfico 5.3

Estados brasileiros que foram avaliados

pelo MPH com variável ambiental- 1987-2014

\begin{tabular}{lc} 
Estados & Quantidade \\
\hline SP & 3 \\
DF & 3 \\
PE & 2 \\
RJ & 2 \\
SC & 2 \\
GO & 1 \\
PR & 1 \\
RN & 1 \\
CE & 1 \\
Total & 16 \\
\hline
\end{tabular}

Fonte: Tabela elaborada pela própria autora (2015)

Tabela C.4- Referente ao gráfico 5.4

Instituições de ensino que colaboraram com as

pesquisas empíricas usando o MPH - 1987 - 2014

\begin{tabular}{lr} 
IES & Quantidade \\
\hline UnB & 4 \\
UFPE & 3 \\
UFC & 1 \\
UFRN & 1 \\
USP & 1 \\
UFF & 1 \\
UCB & 1 \\
UFPR & 1 \\
UFMG & 1 \\
UFSJ & 1 \\
Unifor & 1 \\
Total & 16 \\
\hline
\end{tabular}

Fonte: Tabela elaborada pela própria autora (2015) 


\section{APÊNDICE D}

\section{Apêndice D.1 -Tabelas referentes aos gráficos do capítulo 6}

Tabela D.1 - Referente ao gráfico 6.1

Autores internacionais mais citados em trabalhos brasileiros MVC - 1999- 2014

\begin{tabular}{ll}
\hline Métodos & Quantidade \\
\hline MVC & 30 \\
Hanemann (1994) & 45 \\
Mitchell e Carson (1993) & 32 \\
Pearce e Turner (1990) & 64 \\
Freeman III (1979) & 87 \\
Pearce (1993) & 24 \\
Hanley e Spash (1999) & 51 \\
Bateman e Turner (1993) & \\
& \\
MCV & 38 \\
Pearce (1995) & 33 \\
Hanley e Spash (1993) & 33 \\
Pearce e Turner (1990) & 29 \\
Haab e McConnell (2003) & \\
& \\
MPH & 18 \\
Palmquist (1984) & 22 \\
Hanley e Spash (1993) & 20 \\
Garrod e Willis (1999)
\end{tabular}

Fonte: Tabela elaborada pela própria autora (2015) 
Tabela D.2 - Referente ao gráfico 6.2

Autores nacionais mais citados em com o uso do MVC, MCV e MPH - 1999- 2014

\begin{tabular}{lc}
\hline Métodos & Quantidades \\
\hline MCV & 24 \\
Ortz; Motta e Ferraz (2000) & 40 \\
Motta (1997) & 26 \\
Maia e Romeiro (2008) & \\
MVC & 98 \\
Motta (1997) & \\
Nogueira; Medeiros e Arruda & 63 \\
(2000) & 55 \\
May; Lustosa e Vinha (2003) & 25 \\
Maia e Romeiro (2008) & 46 \\
Noguera e Medeiros (1998) & 31 \\
Mota (2010) & 30 \\
Silva e Lima (2004) & 34 \\
Cirino e Lim,a (2008) & \\
MPH & \\
Motta (1997) & 25 \\
Hermann (2003) & 14 \\
Contador (1981) & 18 \\
\hline Fite: Trab
\end{tabular}

Fonte: Tabela elaborada pela própria autora (2015)

Tabela D.3 - Referente ao gráfico 6.3

Motivos de valoração ambiental no Brasil - MVC, MCV e MPH

\begin{tabular}{lr} 
Motivos & Quantidade \\
\hline Requalificação ambiental urbana & 4 \\
Subsidiar políticas públicas para conservação & 6 \\
Financiar projetos de saneamento & 7 \\
Captação de recursos financieros para a entidade & 4 \\
Verificar a condução da política pública municipal e & \\
estadual & 3 \\
Cobrança de taxas & 4 \\
Total & 28 \\
\hline
\end{tabular}

Fonte: Tabela elaborada pela própria autora (2015) 
Tabela D.4 - Referente ao gráfico 6.4

Instituições de Ensino que mais colaboraram com

a Divulgação das técnicas de valoração ambiental

- MVC, MCV, MPH no Brasil

\begin{tabular}{lc}
\hline IES & Total \\
\hline UnB & 38 \\
UFRJ & 7 \\
UNOCHAPECÓ & 5 \\
UFU & 5 \\
UFSC & 4 \\
UFOP & 4 \\
UFMT & 4 \\
Total & 67 \\
\hline
\end{tabular}

Fonte: Tabela elaborada pela própria autora (2015)

Tabela D.5 - Referente ao gráfico 6.5

Trabalhos empíricos com o uso dos métodos de valoração ambiental - MVC, MCV, MPH para região Centro-Oeste do Brasil

\begin{tabular}{lcccc}
\hline Estados & MVC & MCV & MPH & Total \\
\hline GO & 6 & 7 & 1 & 14 \\
DF & 10 & 6 & 3 & 19 \\
MS & 1 & 3 & 0 & 4 \\
MT & 6 & 1 & 0 & 7 \\
Total & 23 & 17 & 4 & 44 \\
\hline
\end{tabular}

Fonte: Tabela elaborada pela própria autora (2015)

Tabela D.6 - Referente ao gráfico 6.6

Trabalhos empíricos com o uso dos métodos de valoração ambiental - MVC, MCV, MPH para região Sudeste do Brasil

\begin{tabular}{lcccc} 
Estados & MVC & MCV & MPH & Total \\
\hline MG & 11 & 3 & 0 & 14 \\
SP & 10 & 1 & 3 & 14 \\
RJ & 2 & 3 & 2 & 7 \\
ES & 1 & 3 & 0 & 4 \\
Total & 24 & 10 & 5 & 39 \\
\hline
\end{tabular}

Fonte: Tabela elaborada pela própria autora (2015) 
Tabela D.7 - Referente ao gráfico 6.7

Trabalhos empíricos com o uso dos métodos de valoração ambiental - MVC, MCV, MPH para região Sul do Brasil

\begin{tabular}{lcccc} 
Estados & MVC & MCV & MPH & Total \\
\hline RS & 11 & 1 & 2 & 14 \\
SC & 3 & 4 & 1 & 8 \\
PR & 2 & 2 & 0 & 4 \\
Total & 16 & 7 & 3 & 26 \\
\hline
\end{tabular}

Fonte: Tabela elaborada pela própria autora (2015)

Tabela D.8 - Referente ao gráfico 6.8

Trabalhos empíricos com o uso dos métodos de valoração ambiental - MVC, MCV, MPH para região Nordeste do Brasil

\begin{tabular}{lcccc} 
Estados & MVC & MCV & MPH & Total \\
\hline BA & 2 & 2 & 0 & 4 \\
SE & 1 & 0 & 0 & 1 \\
PI & 2 & 0 & 0 & 2 \\
CE & 5 & 0 & 1 & 6 \\
PE & 2 & 0 & 2 & 4 \\
PB & 1 & 1 & 1 & 3 \\
RN & 1 & 0 & 0 & 1 \\
Total & 14 & 3 & 4 & 21 \\
\hline
\end{tabular}

Fonte: Tabela elaborada pela própria autora (2015)

Tabela D.9 - Referente ao gráfico 6.9

Trabalhos empíricos com o uso dos métodos de valoração ambiental - MVC, MCV, MPH para região Norte do Brasil

\begin{tabular}{lcccc} 
Estados & MVC & MCV & MPH & Total \\
\hline RO & 1 & 0 & 0 & 1 \\
AC & 2 & 0 & 0 & 2 \\
AM & 1 & 0 & 0 & 1 \\
RR & 1 & 0 & 0 & 1 \\
PA & 1 & 0 & 0 & 1 \\
AP & 3 & 0 & 0 & 3 \\
TO & 3 & 1 & 0 & 4 \\
Total & 12 & 1 & 0 & 13 \\
\hline
\end{tabular}

Fonte: Tabela elaborada pela própria autora (2015) 
Tabela D.10 - Referente ao gráfico 6.10

Trabalhos de Valoração Ambiental Métodos MVC, MCV, MPH no Brasil- 1993-2014

\begin{tabular}{cc} 
Anos & Quantidade \\
\hline 1993 & 1 \\
1994 & 0 \\
1995 & 1 \\
1996 & 1 \\
1997 & 2 \\
1998 & 5 \\
1999 & 8 \\
2000 & 5 \\
2001 & 4 \\
2002 & 3 \\
2003 & 8 \\
2004 & 7 \\
2005 & 5 \\
2006 & 15 \\
2007 & 9 \\
2008 & 15 \\
2009 & 11 \\
2010 & 13 \\
2011 & 7 \\
2012 & 12 \\
2013 & 17 \\
2014 & 24 \\
Total & 173 \\
\hline Fonte: Tabela elaborada pela própria autora (2015)
\end{tabular}

Fonte: Tabela elaborada pela própria autora (2015) 
Tabela D11 - Referente ao gráfico 6.11

Artigos téoricos publicados por ano e Instituição de Ensino e por tipo de método 1998-2014

\begin{tabular}{|c|c|c|}
\hline Anos & Método & Quantidade \\
\hline 1998 & $\begin{array}{l}\text { MVC } \\
\mathrm{MCV} \\
\mathrm{MPH}\end{array}$ & $\begin{array}{l}1 \\
2 \\
2\end{array}$ \\
\hline 1999 & $\begin{array}{l}\text { MVC } \\
\mathrm{MCV} \\
\mathrm{MPH}\end{array}$ & $\begin{array}{l}3 \\
1 \\
1\end{array}$ \\
\hline 2000 & $\begin{array}{l}\text { MVC } \\
\mathrm{MCV} \\
\mathrm{MPH}\end{array}$ & $\begin{array}{l}1 \\
1 \\
2\end{array}$ \\
\hline 2001 & $\begin{array}{l}\text { MVC } \\
\text { MCV } \\
\text { MPH }\end{array}$ & $\begin{array}{l}0 \\
0 \\
0\end{array}$ \\
\hline 2002 & $\begin{array}{l}\text { MVC } \\
\text { MCV } \\
\text { MPH }\end{array}$ & $\begin{array}{l}0 \\
0 \\
0\end{array}$ \\
\hline 2003 & $\begin{array}{l}\text { MVC } \\
\mathrm{MCV} \\
\mathrm{MPH}\end{array}$ & $\begin{array}{l}3 \\
0 \\
1\end{array}$ \\
\hline 2004 & $\begin{array}{l}\text { MVC } \\
\mathrm{MCV} \\
\mathrm{MPH}\end{array}$ & $\begin{array}{l}0 \\
0 \\
0\end{array}$ \\
\hline 2005 & $\begin{array}{l}\text { MVC } \\
\text { MCV } \\
\text { MPH }\end{array}$ & $\begin{array}{l}1 \\
0 \\
0\end{array}$ \\
\hline 2006 & $\begin{array}{l}\text { MVC } \\
\text { MCV } \\
\text { MPH }\end{array}$ & $\begin{array}{l}2 \\
1 \\
1\end{array}$ \\
\hline 2007 & $\begin{array}{l}\text { MVC } \\
\text { MCV } \\
\text { MPH }\end{array}$ & $\begin{array}{l}1 \\
0 \\
0\end{array}$ \\
\hline 2008 & $\begin{array}{l}\text { MVC } \\
\mathrm{MCV} \\
\mathrm{MPH}\end{array}$ & $\begin{array}{l}3 \\
0 \\
0\end{array}$ \\
\hline 2009 & $\begin{array}{l}\text { MVC } \\
\mathrm{MCV} \\
\mathrm{MPH}\end{array}$ & $\begin{array}{l}2 \\
1 \\
1\end{array}$ \\
\hline 2010 & $\begin{array}{l}\text { MVC } \\
\text { MCV } \\
\text { MPH }\end{array}$ & $\begin{array}{l}3 \\
0 \\
1\end{array}$ \\
\hline 2011 & $\begin{array}{l}\text { MVC } \\
\text { MCV } \\
\text { MPH }\end{array}$ & $\begin{array}{l}0 \\
0 \\
0\end{array}$ \\
\hline 2012 & $\begin{array}{l}\text { MVC } \\
\text { MCV } \\
\text { MPH }\end{array}$ & $\begin{array}{l}3 \\
0 \\
1\end{array}$ \\
\hline 2013 & $\begin{array}{l}\text { MVC } \\
\mathrm{MCV} \\
\mathrm{MPH}\end{array}$ & $\begin{array}{l}3 \\
1 \\
0\end{array}$ \\
\hline 2014 & $\begin{array}{l}\text { MVC } \\
\text { MCV } \\
\text { MPH }\end{array}$ & $\begin{array}{l}2 \\
2 \\
1\end{array}$ \\
\hline & Total & 48 \\
\hline
\end{tabular}

Fonte: Tabela elaborada pela própria autora (2015) 
Tabela D. 12-Trabalhos teóricos por região e ano de publicação- 1998-2014

Anos

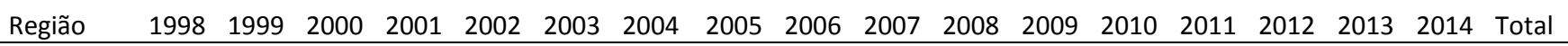

\begin{tabular}{|c|c|c|c|c|c|c|c|c|c|c|c|c|c|c|c|c|c|c|}
\hline Norte & 0 & 0 & 0 & 0 & 0 & 0 & 0 & 0 & 0 & 0 & 0 & 0 & 0 & 0 & 0 & 0 & 0 & 0 \\
\hline $\begin{array}{l}\text { Sul } \\
\text { Centro- }\end{array}$ & 0 & 4 & 0 & 0 & 0 & 0 & 0 & 1 & 0 & 0 & 1 & 1 & 1 & 0 & 0 & 0 & 0 & 8 \\
\hline Oeste & 5 & 1 & 3 & 0 & 0 & 3 & 0 & 0 & 0 & 1 & 0 & 0 & 0 & 0 & 0 & 1 & 3 & 17 \\
\hline Nordeste & 0 & 0 & 0 & 0 & 0 & 0 & 0 & 0 & 1 & 0 & 0 & 0 & 0 & 0 & 0 & 0 & 0 & 1 \\
\hline Sudeste & 0 & 0 & 1 & 0 & 0 & 1 & 0 & 0 & 3 & 0 & 2 & 3 & 3 & 0 & 4 & 3 & 2 & 22 \\
\hline Total & 5 & 5 & 4 & 0 & 0 & 4 & 0 & 0 & 4 & 1 & 3 & 4 & 4 & 0 & 4 & 4 & 5 & 48 \\
\hline
\end{tabular}

Fonte: Tabela elaborada pela própria autora (2015)

Tabela D.13 Trabalhos teóricos por ano e por instituição de ensino -1998 -2014

\begin{tabular}{|c|c|c|c|c|c|c|c|c|c|c|c|c|c|c|c|c|c|c|}
\hline IES & 1998 & 1999 & 2000 & 2001 & 2002 & 2003 & 2004 & 2005 & 2006 & 2007 & 2008 & 2009 & 2010 & 2011 & 2012 & 2013 & 2014 & Total \\
\hline IEA & 0 & 0 & 0 & 0 & 0 & 1 & 0 & 0 & 0 & 0 & 0 & 0 & 0 & 0 & 0 & 0 & 0 & 1 \\
\hline MMA & 2 & 0 & 0 & 0 & 0 & 0 & 0 & 0 & 0 & 0 & 0 & 0 & 0 & 0 & 0 & 0 & 0 & 2 \\
\hline PUC-RIO & 0 & 0 & 0 & 0 & 0 & 0 & 0 & 0 & 0 & 0 & 0 & 0 & 2 & 0 & 0 & 1 & 0 & 3 \\
\hline UEPEL & 1 & 3 & 0 & 0 & 0 & 0 & 0 & 0 & 0 & 0 & 0 & 0 & 0 & 0 & 0 & 0 & 0 & 4 \\
\hline UFF & 0 & 0 & 0 & 0 & 0 & 0 & 0 & 0 & 1 & 0 & 1 & 0 & 0 & 0 & 0 & 0 & 2 & 4 \\
\hline UFG & 0 & 0 & 0 & 0 & 0 & 0 & 0 & 0 & 0 & 0 & 0 & 0 & 0 & 0 & 0 & 0 & 1 & 1 \\
\hline UFLA & 0 & 0 & 0 & 0 & 0 & 0 & 0 & 0 & 1 & 0 & 0 & 0 & 0 & 0 & 2 & 1 & 0 & 4 \\
\hline UFMS & 0 & 0 & 0 & 0 & 0 & 0 & 0 & 0 & 0 & 1 & 0 & 0 & 0 & 0 & 0 & 0 & 0 & 1 \\
\hline UFPE & 0 & 0 & 0 & 0 & 0 & 0 & 0 & 0 & 1 & 0 & 0 & 0 & 0 & 0 & 0 & 0 & 0 & 1 \\
\hline UFRJ & 0 & 0 & 1 & 0 & 0 & 0 & 0 & 0 & 1 & 0 & 0 & 0 & 1 & 0 & 1 & 0 & 0 & 4 \\
\hline UFRS & 0 & 0 & 0 & 0 & 0 & 0 & 0 & 1 & 0 & 0 & 0 & 0 & 1 & 0 & 0 & 0 & 0 & 2 \\
\hline UFSCAR & 0 & 0 & 0 & 0 & 0 & 1 & 0 & 0 & 0 & 0 & 1 & 0 & 0 & 0 & 0 & 0 & 0 & 2 \\
\hline UFSJ & 0 & 0 & 0 & 0 & 0 & 0 & 0 & 0 & 0 & 0 & 0 & 0 & 0 & 0 & 0 & 1 & 0 & 1 \\
\hline UFU & 0 & 0 & 0 & 0 & 0 & 0 & 0 & 0 & 0 & 0 & 0 & 1 & 0 & 0 & 0 & 0 & 0 & 1 \\
\hline UNB & 2 & 1 & 3 & 0 & 0 & 2 & 0 & 0 & 0 & 0 & 0 & 0 & 0 & 0 & 0 & 1 & 2 & 11 \\
\hline UNICAMP & 0 & 0 & 0 & 0 & 0 & 0 & 0 & 0 & 0 & 0 & 0 & 3 & 0 & 0 & 0 & 0 & 0 & 3 \\
\hline UNICENTRO & 0 & 0 & 0 & 0 & 0 & 0 & 0 & 0 & 0 & 0 & 1 & 0 & 0 & 0 & 0 & 0 & 0 & 1 \\
\hline UNIOESTE & 0 & 1 & 0 & 0 & 0 & 0 & 0 & 0 & 0 & 0 & 0 & 0 & 0 & 0 & 0 & 0 & 0 & 1 \\
\hline USP & 0 & 0 & 0 & 0 & 0 & 0 & 0 & 0 & 0 & 0 & 0 & 0 & 0 & 0 & 1 & 0 & 0 & 1 \\
\hline Total & 5 & 5 & 4 & 0 & 0 & 4 & 0 & 1 & 4 & 1 & 3 & 4 & 4 & 0 & 4 & 4 & 5 & 48 \\
\hline
\end{tabular}

Fonte: Tabela elaborada pela própria autora (2015) 
ANEXO A

Quadro 1 - Dólar comercial Oficial, 1970 a 2014

\begin{tabular}{|c|c|c|}
\hline Ano & Mês & Dolar oficial (US\$) \\
\hline 1993 & jul & $62.136,00$ \\
\hline 1994 & jun & $2.230,00$ \\
\hline 1995 & jun & 0,9090 \\
\hline 1996 & jun & 1,0015 \\
\hline 1997 & jun & 1,0745 \\
\hline 1998 & jun & 1,1551 \\
\hline 1999 & jun & 1,7892 \\
\hline 2000 & jun & 1,8079 \\
\hline 2001 & jun & 2,4079 \\
\hline 2002 & jun & 2,7181 \\
\hline 2003 & jun & 2,8570 \\
\hline 2004 & set & 2,9042 \\
\hline 2005 & jun & 2,4455 \\
\hline 2006 & jul & 2,2130 \\
\hline 2007 & jul & 1,9097 \\
\hline 2008 & jul & 1,6368 \\
\hline 2009 & jul & 1,9420 \\
\hline 2010 & jul & 1,7690 \\
\hline 2011 & jul & 1,5743 \\
\hline 2012 & jul & 2,0332 \\
\hline 2013 & jul & 2,2548 \\
\hline 2014 & jul & 2,2195 \\
\hline
\end{tabular}

Fonte: BACEN-Banco Central do Brasil 